Ruth Beatriz Mezzalira Pincinato

\title{
Análise ecológica e econômica da pesca marinha por meio de indicadores multiespecíficos
}

Dissertação apresentada ao Instituto Oceanográfico da Universidade de São Paulo, como parte dos requisitos para obtenção do título de Mestre em Ciências, área de Oceanografia Biológica.

Orientado por: Profa. Dra. Maria de los Angeles Gasalla 
Universidade de São Paulo

Instituto Oceanográfico

\section{Análise ecológica e econômica da pesca marinha por meio de indicadores multiespecíficos}

Ruth Beatriz Mezzalira Pincinato

Dissertação apresentada ao Instituto Oceanográfico da Universidade de São Paulo, como parte dos requisitos para obtenção do título de Mestre em Ciências, área de Oceanografia Biológica.

Julgada em 1

Prof(a). $\operatorname{Dr}(\mathrm{a}) . \quad$ Conceito

Prof(a). Dr(a). Conceito

Prof(a). $\operatorname{Dr}(\mathrm{a}) . \quad$ Conceito 


\section{Sumário}

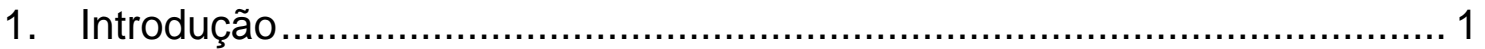

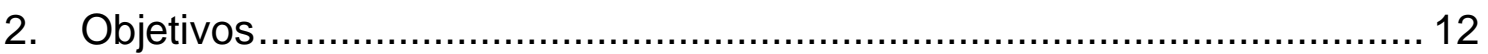

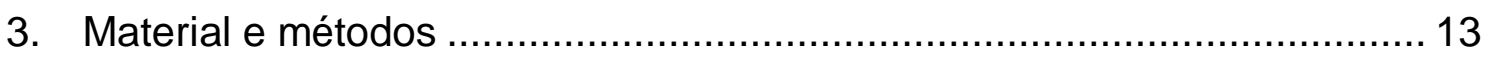

3.1. Compilação e processamento dos dados de estatística pesqueira e de comercialização do pescado .................................................................... 13

3.2. Classificação das categorias de pescado da estatística pesqueira e da

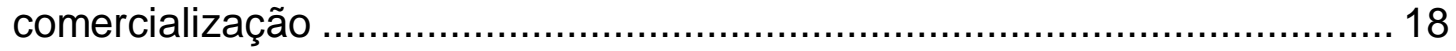

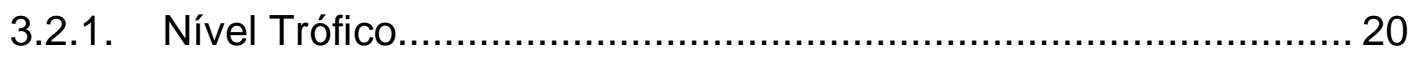

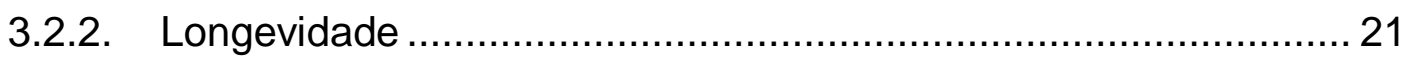

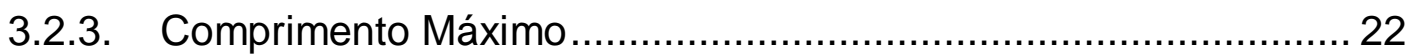

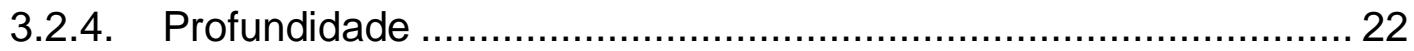

3.2.5. Isóbata Máxima de ocorrência................................................ 23

3.2.6. Características ecológicas: grupo trófico e habitat ....................... 23

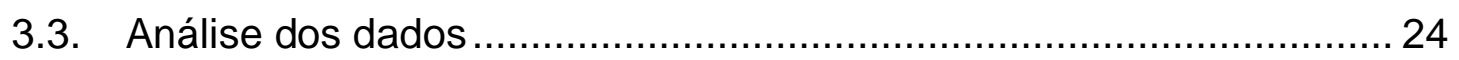

3.3.1. Análise das quantidades desembarcadas e comercializadas....... 24

3.3.1.1. Indicadores Multiespecíficos .............................................. 24

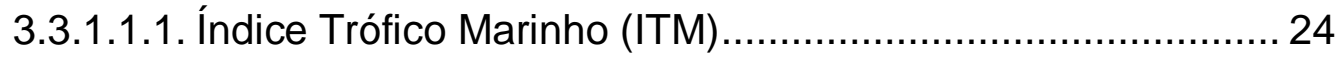

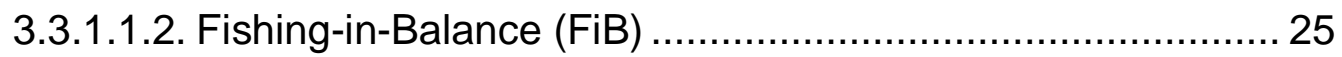

3.3.1.1.3. Longevidade média (Long $\mathrm{m}_{\mathrm{m}}$........................................... 26

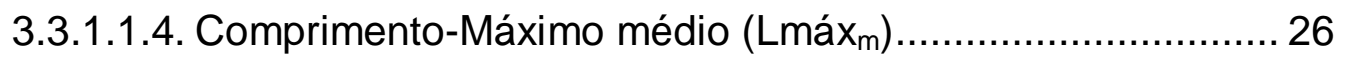

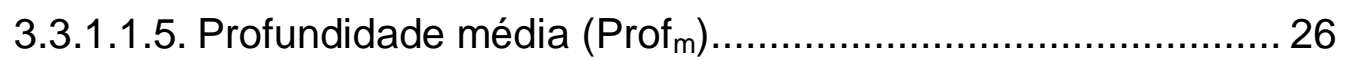

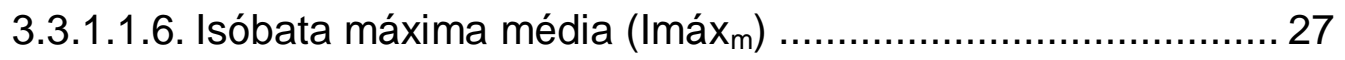

3.3.1.1.7. Razão piscívoros/planctívoros (pis/pla) ............................ 27

3.3.1.1.8. Razão pelágicos/demersais (pel/dem) .............................. 28

3.3.1.2. Importância relativa das categorias em função das diferentes classes de parâmetros ecológicos..................................................... 28

3.3.2. Análise das variáveis de preço e quantidades comercializadas ... 29

3.3.2.1. Preço ponderado das categorias de pescado em função dos parâmetros ecológicos ao longo dos anos

3.3.2.2. Índice do Preço Relativo Logaritmizado (IPRL)..................... 30

3.3.2.3. Valor total das categorias de pescado ................................. 31

3.3.2.4. Análise inferencial das séries temporais de preço e quantidade comercializada das principais categorias de pescado............................ 32

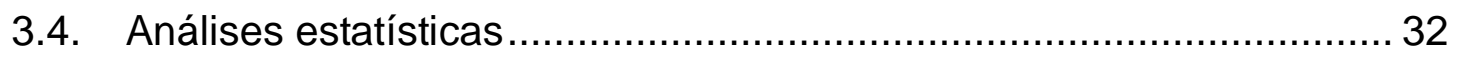

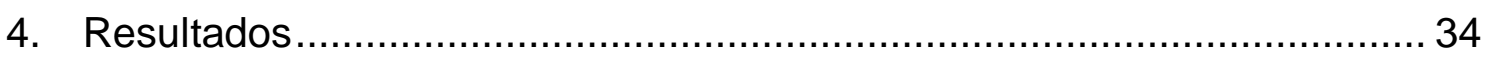

4.1. Análise das quantidades desembarcadas e comercializadas ............. 34

4.1.1. Indicadores Multiespecíficos................................................... 34 
4.1.1.1. Índice Trófico Marinho (ITM) ............................................... 34

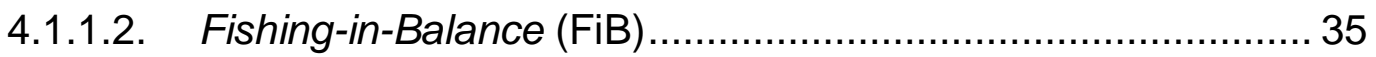

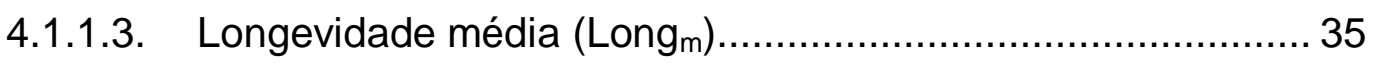

4.1.1.4. Comprimento-Máximo médio (Lmáx $\mathrm{m}$ ) ................................ 36

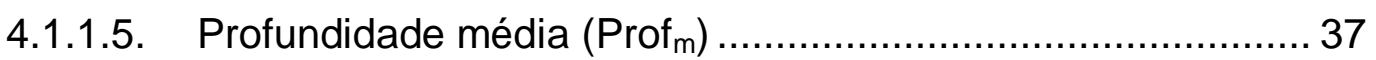

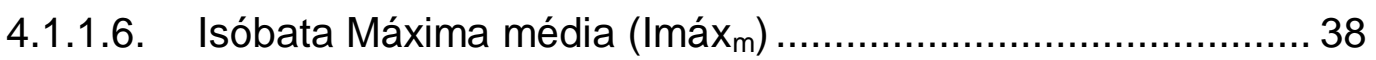

4.1.1.7. Razão piscívoros/planctívoros (pis/pla) ............................... 39

4.1.1.8. Razão pelágicos/demersais (pel/dem) ............................... 40

4.1.2. Importância relativa das categorias em função das classes de

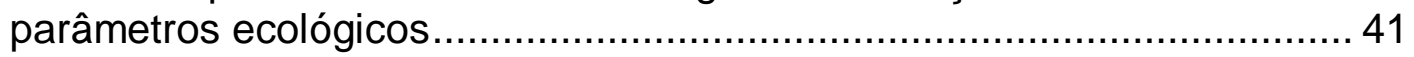

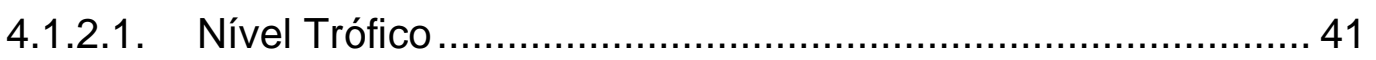

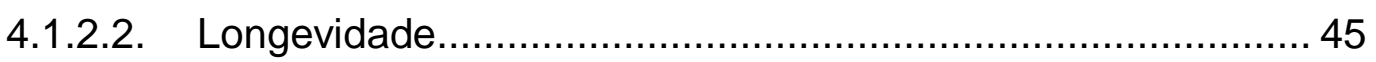

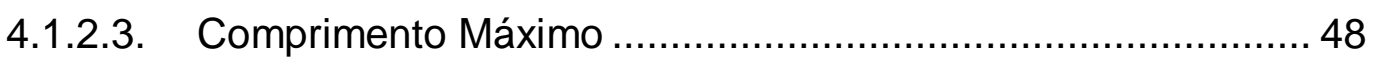

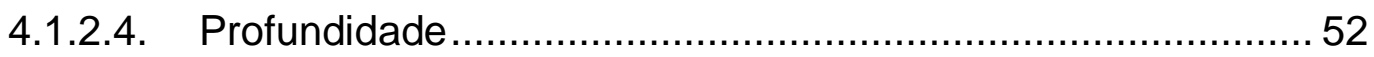

4.2. Análise das variáveis de preço e quantidades comercializadas..........55

4.2.1. Deflação dos preços de comercialização ................................... 55

4.2.2. Indicadores Multiespecíficos.................................................. 59

4.2.2.1. Preço médio ponderado em função dos parâmetros bio-

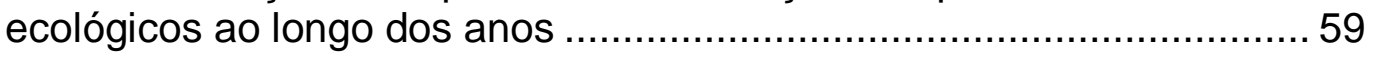

4.2.2.2. Análise inferencial dos dados de mercado ............................... 64

4.2.2.3. Índice do Preço Relativo Logaritmizado (IPRL) ...................... 70

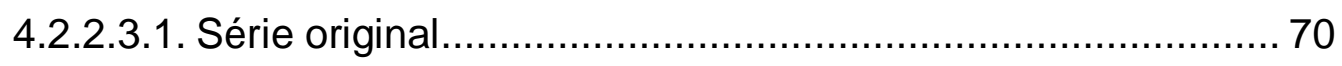

4.2.2.3.2. Série interpolada ....................................................... 72

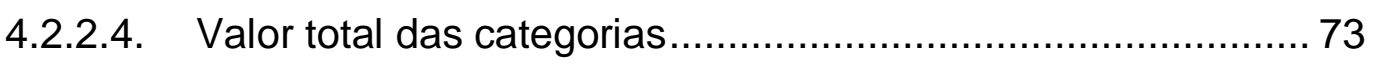

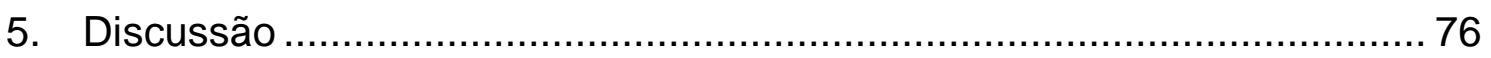

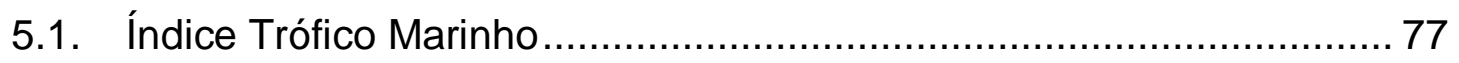

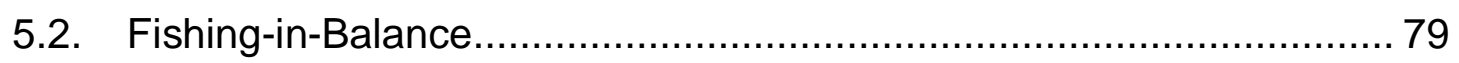

5.3. Longevidade média, Comprimento-Máximo médio, Profundidade média

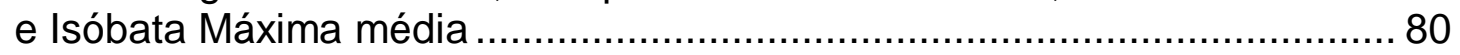

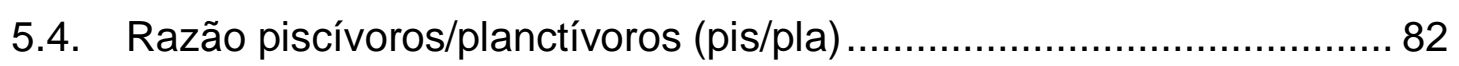

5.5. Razão pelágicos/demersais (pel/dem) ............................................. 83

5.6. Análise dos dados de mercado e dos indicadores econômicos .......... 84

5.7. Vantagens e desvantagens do uso de indicadores ............................. 89

5.8. Efeitos potenciais das mudanças no ecossistema e manejo ............... 94

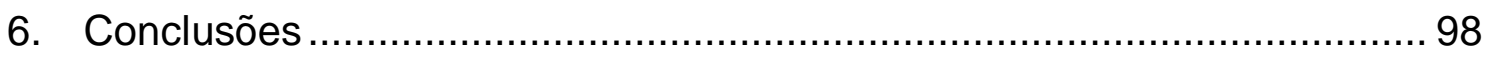

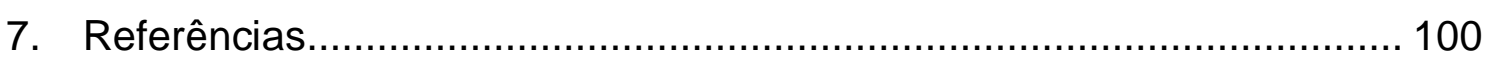

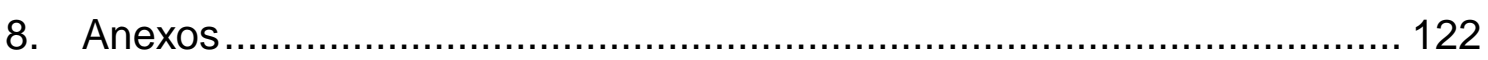


Lista de Figuras

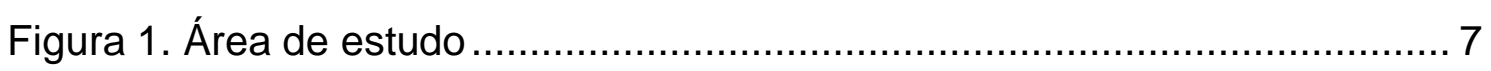

Figura 2. Companhia de Entrepostos e Armazéns Gerais de São Paulo em horário de funcionamento. .................................................. 11

Figura 3. Inflação medida pelo índice de preço ao consumidor no período de

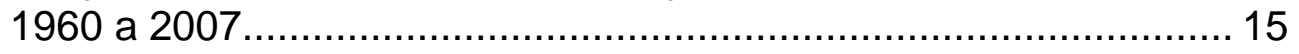

Figura 4. Logaritmo do preço em função do nível trófico de cada categoria para

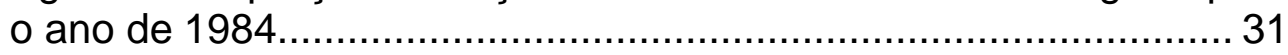

Figura 5. Índice Trófico Marinho para os dados de desembarques e da

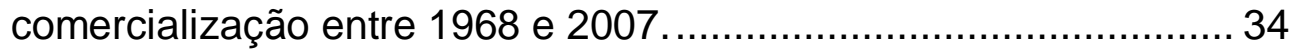

Figura 6. Fishing-in-Balance para os dados de comercialização e de

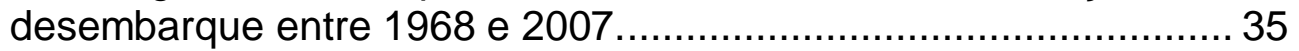

Figura 7. Longevidade média para os dados de comercialização e

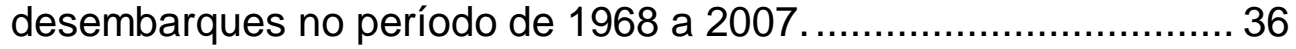

Figura 8. Comprimento Máximo médio para os dados de comercialização e desembarques no período de 1968 a 2007. 37

Figura 9. Profundidade média para os dados de comercialização e

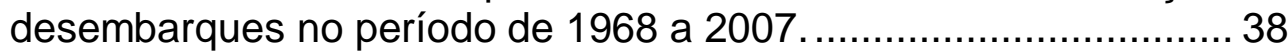

Figura 10. Isóbata Máxima média (Imáx $x_{m}$ ) para os dados de comercialização e desembarques para o período de 1968 a 2007.

Figura 11. Relação piscívoros (pis) e planctívoros (pla) tanto para as quantidades comercializadas como para as desembarcadas. ........ 40

Figura 12. Relação entre pelágicos (pel) e demersais (dem) tanto para as quantidades comercializadas como para as desembarcadas. ........ 41

Figura 13. Importância relativa anual das categorias de pescado desembarcado agrupadas nas diferentes classes de nível trófico entre 1968 e 2007.

Figura 14. Importância relativa anual das categorias de pescado desembarcado de NT-alto entre 1968 e 2007.

Figura 15. Importância relativa anual das categorias de pescado desembarcado de NT-int entre 1968 e 2007. 42

Figura 16. Importância relativa anual das categorias de pescado desembarcado de NT-baixo entre 1968 e 2007.

Figura 17. Importância relativa anual das categorias de pescado comercializadas agrupadas nas diferentes classes de nível trófico entre 1968 e 2007.

Figura 18. Importância relativa anual das categorias de pescado comercializadas de NT-alto entre 1968 e 2007. 
Figura 19. Importância relativa anual das categorias de pescado comercializadas de NT-int entre 1968 e 2007 ................................ 44

Figura 20. Importância relativa anual das categorias de pescado comercializadas de NT-baixo entre 1968 e 2007. .......................... 44

Figura 21. Importância relativa anual das categorias de pescado desembarcado agrupadas nas diferentes classes de longevidade entre 1968 e 2007.

Figura 22. Importância relativa anual das categorias de pescado desembarcado de Long-alta entre 1968 e 2007.

Figura 23. Importância relativa anual das categorias de pescado desembarcado de Long-int entre 1968 e 2007.

Figura 24. Importância relativa anual das categorias de pescado comercializado agrupadas nas diferentes classes de longevidade entre 1968 e 2007.

Figura 25. Importância relativa anual das categorias de pescado comercializado de Long-alta entre 1968 e 2007. 47

Figura 26. Importância relativa anual das categorias de pescado comercializado de Long-int entre 1968 e 2007. 48

Figura 27. Importância relativa anual das categorias de pescado comercializado de Long-baixa entre 1968 e 2007.

Figura 28. Importância relativa anual das categorias de pescado desembarcado agrupadas nas diferentes classes de comprimento máximo (Lmáxalto, Lmáx-int, Lmáx-baixo e invertebrados) entre 1968 e 2007...... 49

Figura 29. Importância relativa anual das categorias de pescado desembarcado de Lmáx-alto entre 1968 e 2007.

Figura 30. Importância relativa anual das categorias de pescado desembarcado de Lmáx-int entre 1968 e 2007.

Figura 31. Importância relativa anual das categorias de pescado desembarcado de Lmáx-baixo entre 1968 e 2007.

Figura 32. Importância relativa anual das categorias de pescado comercializado agrupadas nas diferentes classes de comprimento máximo entre 1968 e 2007 51

Figura 33. Importância relativa anual das categorias de pescado comercializado de Lmáx-alto entre 1968 e 2007. 51

Figura 34. Importância relativa anual das categorias de pescado comercializado de Lmáx-int entre 1968 e 2007. 51

Figura 35. Importância relativa anual das categorias de pescado comercializado de Lmáx-baixo entre 1968 e 2007. 52

Figura 36. Importância relativa anual das categorias de pescado desembarcado agrupadas nas diferentes classes de profundidade (rasas e profundas) entre 1968 e 2007. 
Figura 37. Importância relativa anual das categorias de pescado desembarcado

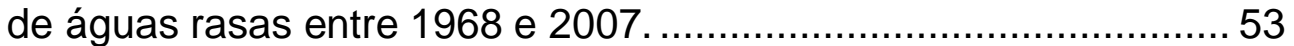

Figura 38. Importância relativa anual das categorias de pescado desembarcado de águas mais profundas entre 1968 e 2007. 53

Figura 39. Importância relativa anual das categorias de pescado comercializado agrupadas nas diferentes classes de profundidade entre 1968 e 2007.

Figura 40. Importância relativa anual das categorias de pescado comercializado de águas rasas entre 1968 e 2007. 55

Figura 41. Importância relativa anual das categorias de pescado comercializado de águas mais profundas entre 1968 e 2007.

Figura 42. Preço da categoria Abrótea em função do tempo, utilizando os quatro índices como deflatores. 56

Figura 43. Preços ponderados deflacionados com os diferentes índices, IGPFGV, IPA-DI-FGV, IPA-OG-carne e pescado e IPC-FIPE. 57

Figura 44. Relação entre o Índice de Preço ao Consumidor - FIPE e o Índice de Preço por Atacado - DI - FGV. 58

Figura 45. Preço médio ponderado para a) todas as categorias comercializadas e b) invertebrados, para o período de 1968-2007. 60

Figura 46. Preço médio ponderado em função das classes de nível trófico, para o período de 1968-2007. 61

Figura 47. Preço médio ponderado em função das classes de longevidade para o período de 1968 a 2007. 62

Figura 48. Preço médio ponderado em função das classes de comprimento máximo para o período de 1968 a 2007.

Figura 49. Preço médio ponderado em função das classes de profundidade para o período de 1968 a 2007. 64

Figura 50. Preços e quantidades comercializadas de 1968-2007 para categorias de NT-alto: a) atum, b) bonito, c) cação-caçonete, d) cação-machote, e) espada, f) espadarte, g) namorado, h) serra, e i) olhete*

Figura 51. Preços e quantidades comercializadas de 1968-2007 para as categorias de NT-int: a) betara, b) castanha, c) garoupa, d) peixegalo, e) pargo, f) pescada-cambucu, g) pescada-maria-mole, h) pescada-tortinha, i) corvina, j) sororoca, k) linguado, I) xixarro* $m$ ) cação-viola*, n) cação-anjo*, e o) pampo*

Figura 52. Preços e quantidades comercializadas de 1968-2007 para categorias de NT-baixo: a) bagre, b) cavalinha, c) manjuba, d) mistura, e) parati, f) robalo, g) sardinha, h) tainha, e i) trilha.

Figura 53. Preços e quantidades comercializadas de 1968-2007 para invertebrados: a) camarão-rosa, b) camarão-sete-barbas, e c) lula.69

Figura 54. Tendência anual do Índice de Preço Relativo Logaritmizado para o período de a) 1968-1989 e de b) 1992-2007, seguidos pelos 
respectivos erros padrões $( \pm 0,35)$ para c) 1968-1989 e d) 19922007.

Figura 55. Tendência anual do Índice de Preço Relativo Logaritmizado (a) com dados interpolados para o período de 1968-2007 e (b) com seu

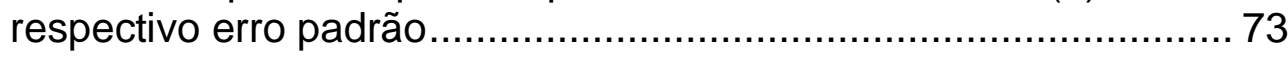

Figura 56. Valor total de comercialização $(R \$)$ por grupos de categorias entre

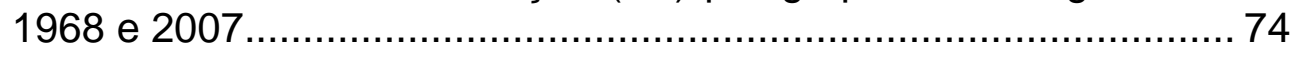

Figura 57. Importância relativa anual do valor dos grupos de categorias entre

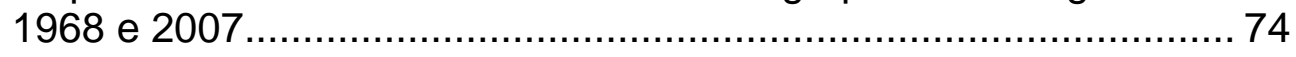

Figura 58. Desembarques totais do Brasil e quantidades totais comercializadas na CEAGESP 75

Figura 59. Síntese das principais mudanças detectadas pela análise de mercado dos grupos ecológicos 
Agradecimentos

Este trabalho é resultado do apoio direto e indireto de muitas pessoas. É difícil, portanto, resumir em um pequeno espaço todos e tudo o que contribuiu para eu chegar até aqui.

Em primeiro lugar quero agradecer a minha orientadora Profa. Dra. Maria de los Angeles Gasalla pela orientação, dedicação, incentivo e oportunidade de aprender mais sobre a complexidade das questões ecológicas e econômicas que envolvem o sistema pesqueiro e seu desenvolvimento ao longo dos anos.

Não posso deixar de citar as pessoas que contribuíram significativamente para a compilação e análise dos dados de mercado. Às Sras. Meire (CEAGESP) e Vilma (biblioteca da ESALQ) pela disponibilização dos dados de mercado do pescado nos boletins da CEAGESP. À Amanda Ricci Rodrigues, Rodrigo Antunes Caíres, e Leandro Ponsoni pela visita à CEAGESP, de madrugada, a fim de confirmar/identificar as espécies de peixes vendidas. E, aos professores da FEA-USP Vera Lúcia Fava e Juarez Rizzieri, pelas dúvidas esclarecidas sobre questões econômicas.

Ao Centro de Estatística Aplicada (IME-USP), às professoras Airlane Pereira Alencar e Clélia Maria de Castro Toloi e ao aluno de graduação em Estatística, Henrique Veichun Lee, pela contribuição nas análises estatísticas dos dados. E, a Leandro Ponsoni pela ajuda nas análises dos dados com 0 Matlab.

Também quero agradecer à Universidade de São Paulo, especialmente, ao Instituto Oceanográfico, não só pelo apoio institucional durante os dois anos de mestrado, mas por permitir um contato com dedicados e atenciosos funcionários e professores. Em especial, à coordenadora do Programa de Pós-graduação em Oceanografia Biológica (Profa. Dra. June Ferraz Dias), aos funcionários da biblioteca (Cida, Claudinha, Maria, Dona Ray e Wagner), da secretaria de pós-graduação (Ana Paula e Silvana), da secretaria do Departamento de Oceanografia Biológica (Marlene e Mirian) e da informática (Valter).

Ao Programa de Aperfeiçoamento de Ensino, pela oportunidade de aprimorar minha formação para a atividade didática de graduação, com suporte financeiro. Nesse sentido, agradeço também às professoras June Ferraz Dias e 
Maria de los Angeles Gasalla pela oportunidade da monitoria do PAE em suas disciplinas para a graduação.

À FAPESP, pelo apoio financeiro, não somente ao longo dos dois anos de mestrado, mas também, pela disponibilidade da reserva técnica a qual tornou possível a participação no congresso internacional 3rd GLOBEC OSM. Marine Ecosystems: from function to prediction, Victoria, BC, Canadá e o estágio no Fisheries Centre, University of British Columbia, Canadá.

Aos revisores anônimos e aos editores da revista Progress in Oceanography pelas valiosas e fundamentais contribuições para o artigo no prelo "Priceless prices and marine food webs: Long term patterns of change and fishing impacts in the South Brazil Bight as reflected by the seafood market", fruto dos resultados encontrados a partir deste projeto de mestrado.

Ao professor Rashid Sumaila (University of British Columbia, Canadá) e toda sua equipe pelo acolhimento durante a visita ao Fisheries Centre e pelas valiosas contribuições e incentivo para este trabalho.

Aos organizadores do International Institute of Fisheries Economics and Trade (IIFET) 2010: Economics of fish resources and aquatic ecosystems: balancing uses, balancing costs, que através do suporte financeiro tornou possível a participação com apresentação de trabalhos relacionados ao tema do mestrado no evento em Montpellier (França).

Aos professores convidados da Banca Examinadora por se disponibilizarem a participar da avaliação da dissertação.

De maneira especial, quero agradecer a todos do Laboratório de Ecossistemas Pesqueiros (LabPesq): Mary, Amanda, Marta, Carol, Felippe e estagiários pela ajuda e amizade durante esses anos.

Às amigas Mariana's (Zezinha, Mari e Mare), Lú, Marta, Carol, Jana, Paula e as amigas de Jundi (Gláu, Carol, Rina e Carla) pelas inúmeras ajudas e companhias em inúmeros momentos!

Agradeço às pessoas que mais amo. A Deus, aos meus pais e irmãos, à minha Família por Tudo.

$E$, finalmente, a todas as demais pessoas e instituições que, direta ou indiretamente colaboraram para a realização deste trabalho. 
Resumo

Alterações no ecossistema marinho e nos estoques pesqueiros devido à pressão da pesca podem ser detectadas por meio de indicadores multiespecíficos. Geralmente, esses indicadores são aplicados a séries temporais de capturas aliados a dados bio-ecológicos dos recursos. Entretanto, abordagens alternativas baseadas em dados de comercialização do pescado podem ser utilizadas. Neste estudo foram aplicados vários indicadores multiespecíficos aos dados disponíveis da região Sudeste/Sul do Brasil, integrando aspectos ecológicos e econômicos de forma inédita para essa região. Para isto, utilizaram-se dados da estatística pesqueira e dados de comercialização de pescado entre 1968-2007, além de dados bio-ecológicos dos recursos (nível trófico, comprimento máximo, longevidade e profundidade). Foram analisadas as tendências desses parâmetros em relação aos desembarques, às quantidades comercializadas e aos preços de mercado. Os indicadores Índice Trófico Marinho, Fishing-in-Balance e Índice de Preço Relativo Logaritmizado também foram explorados. Foi realizada uma análise inferencial das tendências de preço e quantidade das principais categorias de mercado e de suas correlações. A avaliação ecológico-econômica evidencia uma tendência de escassez das espécies-alvo da pesca e de algumas espécies de nível trófico, longevidade e comprimento máximo altos, além do fenômeno "pricing down the food web". Portanto, a base de dados do mercado provou ser valiosa para compreender a dinâmica da pesca numa perspectiva ecossistêmica.

Palavras-chave: indicadores multiespecíficos; preço do pescado; abordagem ecossistêmica; séries temporais; fishing down the food web; dinâmica da pesca; parâmetros bio-ecológicos; alternativas para sistemas pobres em dados. 


\begin{abstract}
Changes in marine ecosystems and fisheries resources due to the fishing pressure can be detected by multispecies indicators. These are, usually, applied to catch or landing time series, jointly the resources bio-ecological data. However, there is an alternative approach, based on market data that could be used. In this study, several multispecies indicators were applied to data from Southeastern/Southern Brazil, integrating ecological and economics aspects to this region in an unprecedented way. Fishery landings and market values for the period 1968-2007 were used, besides bio-ecological classification of seafood categories (trophic level, longevity, maximum length and depth). Trends of these parameters by landings and market quantities and prices were analysed. The Marine Trophic Index, Fishing-in-Balance and the Logarithm Relative Price Index were also applied. Moreover, an inferential analysis of individual categories statistical trends in market prices and quantities and their correlations were done. The joint ecological-economic analysis provided evidence of the scarcity of most higher trophic level, longevity and maximum length categories and fisheries target species, besides the "pricing down the food web" phenomenon. Therefore, the market database proved to be priceless to understand the fishery dynamic in an ecosystem perspective.
\end{abstract}

Keywords: multispecies indicators; market price; ecosystem approach; time series; fishing down the food web; fisheries dynamics; bio-ecological parameters; data-poor systems. 
1. Introdução

A pesca é uma atividade econômica muito importante, pois fornece alimento, emprego e renda para milhares de pessoas (MOORE e JENNINGS, 2000). Segundo o Ministério da Pesca e Aqüicultura (MPA), o Brasil é hoje o $27^{\circ}$ produtor mundial de pescados, mas seu potencial pesqueiro marinho ainda é discutível (BRASIL, 2010a): embora estimativas prévias apontassem um potencial de produção de 1,5 milhões de toneladas de pescado (ROSSIWONGTSCHOWSKI et al., 2007), efetivamente não ultrapassou o patamar das 700 mil toneladas (BRASIL, 2010b).

Evidências mostram que a explotação intensiva dos estoques pesqueiros somada à degradação ambiental têm levado a uma redução substancial de suas abundâncias (CADDY e GARIBALDI, 2000; PAULY et al., 2002; PINNEGAR et al., 2002; ROSSI-WONGTSCHOWSKI et al., 2007), além de mudanças na estrutura e composição das comunidades biológicas (GREENSTREET e HALL, 1996; JENNINGS et al., 1999; GASALLA, 2004a).

Uma das alterações mostradas pelas pesquisas é que a captura intensa dos predadores de topo e a conseqüente depleção desses estoques podem induzir a captura em níveis tróficos (NT) inferiores a esses na comunidade. De fato, a composição da fauna de peixes vem mudando de grandes piscívoros para pequenos planctívoros, numa perspectiva global (PAULY et al., 1998; PAULY et al., 2000).

Outra evidência atual é a expansão da pesca para as regiões mais oceânicas e profundas (KOSLOW et al., 1999; CLARK, 2001; BHATHAL et al., 2008). Recentemente, Morato et al. (2006) constataram que as capturas 
globais tendem, cada vez mais, a atingir profundidades médias maiores, alertando para os sérios riscos de depleção dos estoques demersais profundos, já que, de modo geral, possuem alta longevidade e baixa taxa de crescimento, sendo mais vulneráveis à sobre-pesca.

Nesse sentido, a avaliação e compreensão de mudanças nos ecossistemas é uma questão fundamental no contexto do manejo da pesca baseado no ecossistema (Ecosystem Based Fisheries Management - EBFM) (FAO, 2003). Análises multiespecíficas são necessárias para detectar mudanças ao longo do tempo na estrutura dos ecossistemas marinhos. Portanto, diversos indicadores baseados em aspectos ecológicos são freqüentemente aplicados (GARCIA e STAPLES, 2000; CURY et al., 2005; METHRATTA e LINK, 2005; SUMAILA et al., 2007; SHANNON et al., 2009).

Um primeiro diagnóstico multiespecífico sobre a situação da pesca pode ser feito através de análises das séries temporais das capturas, aliadas a dados bio-ecológicos dos estoques, tais como abundância, comprimento máximo (SUMAILA et al., 1998a), nível trófico (PAULY et al., 1997; VASCONCELLOS e GASALLA, 2001; PAULY et al., 2002; PAULY e PALOMARES, 2005; MILESSI et al., 2005; CURY et al., 2005; BHATHAL e PAULY, 2008), grupo trófico (CADDY e GARIBALDI, 2000; GASALLA, 2004a), profundidade (MORATO et al., 2006), ciclo de vida (JENNINGS et al., 1999) e habitat (DE LEIVA MORENO et al., 2000; GASALLA, 2004a). Porém, uma possível limitação desse tipo de estudo pode ser a indisponibilidade de informações adequadas, já que, muitas vezes, as séries de dados são de difícil acesso e obtenção, não estão completas (contínuas) ou simplesmente não existem (JENNINGS et al., 1999; PINNEGAR et al., 2006). Isto pode ocorrer 
especialmente para aquelas espécies de menor interesse econômico (JENNINGS et al., 1999), e para vários ecossistemas marinhos ao redor do mundo que são considerados como "pobres de dados" (KRUSE, 2003).

Um indicador multiespecífico amplamente utilizado é o nível trófico médio das capturas (PAULY et al., 1998), que tem sido aplicado tanto em análises de escala global como regional. Na escala regional, por exemplo, o nível trófico médio foi aplicado para dados do Golfo da Tailândia (CHRISTENSEN, 1998), da costa oeste do Canadá (PAULY et al., 2001), da costa do Brasil (VASCONCELLOS e GASALLA, 2001; FREIRE e PAULY, 2010), da zona comum de pesca Argentino-Uruguaia (MILESSI et al. 2005), do México (PÉREZ-ESPAÑA et al. 2006), da Índia (BHATHAL e PAULY, 2008) e de Portugal (BAETA et al., 2009). Este indicador foi denominado Índice Trófico Marinho (ITM), desde a última Convenção sobre Diversidade Biológica (CBD) quando foi selecionado para avaliar os progressos quanto à redução da perda de biodiversidade (CBD, 2004). Essa análise é baseada no fato de que os níveis tróficos das categorias de pescado estão relacionados a nichos hierárquicos dentro da cadeia alimentar marinha. Assim, esse indicador refletiu em diversos casos uma captura intensa de predadores e suas conseqüentes depleções que induzem à pesca de NTs inferiores, fenômeno conhecido como "fishing down marine food web", ou seja, "pescando em níves inferiores da cadeia trófica" (PAULY et al., 1998).

Contudo, uma interpretação alternativa para a observação da diminuição do NT médio das capturas foi sugerida por Essington et al. (2006), que se referem como "fishing through marine food web" ("pescando de uma ponta a outra da cadeia trófica"). Neste caso, haveria uma adição seqüencial 
de NTs inferiores, resultando em um declínio na média do NT da captura apesar da pesca de NT altos se manter ou, até mesmo, aumentar (ESSINGTON et al., 2006). No entanto, em alguns ecossistemas, os dados não indicam nem ocorrência do "fishing down marine food web" nem do "fishing through marine food web" (VASCONCELLOS e GASALLA, 2001; PÉREZESPAÑA et al., 2006).

Assim, para que a avaliação da pesca sob enfoque multiespecífico seja mais ampla e sensível às mudanças é recomendável investigar vários tipos de indicadores, pois cada um focaliza um aspecto chave do ecossistema (CURY et al., 2005). Neste contexto, as análises não devem incluir apenas espéciesalvo da pesca, mas também espécies não-alvo, dependentes ou potenciais competidoras, retratando um cenário mais amplo possível, além de procurar abranger tanto aspectos ecológicos como econômicos, sociais, tecnológicos e de governança (CURY e CHRISTENSEN, 2005). Por outro lado, os indicadores multiespecíficos devem apresentar clareza e sensitividade (FULTON et al., 2005), além de serem facilmente parametrizados com base em dados acessíveis e, comunicar uma variedade de processos complexos que ocorrem dentro de um ecossistema através de simples valores numéricos (PAULY e WATSON, 2005).

Deste modo, outra possibilidade de análise recomendada, mas não utilizada com freqüência (LIU et. al., 2005), é aquela que parte de dados econômicos das categorias de pescado, já que essas informações devem existir em alguma instância, são contínuas, e podem evidenciar tendências da explotação dos estoques pesqueiros, uma vez que a economia influencia direta e indiretamente a atividade pesqueira e, portanto, os recursos marinhos 
(PINNEGAR et al., 2006; SUMAILA et al. 2007). Neste sentido, o mercado constitui um aspecto importante que relaciona as dimensões natural (recursos naturais) e humana (consumidores, por exemplo), considerando-se que a pressão pesqueira está diretamente relacionada à demanda de pescado (SUMAILA, 1998b; FAILLER e PAN, 2007).

Por exemplo, os preços carregam a informação de quanto o consumidor está disposto a pagar pelo recurso. Assim, se a demanda é maior do que a oferta, o preço tende a aumentar (ANDERSON, 1977; PINNEGAR et al., 2006). Segundo Hannesson (1998), o aumento da globalização do consumo de produtos pesqueiros significa que seus preços podem ter um comportamento global relacionado com o dos estoques pesqueiros, e a variação no preço pode refletir a abundância ou escassez do recurso no mercado global.

No entanto, dados de mercado de recursos pesqueiros estão normalmente dispersos, incompletos e indisponíveis para os pesquisadores das ciências do mar. Isto tem sido freqüentemente citado pelos economistas como uma lacuna importante tanto para a compreensão das mudanças nos ecossistemas marinhos como para a gestão das pescarias (GUDMUNDSSON et al., 2006; SUMAILA et al., 2007).

No Estado de São Paulo, no estudo de Sonoda et al. (2002) que analisou os preços de mercado do pescado comercializado pela CEAGESP (entre 1980 e 1990), foi verificada uma mudança no preço médio e na quantidade comercializada de pescado, tendo como possíveis fatores a tendência de queda na produção pesqueira devido à sobre-pesca e a busca de canais alternativos a esse mercado. É necessário também considerar que os 
preços de comercialização do pescado podem ser influenciados por mudanças na renda do consumidor, suas preferências e gostos atuais, e pelo preço dos produtos substitutos disponíveis no mercado. Além disso, podem ser afetados pela habilidade e tecnologia utilizada pelos pescadores, bem como por possíveis incentivos financeiros e sociais disponibilizados a esse ramo da economia, além do próprio clima (SUMAILA, 1998; IUDICELLO et al., 1999; PINNEGAR et al., 2006).

Tendo em vista os fatos expostos, o estudo das interações ecológicas e econômicas complementa as avaliações de estoques pesqueiros baseadas em dados populacionais, permitindo um entendimento mais completo do panorama da pesca sendo, portanto, essencial para direcionar ações sustentáveis para essa atividade (DELGADO et al., 2003). De fato, em 2004, durante o congresso internacional "Quantitative Ecosystems Indicators for Fisheries Management" organizado pela Organização das Nações Unidas para a Educação e Cultura (UNESCO), a aplicação desses indicadores foi veemente recomendada (ICES JOURNAL OF MARINE SCIENCE, 2005).

Dessa forma, o presente trabalho pretende analisar os dados disponíveis sobre os volumes de pescado capturado na região Sudeste/Sul do Brasil, sob uma nova ótica, integrando a perspectiva ecológica e econômica, de forma inédita para a região de estudo.

Com isso, espera-se fornecer um panorama multiespecífico sobre os padrões de explotação e comercialização dos recursos vivos marinhos na região, pretendendo elucidar as possíveis alterações no ecossistema e os impactos da pesca. 


\section{Área de Estudo}

A área de estudo (Fig. 1) representa a região onde atua a frota pesqueira industrial do Sudeste do Brasil, concentrada principalmente na plataforma continental adjacente, mas estendendo-se, como um todo, ao largo do Grande Ecossistema Marinho da Plataforma Sul do Brasil.

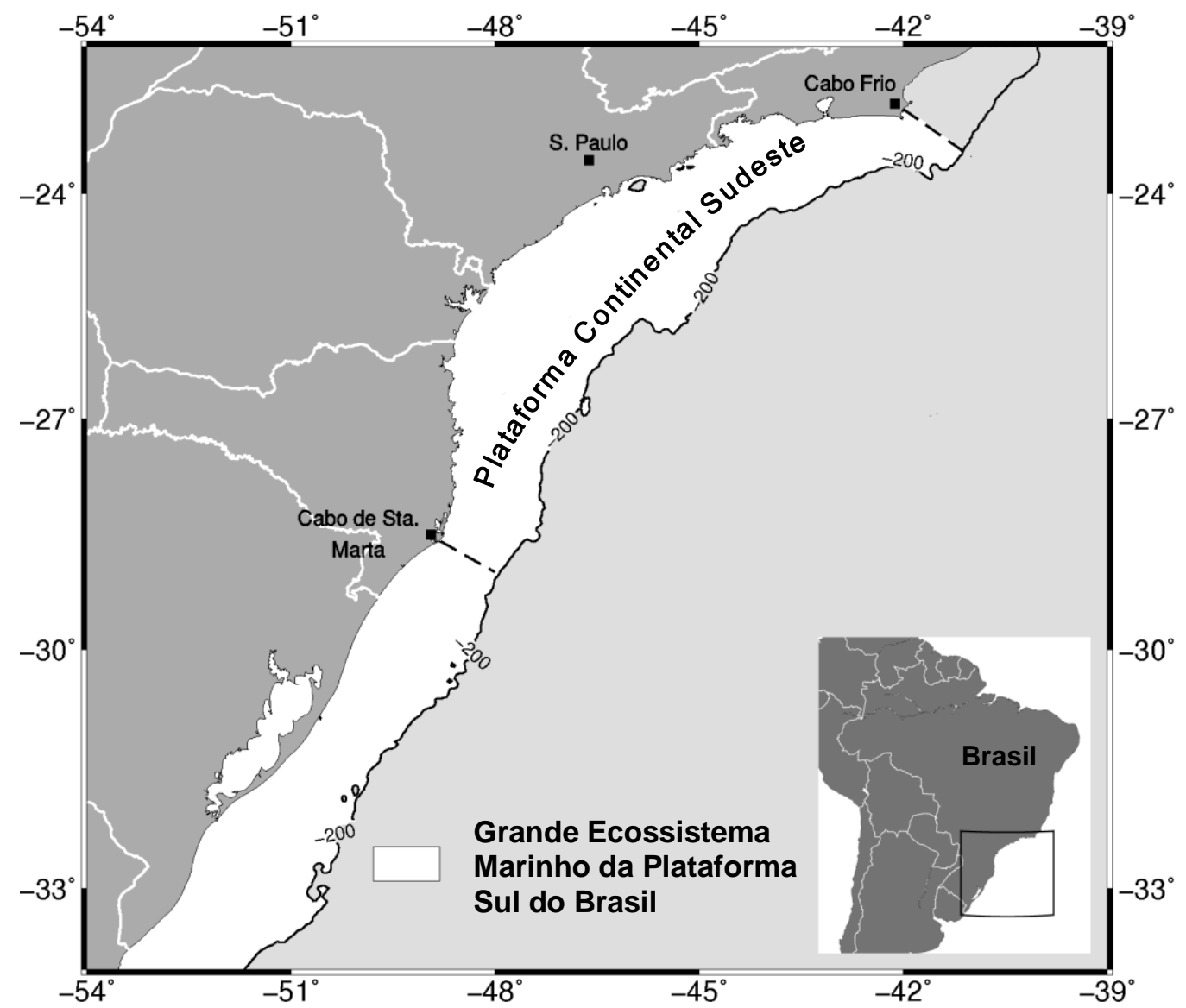

Figura 1. Área de estudo: Plataforma Continental Sudeste do Brasil (PCSE) e o Grande Ecossistema Marinho da Plataforma Sul do Brasil (GEMSB).

Os Grandes Ecossistemas Marinhos (Large Marine Ecosystems ou LMEs) são regiões subdivididas do oceano que englobam a zona costeira, rios e estuários ao largo das plataformas continentais e margens externas dos grandes giros oceânicos (SHERMAN et al., 2009). Estas áreas do oceano são 
diferenciadas por características específicas de batimetria, hidrografia, produtividade e interações tróficas, oferecendo uma abordagem flexível para a gestão baseada no ecossistema e no âmbito do desenvolvimento sustentável (SHERMAN et. al., 2009). Além disso, essa escala de abrangência possibilita uma abordagem para identificar os motivos e padrões de possíveis mudanças no ecossistema marinho.

A Plataforma Continental do Sudeste do Brasil (PCSE) está localizada entre as latitudes $23^{\circ}$ e $28^{\circ} S$, e está compreendida no Grande Ecossistema Marinho da Plataforma Sul do Brasil (GEMSB ou South Brazil Large Marine Ecosystem; Sherman e Hempel, 2008) (Fig. 1). Essa grande região pode ser considerada a mais produtiva da área banhada pela corrente do Brasil, com produtividade moderada alta (150-300 $\left.\mathrm{gCm}^{-2} \mathrm{ano}^{-1}\right)$, e está relacionada ao sistema da confluência Brasil-Malvinas e a fluxos estuarinos (HEILEMAN e GASALLA, 2008).

A região da PCSE pode ser considerada uma unidade biogeográfica sendo definida por pequenos trechos da costa cortados por falésias, pequenas baías e muitas ilhas, isóbatas praticamente paralelas à linha de costa (CASTRO e MIRANDA, 1998) e feições oceanográficas que incluem a ocorrência de vórtices de meso-escala derivados da Corrente do Brasil e ressurgências sazonais (SILVEIRA et al., 2000). Essas características impulsionam a produtividade primária da região e, portanto, a de algumas pescarias, incluindo a pesca da sardinha (CASTRO et al., 1987; GASALLA e ROSSI-WONGTSCHOWSKI, 2004). Além disso, os limites norte e sul dessa região limitam biogeograficamente a distribuição de vários taxa tropicais costeiros e dos sistemas manguezais ao longo da costa Brasileira (LAMARDO 
et al., 2000). Assim sendo, já foi considerada uma unidade apropriada para fins de manejo pesqueiro e para a aplicação de uma abordagem ecossistêmica para a pesca (BRASIL, 1995; GASALLA e TOMÁS). Além disso, essa área é caracterizada pela particular influência e impacto das principais metrópoles brasileiras (São Paulo e Rio de Janeiro).

Entretanto, as frotas pesqueiras não necessariamente respeitam o limite de estudo, e utilizam áreas adjacentes à sua principal concentração (ISAAC et al., 2006). Por outro lado, os dados estatísticos disponíveis são normalmente agrupados por Estado da União, podendo ser subdivididos de modo mais adequado em uma escala diferente do que a da PCSE. Sendo assim, o GEMSB poderia ser considerado como uma escala de análise mais apropriada para o fim deste trabalho, além de possuir características apropriadas para o manejo pesqueiro com base ecossistêmica, pois junto a suas características ambientais particulares, apresenta peculiaridades ecológicas e sócio-econômicas que a diferencia das demais da costa brasileira (HEILEMAN e GASALLA, 2008).

As pescarias que atuam no GEMSB, atualmente, podem ser caracterizadas como normalmente multiespecíficas, devido principalmente à sobre-explotação de alguns recursos-alvo (sardinha, camarões e alguns peixes demersais), como conseqüência, principalmente, da falta de políticas de manejo pesqueiro adequadas, como a política de incentivos à pesca implantada a partir de 1970, que incluiu a redução de taxas para investimentos em empresas pesqueiras (VALENTINI e PEZZUTO, 2006; ABDALLAH e SUMAILA, 2007). O principal tipo de arte de pesca é o arrasto, cujas espéciesalvo são o camarão-rosa, o camarão-sete-barbas e os peixes demersais 
(principalmente corvinas e pescadas). As principais espécies de camarão são consideradas sobre-explotadas, sendo que a pesca do camarão-rosa declinou de 16.629 t. em 1972 para 1.166 t. em 2001 (DIAS NETO e MARRUL FILHO, 2003).

Além disso, a presença de estoques de pequenos peixes pelágicos (particularmente, sardinhas) impulsionou o desenvolvimento da pesca com cerco, especialmente desde 1950 (VASCONCELLOS e GASALLA, 2001). Entretanto, a pesca da sardinha teve seus desembarques reduzidos de 228.000 t. em 1973 para 17.000 t. em 2000. Nos períodos de abundância reduzida da sardinha, as capturas da frota de traineiras (cerco) são diversificadas, inclusive capturando recursos demersais (BRASIL, 2007).

Durante a década de 1980, a pesca de vara-e-linha direcionada para o bonito-listrado (Katsuwonus pelamis) aumentou como consequência da expansão da pesca industrial regional para a plataforma externa e talude (VALENTINI e PEZZUTO, 2006), com as frotas baseadas principalmente no Rio de Janeiro, em Santa Catarina e no Rio Grande do Sul (BRASIL, 2007).

Outras frotas que operam na região sudeste-sul incluem espinhéis, nas zonas de plataforma e oceânicas, capturando espécies que incluem alguns cações, e os emalhes, na zona costeira e na plataforma (ROSSIWONGTSCHOWSKI et al., 2007; HAIMOVICI et al., 2008).

Com relação à comercialização do pescado, um fato relevante é que a Companhia de Entrepostos e Armazéns Gerais de São Paulo (CEAGESP; Fig. 2) localiza-se na maior cidade da região, São Paulo, e historicamente, desde 1966, comercializa pescado oriundo de diversos locais do Brasil, mas 
principalmente da região da PCSE, sendo considerado o maior entreposto de pescados frescos da América Latina (SONODA et al., 2002; CEAGESP, 2009).

Neste estudo, as informações derivadas dos registros de comercialização desse entreposto foram consideradas como um rico acervo histórico de dados pesqueiros, normalmente sub-aproveitado, e que pode ser essencial para uma análise ecológico-econômica inédita da pesca na escala do ecossistema.
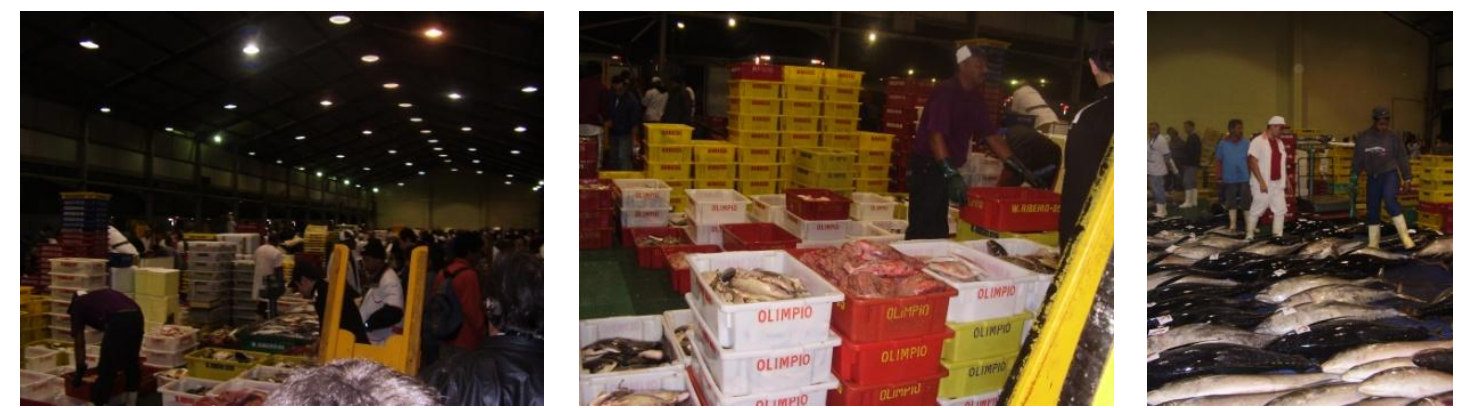

Figura 2. Companhia de Entrepostos e Armazéns Gerais de São Paulo em horário de funcionamento. 


\section{Objetivos}

Este estudo tem como objetivo principal identificar os padrões temporais de explotação pesqueira por meio da aplicação de indicadores multiespecíficos quantitativos, tanto ecológicos (nível trófico, comprimento máximo, longevidade e profundidade média da pesca), quanto econômicos (valores de comercialização).

O trabalho foi norteado por duas hipóteses principais:

(1) o comportamento dos indicadores selecionados deve refletir o processo e as características da intensificação da pesca ao longo do tempo, refletindo mudanças ocorridas no ecossistema marinho.

(2) dados econômicos, como variáveis de mercado, podem ser considerados úteis para identificar alterações na pesca e no ecossistema marinho ao longo do tempo. 


\section{Material e métodos}

A análise dos padrões de explotação dos recursos pesqueiros da região de estudo foi realizada através de duas etapas. A primeira consistiu na compilação, processamento e classificação de informações das estatísticas de desembarque pesqueiro e comercialização de pescado, em uma escala temporal. A segunda etapa consistiu na análise dos dados através da aplicação de diversos indicadores multiespecíficos, e sua plotagem em relação à série temporal de dados de comercialização do pescado (preço e quantidade) e de desembarques pesqueiros, permitindo observar tendências históricas.

3.1. Compilação e processamento dos dados de estatística pesqueira e de comercialização do pescado

Foram compilados tanto dados da estatística pesqueira (quantidades desembarcadas) como dados de comercialização de pescado (preços e quantidades). Os dados da estatística pesqueira são referentes a todo 0 GEMSB, já os dados de comercialização são principalmente relacionados à área da PCSE.

As estatísticas de desembarque pesqueiro entre 1968 e 1985 foram obtidas a partir da base de dados de Sea Around Us (2007), enquanto que valores para o período 1986-2004 foram obtidos a partir de uma revisão de Valentini e Pezzuto (2006) e, também, de outras fontes complementares com outras categorias como textos da SUDEPE (1969, 1978), Araújo (1979), Nakatani et al. (1980), Krug e Haimovici (1991), Valentini e Cardoso (1991), 
Valentini et al. (1991a, b), IBAMA (1993a, b, 1994) e Paiva, 1997. Entretanto, algumas categorias como a merluza e o calamar-argentino foram excluídas das análises, pois os dados de Sea Around Us (2007) pareceram superestimados como já observado em Heileman e Gasalla (2008).

Foi feita, também, uma compilação inédita dos dados mensais do mercado atacadista de pescado de São Paulo (CEAGESP-SP) para o período 1968-2007, incluindo preços e quantidades (em kg) por categoria de pescado. A digitalização de todos os boletins disponíveis (BOLETIM MENSAL CEAGESP, 1968-2007) resultou em uma matriz de 168 categorias de pescado (Anexo 2) por 480 meses, totalizando 80.640 registros.

Os dados históricos de preço do pescado foram convertidos para a moeda Real, no caso dos períodos anteriores ao Plano Real, conforme o histórico de alterações da moeda nacional fornecido pelo Banco Central e IBGE (IPEA, 2008 - Anexo 1).

Além disso, após a devida conversão dos preços, estes foram adequadamente deflacionados a fim de minimizar o possível efeito da inflação e obter os preços ditos "reais". A deflação é necessária, uma vez que durante o período analisado houve no Brasil níveis inflacionários elevados (Fig. 3). 


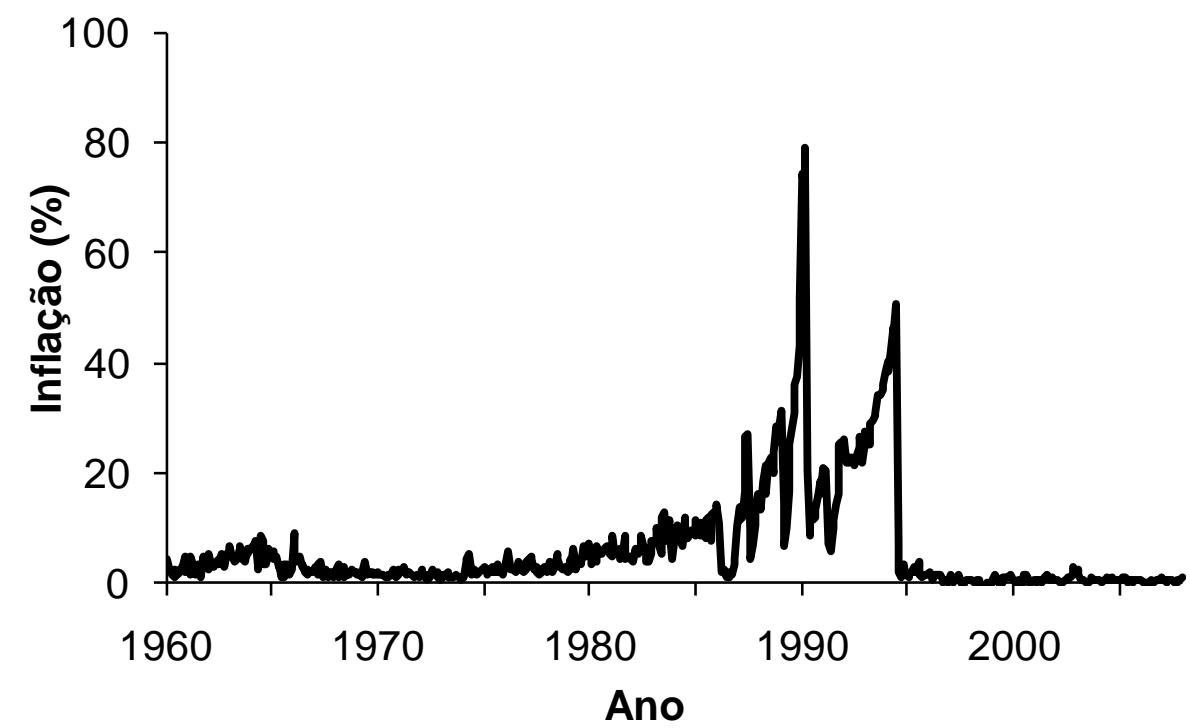

Figura 3. Inflação medida pelo índice de preço ao consumidor no período de 1960 a 2007 (ano base = 2007) (Fonte: IPEA, 2008).

No começo da década de 60 no Brasil, segundo Giambiagi et al. (2005), principalmente a partir do governo militar (1964) foi instaurada uma rígida política monetária, fiscal e salarial, com indexação da economia, que contribuiu para tornar a inflação relativamente sob controle.

$\mathrm{Na}$ década de 70, ocorreram dois choques na economia relativos aos preços do petróleo, causando um aumento da dívida externa brasileira, conduzindo, posteriormente, a algumas crises cambiais. Esse choque do petróleo importado, por exemplo, pode ter atuado na alta de custos de combustíveis utilizados para o transporte de alimentos, inclusive pescado. De modo geral, pelo alto grau de indexação da economia brasileira, as elevações de preços, provocadas por fatores autônomos e outros, se espalharam pela economia, trazendo novos aumentos e, assim, sucessivamente, caracterizando uma inflação inercial. Nesse período, a política econômica governamental promoveu uma tentativa de manter o ritmo de crescimento do país igual ao da década anterior. No caso da pesca, houve um grande incentivo à 
modernização das frotas pesqueiras, resultando em um aumento expressivo das capturas (ABDALLAH e SUMAILA, 2007).

$\mathrm{Na}$ década de 80, a inflação atingiu níveis acima das expectativas do controle oficial, alcançando seu máximo no começo da década de 90. Foram instaurados, nesse período, diversos planos com o objetivo de diminuir o nível da inflação: o Plano Cruzado (1986), Plano Bresser (1987), Plano Verão (1988) e Planos Collor (1990). Esses planos, com eficácia temporária, atuavam no congelamento dos preços, no contingenciamento de importações, na taxação sobre a exportação, na indexação salarial e outros (GIAMBIAGI et al., 2005).

O último plano aplicado para tentar reduzir o nível de inflação foi o Plano Real (desde 1994), o qual nos últimos anos apresentou níveis mais baixos do índice inflacionário (IPEA). Entretanto, apesar de alcançar níveis próximos aos de países desenvolvidos, a inflação persiste (Fig. 3).

Assim, dentre os possíveis deflatores, quatro foram testados: Índice Geral de Preços - Disponibilidade Interna da Fundação Getúlio Vargas (IGPDI-FGV), Índice de Preço por Atacado - Disponibilidade Interna da Fundação Getúlio Vargas (IPA-DI-FGV), Índice de Preço por Atacado da Fundação Getúlio Vargas - Oferta Global - carnes e peixes (IPA-OG-FGV) e Índice de Preços ao Consumidor da região metropolitana de São Paulo- Fundação Instituto de Pesquisas Econômicas (IPC-RMSP-FIPE).

O Índice Geral de Preços - Disponibilidade Interna (FGV) registra a inflação dos preços, desde matérias-primas agrícolas e industriais, até bens e serviços finais. O fato de ser disponibilidade interna indica que no cálculo não fazem parte produtos de exportação (PINHO e VASCONCELLOS, 2003). Esse índice é composto por três outros: Índice de Preços por Atacado (IPA), Índice 
de Preços ao Consumidor - Brasil (IPC) e Índice Nacional de Custos da Construção (INCC), com ponderações de 60\%, 30\% e 10\%, respectivamente (FGV, 2009). O IGP é calculado desde 1944.

O Índice de Preço por Atacado - Disponibilidade Interna (IPA-DI-FGV) considera em seu cálculo somente os preços de produtos no atacado, sendo que não fazem parte os produtos de exportação, refletindo melhor a inflação dita doméstica (FGV, 2009). Já o Índice de Preço por Atacado - Oferta Global (IPA-OG-FGV) é calculado em relação aos produtos no atacado, porém considerando tanto produtos de uso interno como os de exportação. Esses índices estão disponíveis desde julho de 1944.

O Índice de Preços ao Consumidor - RMSP (IPC-RMSP-FIPE), disponível desde o ano de 1960, reflete o comportamento do preço no varejo dos produtos de importância na cesta básica do consumidor. No caso específico, são produtos comercializados na região metropolitana de São Paulo. O cálculo deste índice é feito através da média geométrica, obtendo-se, portanto, de modo geral, valores mais baixos que os dos outros índices que utilizam a média aritmética (PINHO e VASCONCELLOS, 2003).

O dólar poderia, do mesmo modo, ser utilizado como deflator. Entretanto, neste caso, não foi recomendado, uma vez que a política cambial de certos períodos em questão manteve a taxa de câmbio fixa, gerando assim preços irreais para o pescado (FAVA, com. pess. ${ }^{1}$ ).

Após as análises dos deflatores, foi escolhido o mais apropriado para utilização nas análises do presente trabalho.

\footnotetext{
${ }^{1}$ Professora Dra. Vera Fava, Faculdade de Economia e Administração, Universidade de São Paulo.
} 
Por fim, para todas as análises, as séries temporais dos dados de comercialização foram utilizadas adotando-se as médias anuais dos preços e a soma das quantidades mensais anualmente calculadas para cada categoria de pescado. Para a série de desembarques, foram utilizados os valores anuais de quantidade desembarcada para cada categoria.

3.2. Classificação das categorias de pescado da estatística pesqueira e da comercialização

As categorias de pescado correspondem àquelas originárias principalmente da PCSE e áreas adjacentes. A maioria das categorias de pescado coincide com o nível de espécie. No entanto, algumas categorias são uma agregação de diversas espécies, representando, portanto, aproximadamente 400 espécies comercializadas. A correspondência feita entre os nomes populares e científicos das espécies (Anexo 2) foi baseada em Silva (1944), Zavala-Camin (1974), Ferreira e Souza (1990), Paiva e Andrade (1994), Carvalho-Filho (2002), SÃO PAULO (2004), IBAMA (2007) e Begossi et al. (2008). Além disso, a fim de confirmar a identificação taxonômica de algumas categorias foi realizada uma visita ao referido Entreposto durante o seu período comercial (à noite), com uma equipe de especialistas em sistemática de peixes (Amanda Ricci Rodrigues e Rodrigo Antunes Caíres).

As categorias de pescado foram classificadas de acordo com os seguintes parâmetros ecológicos: nível trófico, longevidade, grupo trófico (piscívoro/zooplanctívoro), habitat (pelágicos/demersais) e profundidade em que ocorrem. Tais parâmetros foram compilados de informações disponíveis na 
literatura científica, além de bases bibliográficas, teses, dissertações, bases de dados globais, como o FishBase (www.fishbase.org), entre outros.

A classificação adotou, sempre que possível, os seguintes critérios baseados em Caddy e Garibaldi (2000):

(a) o estágio de vida considerado é aquele em que a espécie é explotada, geralmente, os adultos.

(b) as espécies que apresentam variações sazonais nos diversos parâmetros foram classificadas, em cada caso, de acordo com a literatura disponível.

(c)quando diferenças geográficas foram encontradas, foram classificadas de acordo com o dado coletado na área de pesca onde as espécies foram selecionadas.

E, apesar de constituírem uma importante fração tanto dos desembarques como da comercialização, categorias como "mistura" e "outros peixes" não foram consideradas nas análises, uma vez que não há informações detalhadas que permitam classificá-las para os cálculos dos indicadores.

Os parâmetros para as categorias gerais como "cações", "pescadas", "pescada-pequena", "pescada-média" e "pescada-grande" foram calculados pela média das categorias específicas, no caso do nível trófico, profundidade, longevidade, comprimento máximo e isóbata máxima, e definidos pelos parâmetros da maioria das categorias específicas, no caso de habitat e de grupo trófico. 


\subsubsection{Nível Trófico}

No caso da estimativa do nível trófico, foi possível classificar categorias de pescado (116; Anexo 2) baseando-se em estudos locais de hábitos alimentares, modelagem e isótopos estáveis. Além disso, foi utilizada a base de dados FishBase (FROESE e PAULY, 2010), que disponibiliza estimativas de NT a partir de itens alimentares para muitas espécies (www.fishbase.org.br). Quando valores de fontes diferentes foram encontrados, adotou-se um valor médio.

Quando a fonte utilizou análises de conteúdos estomacais, foram adotados, sempre que possível, valores de importância relativa em peso, ou realizados cálculos da importância das categorias de presas que compõem o espectro alimentar dos recursos pesqueiros estudados com base nas informações disponíveis. A definição do cálculo do nível trófico fracional (NTF) para cada recurso (ODUM e HEALD,1975; CHRISTENSEN e PAULY, 1993; CADDY e GARIBALDI, 2000) é:

$$
N T F_{i}=1+\sum D C_{i j} * N T_{j}
$$

onde, $\mathrm{DC}_{\mathrm{ij}}$ é a proporção da espécie $j$ na dieta da espécie $i$ e NT $j$ é o nível trófico da espécie $j$. O valor 1,0 refere-se aos produtores primários e detrito, e 2,0, 3,0... indicam os níveis tróficos heterotróficos sucessivos.

Quando os níveis tróficos foram baseados em isótopos estáveis sua definição seguiu a equação (MINAGAWA e WADA, 1984):

$$
N T I_{i}=\frac{\left[\delta_{\text {animal }}^{15}-\delta_{\text {fitoplâncton }}^{15}\right]}{3,14}+1
$$


onde 3,14 representa o fator médio de enriquecimento entre os níveis tróficos e 1 é o nível trófico do produtor primário.

\subsubsection{Longevidade}

As categorias de pescado (74; Anexo 2) foram classificadas quanto sua longevidade. Quando disponível, foi calculada a longevidade através da compilação de parâmetros de crescimento das espécies, tais como o comprimento assintótico $\left(L_{\infty}\right)$ e a taxa de crescimento $(k)$ em relação ao $L_{\infty}$, descritos pela equação do crescimento de von Bertalanffy:

$$
L_{t}=L_{\infty}\left(1-e^{-k\left(t-t_{0}\right)}\right)
$$

onde $L_{t}$ é o comprimento na idade $t$ e $t_{0}$ é o tempo em que o comprimento é zero no modelo da trajetória de crescimento.

Foram considerados os diversos procedimentos para a estimação dos parâmetros da curva de von Bertalanffy, como através da distribuição das freqüências de comprimento, experimentos de captura e marcação e da análise do crescimento dos otólitos, vértebras e escamas, por exemplo (KING, 1995).

A partir dos parâmetros de crescimento estabelecidos para os recursos, foi obtida a respectiva longevidade, que é definida como o tempo necessário para o indivíduo alcançar $95 \%$ do $L_{\infty}$, conforme descrito na equação abaixo (KING, 1995):

$$
t_{\text {máx }}=-\frac{1}{k} * \ln \left(1-\frac{0,95 L_{\infty}}{L_{\infty}}\right)
$$

Além disso, também foram compilados dados de longevidade de estudos onde tal parâmetro já havia sido calculado e fornecido. Quando diversos valores de fontes diferentes foram encontrados adotou-se uma média. 


\subsubsection{Comprimento Máximo}

Foi compilado o comprimento máximo (Lmáx.) de 116 categorias de pescado (Anexo 2), baseando-se principalmente em: Figueiredo (1977); Figueiredo e Menezes (1978); Figueiredo e Menezes (1980); Menezes e Figueiredo (1980); Menezes e Figueiredo (1980); Menezes e Figueiredo (1985); Figueiredo e Menezes (2000), sendo que quando em outros estudos da região foram encontrados exemplares maiores, o valor mais alto foi adotado.

\subsubsection{Profundidade}

Foram compiladas informações referentes à profundidade comum onde as categorias (120; Anexo 2) se encontram. Essa faixa é definida como a faixa onde adultos são frequentemente encontrados, e é mais precisamente definida como a faixa em que $95 \%$ da biomassa das espécies ocorrem (FROESE e PAULY, 2004). A profundidade média de ocorrência para taxa identificados ao nível específico foi estimada como a média da profundidade comum. Para aqueles taxa não reportados a nível específico, a média para o gênero ou família foi calculada usando as espécies mais presentes naquela localidade. Quando informações sobre o mínimo e o máximo de profundidade foram compiladas, a profundidade média de ocorrência foi calculada como sendo um terço da faixa de distribuição total. Segundo Morato et al. (2006), a abundância dos peixes apresenta uma distribuição lognormal com a profundidade, cujo pico 
corresponde a um terço da faixa de distribuição total (ALVERSON et al., 1964; PAULY e CHUA, 1988).

Quando houve mais de uma fonte com valores diferentes de máximo e mínimo de profundidade foram utilizados os valores extremos de cada trabalho e seguido o cálculo anteriormente descrito.

\subsubsection{Isóbata Máxima de ocorrência}

Quando disponível, a isóbata máxima de pesca de cada categoria foi compilada (140; Anexo 2). Esse valor pode ser relacionado com a distância da costa em que o pescado ocorre e não somente com sua profundidade. A classificação de cada categoria foi baseada na sua distribuição espacial (zona nerítica, oceânica, etc.) e também naquela das frotas pesqueiras que capturam os recursos (GASALLA e TOMÁS, 1998; CERGOLE et al., 2005; ROSSIWONGTSCHOWSKI et al., 2005, 2007; ISAAC et al., 2006).

\subsubsection{Características ecológicas: grupo trófico e habitat}

Além disso, através do nível trófico considerado (ver item 3.2.1) e também por informações adicionais da literatura sobre as dietas específicas, as categorias de pescado foram classificadas quanto ao seu tipo de alimentação, como piscívoras e planctívoras (84; Anexo 2), conforme proposto por Caddy e Garibaldi (2000), Gasalla (2004a) e Cury et al., 2005. Como piscívoros foram

classificados recursos cujas dietas continham principalmente peixes e 
cefalópodes pelágicos, e como planctívoros, dietas cujo item alimentar predominante era plâncton (fito e zooplâncton).

As categorias de pescado também foram distinguidas entre pelágicas ou demersais, sendo que do total de categorias, 116 (Anexo 2), foram classificadas quanto a esse parâmetro. Categorias cujo habitat pode ser considerado tanto pelágico como demersal não foram computadas.

\subsection{Análise dos dados}

3.3.1. Análise das quantidades desembarcadas e comercializadas

\subsubsection{Indicadores Multiespecíficos}

\subsubsection{1. Índice Trófico Marinho (ITM)}

O Índice Trófico Marinho (PAULY e WATSON, 2005) foi estimado para os desembarques e para as séries de mercado:

$$
I T M=\frac{\sum N T_{i} Y_{i j}}{\sum Y_{i j}}
$$

onde $Y_{i j}$ é o desembarque (ou quantidade comercializada) das espécies $i$ no ano $j$ e $\mathrm{NT}_{i}$ são seus respectivos níveis tróficos.

Este índice foi proposto inicialmente como o NT médio das capturas (PAULY et al., 1998) a fim de testar o fato de que as pescarias tendem a remover do ecossistema primeiro os peixes maiores e de crescimento tardio induzindo a uma contínua redução do NT médio dos peixes que permanecem no ecossistema. 


\subsection{Fishing-in-Balance (FiB)}

Foi calculado também o Fishing-in-Balance (FiB) (PAULY et al., 2000), cuja equação é:

$$
F i B=\log \left[\frac{\left(\sum_{i} Y_{i j}\left(\frac{1}{E T}\right)^{N T_{i}}\right)}{\left(\sum_{i} Y_{i 0}\left(\frac{1}{E T}\right)^{N T_{i}}\right)}\right]
$$

onde, $Y_{i k}$ é a quantidade desembarcada ou comercializada de cada categoria $i$ em cada ano $j, Y_{i 0}$ é a quantidade desembarcada ou comercializada de cada categoria $i$ no ano utilizado como base (1968), NT é o nível trófico da categoria de pescado $i$, e ET é a eficiência de transferência de energia média entre os níveis tróficos, sendo geralmente 10\% (PAULY e CHRISTENSEN, 1995; VASCONCELLOS e GASALLA, 2001).

Este índice foi proposto para verificar se há balanço nos padrões de explotação em termos ecológicos. Esse índice permite minimizar possíveis erros quanto ao fenômeno denominado "fishing down marine food web" (PAULY et al., 1998) e o ITM.

Portanto, o FiB aborda a quantidade de captura e sua composição ecológica, permitindo presumir sobre a estrutura do ecossistema subjacente. 


\subsection{Longevidade média ( Long $\left._{\mathrm{m}}\right)$}

O parâmetro ecológico "longevidade" foi ponderado em função dos desembarques e das quantidades comercializadas na CEAGESP (Long $\mathrm{m}_{\mathrm{m}}$ ), seguindo a definição:

$$
\operatorname{Long}_{m}=\frac{\sum \operatorname{Long}_{i} Y_{i j}}{\sum Y_{i j}}
$$

onde Long $_{i}$ é longevidade definida para cada categoria $i, Y_{i j}$ é 0 desembarque (ou quantidade comercializada) da categoria $i$ no ano $j$.

\subsection{Comprimento-Máximo médio (Lmáx $\mathrm{m}$ )}

O Comprimento-Máximo médio (Lmáx $\mathrm{m}_{\mathrm{m}}$ é a ponderação dos comprimentos máximos de cada categoria em função dos desembarques e das quantidades comercializadas na CEAGESP, seguindo a definição:

$$
\text { Lmáx } x_{m}=\frac{\sum L \text { máx } x_{i} Y_{i j}}{\sum Y_{i j}}
$$

onde Lmáx $x_{i}$ e o comprimento máximo definido para cada categoria $i, Y_{i j}$ é o desembarque (ou quantidade comercializada) da categoria $i$ no ano $j$.

\subsection{Profundidade média ( $\left.\operatorname{Prof}_{m}\right)$}

Para cada ano foi estimada a média ponderada de profundidade de ocorrência das categorias de pescado, em função de seus desembarques e quantidades comercializadas, seguindo a definição: 


$$
\text { Prof }_{m}=\frac{\sum \operatorname{Prof}_{i} Y_{i j}}{\sum Y_{i j}}
$$

onde $\operatorname{Prof}_{i}$ é a profundidade média definida para cada categoria $i, Y_{i j}$ é 0 desembarque (ou quantidade comercializada) da categoria $i$ no ano $j$.

Morato et al. (2006) propôs este método para verificar a tendência de eventual expansão (ou recuo) das pescarias para as águas profundas.

\subsection{Isóbata máxima média (Imáx $\left.x_{m}\right)$}

Foi também estimada a isóbata máxima média ao longo dos anos ponderada tanto pelos dados de desembarque como pelas quantidades comercializadas dos pescados, conforme a equação:

$$
\text { Imáx } x_{m}=\frac{\sum \operatorname{Imáx} x_{i} Y_{i j}}{\sum Y_{i j}}
$$

onde Imáx $x_{i}$ é a profundidade média definida para cada categoria $i, Y_{i j}$ é $o$ desembarque (ou quantidade comercializada) da categoria $i$ no ano $j$.

\subsection{Razão piscívoros/planctívoros (pis/pla)}

A razão das categorias de pescado que pertencem aos grupos tróficos determinados como piscívoros e planctívoros ao longo de um período de tempo foi estimada para os dados de desembarques e para as quantidades comercializadas.

Conforme Caddy e Garibaldi (2000) e Gasalla (2004a), a relação entre piscívoros/zooplanctívoros (PS/ZP) é um importante indicador para monitorar mudanças no ecossistema, pois suporta mecanismos tanto top-down como 
bottom-up. Tais autores recomendam seu uso em escalas menores, como esta em questão. Entretanto, neste trabalho, foi utilizada uma variação dessa razão tal como sugerida por Cury et al. (2005), que envolve a utilização da categoria "planctívoros" (Pla) ao invés de "zooplanctívoros", isto é, são incluídos os organismos que se alimentam de fitoplâncton também.

\subsection{Razão pelágicos/demersais (pel/dem)}

Foi também analisada a razão pel/dem tanto para a série de dados de desembarques como para a de quantidades comercializadas. Tanto De Leiva Moreno et al. (2000) como Cury et al. (2005) sugerem utilizar essa razão entre as capturas de recursos pel/dem em um período de tempo (p. ex., por ano), para avaliar tendências multiespecíficas.

3.3.1.2. Importância relativa das categorias em função das diferentes classes de parâmetros ecológicos

A fim de detalhar as mudanças relacionadas aos indicadores multiespecíficos referentes às quantidades desembarcadas e comercializadas a importância relativa dessas variáveis foram calculadas anualmente em função das classes definidas para cada parâmetro. No caso, do NT, 116 categorias foram agrupadas em quatro diferentes classes de NT: NT-alto $(\mathrm{NT} \geq 4,0), \quad \mathrm{NT}$ intermediário $\quad(\mathrm{NT}$-int $) \quad(4,0>\mathrm{NT}>3,3), \quad \mathrm{NT}$-baixo $\quad(\mathrm{NT} \leq 3,3) \quad \mathrm{e}$ Invertebrados. Já em relação à longevidade, 74 categorias foram agrupadas nas três classes: Long-baixa (Long $\leq 5$ anos), Long-int (5>Long>20 anos) e 
Long-alta (Long $\geq 20$ anos). Adicionalmente, 116 categorias foram agrupadas conforme seu comprimento máximo: Lmáx-baixo (Lmáx<300 mm), Lmáx-int

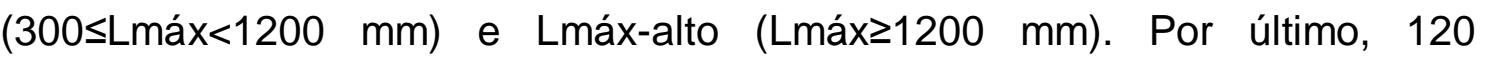
categorias foram reunidas em duas classes em relação às suas profundidades médias: rasas (Prof $\leq 66$ metros) e profundas (Prof $>66$ metros).

3.3.2. Análise das variáveis de preço e quantidades comercializadas

3.3.2.1. Preço ponderado das categorias de pescado em função dos parâmetros ecológicos ao longo dos anos

O preço anual de cada categoria do mercado ponderado pela sua quantidade comercializada foi utilizado como indicador, já que o preço pode estar linearmente correlacionado com a quantidade comercializada (SUMAILA 1998a; PINNEGAR et al. 2002; 2006). Esse indicador segue a seguinte definição:

$$
P_{m}=\frac{\sum P_{i j} Y_{i j}}{\sum Y_{i j}}
$$

onde $Y_{i j}$ é a quantidade comercializada da categoria $i$ no ano $j$, e $\mathrm{P}_{i j}$ é seu preço no ano $j$.

Para esta análise, categorias comercializadas na CEAGESP foram classificadas em grupos de acordo com os parâmetros ecológicos, conforme descrito anteriormete (ver item 3.3.1.2) 
3.3.2.2. Índice do Preço Relativo Logaritmizado (IPRL)

O Índice do Preço Relativo Logaritmizado ou Logarithm Relative Price Index (LRPI), proposto por Pinnegar et al. (2002; 2006) e baseado em Sumaila (1998b), foi calculado ajustando as regressões lineares anuais do logaritmo dos preços versus o NT das respectivas categorias. O conceito é baseado no fato de que espécies de NT-alto geralmente obtêm valores maiores de mercado que as espécies de NT-baixo (PINNEGAR et al., 2002; 2006).

O IPRL representa o coeficiente angular (b) da regressão linear entre o logarítimo do preço (neste caso, em $\mathrm{R} \$ \mathrm{~kg}^{-1}$ ) para um ano particular, e os NTs de cada categoria de pescado (e.g., Fig. 4), conforme apresentado abaixo:

$$
b=\frac{\log P R-a}{N T}
$$

onde $b$ é o índice, o Log PR é o logarítimo do preço relativo ao preço de todas as categorias para um ano particular e NT, o nível trófico de todas as categorias de pescado. O logaritimo é usado para minimizar o efeito da inflação, já que essa age de forma não-linear e resulta em maiores aumentos absolutos no preço das categorias de maior valor comparado com as de menor valor (PINNEGAR et al., 2006). E, também, porque tal estratégia destaca a diferença entre os preços das espécies.

Duas séries temporais diferentes foram utilizadas para a aplicação deste indicador: i) somente com dados originais completos e ii) com mais categorias, porém com a série de dados interpolados. No primeiro caso (i), somente as categorias, com a série original completa, incluindo invertebrados, foram consideradas. A fim de melhorar as análises, considerando tantas 
categorias quanto possível, o período foi dividido em duas partes: 1968-1989 (com 42 categorias) e 1992-2007 (com 38 categorias). A segunda série temporal utilizada (ii) baseou-se em 99 categorias, cujos valores faltantes foram interpolados seguindo critérios sugeridos por Sumaila et al. (2007): 1) quando havia categorias semelhantes, os valores faltantes seguiram os da categoria similar, 2) quando somente alguns anos estavam faltando a média ponderada foi utilizada, e 3) quando os dados do início ou do final do período estavam faltando, o valor do período mais próximo foi considerado constante.

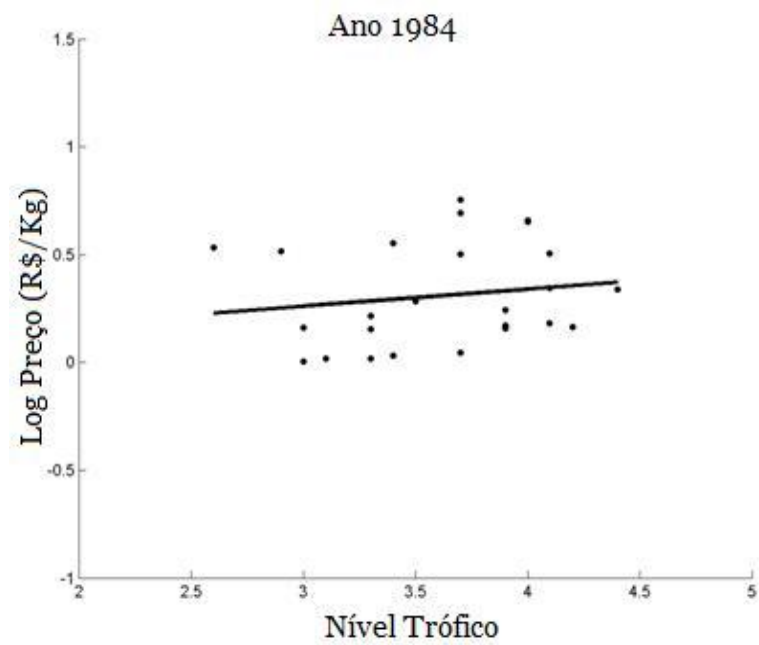

Figura 4. Logaritmo do preço em função do nível trófico de cada categoria para o ano de 1984 (exemplo), com coeficiente angular igual a 0,11.

\subsubsection{Valor total das categorias de pescado}

Valores anuais totais das categorias de mercado e suas importâncias relativas foram calculadas para o período de $1968-2007$ a fim de verificar se 0 máximo da receita da comercialização do pescado correspondeu ao máximo da quantidade comercializada e desembarcada. O valor total anual corresponde à soma de cada valor total da quantidade comercializada (preço $\mathrm{x}$ quantidade, em $R \$$ ) por grupo taxonômico e por ano. 
3.3.2.4. Análise inferencial das séries temporais de preço e quantidade comercializada das principais categorias de pescado

Os preços altos, geralmente, se referem à escassez da oferta de pescado (quantidades comercializadas) (CLARK, 2006). Embora, as alterações no gosto e preferência dos consumidores e substituição possam influenciar a relação do preço e da quantidade, os preços podem ser utilizados para detectar o "efeito da escassez" nas categorias de pescado e, assim, podem ser considerados como um indicador de pressão ou mesmo um sinal de sobreexplotação.

A fim de compreender as mudanças relativas aos indicadores multiespecíficos e verificar se eles mostram uma mudança real, foi realizada uma análise detalhada de 44 categorias de pescado comercializadas na CEAGESP (Tab. 1), incluindo uma análise inferencial (ver seção Análises estatísticas). Estas categorias de mercado correspondem a $62-90 \%(\mathrm{em} \mathrm{Kg})$ do volume do mercado total anual e possuem as séries temporais mais completas (<10\% de dados faltantes) durante o período de 1968-2007.

\subsection{Análises estatísticas}

A fim de testar a significância das tendências das séries temporais, foi aplicado o teste não-paramétrico de Cox-Stuart (CONOVER, 1980) para o ITM, o FiB, o IPRL, as razões de pel/dem e pis/pla, o preço e as quantidades (comercialização e desembarques) ponderados em função dos parâmetros 
ecológicos (nível trófico, longevidade, comprimento máximo e profundidade). O nível de significância de $5 \%$ foi adotado para todos os testes.

Além disso, a fim de testar a teoria econômica da lei do mercado para o banco de dados da CEAGESP, as seguintes questões foram avaliadas estatisticamente: i) a correlação entre o preço e a quantidade de cada categoria através do coeficiente linear de Pearson; ii) a significância dessa correlação, e iii) a significância das tendências dos preços e das quantidades das categorias utilizando o teste não-paramétrico de Cox-Stuart (CONOVER, 1980; BUSSAB e MORETTIN, 2006). 
4. Resultados

4.1. Análise das quantidades desembarcadas e comercializadas

\subsubsection{Indicadores Multiespecíficos}

\subsubsection{1. Índice Trófico Marinho (ITM)}

O Índice Trófico Marinho (ITM) exibiu tendências crescentes ao longo dos 40 anos, tanto para as quantidades desembarcadas quanto para as comercializadas na CEAGESP (Fig. 5). No caso dos desembarques, esse indicador aumentou significativamente de 3,05 até 3,47 ( $p<0,05)$, e de 3,09 até 3,60 $(p<0,05)$ com os dados de mercado. A tendência crescente tornou-se mais suave quando as sardinhas, camarões e atuns e afins foram excluídos da análise, variando entre 3,42 e 3,62 ( $p>0,05)$ para os dados de mercado, e entre $3,26$ e 3,53 ( $p<0,05)$ para os dados de desembarque pesqueiro (Fig. 5).

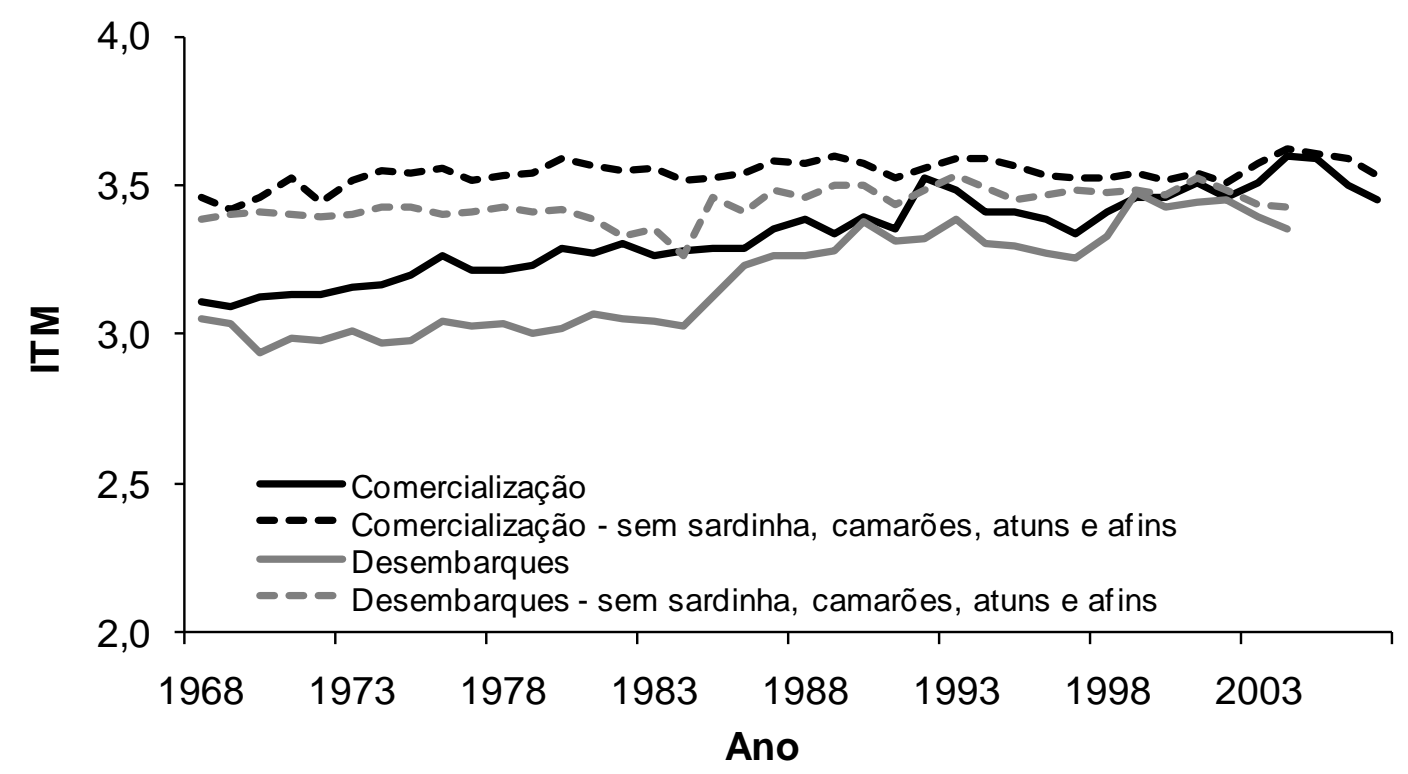

Figura 5. Índice Trófico Marinho para os dados de desembarques e da comercialização entre 1968 e 2007. 
O Fishing-in-Balance $(\mathrm{FiB})$ referente aos desembarques apresentou uma tendência geral crescente $(p<0,05)$ (Fig. 6). Quanto aos dados de comercialização, o FiB apresentou uma tendência ascendente $(p<0,05)$ até 1985, quando permaneceu aproximadamente constante com uma suave queda a partir de 1997 (Fig. 6).

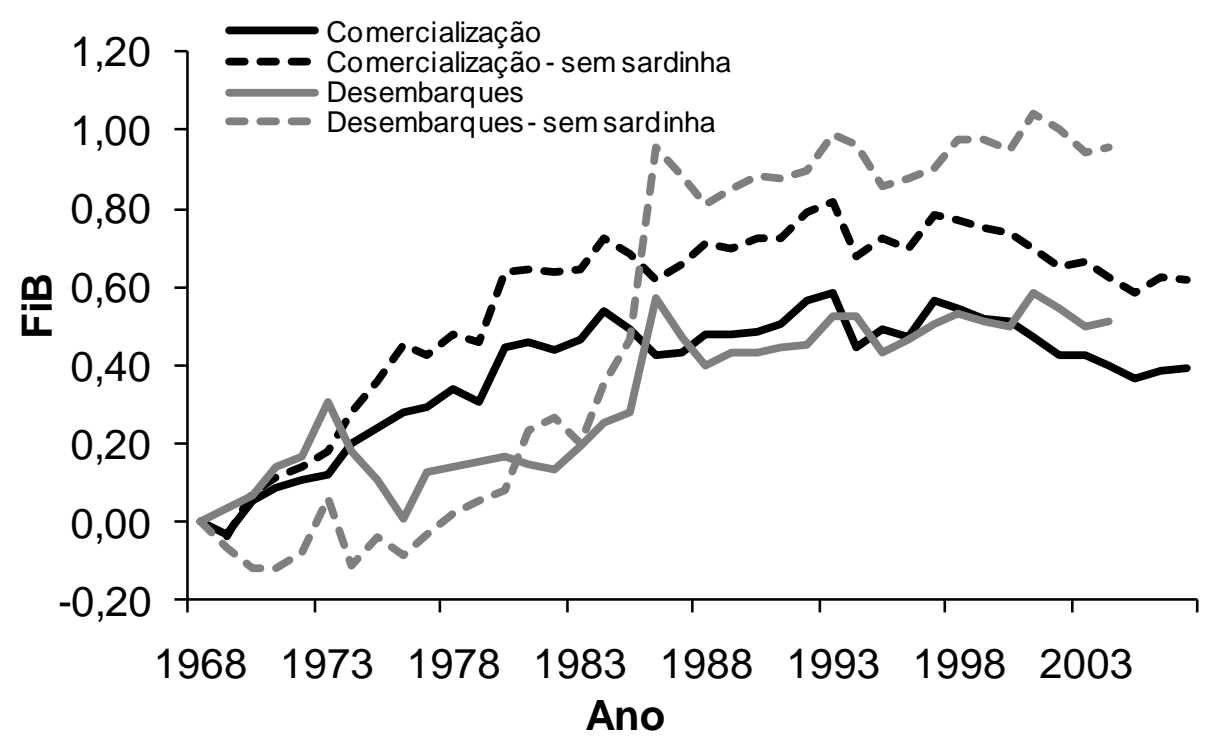

Figura 6. Fishing-in-Balance para os dados de comercialização e de desembarque entre 1968 e 2007.

\subsubsection{Longevidade média (Long $\mathrm{m}_{\mathrm{m}}$}

A longevidade média ao longo dos anos para os desembarques e para as quantidades comercializadas é mostrada na figura 7 , exibindo tendências crescentes significativas $(p<0,05)$. $O$ aumento da longevidade média variou de 7,98 a 17,19 anos nos desembarques e de 4,92 a 10,74 anos na comercialização. Quando sardinhas e atuns foram excluídos da análise, a tendência crescente dos dados de desembarque, ainda que significativa, 
tornou-se mais suave, variando de 5,20 a 12,06, enquanto que na comercialização a tendência tornou-se decrescente $(p<0,05)$, oscilando de 12,75 a 16,60 anos.

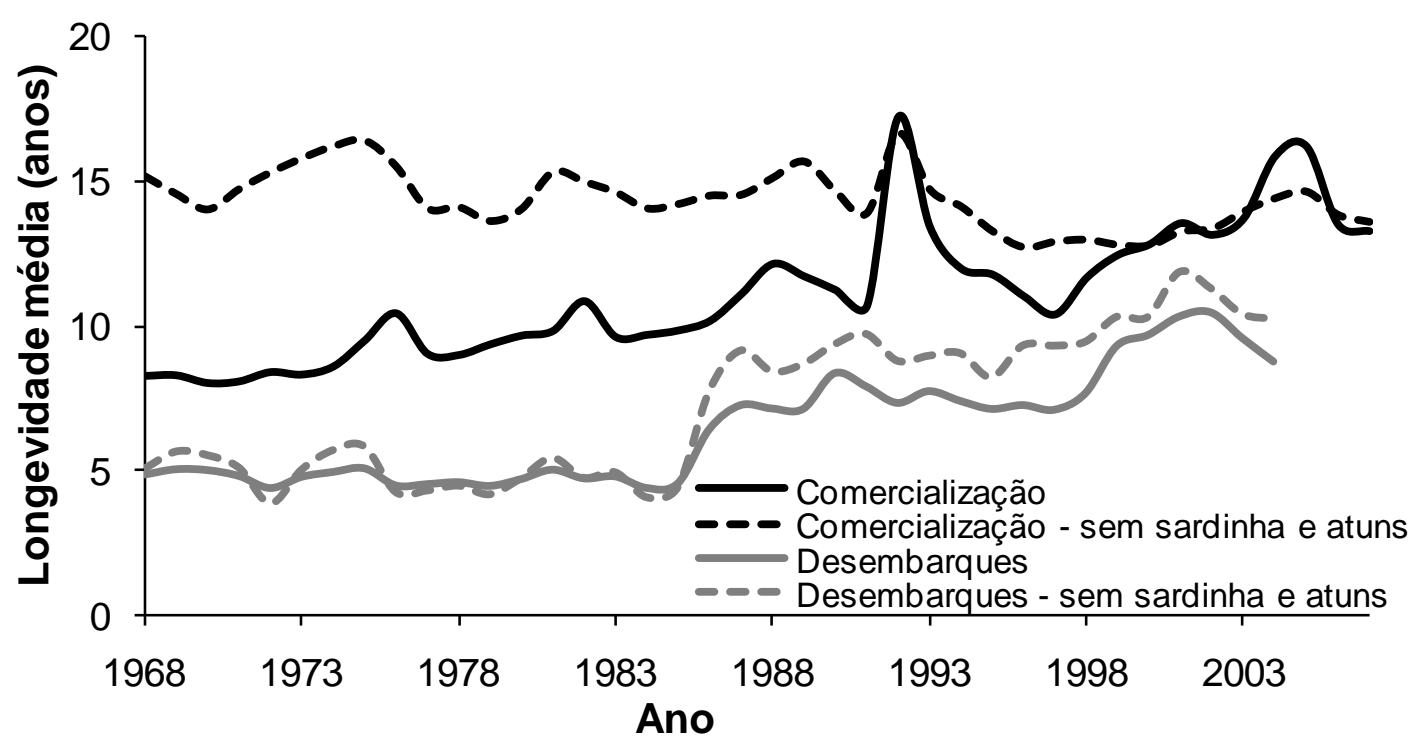

Figura 7. Longevidade média para os dados de comercialização e desembarques no período de 1968 a 2007.

\subsubsection{Comprimento-Máximo médio (Lmáx $\mathrm{m}$ )}

O Comprimento-Máximo médio do pescado ao longo dos anos para os dados de desembarques e comercialização são mostrados na figura 8. De modo geral, houve um aumento $(p<0,05)$ entre 344,2 e $614,6 \mathrm{~mm}$ considerando os desembarques, e entre 504,6 e 1119,2 mm considerando o mercado. Ao excluir sardinhas, camarões e atuns da análise, a tendência tornou-se decrescente para ambos os dados, exibindo uma variação entre 608,3 e 802,2 $\mathrm{mm}(p<0,05)$, e entre 740,5 e $1897,8 \mathrm{~mm}(p>0,05)$, para desembarques e comercialização, respectivamente. 


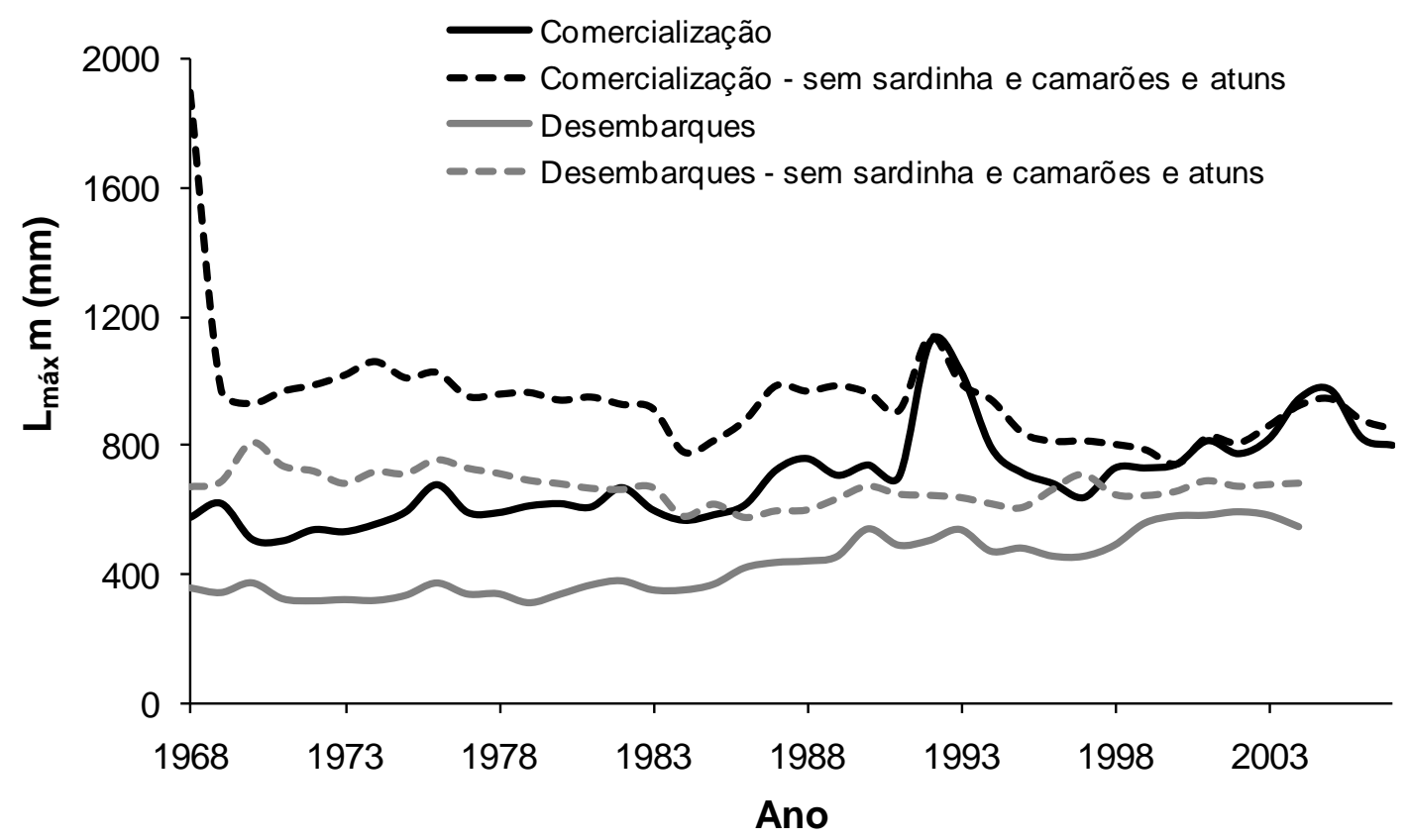

Figura 8. Comprimento Máximo médio para os dados de comercialização e desembarques no período de 1968 a 2007.

\subsubsection{Profundidade média ( $\left.\operatorname{Prof}_{m}\right)$}

Os dados de desembarques e de comercialização ponderados pela profundidade ao longo dos anos são apresentados na figura 9, com tendência crescente significativa $(p<0,05)$ para os desembarques e não-significativa $(p>0,05)$ para a comercialização. A Profundidade média para os desembarques aumentou significativamente de 39,8 até $114,0 \mathrm{~m}$, e para os dados de mercado aumentou de 49,8 até 76,6 m. Quando as categorias sardinha e camarões foram excluídas da análise, a tendência manteve-se crescente $(p<0,05)$ para os dados de desembarque de 33,8 até $137,4 \mathrm{~m}$, e tornou-se decrescente, porém não-significativa para os dados de mercado, variando entre 51,6 a 68,2 m. 


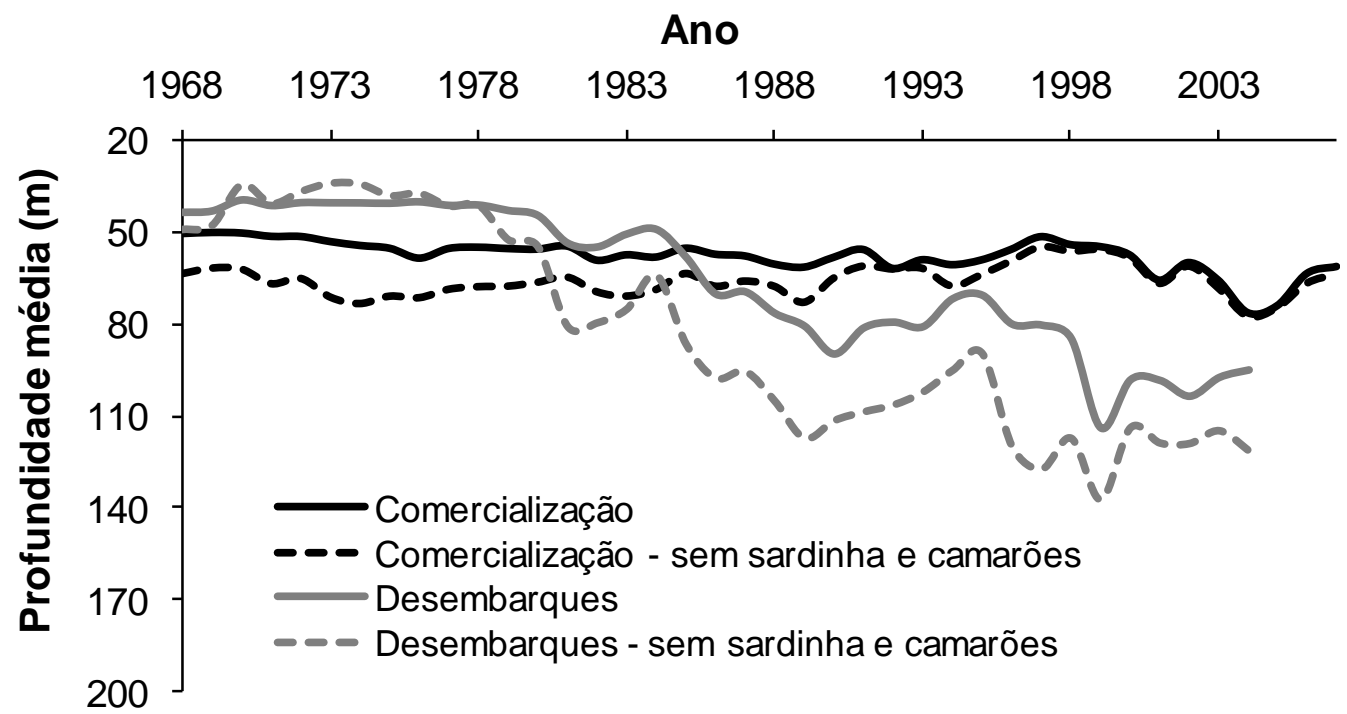

Figura 9. Profundidade média para os dados de comercialização e desembarques no período de 1968 a 2007.

\subsubsection{Isóbata Máxima média (Imáx $\left.x_{m}\right)$}

A Isóbata Máxima média (Imáx $\left.\mathrm{m}_{\mathrm{m}}\right)$ é apresentada na figura 10 para os dados de desembarques e de comercialização. Para os dados de desembaque a tendência da Imáx m aumentou significativamente ao longo dos anos tanto considerando como desconsiderando a categoria sardinha e camarões. Nestes casos a Imáxm variou de 101,9 a $349,7 \mathrm{~m}$ e de 100,7 a $479,3 \mathrm{~m}$, respectivamente. Já para as quantidades comercializadas, a Imáx $x_{m}$ aumentou ao longo dos anos, entretanto de forma significativa somente quando a sardinha e os camarões estavam inclusos na análise. A variação do índice foi de 160,59 a 389,29 m para a Imáx m considerando a sardinha e camarões e de 198,76 a 394,71 m para a Imáx $x_{m}$ desconsiderando tais categorias. 


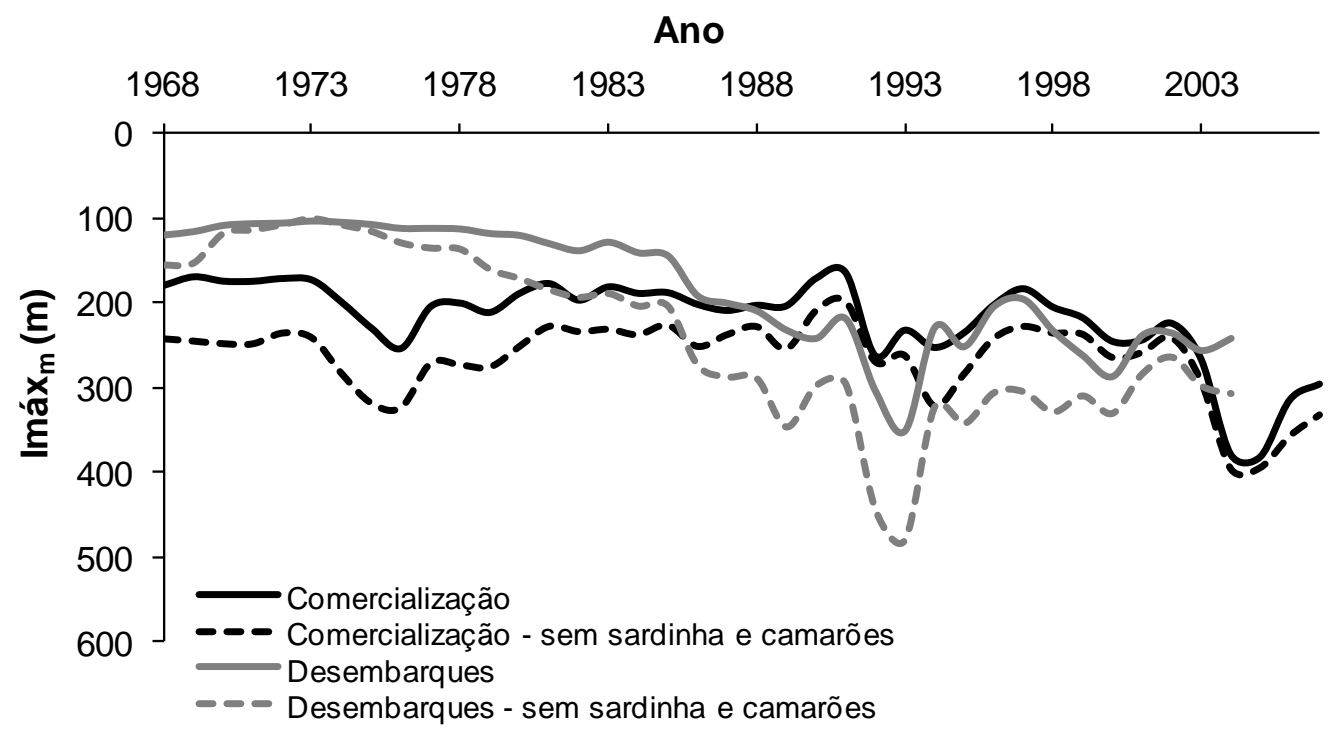

Figura 10. Isóbata Máxima média (Imáx ) para os dados de comercialização e desembarques para o período de 1968 a 2007.

\subsubsection{Razão piscívoros/planctívoros (pis/pla)}

A figura 11 ilustra a razão entre piscívoros e planctívoros ao longo dos anos, a qual aumentou significativamente tanto para os dados de desembarque como para os dados de comercialização, de 0,10 a 2,97 e de 0,25 a 8,68, respectivamente. As tendências permaneceram crescentes $(p<0,05)$, mesmo quando a sardinha foi excluída da análise, variando de 1,38 a 15,93 e de 0,57 a 13,44 para comercialização e desembarques, respectivamente. 


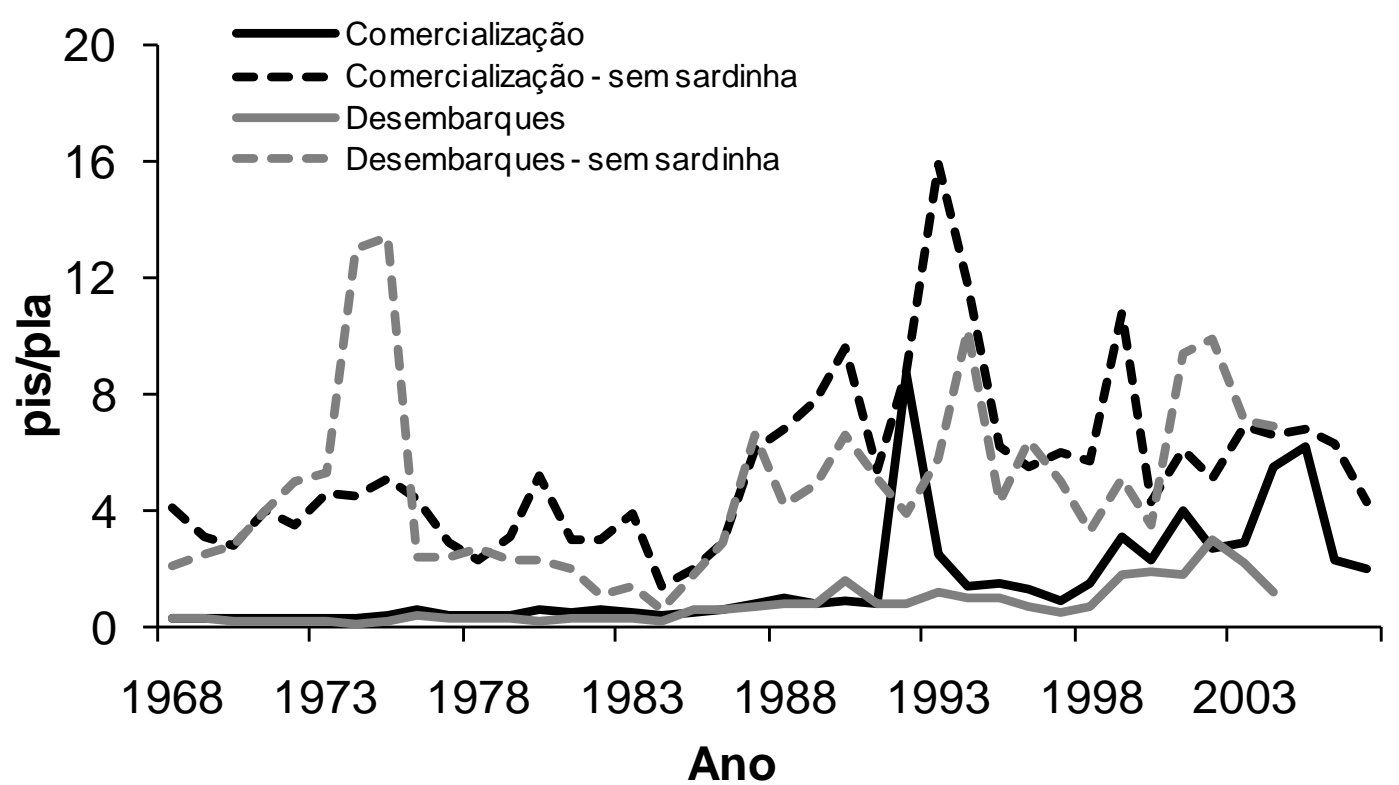

Figura 11. Relação piscívoros (pis) e planctívoros (pla) tanto para as quantidades comercializadas como para as desembarcadas.

\subsubsection{Razão pelágicos/demersais (pel/dem)}

A razão que compara a relação entre pelágicos e demersais de 1968 a 2007 é ilustrada na figura 12. Esse indicador apresentou uma significativa tendência decrescente $(p<0,05)$ para ambos os conjuntos de dados (de 0,19 a 2,68 no mercado e de 0,62 a 3,22 no desembarque). A análise do pel/dem excluindo sardinha e camarões revelou que a tendência da razão tornou-se significativamente crescente (de 0,15 a 0,67 ) para as quantidades desembarcadas, enquanto que essa tendência permaneceu decrescente $(\mathrm{p}<0,05)$ (variando entre 0,06 e 0,99$)$ no cálculo para os dados referentes ao mercado. 


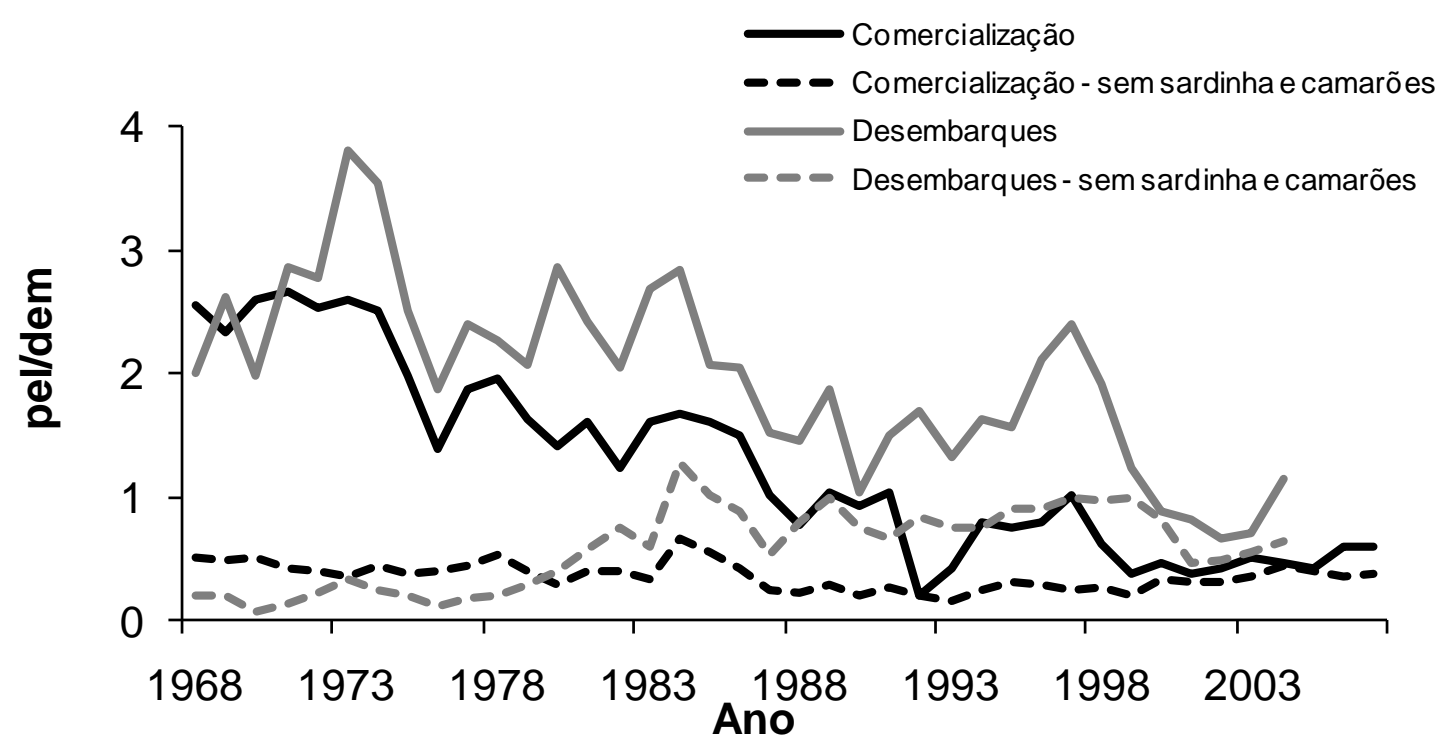

Figura 12. Relação entre pelágicos (pel) e demersais (dem) tanto para as quantidades comercializadas como para as desembarcadas.

4.1.2. Importância relativa das categorias em função das classes de parâmetros ecológicos

\subsubsection{Nível Trófico}

A fim de detalhar a análise relativa ao ITM, foi observada a composição relativa das quantidades desembarcadas e das comercializadas ao longo dos anos, ordenadas conforme quatro diferentes classes (três de NT e uma de invertebrado; Figs. 13-16).

A figura 14, no caso dos desembarques (desconsiderando a sardinha) mostra que houve uma maior importância relativa no começo da série para categorias como cherne, espada e dourado (NT-alto), da mesma forma que corvina, savelha, pargo-rosa e raias (NT-int), na figura 15. Ao longo dos anos tal importância mudou e tornaram-se mais relevantes categorias como bonito- 
listrado, albacora-lage e sapo (NT-alto, Fig. 14) e castanha, pescada real e olhuda, palombeta e cabra (NT-int, Fig. 15).

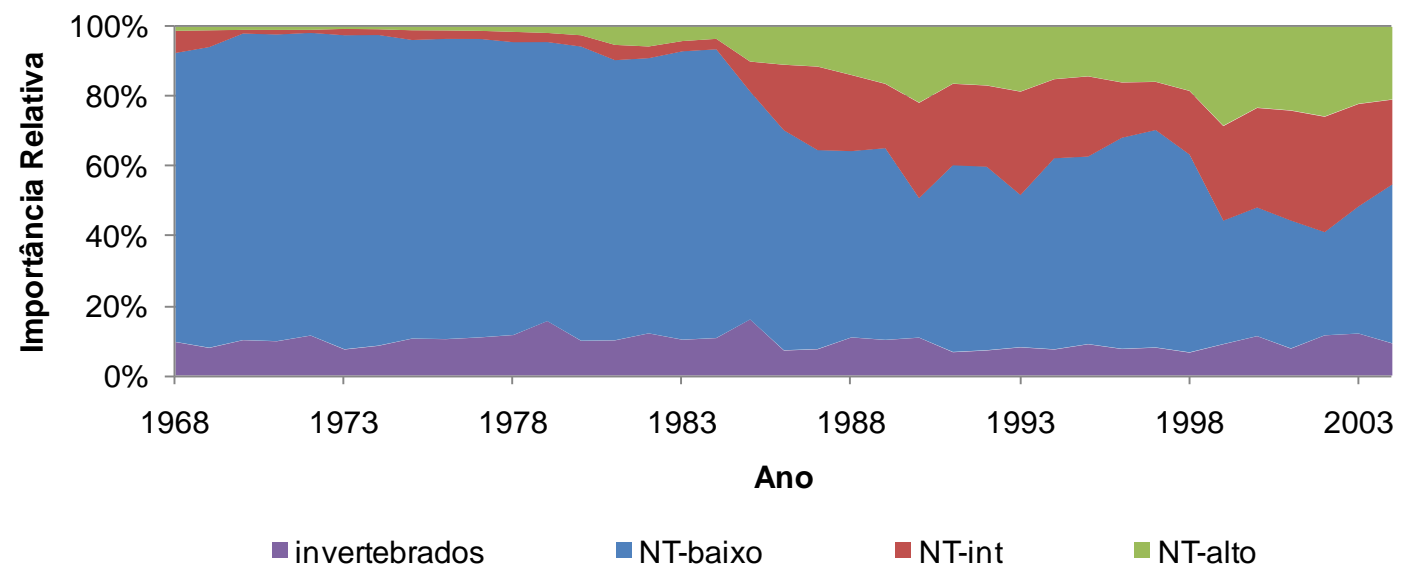

Figura 13. Importância relativa anual das categorias de pescado desembarcado agrupadas nas diferentes classes de nível trófico entre 1968 e 2007.

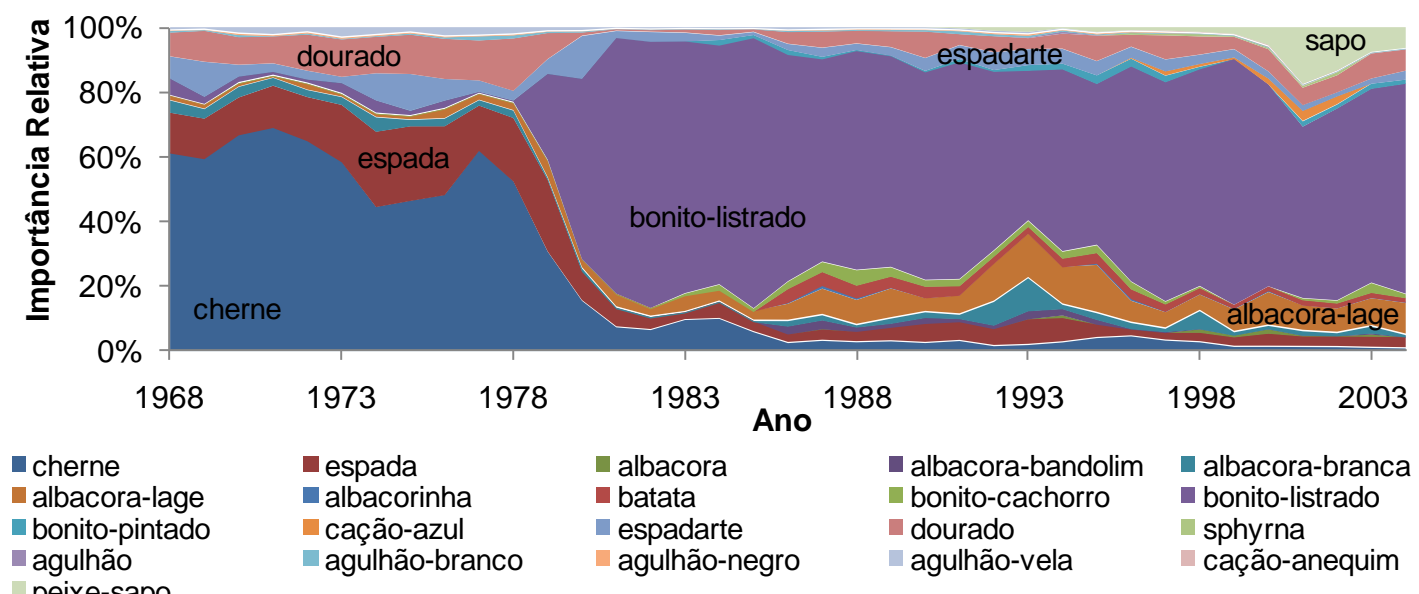

peixe-sapo

Figura 14. Importância relativa anual das categorias de pescado desembarcado de NT-alto entre 1968 e 2007.

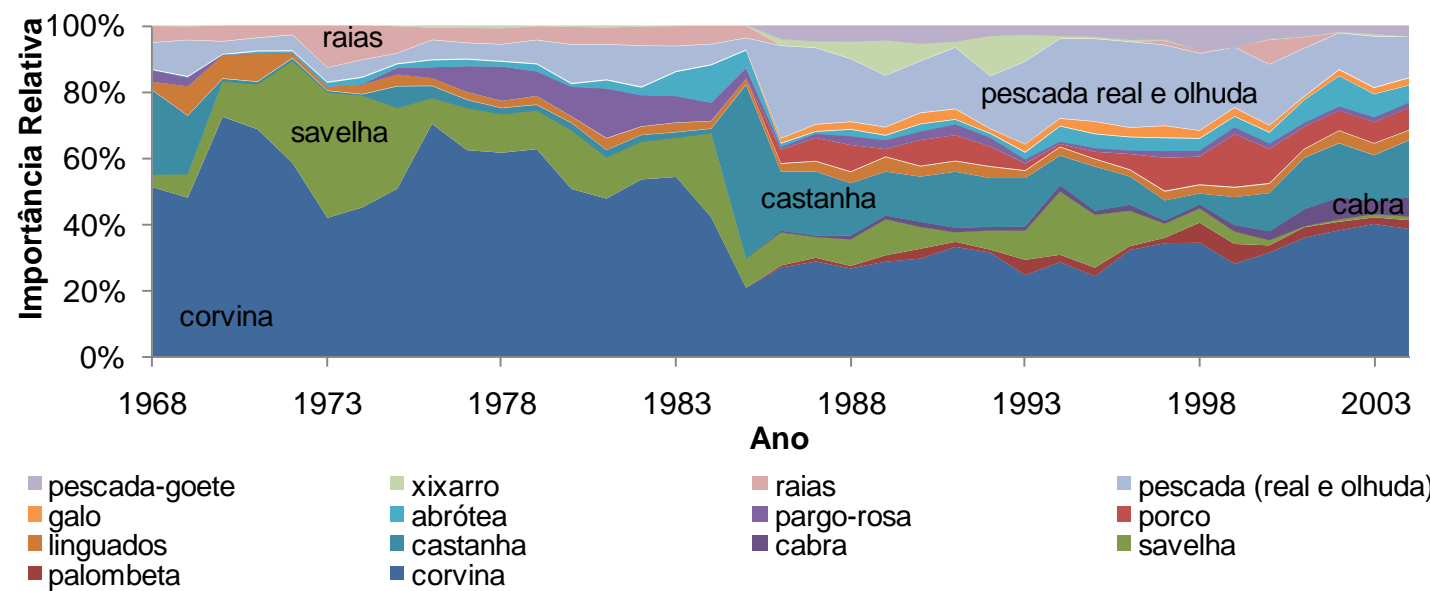

Figura 15. Importância relativa anual das categorias de pescado desembarcado de NT-int entre 1968 e 2007. 


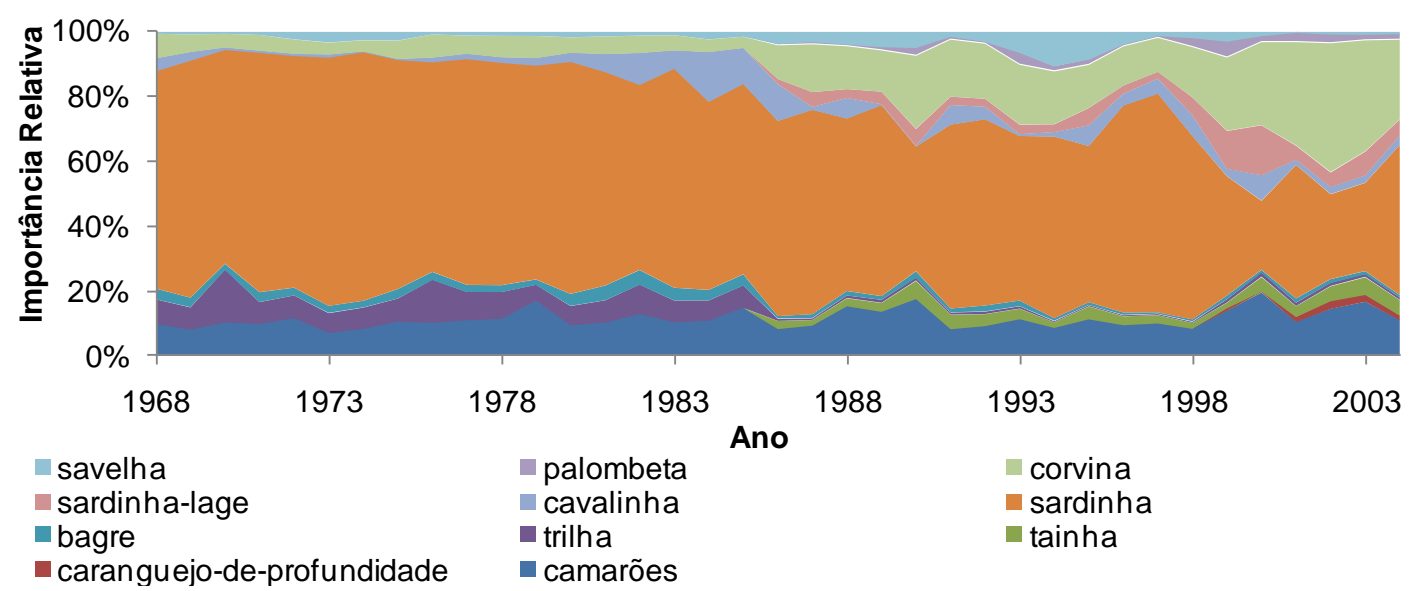

Figura 16. Importância relativa anual das categorias de pescado desembarcado de NT-baixo entre 1968 e 2007.

As Figs. 18 e 19 mostram que, no início do período da comercialização, alguns recursos pesqueiros de NT-superior como, namorado (Fig. 18), serra (Fig. 18), cação-machote (Fig. 18), pescada-goete (Fig. 19) e castanha (Fig. 19) apresentaram uma relevante importância relativa, porém em 2007 o predomínio foi de espécies de NT-int (cerca de 50\%), como o peixe-porco (Fig. 19), além de outras espécies de NT-alto (cerca de 10\%), como atuns (Thunnus spp.), bonito-listrado (Katsuwonus pelamis) e afins (Auxis thazard e Euthynnus alletteratus) (Fig. 18).

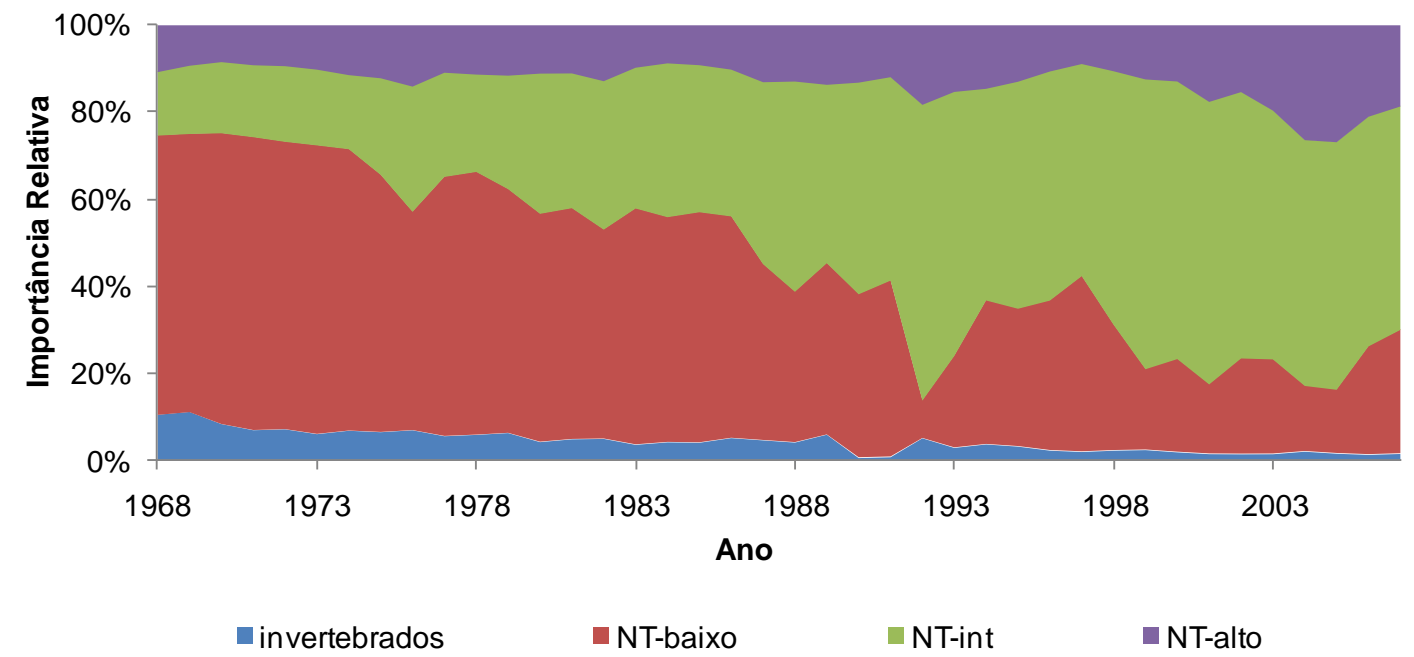

Figura 17. Importância relativa anual das categorias de pescado comercializadas agrupadas nas diferentes classes de nível trófico entre 1968 e 2007. 


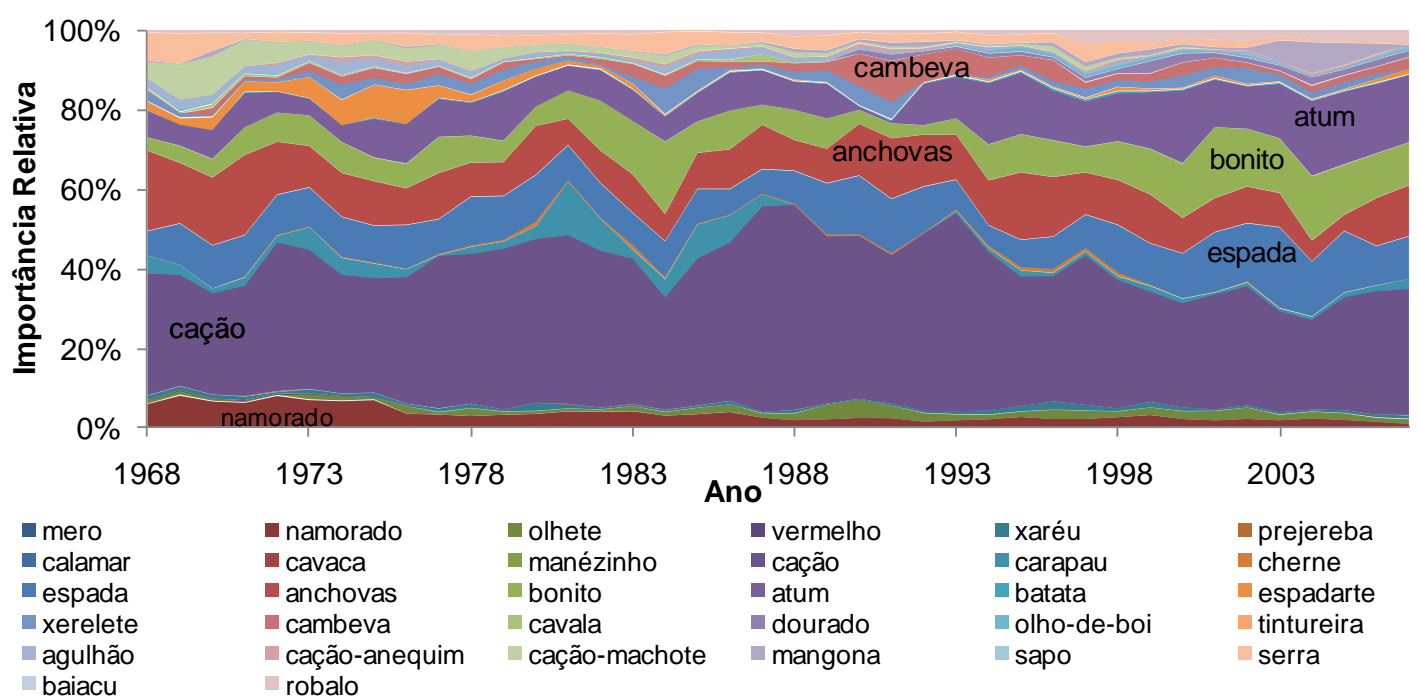

Figura 18. Importância relativa anual das categorias de pescado comercializadas de NT-alto entre 1968 e 2007.

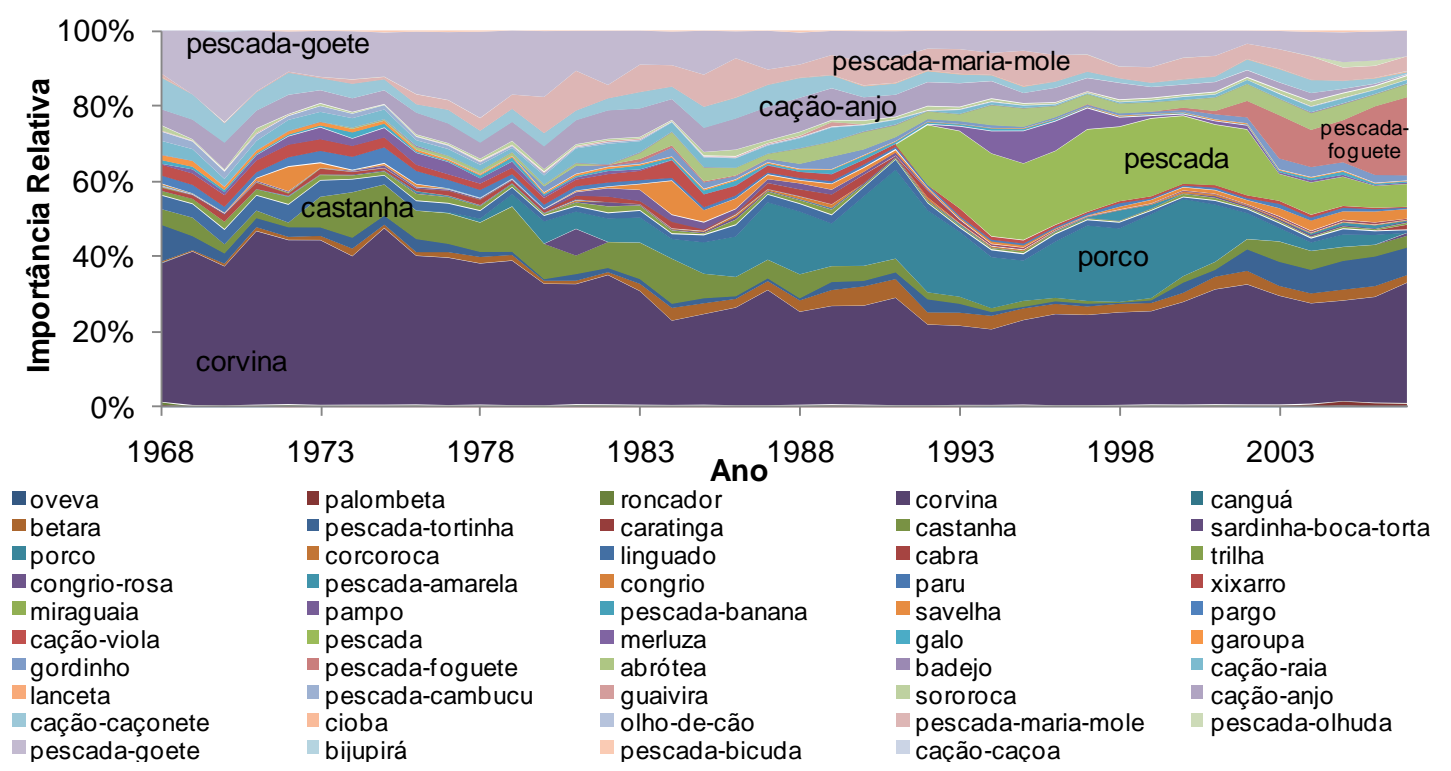

Figura 19. Importância relativa anual das categorias de pescado comercializadas de NT-int entre 1968 e 2007.

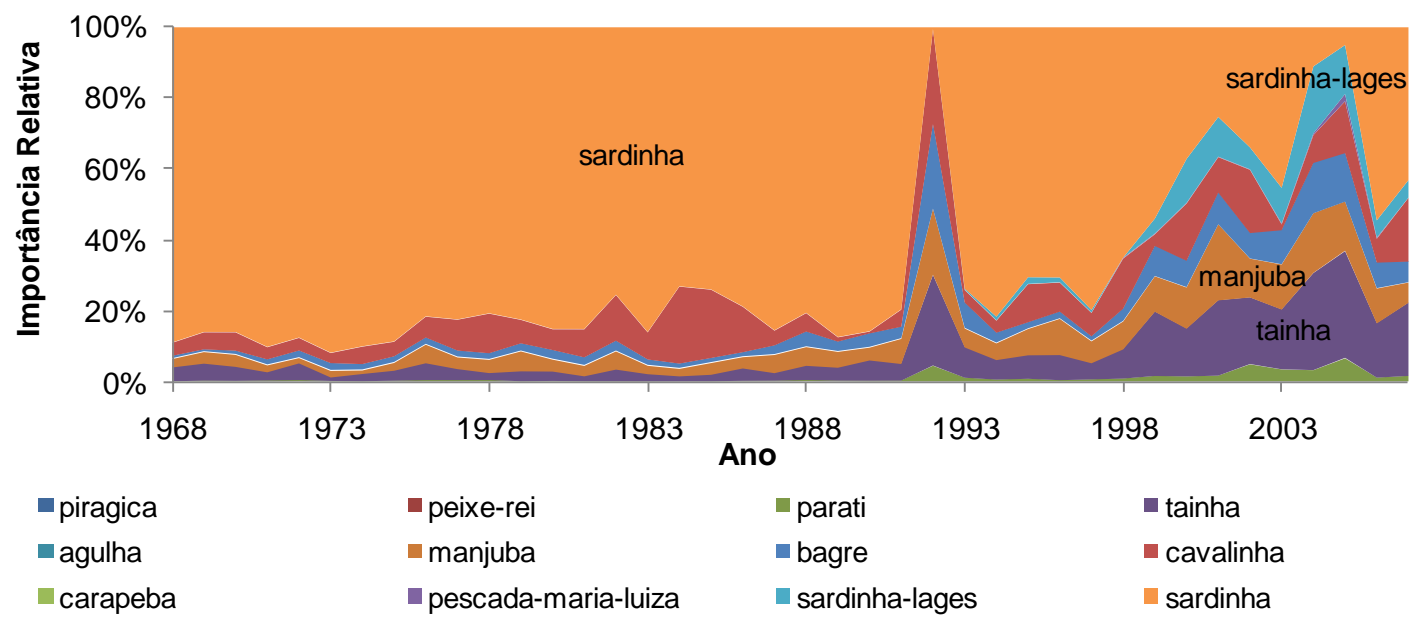

Figura 20. Importância relativa anual das categorias de pescado comercializadas de NT-baixo entre 1968 e 2007. 


\subsubsection{Longevidade}

Nas figuras 21-27 são apresentadas as importâncias relativas conforme a classificação feita anteriormente para grupos de longevidade (alta, intermediária e baixa). O grupo Long-baixa foi constituído apenas pela categoria sardinha.

Do início do período até 1986, a categoria "tainha" representava cerca de $40-70 \%$ dos dados de desembarques, passando a ocupar menos de $10 \%$ após 1986 (Fig. 23). Entre os recursos que aumentaram sua importância relativa ao longo dos anos estão o peixe-sapo e a abrótea (Long-alta, Fig. 22), além do bonito-listrado, da castanha e da pescada real e ollhuda (Long-int, Fig. 23).

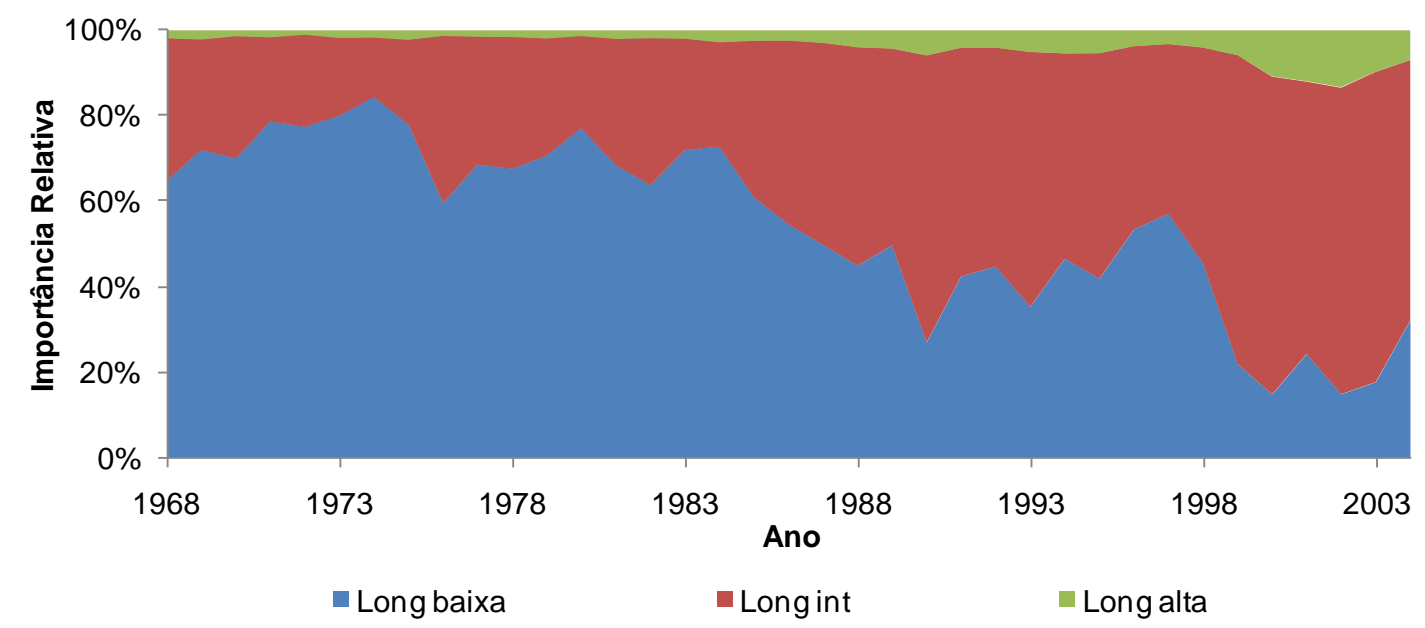

Figura 21. Importância relativa anual das categorias de pescado desembarcado agrupadas nas diferentes classes de longevidade entre 1968 e 2007. 


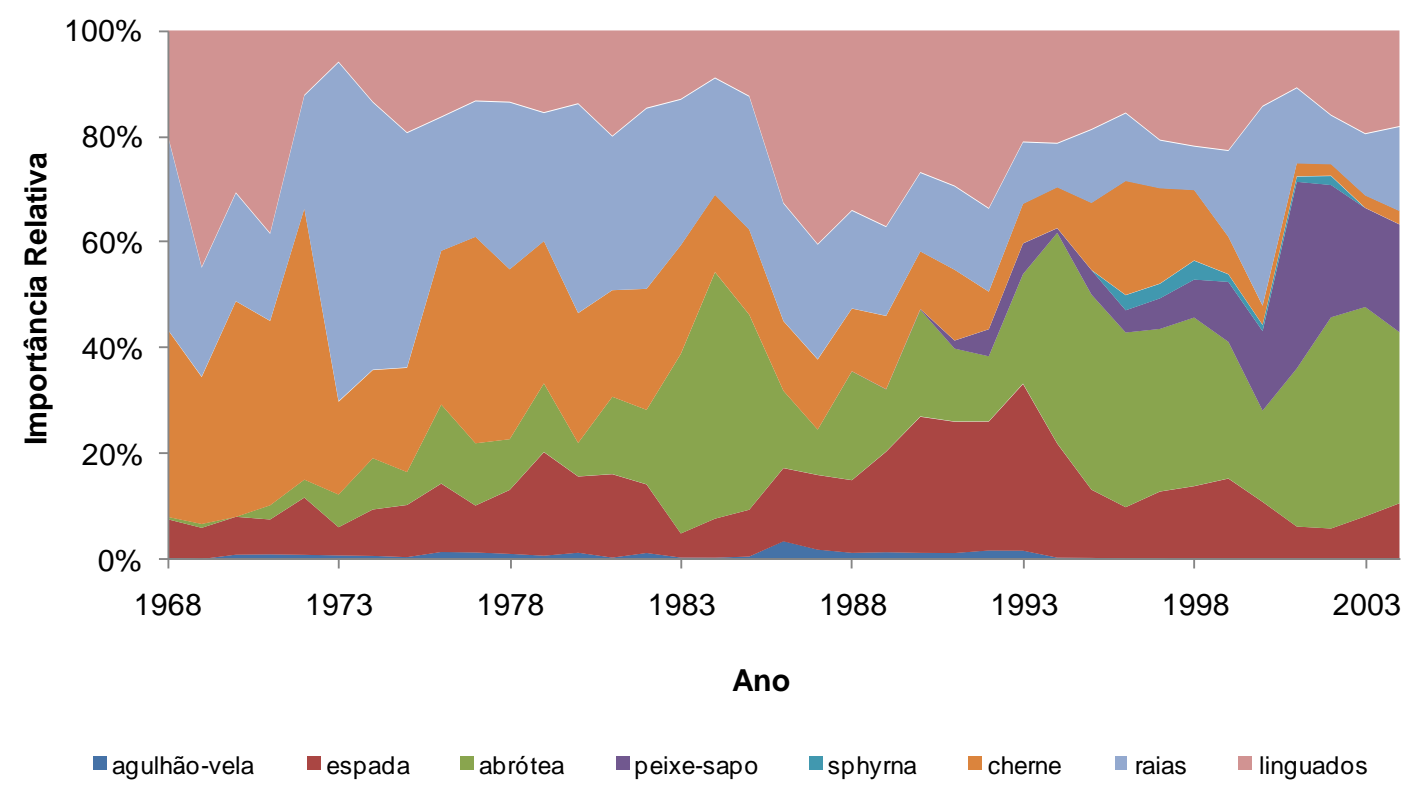

Figura 22. Importância relativa anual das categorias de pescado desembarcado de Long-alta entre 1968 e 2007.

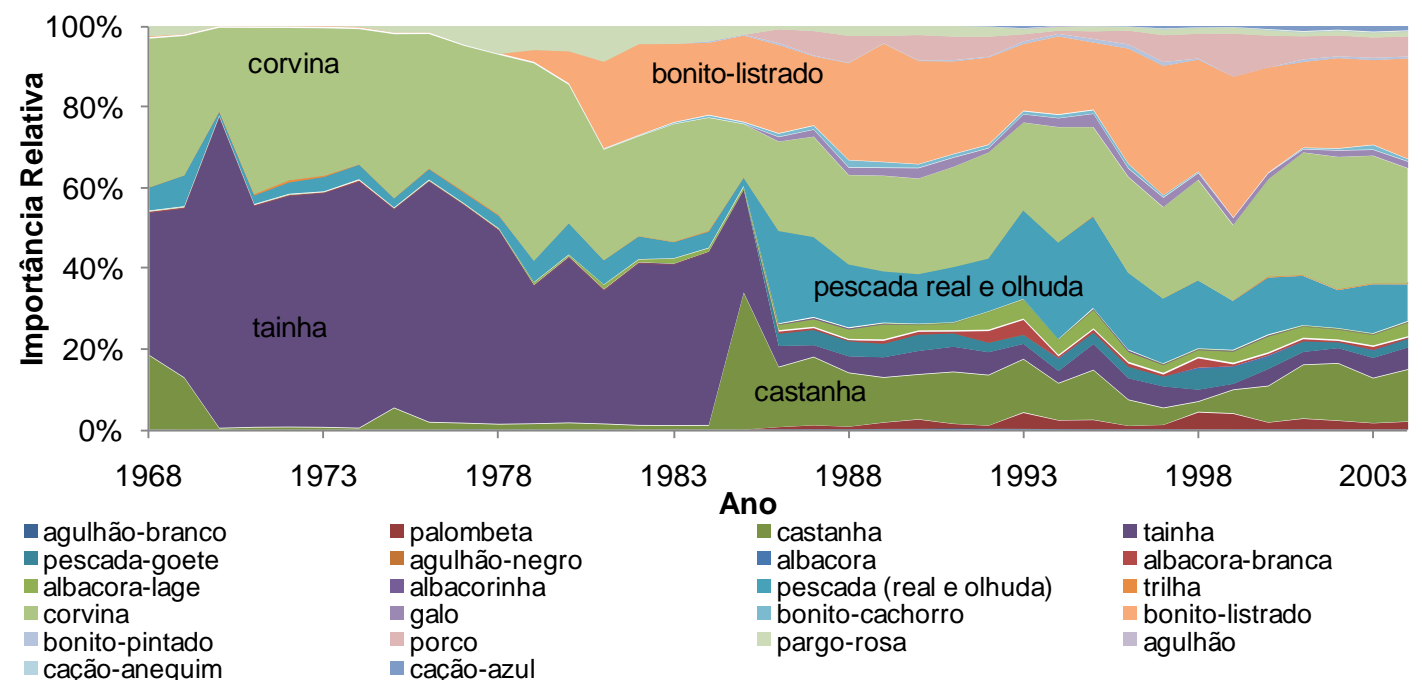

Figura 23. Importância relativa anual das categorias de pescado desembarcado de Long-int entre 1968 e 2007.

Da mesma forma que nos dados de desembarques, a comercialização classificada em função da longevidade apresentou uma mudança na sua composição (Fig. 24) ao longo dos anos. Inicialmente ela era constituída principalmente por pescadas (Long-int, Fig. 26), namorado e cação-machote (Long-alta, Fig. 25), mas foi posteriormente modificada por um aumento da 
comercialização dos recursos de Long-int como porco, pescada-maria-mole, tainha e betara (Fig. 26) e de Long-alta como atum e abrótea (Fig. 25).

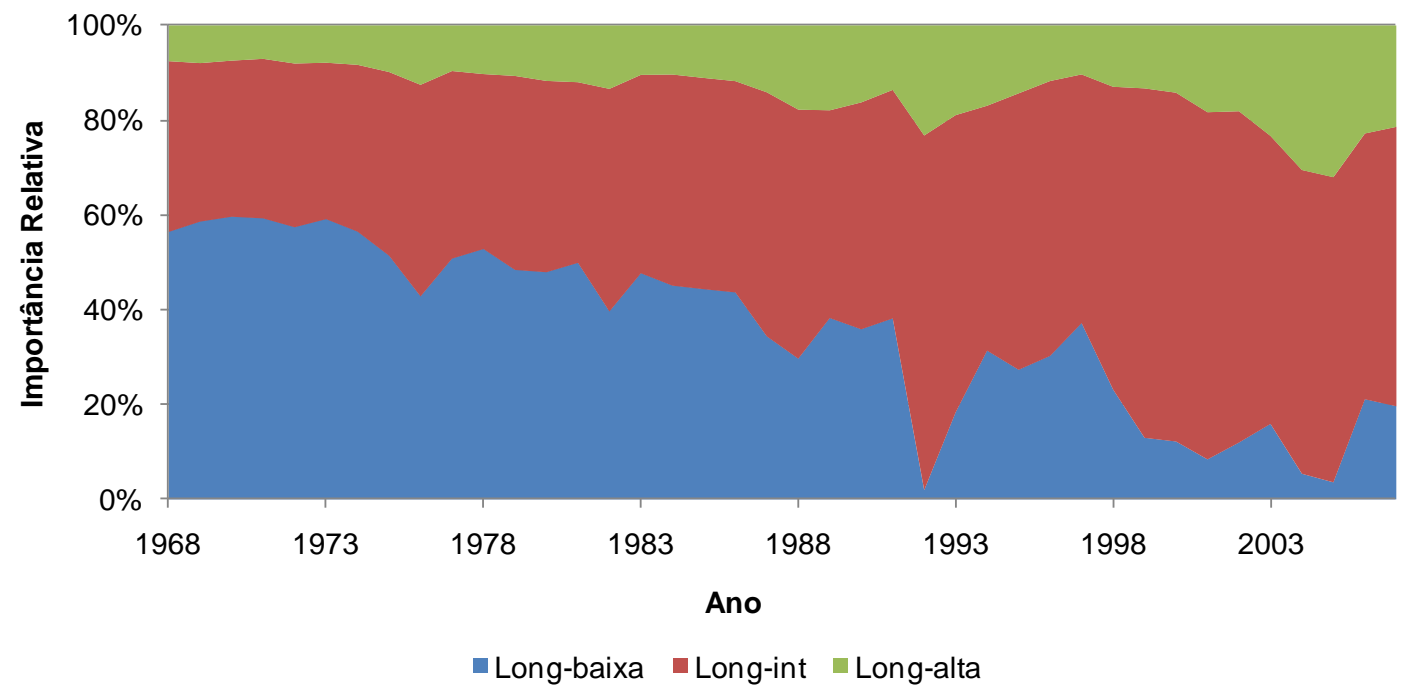

Figura 24. Importância relativa anual das categorias de pescado comercializado agrupadas nas diferentes classes de longevidade entre 1968 e 2007.

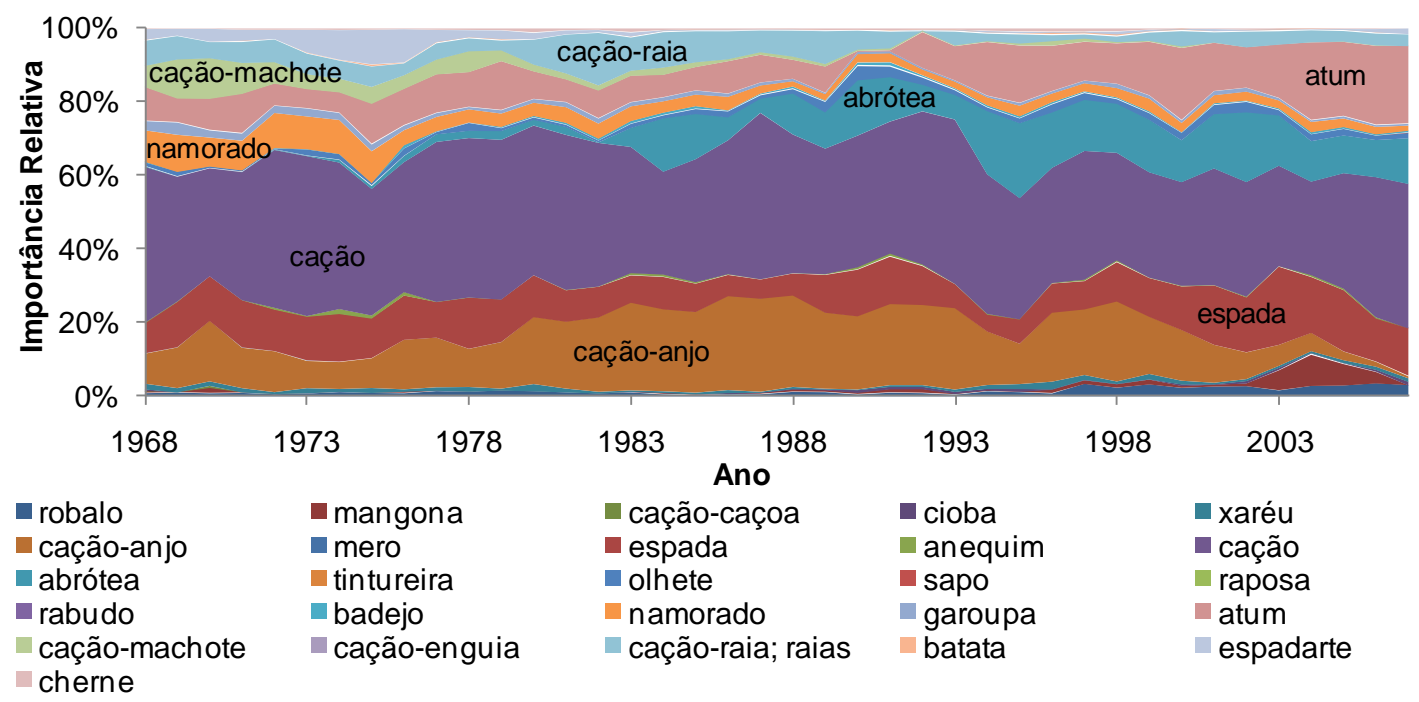

Figura 25. Importância relativa anual das categorias de pescado comercializado de Long-alta entre 1968 e 2007. 


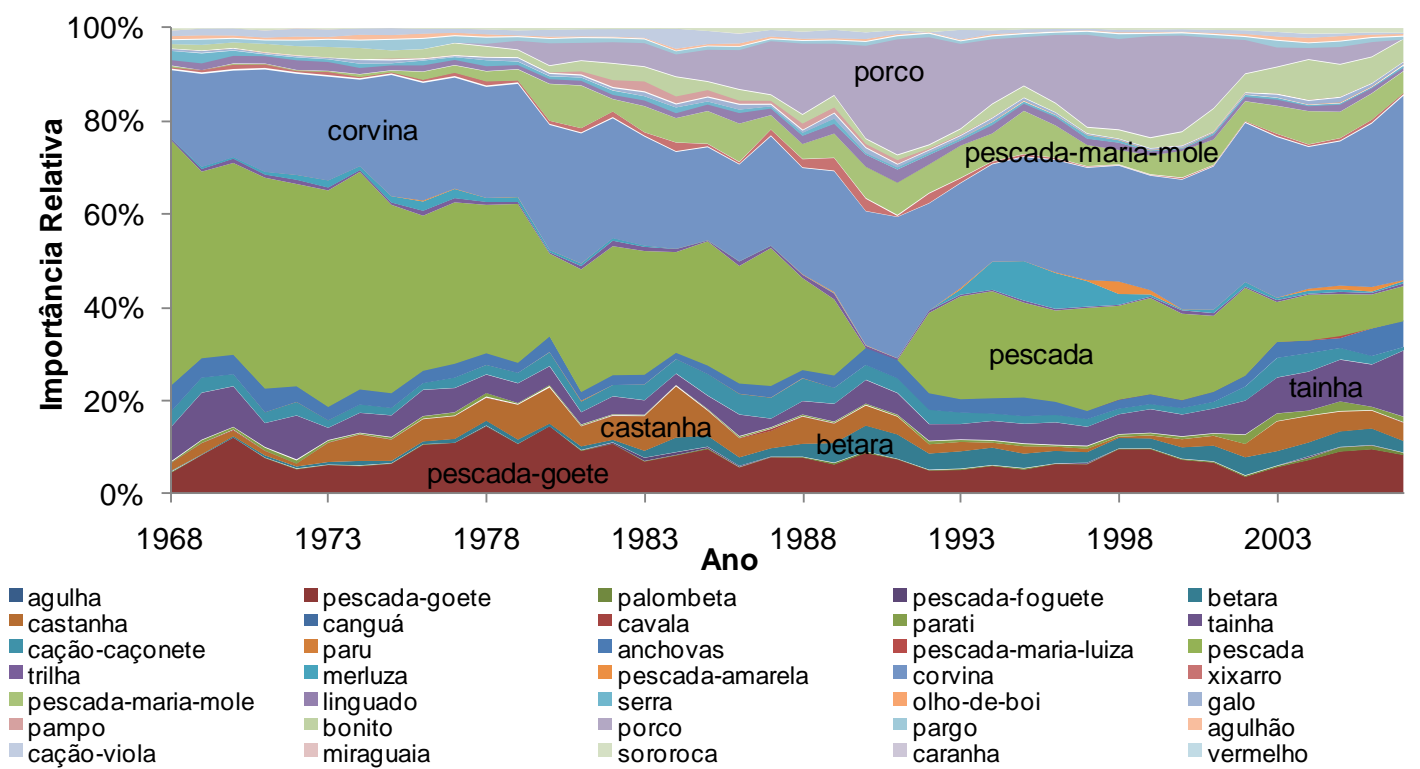

Figura 26. Importância relativa anual das categorias de pescado comercializado de Long-int entre 1968 e 2007.

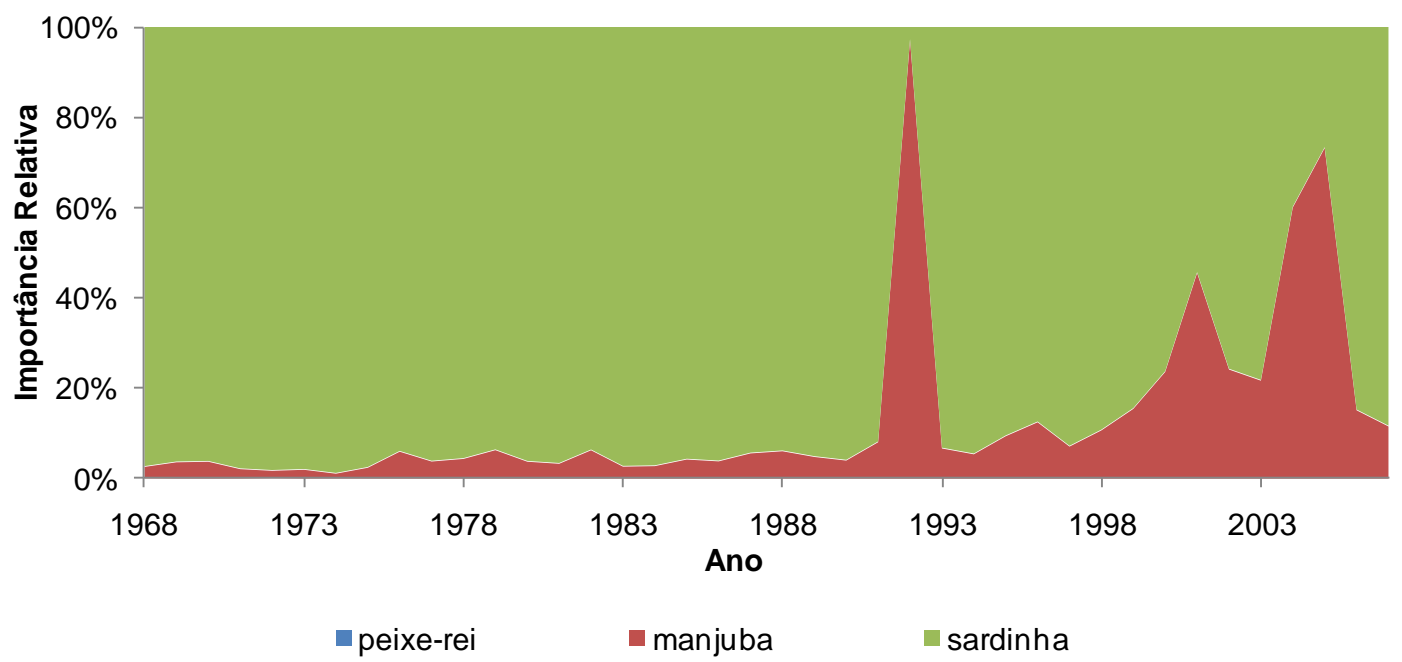

Figura 27. Importância relativa anual das categorias de pescado comercializado de Long-baixa entre 1968 e 2007.

\subsubsection{Comprimento Máximo}

Nas figuras 28 a 35 pode ser constatada a importância relativa daqueles recursos utilizados na análise do Lmáx médio ordenados pelos grupos definidos na seção 3.3.1.2. Na análise dos desembarques, as categorias de Lmáx-int como tainha, bagre, savelha e cavalinha perderam importância relativa, e a de bonito-listrado ganhou (Fig. 30) maior relevância. 
Na análise do Lmáx-alto (Fig. 29), enquanto que no início era alta a importância do cherne, no final do período os recursos pesqueiros como dourado, albacoralage, e cação-azul tornaram-se mais importantes.

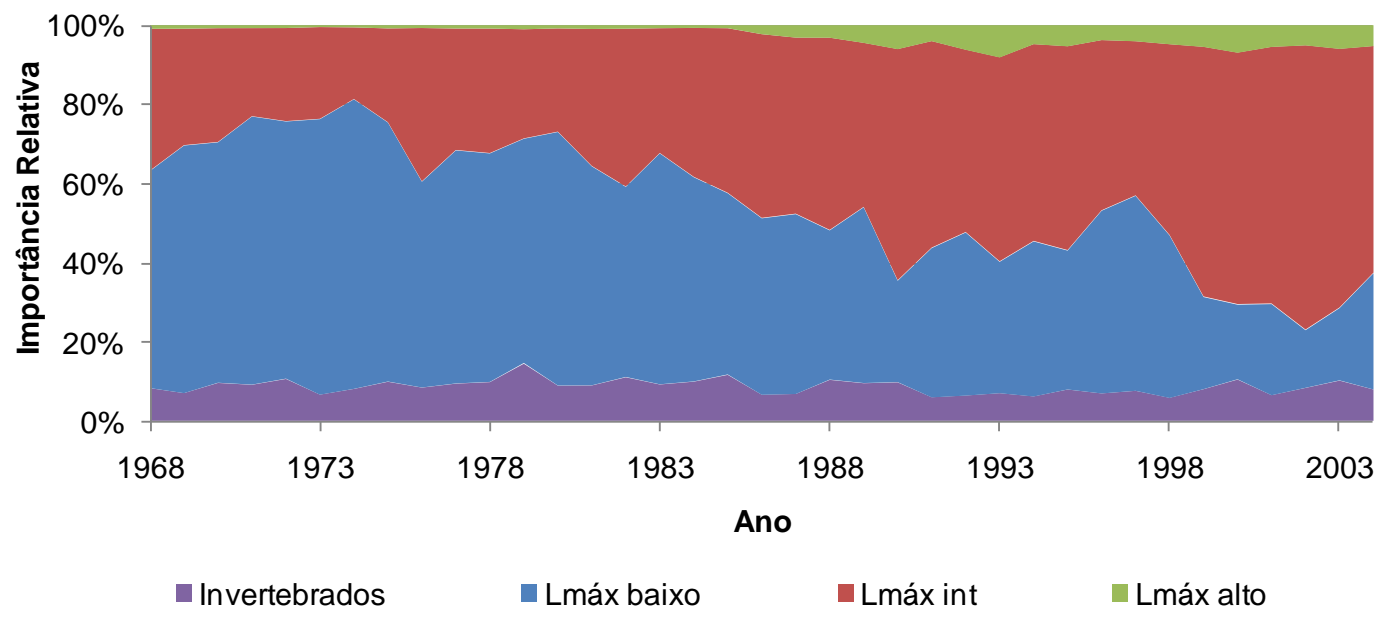

Figura 28. Importância relativa anual das categorias de pescado desembarcado agrupadas nas diferentes classes de comprimento máximo (Lmáx-alto, Lmáxint, Lmáx-baixo e invertebrados) entre 1968 e 2007.

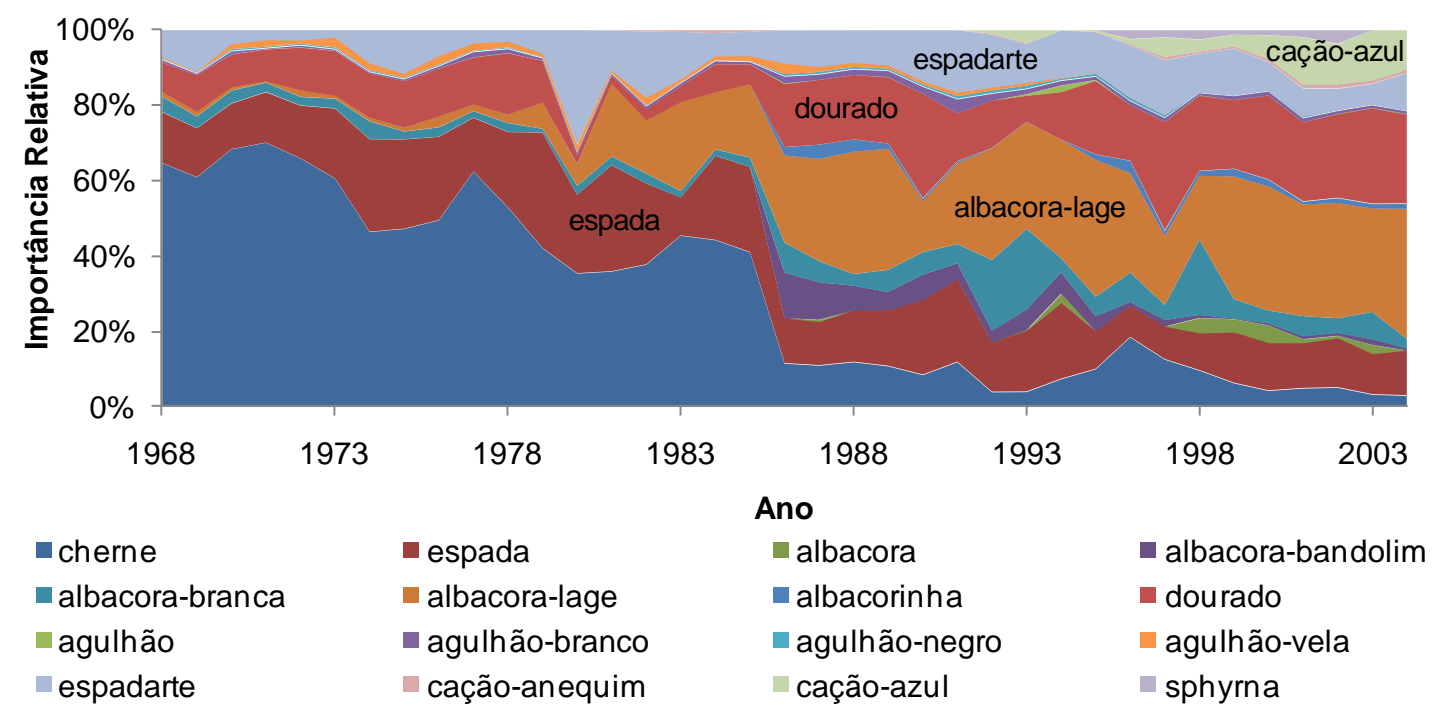

Figura 29. Importância relativa anual das categorias de pescado desembarcado de Lmáx-alto entre 1968 e 2007. 


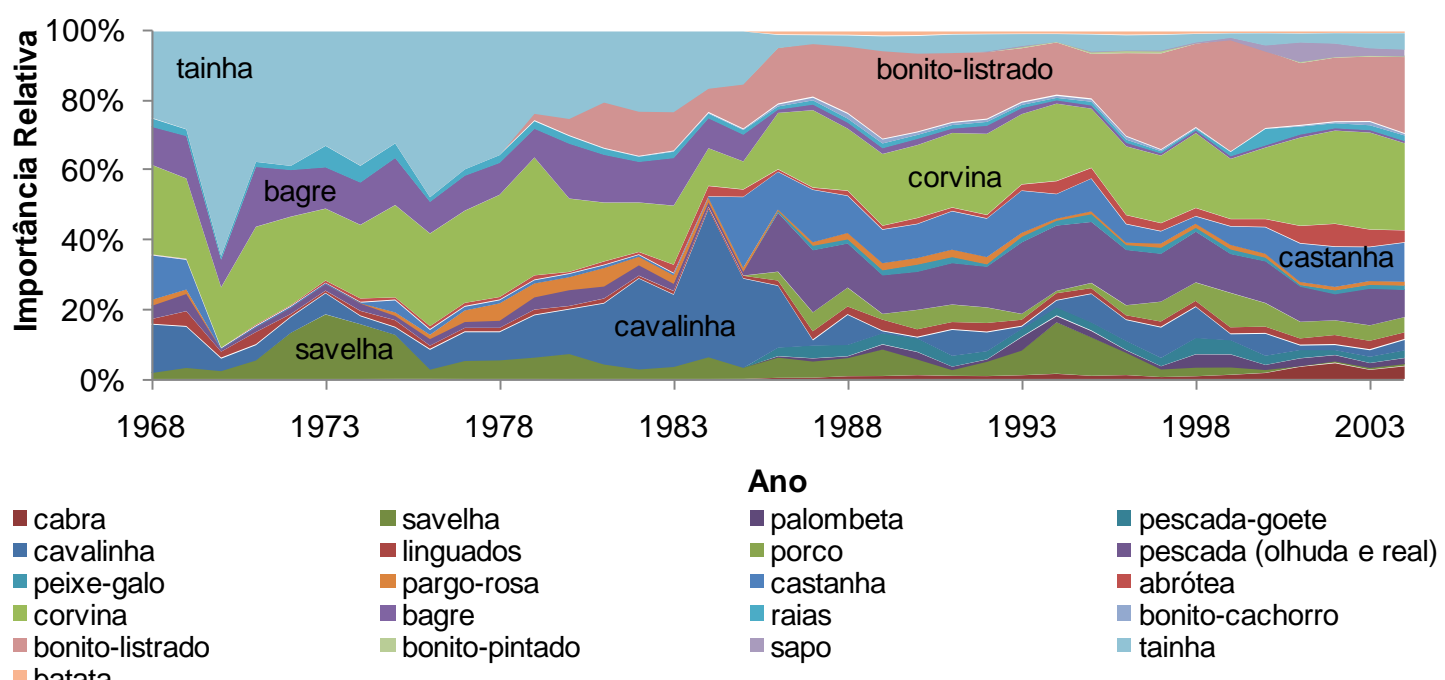

Figura 30. Importância relativa anual das categorias de pescado desembarcado de Lmáx-int entre 1968 e 2007.

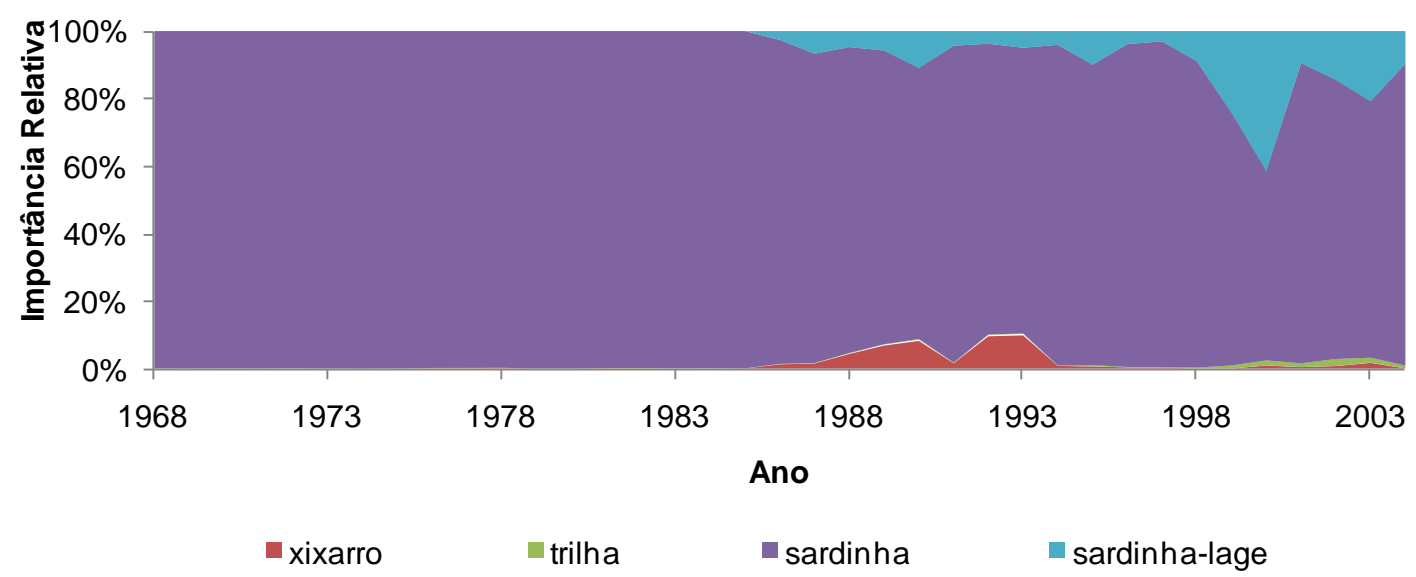

Figura 31. Importância relativa anual das categorias de pescado desembarcado de Lmáx-baixo entre 1968 e 2007.

Na comercialização, tanto categorias de Lmáx-alto (Fig. 33) como atum quanto categorias de Lmáx-int (Fig. 34) como porco, pescada-foguete e abrótea aumentaram em importância relativa ao longo dos 40 anos. 


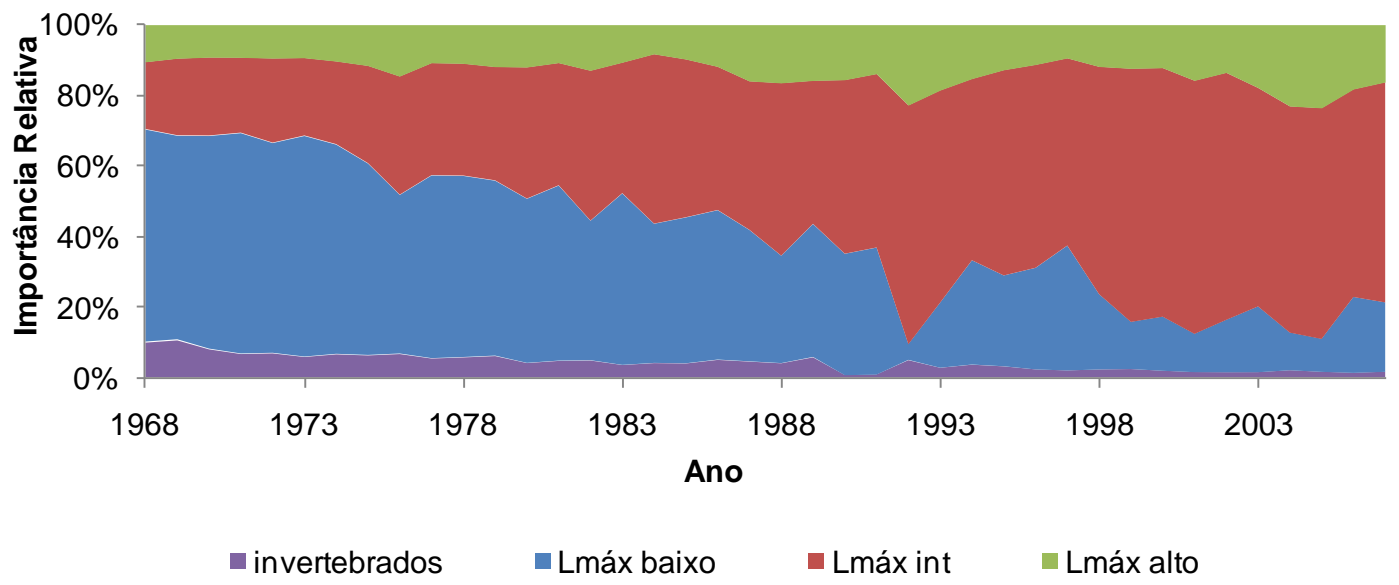

Figura 32. Importância relativa anual das categorias de pescado comercializado agrupadas nas diferentes classes de comprimento máximo entre 1968 e 2007.

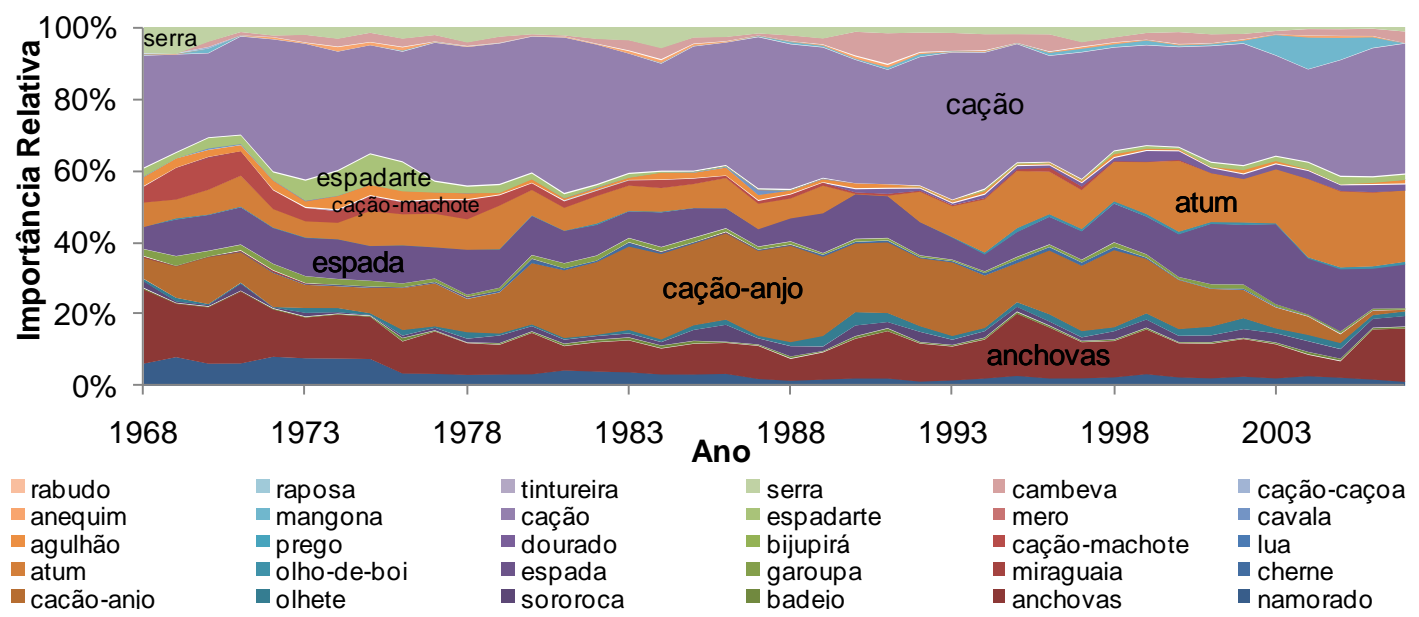

Figura 33. Importância relativa anual das categorias de pescado comercializado de Lmáx-alto entre 1968 e 2007.

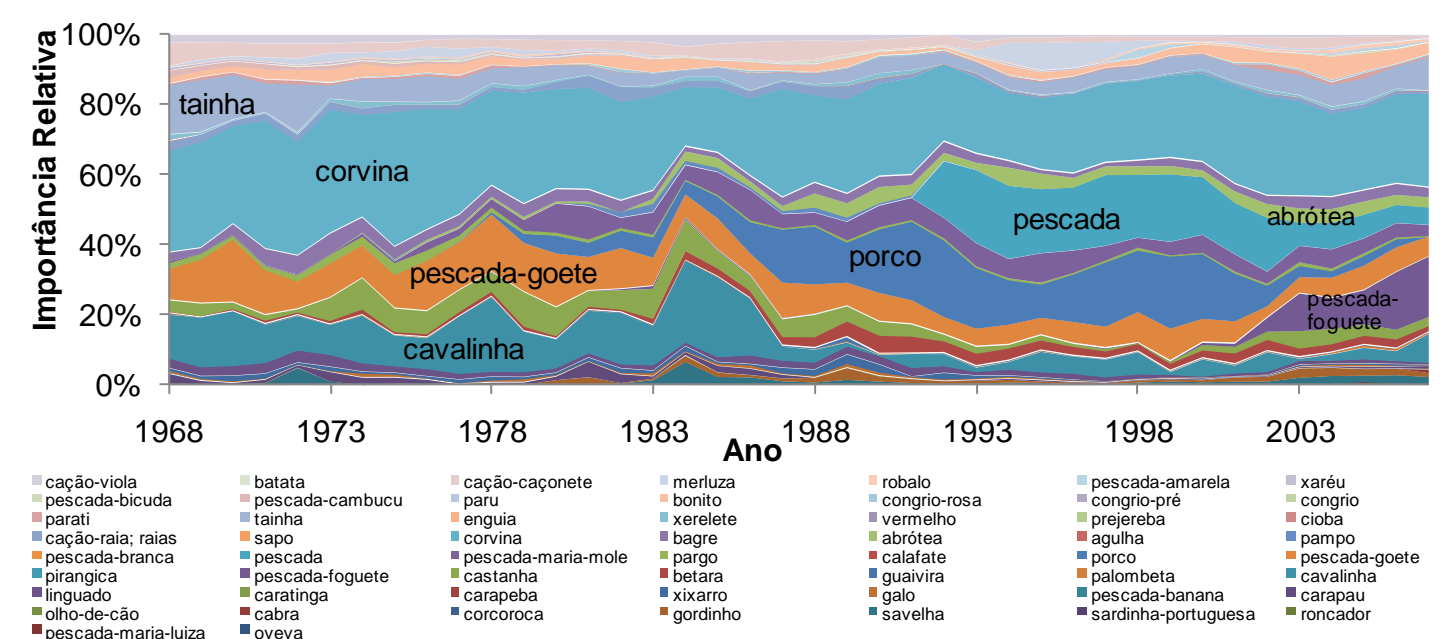

Figura 34. Importância relativa anual das categorias de pescado comercializado de Lmáx-int entre 1968 e 2007. 


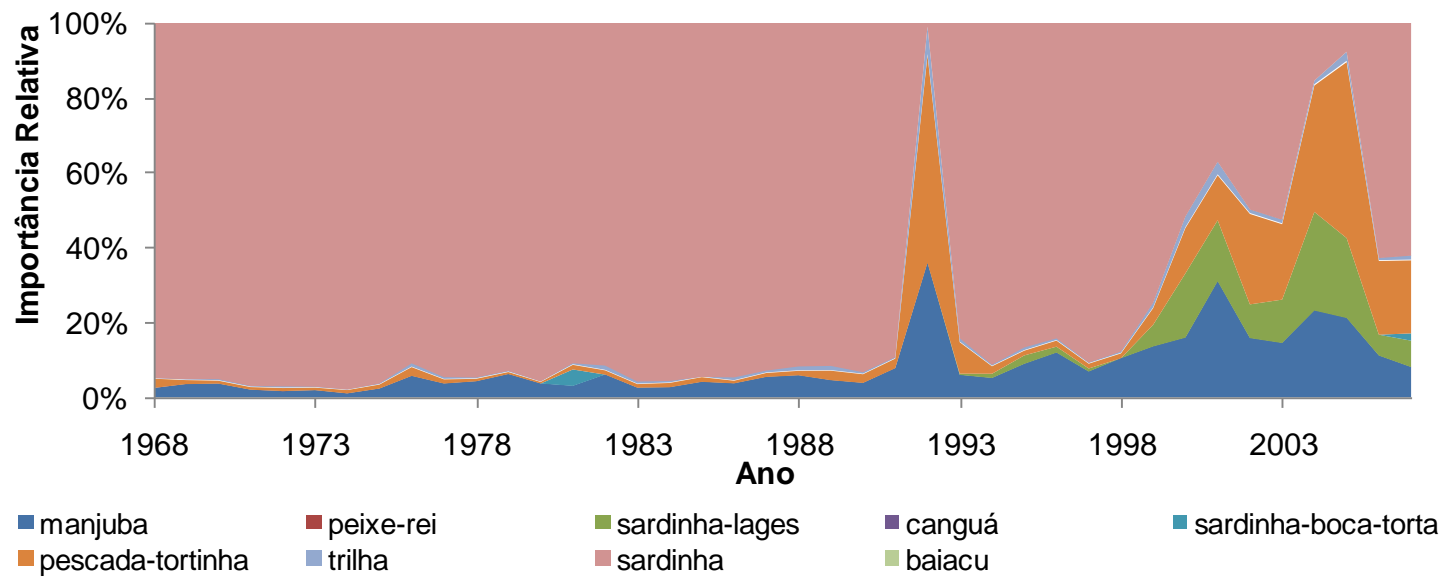

Figura 35. Importância relativa anual das categorias de pescado comercializado de Lmáx-baixo entre 1968 e 2007.

\subsubsection{Profundidade}

A análise da profundidade média foi detalhada classificando-se as quantidades comercializadas e desembarcadas em dois tipos: de águas "rasas" e de águas "profundas" (Figs. 36-41), sendo a maior parte dos recursos classificados como de águas rasas (Figs. 36 e 39). Nos desembarques, verificou-se ao longo dos anos uma diminuição da importância relativa da tainha e um aumento da importância da corvina e da pescada real e olhuda, todos recursos de águas rasas (Fig. 36). Da mesma forma, diminuiu a importância relativa de alguns recursos de águas mais profundas (Fig. 38) como o cherne e as raias, enquanto que aumentou a de outros como o bonitolistrado, a castanha, a abrótea e o sapo. 


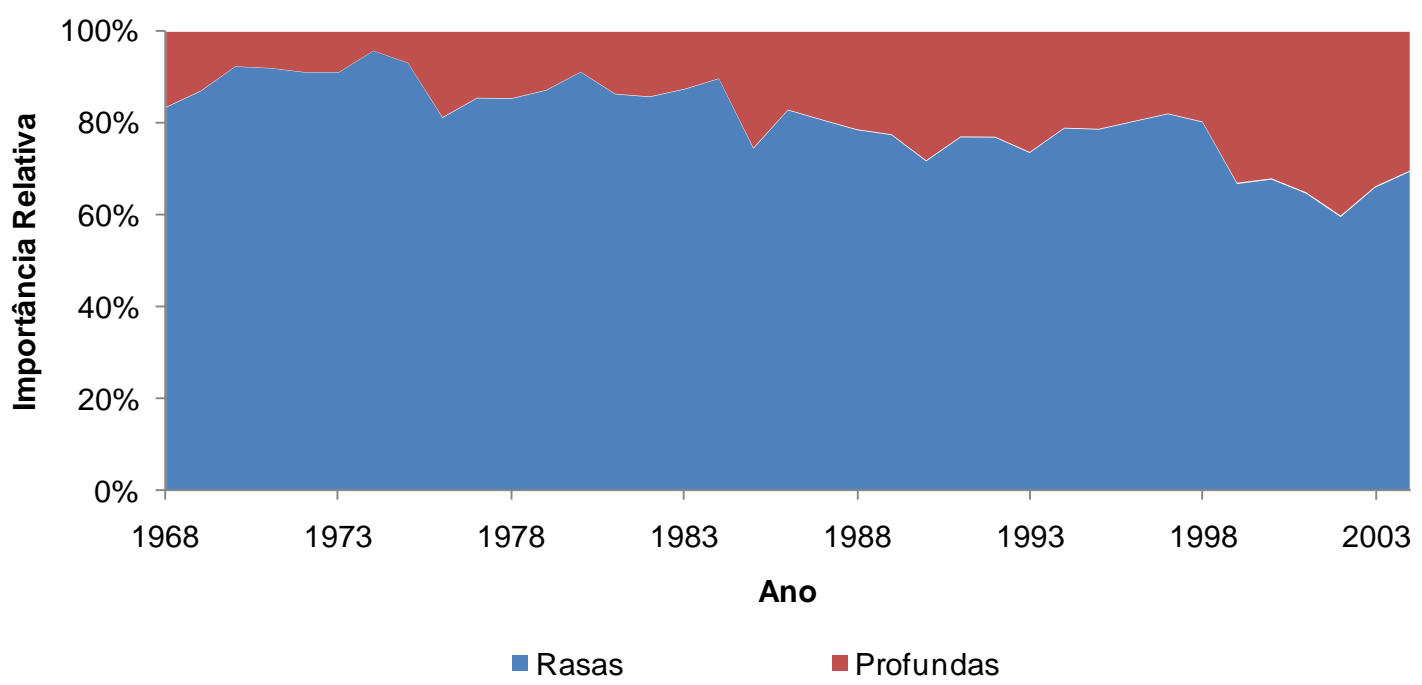

Figura 36. Importância relativa anual das categorias de pescado desembarcado agrupadas nas diferentes classes de profundidade (rasas e profundas) entre 1968 e 2007.

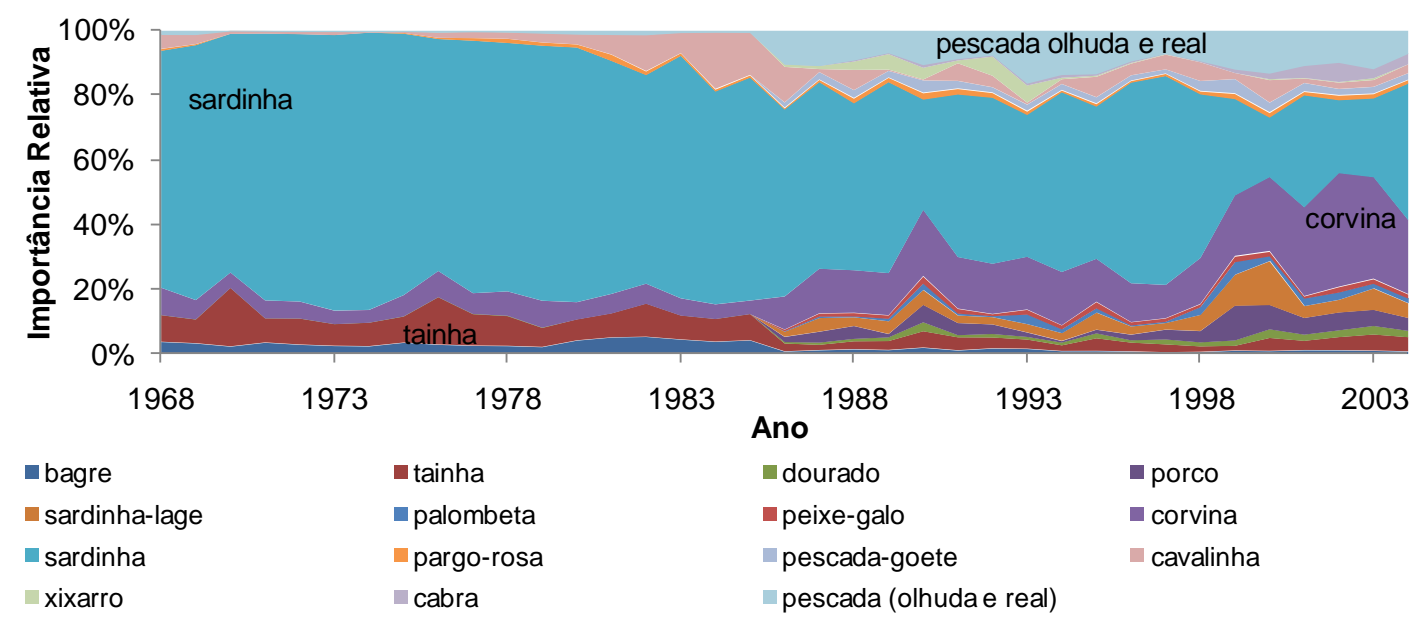

Figura 37. Importância relativa anual das categorias de pescado desembarcado de águas rasas entre 1968 e 2007.

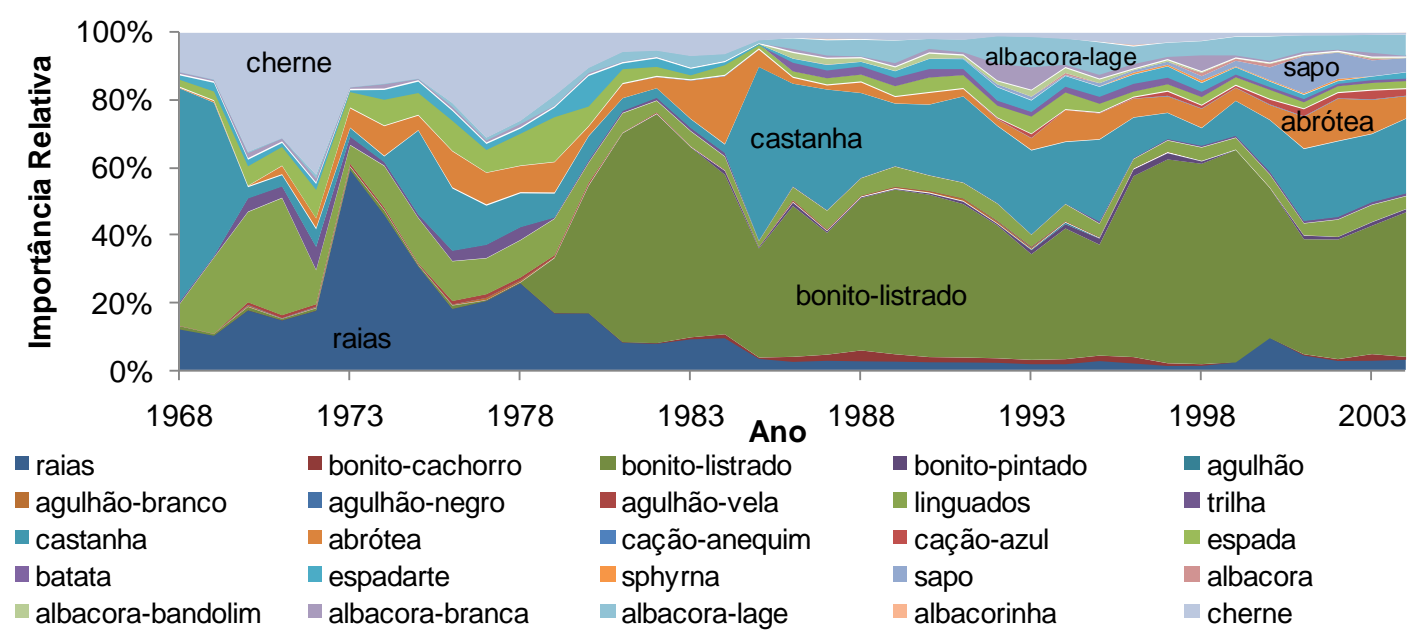

Figura 38. Importância relativa anual das categorias de pescado desembarcado de águas mais profundas entre 1968 e 2007. 
Na comercialização, a importância relativa do grupo de categorias de águas rasas como corvina, pescada-foguete e porco aumentou, enquanto que a da sardinha diminuiu (Fig. 40). Além disso, houve um aumento de importância relativa de categorias de águas mais profundas como o atum e bonito, enquanto que diminuiu a importância relativa de espécies como 0 espadarte, o cação-anjo, serra e a garoupa, também de águas profundas (Fig. 41).

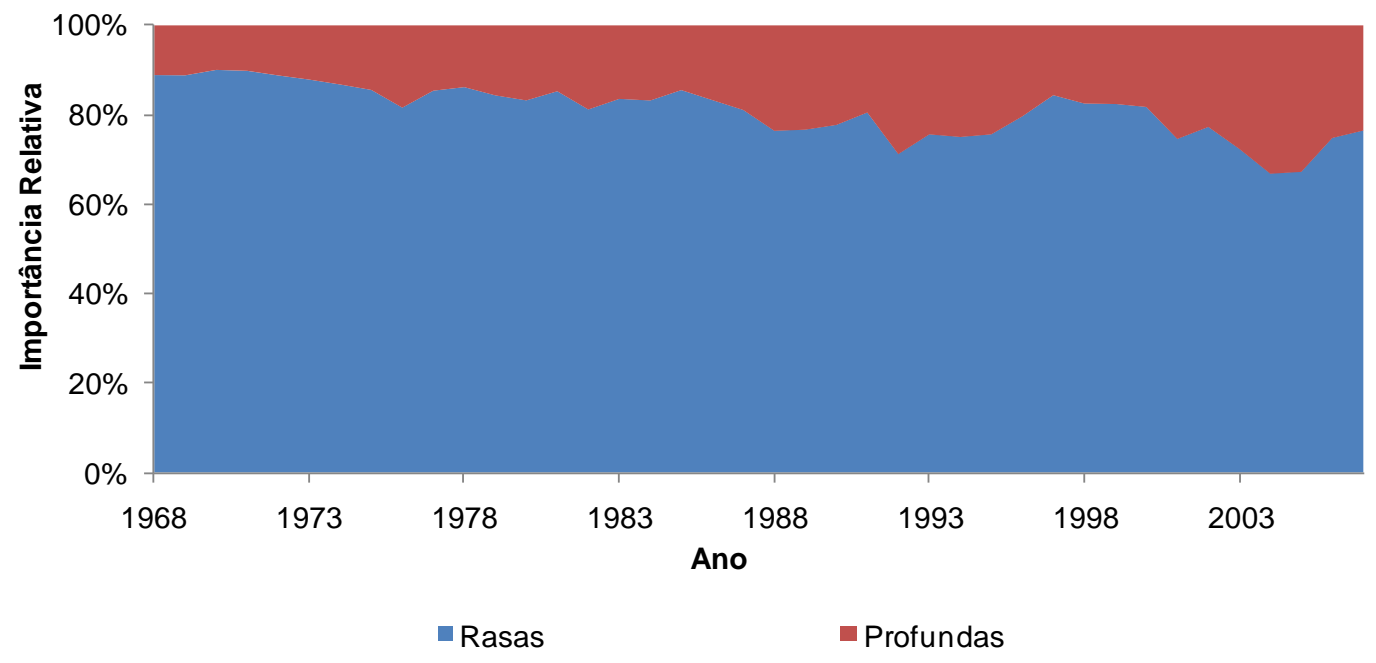

Figura 39. Importância relativa anual das categorias de pescado comercializado agrupadas nas diferentes classes de profundidade (rasas e profundas) entre 1968 e 2007. 


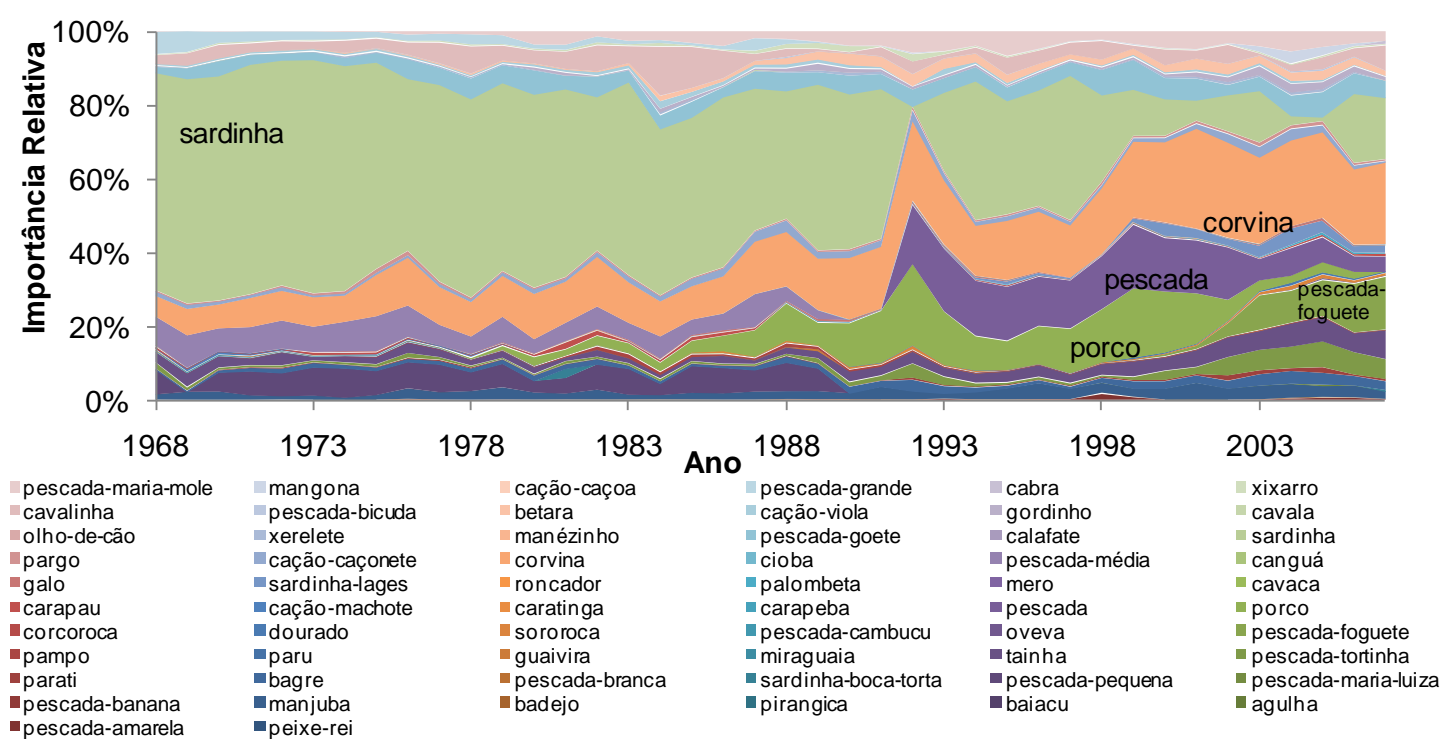

Figura 40. Importância relativa anual das categorias de pescado comercializado de águas rasas entre 1968 e 2007.

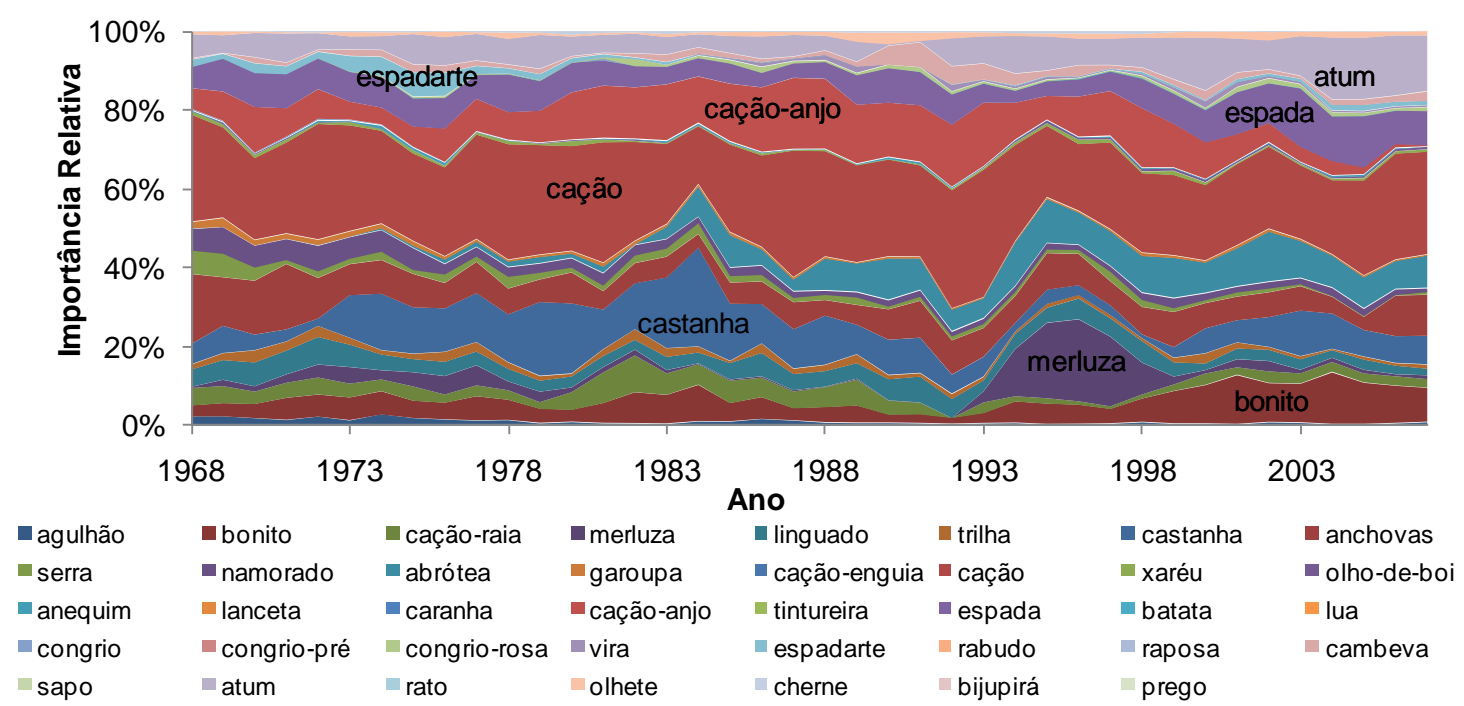

Figura 41. Importância relativa anual das categorias de pescado comercializado de águas mais profundas entre 1968 e 2007.

4.2. Análise das variáveis de preço e quantidades comercializadas

\subsubsection{Deflação dos preços de comercialização}

Para as análises temporais que utilizam os dados de preço da CEAGESP foi necessário retirar a influência da inflação nos preços do pescado 
para o período analisado, isto é, foi necessário deflacionar essa série temporal, pois houve no Brasil períodos com altos níveis inflacionários (Fig. 3), já apresentados anteriormente.

Os quatro índices inicialmente propostos apresentaram tendências semelhantes entre o IGP-DI (FGV) e o IPA-OG (FGV) e entre o IPA-DI (FGV) e o IPC (FIPE), conforme mostra o gráfico a seguir comparando o preço (R\$) em função do tempo para a categoria Abrótea (Fig. 42), como exemplo.

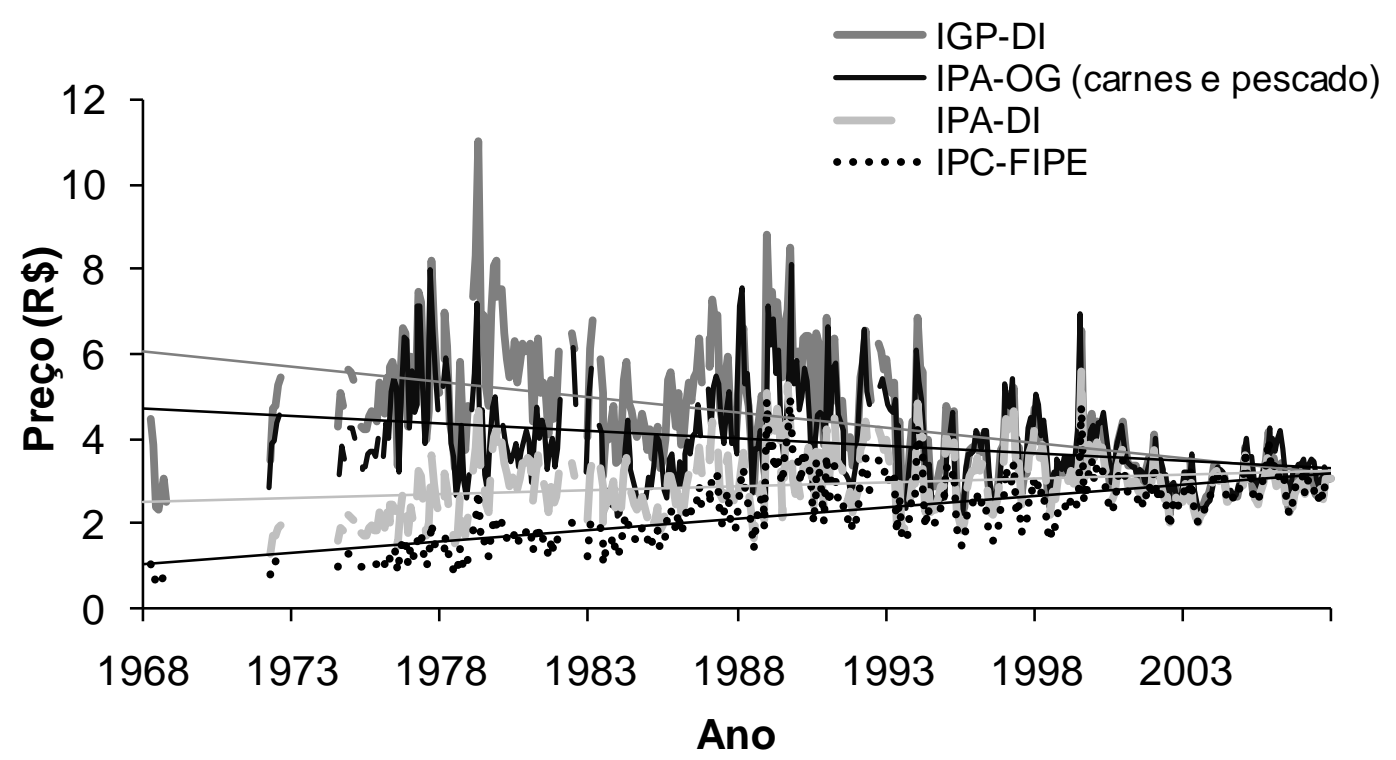

Figura 42. Preço da categoria Abrótea em função do tempo, utilizando os quatro índices como deflatores.

Assim, quando os indicadores foram aplicados usando os diferentes deflatores, obtivemos diferentes resultados. No caso do preço ponderado do pescado ao longo do tempo, foi possível verificar que considerando o IGP-DIFGV não está ocorrendo um aumento generalizado do preço do pescado, mas o aumento aparece quando consideramos o IPA-DI-FGV ou o IPC-FIPE (Fig. 43). 

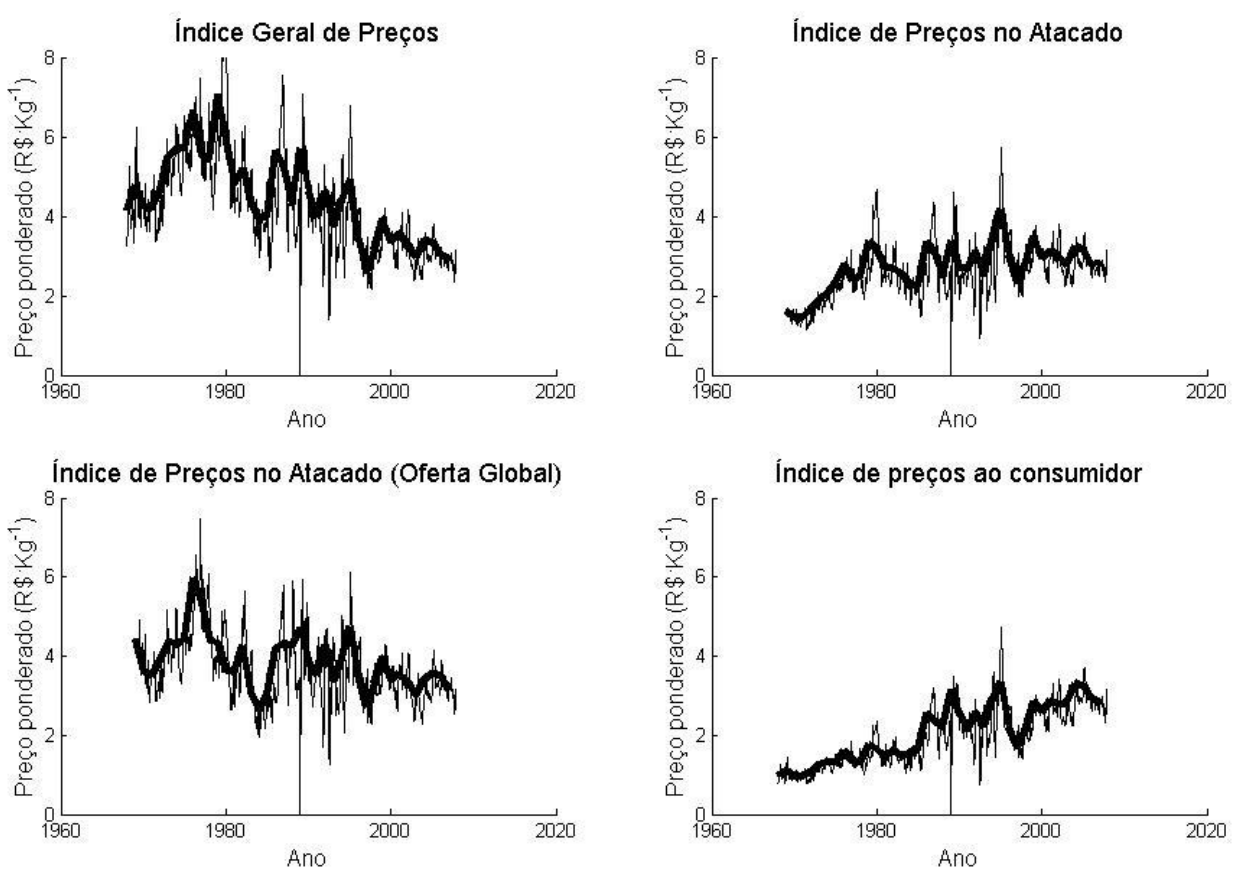

Figura 43. Preços ponderados deflacionados com os diferentes índices, IGPFGV, IPA-DI-FGV, IPA-OG-carne e pescado e IPC-FIPE (linha mais espessa é a média anual e a linha mais fina a mensal).

Essas diferenças ocorreram principalmente porque os índices consideram produtos diferentes com pesos diferentes. Por exemplo, o índice IPA-OG-FGV, apesar de incluir apenas carnes e pescado, torna-se inadequado por considerar também a exportação de alguns tipos de pescado, enquanto que o mercado da CEAGESP é essencialmente regional (SONODA et al., 2002).

O IGP-DI-FGV também não foi considerado um deflator adequado por incluir o INCC e o IPC para todo o Brasil.

De fato, os índices mais adequados seriam o IPA-DI-FGV e o IPCFIPE. Entretanto, o IPA-DI leva em conta os preços no atacado e, segundo Pinho e Vasconcellos (2003), 64,9\% do índice é composto pelo preço no atacado dos bens de produção, isto é, matérias primas, materiais de construção, máquinas, veículos, equipamentos e outros. Portanto, o uso desse 
deflator introduziria um viés referente a esses outros produtos nos preços do pescado.

Alem disso, o IPC-FIPE, apesar de refletir a inflação dos preços ao consumidor, pode ser o índice mais adequado, se consideramos que a produção da CEAGESP é prioritariamente destinada ao consumo de pescado da região de São Paulo (SONODA et al., 2002). E também, o IPC-FIPE é proporcional ao IPA-DI-FGV o que confirma ainda mais sua adequação como deflator (Fig. 44).

Assim, para retirar o efeito da inflação nos preços de pescado foi adotado o índice IPC-FIPE.

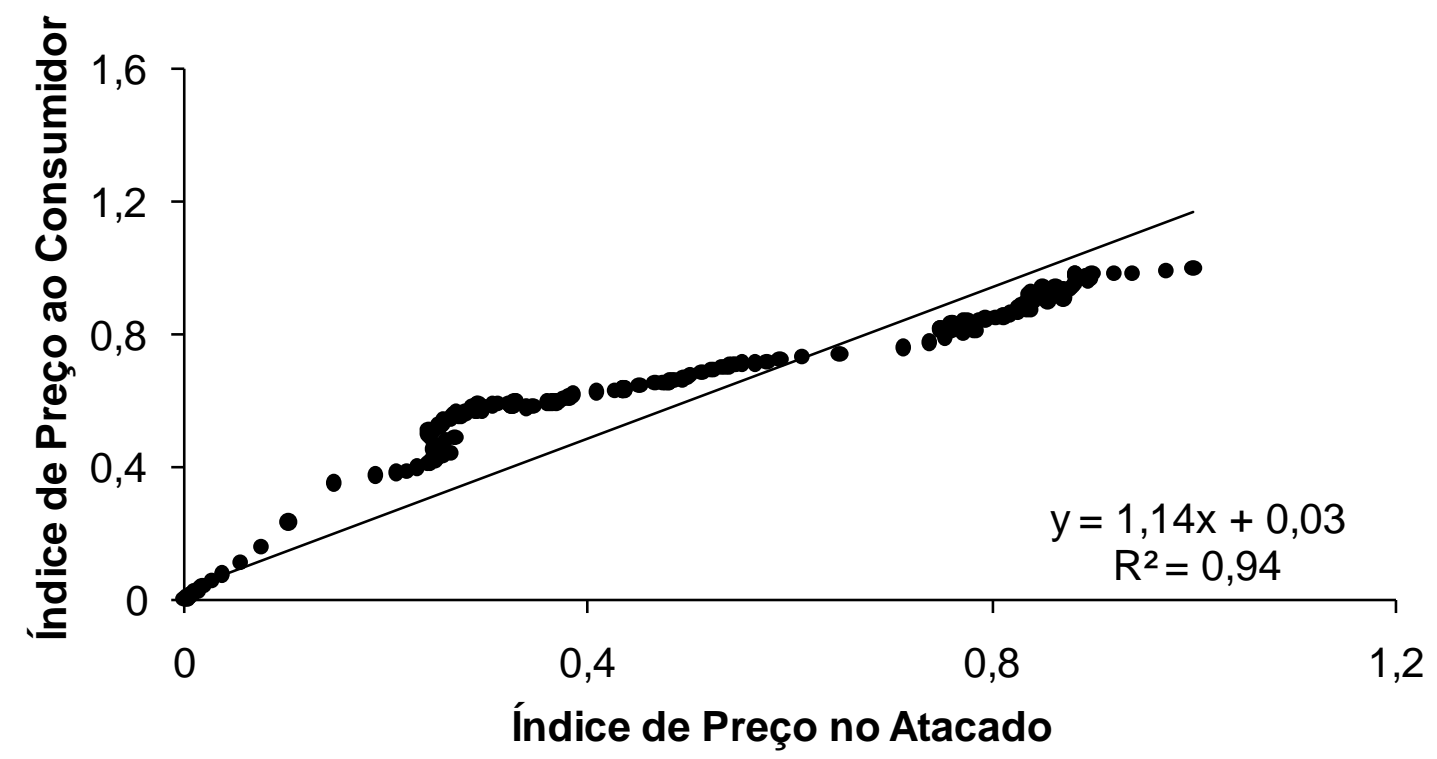

Figura 44. Relação entre o Índice de Preço ao Consumidor - FIPE e o Índice de Preço por Atacado - DI - FGV. 
4.2.2. Indicadores Multiespecíficos

4.2.2.1. Preço médio ponderado em função dos parâmetros bio-ecológicos ao longo dos anos

A figura 45 mostra, de maneira geral, uma tendência crescente $(\mathrm{p}<0,05)$ dos preços médios ponderados pela quantidade das categorias de pescado comercializadas. Os preços variaram de $R \$ 0,89$ a $R \$ 3,76$ (Fig. 45a). Os invertebrados também mostraram a tendência ascendente nos preços (Fig. 45b), que variou de um mínimo de $R \$ 2,09$ a um máximo de $R \$ 12,22$. Esse preço relativamente alto corresponde à influência do preço do camarão-rosa (Farfantepenaeus brasiliensis, F. paulensis). Os peixes foram analisados conforme as classificações dos parâmetros ecológicos: nível trófico, longevidade, comprimento máximo e profundidade (Figs. 46-49).

(a) 

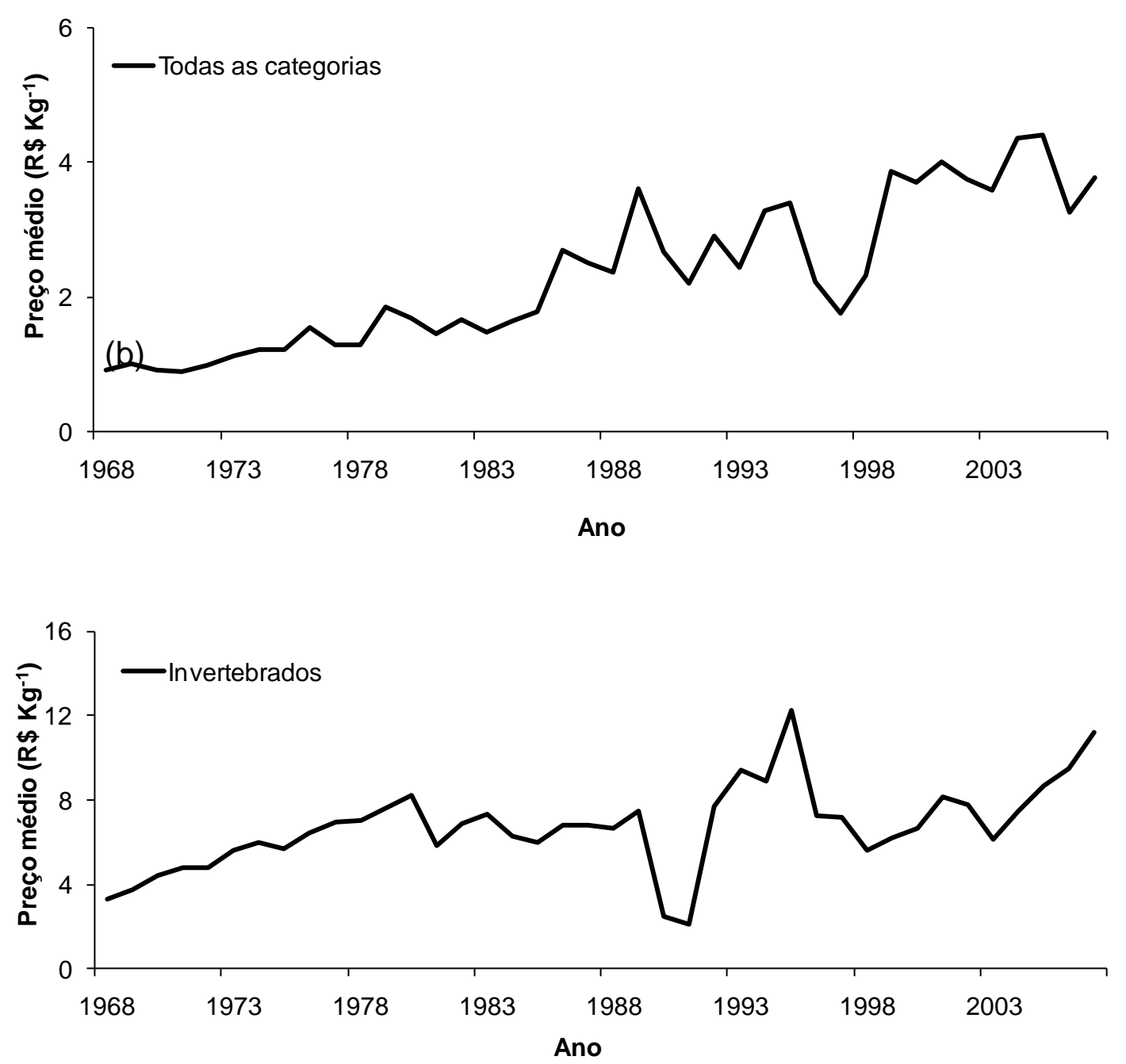

Figura 45. Preço médio ponderado para a) todas as categorias comercializadas e b) invertebrados, para o período de 1968-2007.

\section{Nível Trófico}

As categorias de pescado agrupadas por classes de NT mostraram tendências de aumento significativamente diferentes $(p<0,05)$ (Fig. 46). A classe de NT-alto aumentou comparativamente mais (coeficiente angular $=$ 0,13 ) que as classes de NT-baixo (coeficiente angular $=0,06$ ) e de NT-int (coeficiente angular $=0,10$ ) (Fig. 46). 


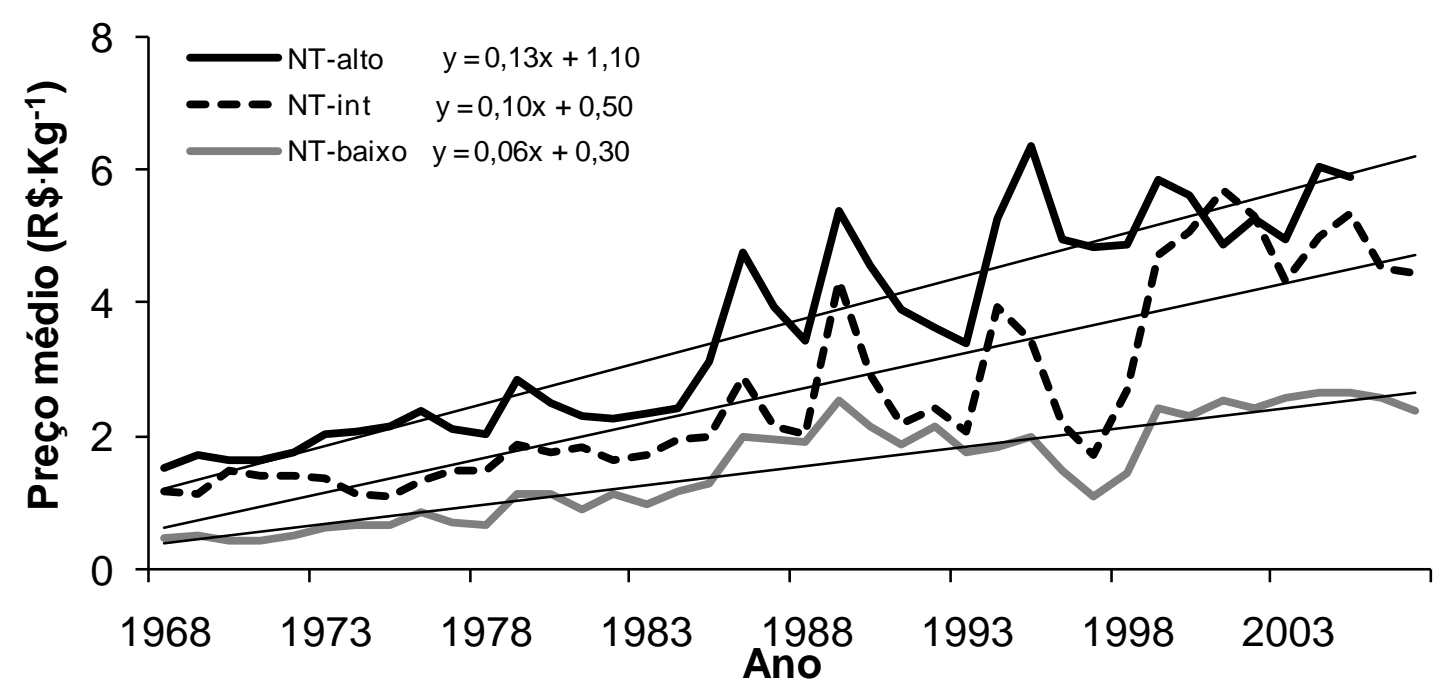

Figura 46. Preço médio ponderado em função das classes de nível trófico, para o período de 1968-2007.

\section{Longevidade}

O preço médio ponderado classificado segundo as classes de longevidade é apresentado na figura 47. A variação dos preços da classe das categorias de Long- baixa (long $<5$ anos) foi de $R \$ 0,30$ a $R \$ 3,94$, enquanto que para a classe das categorias de Long-int (5>long>20 anos) e alta (long>20 anos) houve oscilação de $R \$ 1,04$ a $R \$ 3,40$ e de $R \$ 1,63$ a $R \$ 6,54$, respectivamente. Todas as tendências são significativas $(p<0,05)$. A classe das categorias de Long-alta (coeficiente angular=0,12) apresentou um aumento no preço relativamente maior do que as de Long-int e Long-baixa (coeficiente angular $=0,06$ e 0,08$)$. 


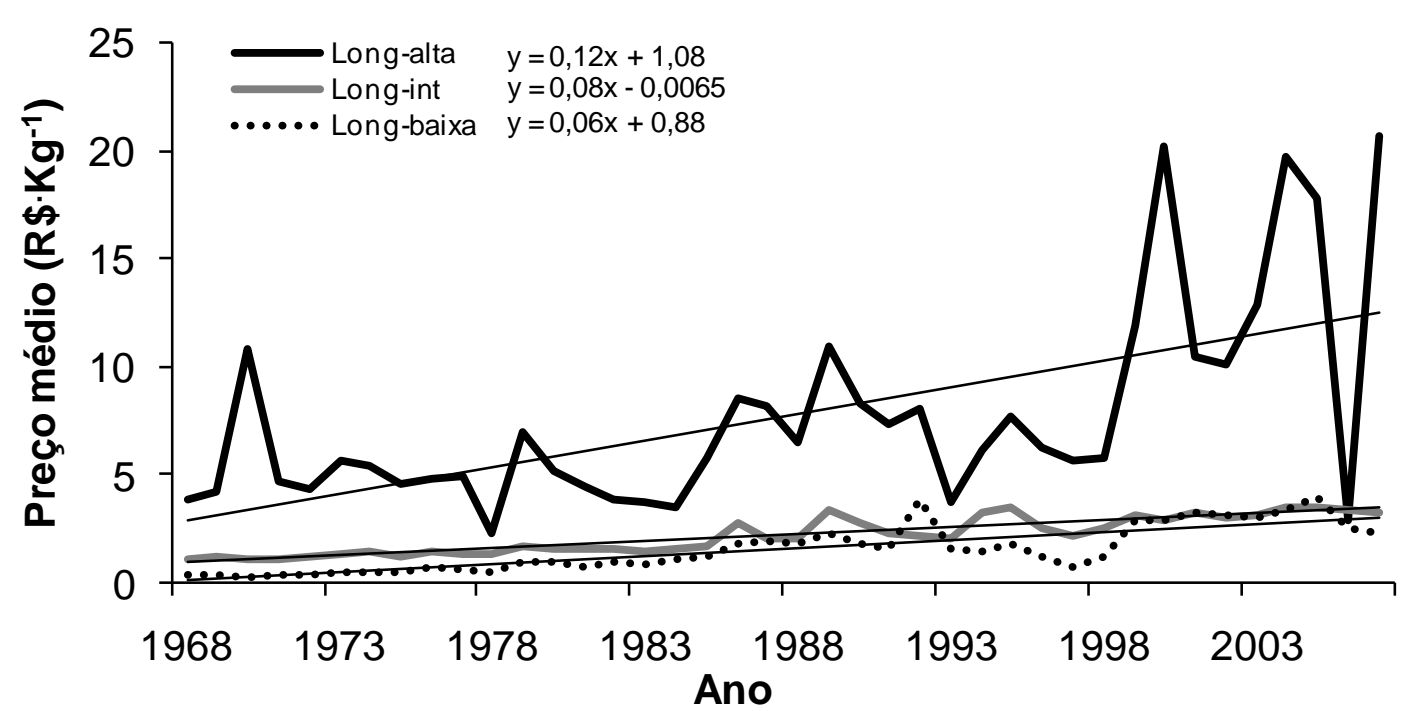

Figura 47. Preço médio ponderado em função das classes de longevidade (Long) para o período de 1968 a 2007.

\section{Comprimento Máximo}

As classes de comprimento máximo apresentaram um aumento significativo $(p<0,05)$ em relação aos seus preços ponderados (Fig. 48). A classe de Lmáx-alto (Lmáx>1200 mm) variou de $R \$ 1,53$ a $R \$ 14,20$, já a de Lmáx-int (300<Lmáx<1200 mm) oscilou de $R \$ 0,96$ a $R \$ 3,32$ e a de Lmáx-baixo (Lmáx<300 mm) de $R \$ 0,30$ a $R \$ 2,78$. As categorias de Lmáx-alto (coeficiente angular $=0,15)$ apresentaram um aumento relativamente maior do que as de Lmáx-int e baixo (coeficiente angular=0,06 e 0,03, respectivamente). 


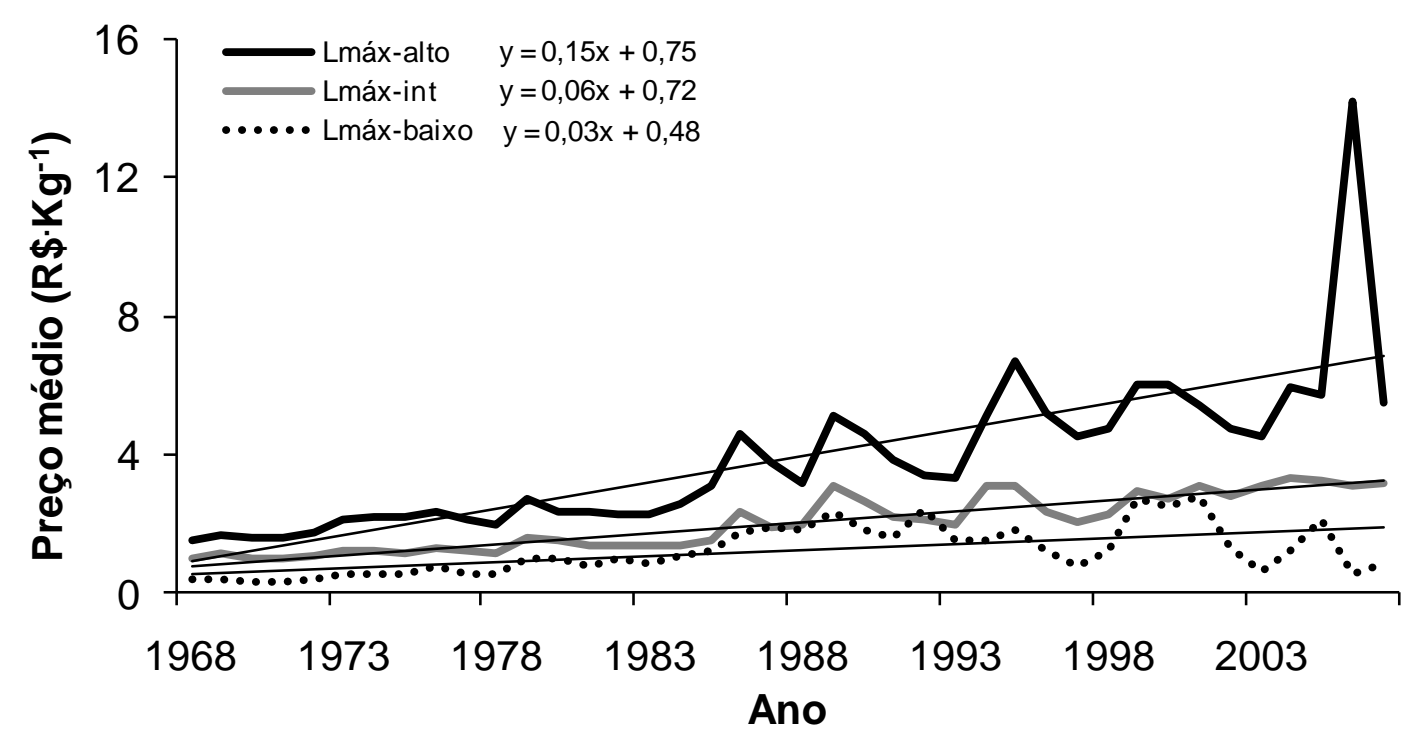

Figura 48. Preço médio ponderado em função das classes de comprimento máximo (Lmáx) para o período de 1968 a 2007.

\section{Profundidade}

A figura 49 ilustra o preço médio classificado segundo as duas classes de profundidade. A variação dos preços para as categorias de profundidade rasa (prof $<66 \mathrm{~m}$.) foi de $\mathrm{R} \$ 0,45$ a $\mathrm{R} \$ 3,10$ e para as de profundidade maior (prof $>66 \mathrm{~m}$.) foi de $R \$ 1,24$ a $R \$ 11,03$, sendo ambas as tendências significativas $(p<0,05)$. Verificou-se um aumento no preço das categorias de profundidade rasa (coeficiente angular $=0,07$ ) relativamente menor do que as de águas mais profundas (coeficiente angular $=0,21$ ). 


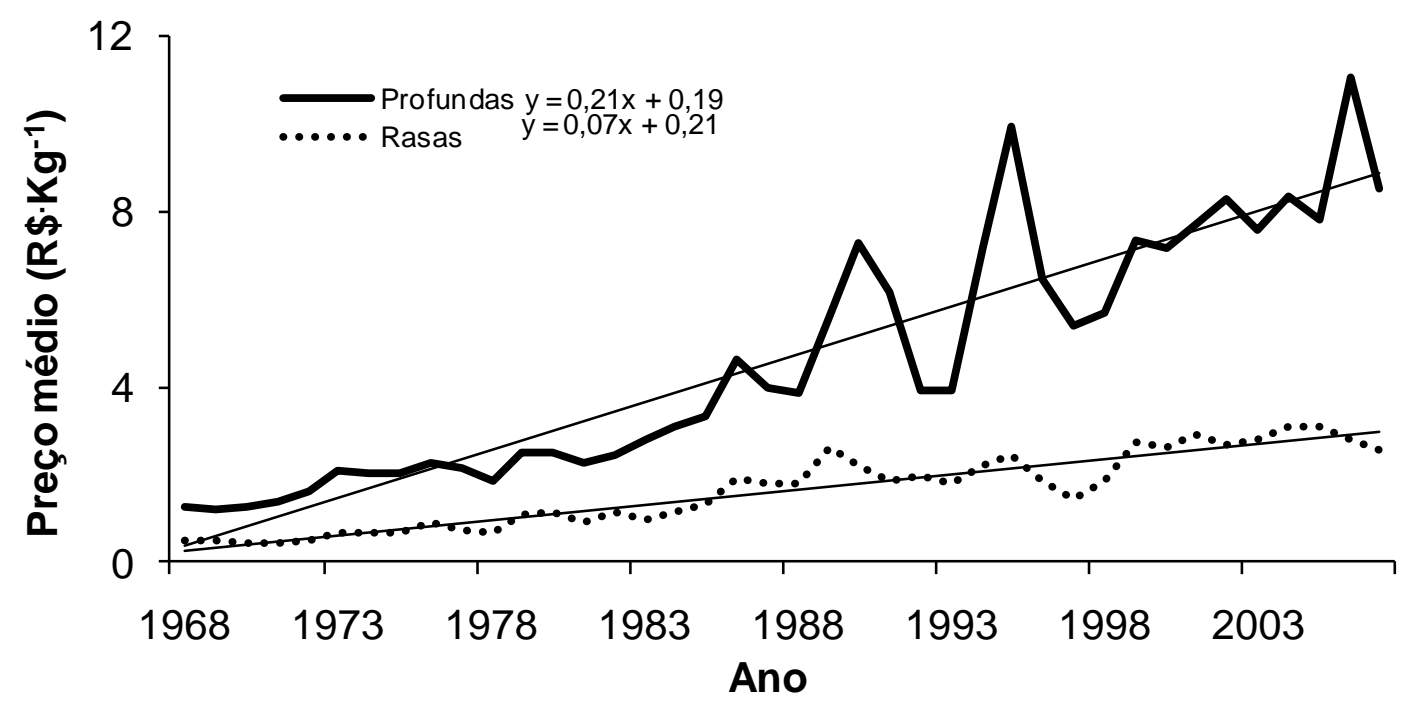

Figura 49. Preço médio ponderado em função das classes de profundidade para o período de 1968 a 2007.

\subsubsection{Análise inferencial dos dados de mercado}

As figuras de 50 a 53 mostram a tendência dos preços versus as quantidades de mercado para as categorias de pescado agrupadas nas três classes de NT, mais invertebrados, respectivamente. A tabela 1 mostra a significância estatística das correlações lineares e das tendências das séries temporais de preço e quantidade. Das 44 categorias incluídas nas análises, 30 apresentaram correlação linear significativa $(p<0,05)$ entre as tendências dos preços versus quantidades comercializadas (Tab. 1).

Correlações negativas entre os preços de mercado e as quantidades, isto é, o aumento do preço e a diminuição da quantidade foram observadas em dezessete categorias (Tab. 1; ver Figs. 50-53): cação-caçonete, caçãomachote, espadarte, namorado, serra apresentadas na figura 50; garoupa, pargo, pescada-cambucu na figura 51, cavalinha, manjuba, sardinha, tainha, trilha na figura 52; e, camarão-rosa, camarão-sete-barbas e lulas na figura 53. Assumindo uma demanda constante, essa relação preço-quantidade é 
principalmente determinada pela oferta de pescado, a qual depende principalmente das condições ambientais, que são variáveis (BAKUN, 1996). A correlação negativa foi particularmente forte para as categorias de NT-alto, especialmente piscívoros, como namorado (-0,43; Fig. 50g), e também para algumas espécies-alvo e comercialmente importantes de NT-baixo, como a sardinha (-0,69; Fig. 52g) e o camarão-rosa (-0,80; Fig. 53a). Já correlações positivas significativas entre os preços de mercado e suas quantidades foram encontradas para 13 categorias (ver Fig. 50a, b, e; Fig. 51a, b, d, h-j; Fig. 52a, d-f), incluindo os atuns e bonitos (Fig. 50a e b).

A tendência dos preços para 40 de 44 categorias apresentaram significância estatística (Tab. 1). No entanto, apenas 19 categorias mostraram uma tendência significativa em relação às variações de suas quantidades comercializadas ao longo do período (Tab. 1). As categorias que não apresentaram tendências significativas quanto as suas quantidades, como cação-caçonete e serra (Fig. 50c e h) e linguados (Fig. 51k), apresentaram, em geral, um aumento da quantidade comercializada inicialmente, seguido por uma diminuição da mesma, enquanto os preços aumentaram ao longo do período. 
Tabela 1. Significância estatística das correlações lineares e das tendências das series temporais de preço e quantidade das categorias de pescado. ( $P$ indica uma tendência positiva, $\mathrm{N}$ indica uma tendência negativa, $\mathrm{P}-\mathrm{N}$ indica uma tendência inicialmente positive seguida por uma tendência negativa, e "-" indica nenhuma significância estatística).

\begin{tabular}{|c|c|c|c|c|}
\hline Categoria de pescado & Espécie & $\begin{array}{l}\text { Preço x quantidade } \\
\text { Coeficiente de } \\
\text { Pearson (valor de p) }\end{array}$ & $\begin{array}{l}\text { Tendência } \\
\text { dos preços } \\
\text { (valor de p- } \\
\text { Cox-Stuart) } \\
\end{array}$ & $\begin{array}{l}\text { Tendência das } \\
\text { quantidades } \\
\text { (valor de p-- } \\
\text { Cox-Stuart) }\end{array}$ \\
\hline agulhões & $\begin{array}{c}\text { Tetrapturus albidus, } T . \\
\text { pfluegeri, Makaira nigricans, } \\
\text { Istiophorus albicans }\end{array}$ & - & 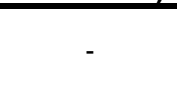 & $N(0,0004)$ \\
\hline $\begin{array}{l}\text { pescada-maria-mole, } \\
\text { pescada-olhuda }\end{array}$ & Cynoscion guatucupa & - & $P(<0,0001)$ & - \\
\hline pescada-goete & Cynoscion jamaicensis & - & $P(<0,0001)$ & - \\
\hline badejo & Mycteroperca bonaci & - & $P(<0,0001)$ & - \\
\hline cação-viola & Rhinobatos horkelli & - & $P(<0,0001)$ & - \\
\hline olhete & Seriola lalandi & - & $P(<0,0001)$ & $P(0,0004)$ \\
\hline cação-martelo & Sphyrna spp. & - & - & P-N $(0,0414)$ \\
\hline cação-anjo & Squatina spp. & - & $P(<0,0001)$ & - \\
\hline pampo & Trachinotus spp. & - & $P(0,0005)$ & - \\
\hline xixarro & $\begin{array}{c}\text { Trachurus lathami } \\
\text { Lamnidae, Carcharhinidae, }\end{array}$ & - & $P(<0,0001)$ & - \\
\hline cações & $\begin{array}{c}\text { Triakidae, Odontaspididae, } \\
\text { Sphyrnidae, Alopiidae e } \\
\text { Squalidae }\end{array}$ & - & $P(<0,0001)$ & - \\
\hline linguado & $\begin{array}{c}\text { Paralichthyidae e Bothidae, } \\
\text { Achiridae } \\
\text { Rajidae, Rhinobatidae, }\end{array}$ & - & $\mathrm{P}(<0,0001)$ & - \\
\hline raias & $\begin{array}{c}\text { Myliobatidae, Gymnuridae, } \\
\text { Narcinidae e Dasyatidae }\end{array}$ & - & $P(<0,0001)$ & - \\
\hline pescada-branca & Cynoscion leiarchus & - & - & - \\
\hline camarão-rosa & Farfantepenaeus spp. & $-0,805(<0,001)$ & $P(<0,0001)$ & $N(<0,0001)$ \\
\hline sardinha & Sardinella brasiliensis & $-0,696(<0,001)$ & $P(<0,0001)$ & $N(<0,0001)$ \\
\hline cação-machote & Carcharhinus spp. & $-0,514(<0,001)$ & $P(<0,0001)$ & $N(<0,0001)$ \\
\hline namorado & Pseudopercis spp. & $-0,434(<0,001)$ & $P(<0,0001)$ & $\mathrm{N}(0,0001)$ \\
\hline pescada-cambucu & Cynoscion virescens & $-0,383(<0,001)$ & $P(0,0044)$ & $\mathrm{N}(<0,0001)$ \\
\hline garoupa & Epinephelus marginatus & $-0,340(<0,001)$ & $P(<0,0001)$ & $\mathrm{N}(0,0026)$ \\
\hline manjuba & Anchoa spp. & $-0,268(<0,001)$ & $P(<0,0001)$ & - \\
\hline cavalinha & $\begin{array}{c}\text { Scomber japonicus } \\
\text { Pristis pectinata, Sarda }\end{array}$ & $-0,255(<0,001)$ & $P(<0,0001)$ & - \\
\hline serra & $\begin{array}{c}\text { sarda, Scomberomorus } \\
\text { brasiliensis }\end{array}$ & $-0,210(<0,001)$ & $P(<0,0001)$ & - \\
\hline espadarte & Xiphias gladius & $-0,205(0,002)$ & $P(0,0039)$ & $(0,0075)$ \\
\hline pargo & Pagrus pagrus & $-0,202(<0,001)$ & $P(<0,0001)$ & - \\
\hline lulas & Loligo spp. & $-0,177(<0,001)$ & $P(<0,0001)$ & - \\
\hline anchovas & Pomatomus saltatrix & $-0,155(0,001)$ & $P(<0,0001)$ & - \\
\hline trilha & Mullidae & $-0,139(0,006)$ & $P(<0,0001)$ & - \\
\hline camarão-sete-barbas & Xiphopenaeus kroyeri & $-0,098(0,045)$ & - & $\mathrm{N}(<0,0001)$ \\
\hline cação caçonete & Rhizoprionodon spp. & $-0,132(0,004)$ & $P(<0,0001)$ & - \\
\hline tainha & Mugil spp. & $-0,131(0,004)$ & $N(0,0118)$ & $P(0,0026)$ \\
\hline peixe-galo & Selene setapinnis & $0,103(0,043)$ & $P(<0,0001)$ & - \\
\hline castanha & Umbrina canosai & $0,104(0,037)$ & $P(<0,0001)$ & - \\
\hline bagre & $\begin{array}{c}\text { Arius spp., Cathorops spp., } \\
\text { Netuma spp. } \\
\text { Auxis thazard, Katsuwonus }\end{array}$ & $0,126(0,006)$ & $P(<0,0001)$ & - \\
\hline bonitos & $\begin{array}{c}\text { pelamis, Euthynnus } \\
\text { alletteratus }\end{array}$ & $0,166(<0,001)$ & $P(<0,0001)$ & $P(0,0118)$ \\
\hline sororoca & Scomberomorus brasiliensis & $0,185(0,002)$ & $P(<0,0001)$ & $P(0,0026)$ \\
\hline parati & Mugil curema & $0,203(<0,001)$ & $P(<0,0001)$ & $P(0,0414)$ \\
\hline corvina & Micropogonias furnieri & $0,209(<0,001)$ & $P(<0,0001)$ & - \\
\hline mistura & várias espécies de peixes & $0,218(<0,001)$ & $P(0,0026)$ & - \\
\hline espada & Trichiurus lepturus & $0,269(<0,001)$ & $P(<0,0001)$ & - \\
\hline robalo & Centropomus spp. & $0,340(<0,001)$ & $P(<0,0001)$ & $P(<0,0001)$ \\
\hline pescada-tortinha & Isopisthus parvipinnis & $0,342(<0,001)$ & $P(<0,0001)$ & $P(0,0118)$ \\
\hline atum & Thunnus spp. & $0,401(<0,001)$ & $P(0,0001)$ & $P(<0,0001)$ \\
\hline betara & Menticirrhus spp. & $0,561(<0,001)$ & $P(<0,0001)$ & $P(0,0026)$ \\
\hline
\end{tabular}



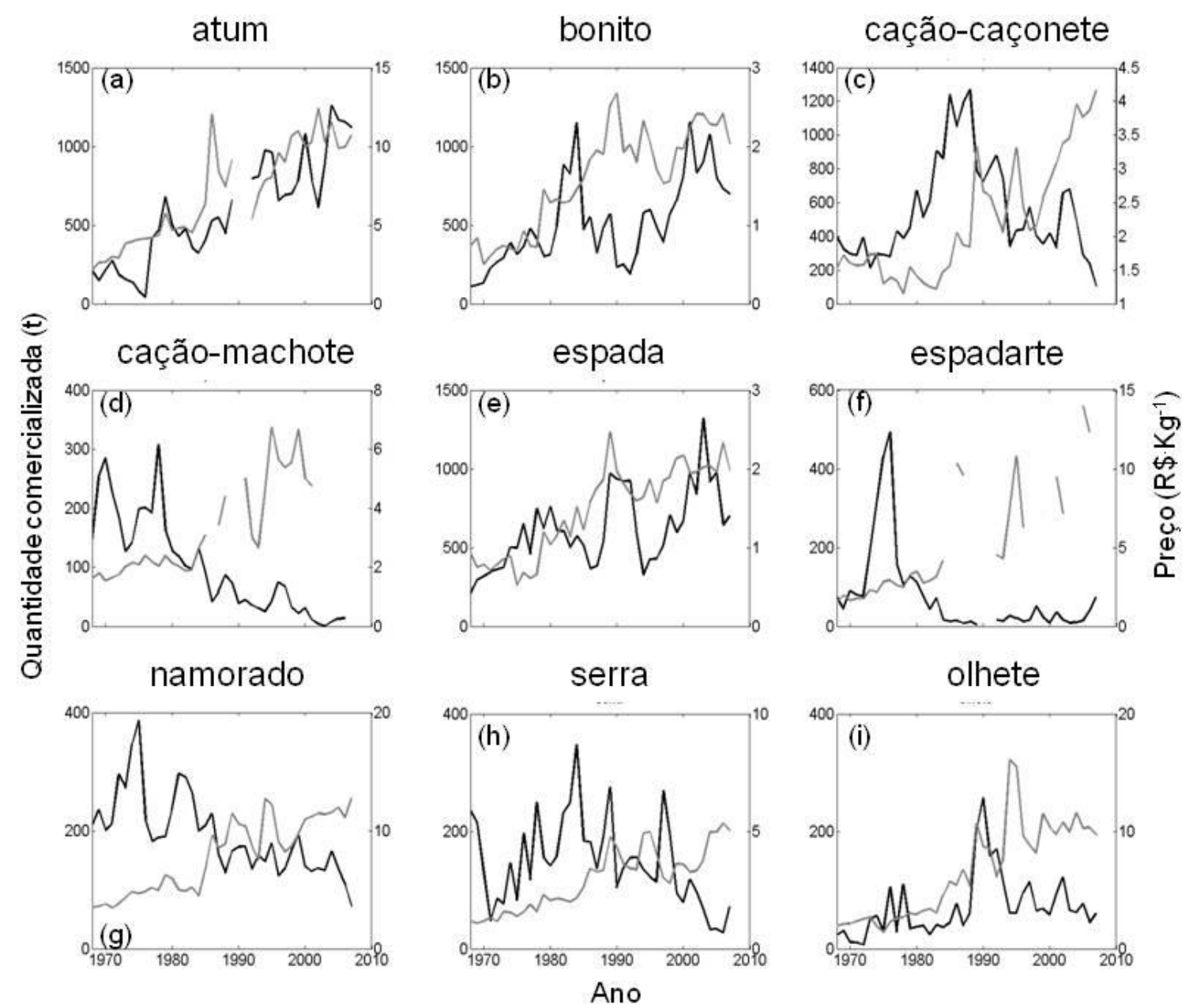

Preço —_ Quantidade comercializada

Figura 50. Preços e quantidades comercializadas de 1968-2007 para categorias de NT-alto: a) atum, b) bonito, c) cação-caçonete, d) caçãomachote, e) espada, f) espadarte, g) namorado, h) serra, e i) olhete* (asterisco indica uma correlação de Pearson entre as váriáveis de preço e quantidade não significativa). 


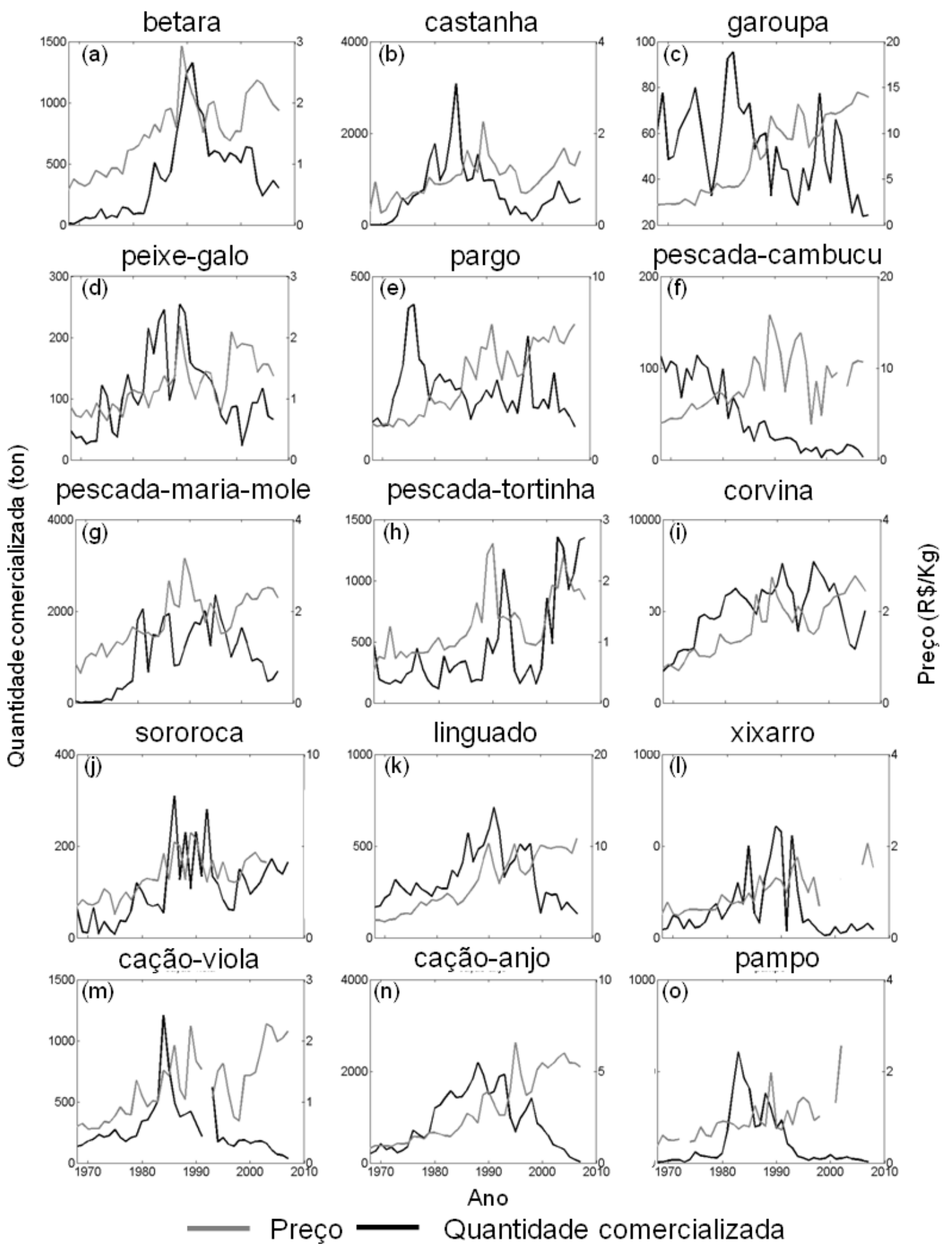

Figura 51. Preços e quantidades comercializadas de 1968-2007 para as categorias de NT-int: a) betara, b) castanha, c) garoupa, d) peixe-galo, e) pargo, f) pescada-cambucu, g) pescada-maria-mole, h) pescada-tortinha, i) corvina, j) sororoca, k) linguado, I) xixarro*, m) cação-viola*, n) cação-anjo*, e o) pampo* (asterisco indica uma correlação de Pearson entre as váriáveis de preço e quantidade não significativa). 

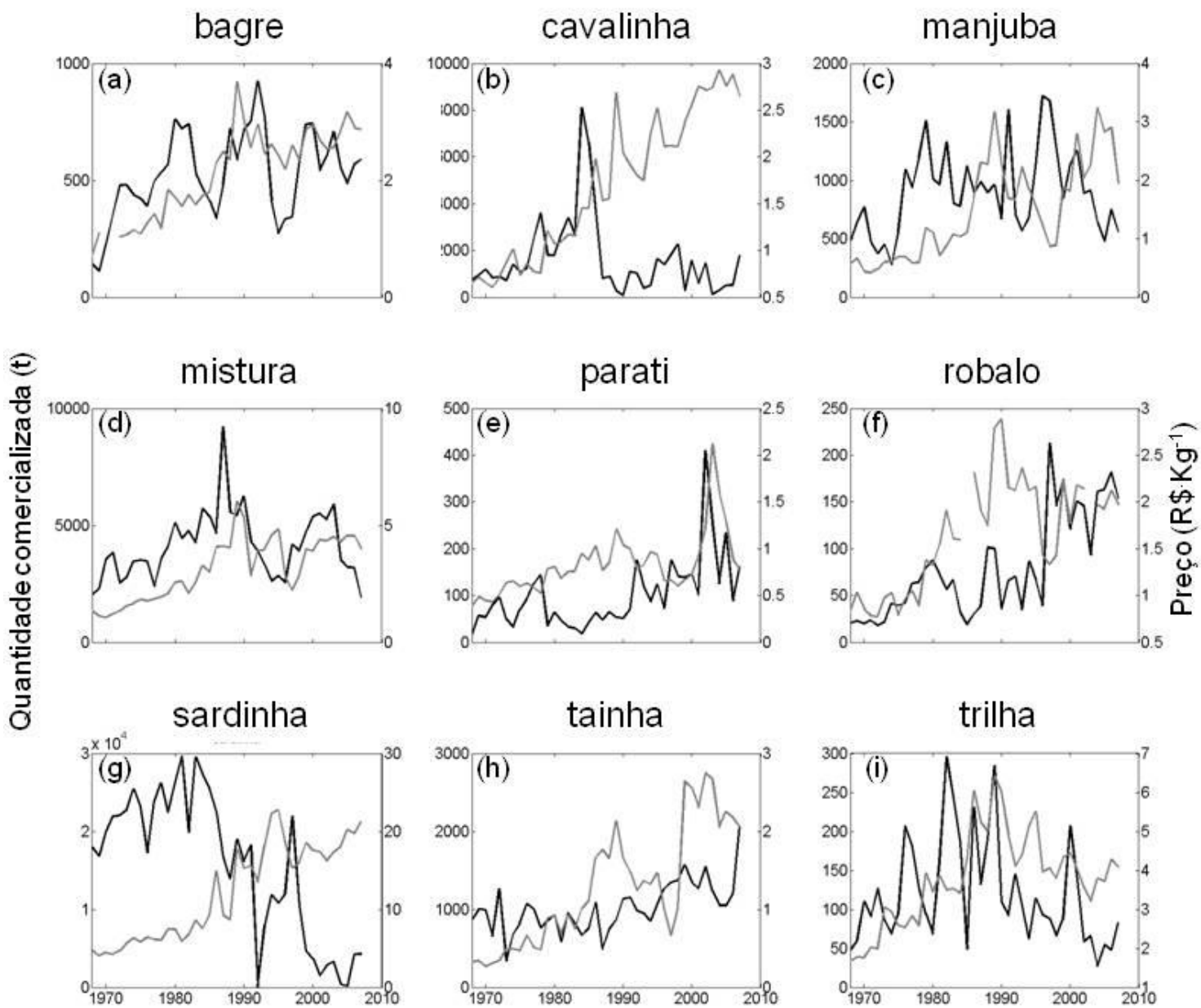

Ano

— Preço —_ Quantidade comercializada

Figura 52. Preços e quantidades comercializadas de 1968-2007 para categorias de NT-baixo: a) bagre, b) cavalinha, c) manjuba, d) mistura, e) parati, f) robalo, g) sardinha, h) tainha, e i) trilha.
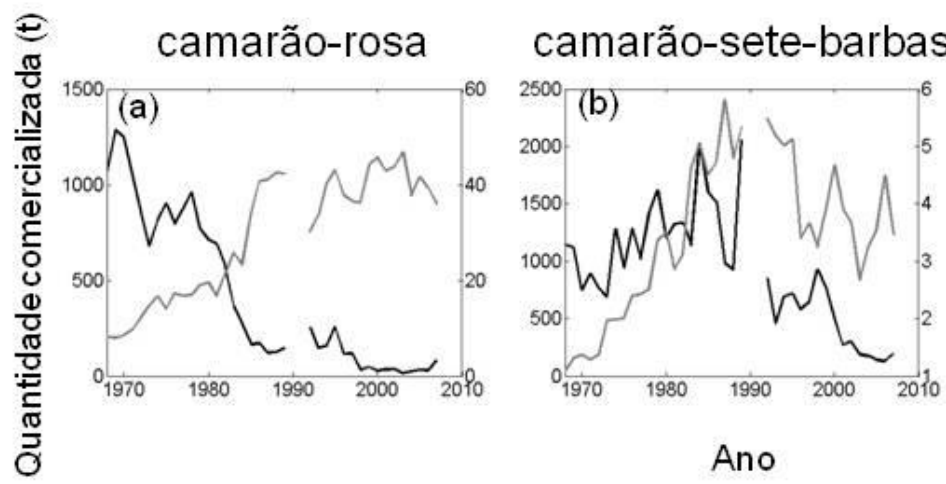

Iula
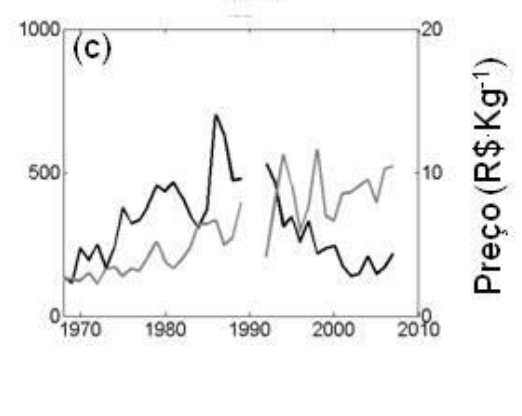

Figura 53. Preços e quantidades comercializadas de 1968-2007 para invertebrados: a) camarão-rosa, b) camarão-sete-barbas, e c) lula. 
4.2.2.3. Índice do Preço Relativo Logaritmizado (IPRL)

\subsection{Série original}

O resultado para o primeiro período (1968-1989) mostrou uma tendência do IPRL de diminuição significativa (Figs. 54a, 54c; $p<0,05$ ), variando de 0,1 a 0,03. O aumento suave antes de 1971 pode ser explicado pelo fato de que o preço de algumas categorias de NT-alto, como xáreu, xerelete, cavala e atum, aumentaram $58 \%, 54 \%, 33 \%$, e $39 \%$, respectivamente, enquanto a maioria das categorias de NT-baixo diminuiu ( $p$. ex., caranguejo, sardinha, cavalinha, corvina e bagre) (BOLETIM MENSAL CEAGESP, 1968, 1971). A tendência decrescente do índice no período seguinte é explicada por um aumento nos preços de todas as categorias, mas esse aumento foi maior para algumas de NT-baixo (783\% para caranguejo, 694\% para sardinha e 758\% para cavalinha) (BOLETIM MENSAL CEAGESP, 1971, 1989).

Para o período 1992-2007 (Figs. 54b, 54d), o IPRL apresentou uma variação maior do que no período anterior (1968-1989). A tendência crescente de IPRL durante 1992-1996 foi devido ao fato de que as categorias de NT-alto, tais como o cação-anjo, se tornaram mais valiosas ( $83 \%$ de aumento no preço) em comparação com as categorias de NT-baixo, tais como cavalinha (BOLETIM MENSAL CEAGESP, 1992; 1996). Entre 1996 e 2003, o índice diminuiu, refletindo um aumento nos preços das categorias de NT-baixo, tais como a corvina (222\%), a pescada-tortinha (241\%), e a sardinha $(269 \%)$ 
(BOLETIM MENSAL CEAGESP, 1996; 2003). Após 2003, as categorias de NTbaixo desvalorizaram, resultando em um índice crescente (BOLETIM MENSAL CEAGESP, 2003, 2007). No entanto, para todo o período (1992-2007), a tendência dinâmica não foi estatisticamente significativa $(p<0,05)$.

Em ambos os períodos, a tendência do IPRL parece ser suavizada quando as barras de erro são consideradas (Figs. 54c e 54d), uma vez que o erro associado ao índice é relativamente alto (cerca de 0,35 ) em comparação com a variação da tendência do IPRL.
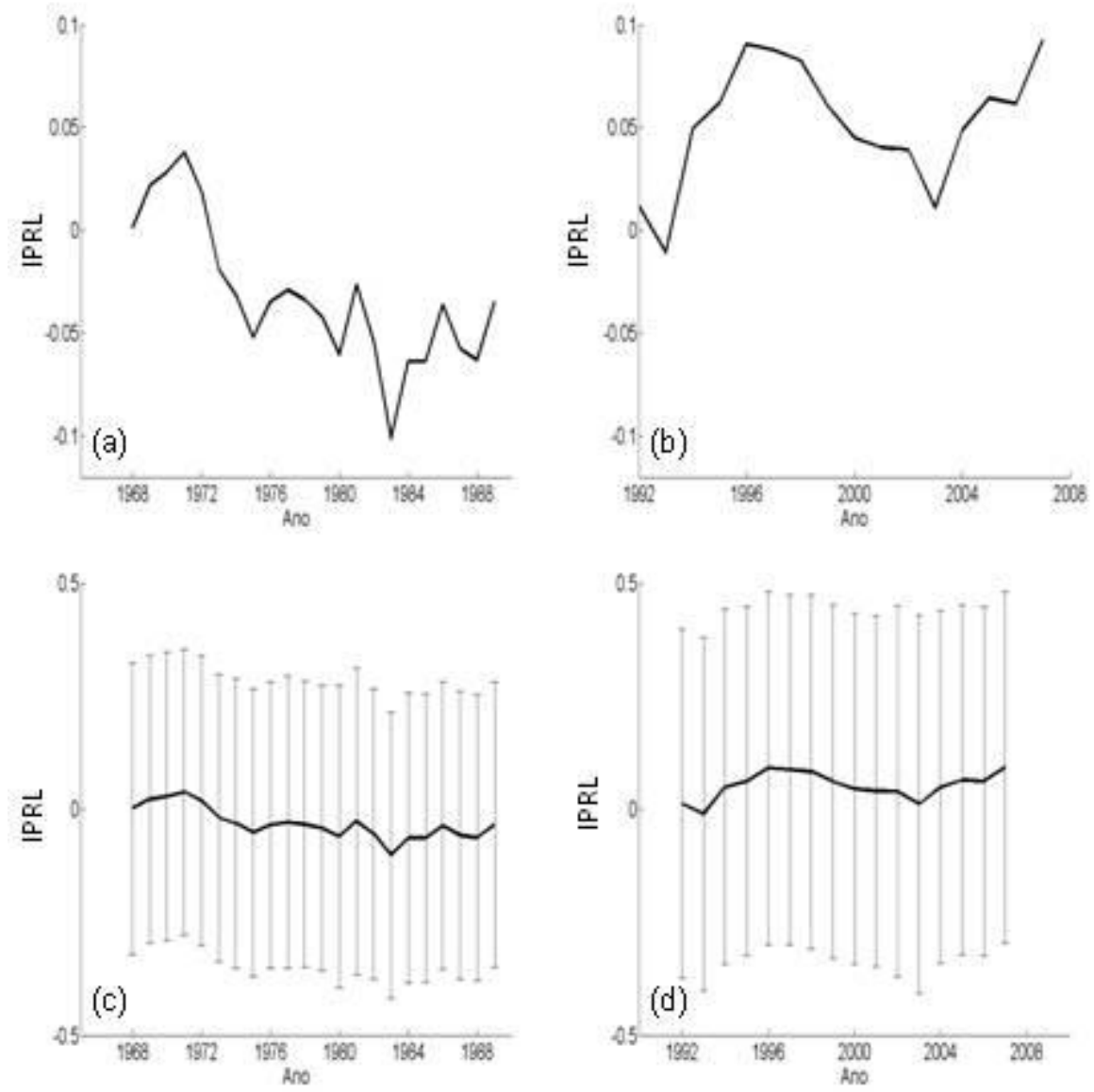

Figura 54. Tendência anual do Índice de Preço Relativo Logaritmizado para o período de a) 1968-1989 e de b) 1992-2007, seguidos pelos respectivos erros padrões $( \pm 0,35)$ para c) $1968-1989$ e d) 1992-2007. 


\subsection{Série interpolada}

Uma tendência decrescente significante do IPRL $(p<0,05)$, variando de 0,09 a -0,06 foi observada (Fig. 55). A primeira tendência decrescente (19681993) ocorreu em parte porque o preço aumentou $1475 \%$ para o congrio-rosa, $1009 \%$ para o olho-de-boi, $986 \%$ para o cherne, $969 \%$ para o olhete, e de forma geral para as espécies de NT-alto (BOLETIM MENSAL CEAGESP, 1968; 1993, com dados interpolados não-publicados). A mudança de tendência observada entre 1993 e 1995 (Fig. 55) é explicada pelo aumento de preços de algumas categorias de NT-baixo, tais como $868,7 \%$ para o berbigão, $168,05 \%$ para o mexilhão, e 128\% para xixarro, e também para algumas categorias de NT-alto, tais como $143,61 \%$ para o xaréu e $131,99 \%$ para a sororoca (BOLETIM MENSAL CEAGESP, 1993; 1995, com dados interpolados nãopublicados).

Mais recentemente, entre 1995 e 2007, a tendência do IPRL observada foi mais influenciada pelas espécies de NT-alto, tais como dourado, olho-de-boi e olhete, que se tornaram mais valiosas que as espécies de NT-baixo, apesar do aumento no preço da trilha e de alguns camarões (ambos de NT-baixo) (BOLETIM MENSAL CEAGESP, 1995; 1997, com dados interpolados nãopublicados). 

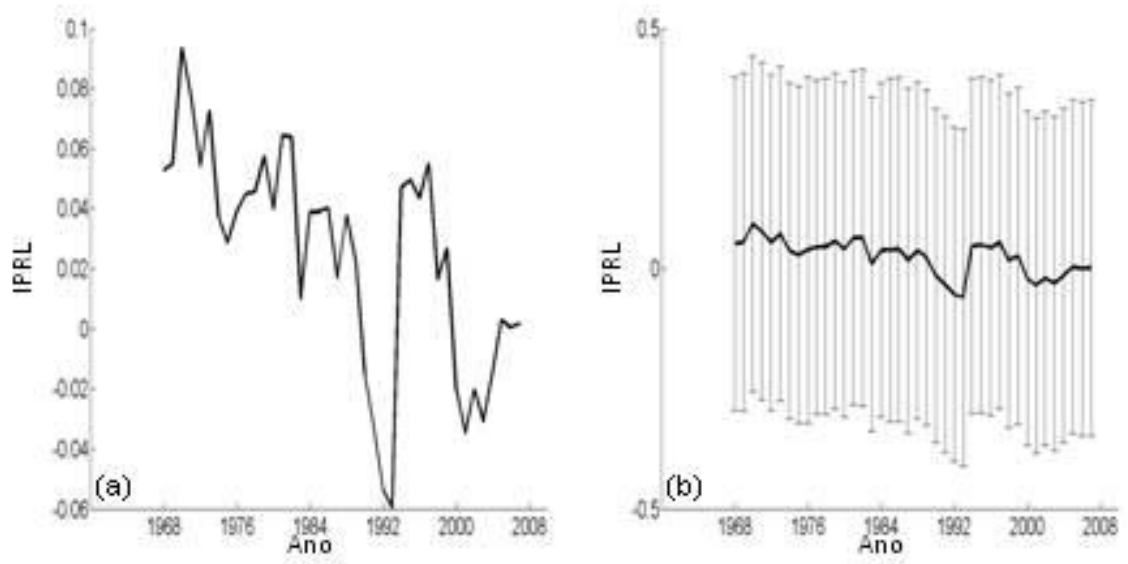

Figura 55. Tendência anual do Índice de Preço Relativo Logaritmizado (a) com dados interpolados para o período de 1968-2007 e (b) com seu respectivo erro padrão $( \pm 0,35)$.

\subsubsection{Valor total das categorias}

O valor comercial total do pescado (Fig. 56) mostra uma tendência ascendente durante o período de 1968 a 1989, quando atingiu $R \$ 266$ milhões e uma tendência decrescente desde então. Este declínio foi acompanhado por mudanças na importância relativa de algumas categorias, como invertebrados e clupeídeos e engraulídeos (Fig. 56). De 1968 a 2007, peixes como Clupeidae e Engraulidae, diminuíram de $45 \%$ para $23 \%$ do valor total e invertebrados diminuíram de $21 \%$ para $1 \%$. Porém os atuns aumentaram de $1 \%$ do valor total inicialmente, representando 13\% em 2007 (Fig. 57). Da mesma forma a categoria cações se tornou relativamente mais importante no fim do período, passando de $5 \%$ para $15 \%$ do valor total (Fig. 57 ). 


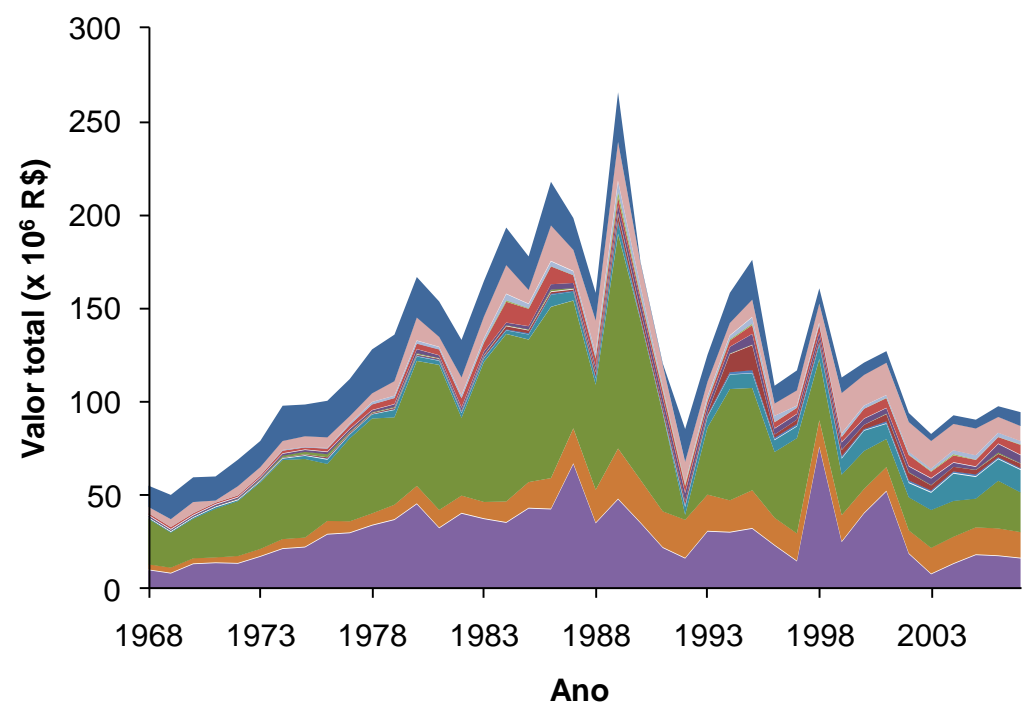

- invertebrados

outros peixes

Carangidae

- Lutjanidae

- congrio-rosa e enguia

- outros Scombridae

anchovas

- agulhão e espadarte

- abrótea e merluza

- Serranidae

atuns

- Clupeidae e Engraulidae

cações

- Sciaenidae

Figura 56. Valor total de comercialização $(R \$)$ por grupos de categorias entre 1968 e 2007.
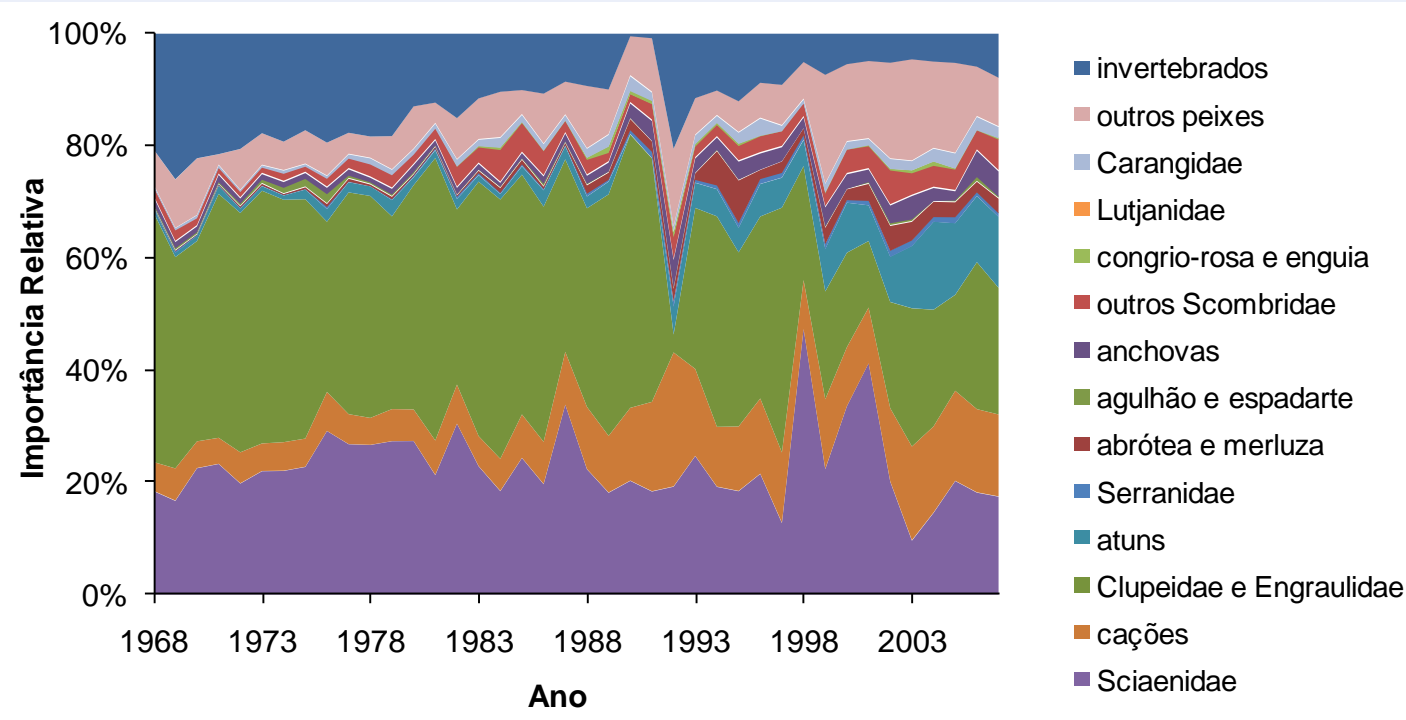

Figura 57. Importância relativa anual do valor dos grupos de categorias entre 1968 e 2007.

Além disso, é importante notar que o valor máximo total $(R \$ 266$ milhões, alcançado em 1989) (Fig. 56), a quantidade máxima comercializada (cerca de 85.000 t, atingida em 1984) (Fig. 58) e o valor máximo total de desembarques no Brasil (cerca de 350.000 toneladas, atingido em 1972) (Fig. 58) não ocorrem no mesmo período. Outro ponto relevante é que a tendência das quantidades totais de pescado ao longo do período aparentemente se 
correlaciona com a evolução do total das estatísticas da pesca para Brasil (Fig. 58), apesar de suas escalas espaciais diferentes.

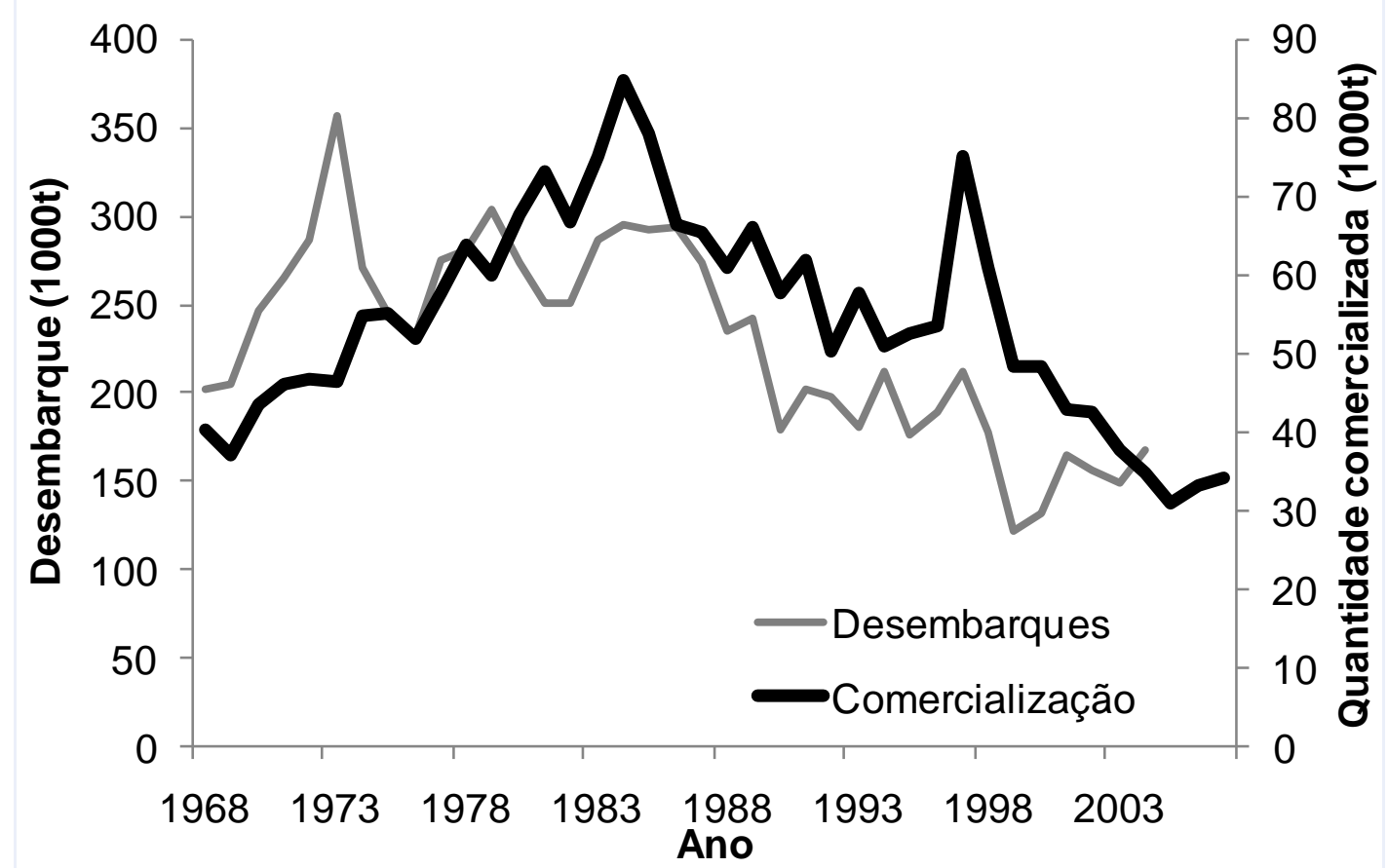

Figura 58. Desembarques totais do Brasil e quantidades totais comercializadas na CEAGESP, em toneladas (fonte: IBAMA; CEAGESP) 


\section{Discussão}

Os resultados obtidos foram influenciados principalmente pela categoria sardinha (Figs. 5-12), a qual constituía, no início da série temporal, uma importante fração tanto no desembarque como na comercialização (Figs. $16,20,27,31,35,37$ e 40). Ao longo dos anos, entretanto, devido ao seu declínio (VALENTINI e PEZZUTO, 2006), essa categoria perdeu sua influência. Assim, a tendência dos indicadores incluindo a sardinha, reflete esse declínio, e, portanto, na maior parte das análises os indicadores também foram calculados sem tal categoria. Além disso, a exclusão dessa categoria de nível trófico baixo foi sugerida por Pauly e Watson (2005), a fim de eliminar o possível viés que pequenos peixes pelágicos podem adicionar à análise do

ITM. Isso porque tais peixes podem variar em abundância no ecossistema devido a variações nas condições ambientais e não necessariamente ao impacto da pesca.

Os camarões também foram excluídos de algumas análises porque representam uma categoria de invertebrados com nível trófico e comprimento máximo baixo e profundidade rasa, que mostrou uma relevante importância inicial em quantidade, porém perdida ao longo dos anos.

A interpretação dos resultados para cada conjunto de dados (desembarques e comercialização) foi diferente, em alguns casos, porque tais conjuntos de dados têm composição distinta (Anexo 2). Nos dados de desembarque (VALENTINI e PEZZUTO, 2006) está incluída a categoria "outros", que agrupa categorias que aparecem especificadas nos dados de mercado. Além disso, os dados de desembarque neste estudo são constituídos 
em sua maioria por categorias pelágicas de NT alto (com exceção da sardinha), enquanto que os dados de comercialização contêm muitas espécies de NT intermediário e demersais (Anexo 2).

De modo geral, a análise do Índice Trófico Marinho não refletiu claramente o padrão do fenômeno "fishing down the marine food web" (PAULY et al., 1998). Entretanto, sinais de mudanças neste sentido foram verificados por outros indicadores, como a escassez de algumas categorias comercializadas com características de NT-alto, Long-alta e Lmáx-alto, além do declínio das principais espécies-alvo da região da plataforma sudeste. No entanto, a análise de cada indicador multiespecífico demonstrou diferentes aspectos e não-linearidades das mudanças, como segue.

\section{1. Índice Trófico Marinho}

A suave tendência crescente do Índice Trófico Marinho (ITM) encontrado neste estudo (Fig. 5) indica que o NT médio tanto dos desembarques quanto das quantidades comercializadas aumentou durante os 40 anos de análise. Isso pode ser explicado, em parte, pela diminuição dos desembarques da sardinha e dos camarões, os quais, historicamente, têm sido os recursos pesqueiros mais importantes da região (MATSUURA, 1981; VASCONCELLOS e GASALLA, 2001; ROSSI-WONGTSCHOWSKI et al., 2007) (Fig. 52g e Fig. 53a). Além disso, embora a quantidade da maioria das categorias de NT-alto tenha diminuído ao longo do período (p. ex., espadarte e alguns cações), tanto nos dados de desembarques (Fig. 14) como nos de comercialização (Fig. 18), houve um aumento da categoria atum no período 
final da série temporal, o que contribuiu para o aumento do ITM. Isto se mostra coerente com a expansão da pesca oceânica de pelágicos (i.e., espinhel para atuns e linha e vara para bonito-listrado), e também com a crescente demanda por essas espécies para suprir restaurantes japoneses que se tornaram moda na cidade de São Paulo (TEIXEIRA et al., 2004; GERMANO e SOARES, 2004).

Além disso, outras mudanças que foram identificadas pela série de mercado podem explicar parte da tendência do ITM. Durante alguns períodos, espécies de NT-int aumentaram nos desembarques (Fig. 13) e na quantidade comercializada (Fig. 17), detacando-se o peixe-porco e alguns cienídeos ( $p$. ex., Menticirrhus spp.). Estas categorias fazem parte da fauna acompanhante da pesca do camarão-rosa e do camarão-sete-barbas (ROSSIWONGTSCHOWSKI et al. 2007) e se valorizaram, enquanto que as espéciesalvo se tornaram mais escassas.

Há alguns motivos pelos quais o ITM pode não variar significativamente, mascarando, então, algumas mudanças. Por um lado, está a não-linearidade e eventual substituição ecológica das espécies sobreexplotadas por outras de mesmo nível trófico ou abaixo, muitas vezes chamada de "compensação ecológica" (JACKSON, 2001; JACKSON et al., 2001). Por outro lado, está a alta biodiversidade e os padrões de ciclo de vida das espécies de peixes tropicais (PAULY, 1998; PEREZ-ESPAÑA et al., 2006). A PCSE está localizada numa zona de transição no Oceano Atlântico subtropical, que é caracterizada por feições oceanográficas que são pouco diferentes daquelas típicas de regiões tropicais. No entanto, o sistema é altamente diversificado, o que certamente pode aumentar sua resiliência (HOLLING, 1973). Em geral, isso pode dificultar a detecção e o registro de 
mudanças estruturais no ecossistema marinho ao longo do tempo através da utilização de um único indicador.

Estudos prévios realizados em ecossistemas marinhos brasileiros, utilizando bases de dados e escalas espaciais diferentes, encontraram uma tendência crescente do ITM (VASCONCELLOS e GASALLA, 2001; SEA AROUND US, 2007 apud HEILEMAN e GASALLA de 2008).

\subsection{Fishing-in-Balance}

O Fishing-in-Balance (FiB), outro indicador multiespecífico freqüentemente utilizado (CHRISTENSEN, 2000; PAULY e PALOMARES, 2005; MILESSI et al., 2005; VIVEKANANDAN et al., 2005; BHATHAL e PAULY, 2009; FREIRE e PAULY, 2010), demonstrou ter uma maior capacidade para detectar mudanças. Nos dados de comercialização, o FiB (Fig. 6) exibiu inicialmente um período de desenvolvimento até 1993, seguido por um declínio. Esse padrão coincide em parte com o período de expansão e declínio sugerido por Abdallah e Sumaila (2007), na análise histórica dos subsídios para a pesca no Brasil. O declínio do indicador na comercialização pode ser explicado por: (a) um ecossistema que se encontra desbalanceado, provavelmente por causa da intensa explotação dos estoques e seus consecutivos declínios, e/ou (b) um aumento na busca de canais alternativos à CEAGESP pelas grandes redes varejistas (SONODA et al., 2002). Já nos dados de desembarque o padrão ascendente apresentado (Fig. 6) sugere um período de intensa explotação e expansão da pesca. Entretanto, é possível que o fato de serem utilizadas duas 
fontes de dados diferentes (SEA AROUND US, 2007 e VALENTINI e PEZZUTO, 2006) cause um viés na análise da tendência.

Segundo Christensen (2000), considerando uma eficiência de transferência de $10 \%$ entre os níveis tróficos, espera-se que as capturas aumentem em dez vezes a cada redução de um nível trófico na pesca. Se isso ocorrer, o índice permanece constante e a pesca é tida como "em balanço". No presente trabalho, tanto para as estatísticas de desembarques como para as de comercialização, o índice não permaneceu constante ao longo dos anos, isto é, a pesca não é considerada como "em balanço".

Um padrão decrescente e desbalanceado do FiB foi encontrado também em outras regiões, como o Atlântico Norte (CHRISTENSEN, 2000; PAULY e PALOMARES, 2005), Portugal (BAETA et al., 2009), Índia (BHATHAL e PAULLY, 2008) e nordeste do Brasil (FREIRE e PAULY, 2010), relacionado, também, com a pressão pesqueira.

Outros parâmetros ecológicos, além do nível trófico, também podem e devem ser utilizados para identificar mudanças ao longo dos anos no ecossistema, principalmente porque ocorrem limitações referentes à classificação dos níveis tróficos, como será discutido posteriormente (item 5.7).

5.3. Longevidade média, Comprimento-Máximo médio, Profundidade média e Isóbata Máxima média

Da mesma forma que para o ITM, as tendências crescentes apresentadas pela Longevidade média (Fig. 7), Comprimento-Máximo médio (Fig. 8) e Profundidade média (Fig. 9) foram relacionadas principalmente com a 
participação da sardinha, atuns e camarões (na longevidade não foram incluídos invertebrados). Quando excluídas essas três categorias, algumas mudanças puderam ser observadas.

Nas quantidades desembarcadas, a Longevidade média e a Profundidade média tornaram-se crescentes ao longo dos anos, o que pode ser explicado pelo aumento dos desembarques de peixe-sapo e bonito-listrado (Figs. 23 e 30). Contudo, no caso da Longevidade média no início da série a importância relativa da tainha foi de aproximadamente $40-70 \%$ (Fig. 23), apontando uma longevidade média mais baixa e, então, uma tendência crescente do indicador mais acentuada.

O Comprimento-Máximo médio para os dados de desembarque apresentou um decréscimo ao longo dos anos, influenciado pela categoria cherne (Fig. 29), cuja importância relativa inicialmente alta foi reduzida ao longo dos anos. Foi possível observar que, a partir de 1986, o Comprimento-Máximo médio tornou a aumentar, apesar de não ser significativo no total da série, uma vez que o dourado, a albacora-lage, o cação-azul (Fig. 29) e o bonito-listrado (Fig. 30) tornaram-se mais importantes no fim do período. Os resultados tanto para o Comprimento-Máximo médio como para a longevidade e a profundidade média foram possivelmente devido ao aumento das pescarias oceânicas.

A análise dos dados de mercado indicou que os índices (longevidade média, comprimento máximo médio e profundidade média) diminuíram ao longo dos anos. No caso da Longevidade e do Comprimento-Máximo médios, isso pode mostrar uma sobre-explotação das categorias de Long-alta e Lmáxalto, como alguns cações, serra, namorado e espadarte (Figs. 25 e 33), pois a quantidade dessas categorias diminuiu. Além disso, o comportamento dos 
indicadores reflete o aumento de algumas categorias da fauna acompanhante da pesca de espécies-alvo (sardinha e os camarões) que tiveram sua comercialização expandida, como o porco e pescada-foguete, espécies de Long-int e Lmáx-int (Figs. 26 e 34).

Apesar de existirem indícios da expansão oceânica nas tendências desses indicadores (no caso dos desembarques), a Profundidade média absoluta não ultrapassou os 140 m (Fig. 9). No caso da região sudeste, isso significa a área aquém do talude continental, onde ocorre a pesca das categorias responsáveis pela expansão espacial das frotas. Por isso, foi proposto um indicador que levasse em consideração a distância da costa e não somente a profundidade de ocorrência, uma vez que a profundidade de ocorrência da categoria não necessariamente distingue a região oceânica da nerítica. Alternativamente, a Isóbata Máxima média, nesse caso, indicou tanto para os dados de mercado quanto para os desembarques essa expansão das frotas para além do talude (Fig. 10).

\subsection{Razão piscívoros/planctívoros (pis/pla)}

A razão entre piscívoros e planctívoros (Fig. 11) é recomendada em Caddy e Garibaldi (2000) por ser um indicador independente das relações tróficas entre as categorias de pescado. Estes autores ressaltam que 0 comportamento decrescente desse indicador pode significar outros efeitos que não o "fishing down marine food web" observado por Pauly et al. (1998), tais como o controle base-topo devido à eutrofização (CADDY et al., 1998), mudanças na composição trófica das capturas devido a mudanças na 
demanda, na tecnologia de captura, ou nas condições ambientais e ecológicas de longo-prazo (CADDY e GARIBALDI, 2000).

Nesse sentido, os resultados obtidos neste trabalho não mostraram a tendência decrescente da relação pis/pla, que seria esperada. Os desembarques apresentaram uma tendência crescente dessa razão, indicando, quando excluída a sardinha, uma diminuição da quantidade de outros planctívoros (como a cavalinha) nas capturas, responsável pelo pico da razão pis/pla em 1974/1975; e, sugerindo um aumento dos desembarques de piscívoros, como o bonito-listrado após 1984. Já para o mercado, a razão crescente é explicada por um contínuo aumento dos piscívoros até 1997 e seu posterior declínio, fato que ocorreu também para os planctívoros. Os dados sugerem que o pico da relação pis/pla em 1984 deve-se ao aumento pontual da categoria "savelha".

Diferentemente deste estudo, Gasalla (2004a), comparando dados da estatística de desembarque das décadas de 1950 e 1990 agrupadas, constatou uma diminuição da razão pis/pla condizente com o fenômeno "fishing down marine food web" (PAULY et al., 1998).

5.5. Razão pelágicos/demersais (pel/dem)

A razão pel/dem visa refletir, de certa forma, os impactos da disponibilidade diferenciada de nutrientes nos ecossistemas marinhos. Basicamente, a disponibilidade local de nutrientes (naturais e/ou antropogênicos) tem efeitos diferentes nos estoques pelágicos e demersais locais, sob diferentes condições de enriquecimento (CADDY et al., 1998). No 
presente estudo, a tendência crescente dessa razão para os desembarques está relacionada com o aumento das capturas dos grandes pelágicos. Já para os dados de mercado (Fig. 12), verifica-se que a quantidade de recursos demersais é normalmente maior que a de pelágicos, como descrito anteriormente. Além disso, devido ao declínio das espécies-alvo da frota de arrasto, houve aumento de outros recursos demersais, como pescada-tortinha e porco. Apesar de ocorrer também um aumento em certas categorias pelágicas da fauna acompanhante da frota de cerco (sardinha), como a palombeta e o bonito, outras declinaram como é o caso da cavalinha e do galo, fato que contribuiu para a tendência da razão pel/dem decrescente (quando excluída a sardinha) da comercialização.

Ainda, conforme apresentado por De Leiva Moreno (2000), regiões do globo que apresentaram razões pel/dem abaixo de 6 foram consideradas oligotróficas e, portanto, não associadas a processos controlados na direção base-topo. O presente estudo apresentou valores abaixo de 4, tanto para os dados de desembarque como para os de comercialização. Assim, dentro do panorama apresentado por De Leiva Moreno (2000), é possível que as mudanças detectadas não estejam relacionadas a um controle trófico de basetopo.

5.6. Análise dos dados de mercado e dos indicadores econômicos

Este estudo demonstra que os preços podem ser variáveis relevantes para o estudo das alterações estruturais nos ecossistemas marinhos, especialmente para situações consideradas pobres em dados (i.e., quando a 
série temporal de biomassa ou abundância das populações marinhas é ausente). Isso porque mudanças nas preferências da pesca são frequentemente dirigidas por razões econômicas. O valor das especies irá determinar o investimento que o setor pesqueiro está disposto a fazer para capturá-las e o quão elevado é o custo de sua captura em baixa abundância (PINNEGAR et al., 2002, 2006; BAETA et al., 2009).

Em geral, é evidente que os preços de pescado podem ser influenciados por mudanças na renda do consumidor, gostos ou preferências atuais ou pelo preço de substitutos no mercado. Eles também podem ser influenciados pela atuação das frotas pesqueiras em fornecer (desembarques) o pescado desejável que, por sua vez, depende da existência ou não das espécies-alvo no ambiente e das condições climáticas, além da influência da inovação tecnológica (IUDICELLO et al., 1999). No entanto, no presente estudo, os preços e quantidades comercializadas no CEAGESP, de modo geral, seguiram a lei da oferta e da procura, como indicado pela análise inferencial dos preços e quantidades (Tab. 1).

Sinais de declínio são observados particularmente para a maioria das categorias com características de NT-alto, Long-alta, Lmáx-alto e também para as principais espécies-alvo da pesca (isto é, sardinha e camarão-rosa) (Figs. $52 \mathrm{~g}$ e 53a), analisando-se as correlações negativas significativas entre os preços de mercado e suas quantidades (Tab. 1; Fig. 50c, d, f, g, h; Fig. 51c, e, f; Fig. 52b, c, g, h, i, Fig.53a-c), considerada constante a demanda.

Para outras categorias, como alguns tunídeos (Fig. 50a, b), a demanda não pôde ser considerada constante, já que a procura local parece exceder sua oferta, como indicam as correlações positivas entre os preços de mercado e 
suas quantidades (Tab. 1). Conforme mencionado anteriormente, o aumento do esforço de pesca oceânica (TEIXEIRA et al., 2004) e da demanda local por restaurantes japoneses (GERMANO e SOARES, 2004) podem explicar isso. Além disso, algumas categorias, como cação-caçonete (Fig. 50c), linguados (Fig. 51k), e serra (Fig. 50h), apresentaram um aumento inicial de suas quantidades comercializadas, seguido por uma tendência decrescente, enquanto seus preços aumentaram continuamente. Isso parece refletir as fases de desenvolvimento da pesca desde sua expansão até sua sobre-explotação (JENNINGS et al., 2001). Na fase inicial, a demanda provavelmente foi maior que a oferta, enquanto houve também o aumento do preço. Já na fase posterior, a quantidade comercializada diminui enquanto há um aumento dos preços, refletindo a pressão da pesca, considerando uma demanda constante.

Em termos de indicadores econômicos multiespecíficos, tanto o preço ponderado ao longo do tempo como o IPRL (com ressalvas, veja seção 5.7), mostraram sinais de pressão da pesca e sobre-explotação. Isso porque houve um aumento nos preços das espécies de NT-alto, Long-alta e Lmáx-alto (exceto para os atuns), além do aumento dos preços do camarão e da sardinha como conseqüência de sua escassez, forçando possivelmente um aumento dos preços de outras espécies de NT-int, Long-int e Lmáx-int, enquanto as espécies-alvo tornam-se comercialmente extintas. Isso pode ser comprovado pelo fato de que, enquanto as principais espécies-alvo da pesca de arrasto de camarão estavam em declínio, algumas categorias com parâmetros intermediários, tais como o peixe-porco e alguns Sciaenidae (por exemplo, Umbrina canosai e Menticirrhus spp.) tornaram-se mais importantes como fauna acompanhante (Vianna e Almeida, 2005). Um padrão similar foi 
observado para a pesca do camarão-sete-barbas, pois a quantidade comercializada desta espécie diminuiu com o tempo, enquanto que sua fauna acompanhante, como por exemplo, a pescada-tortinha, aumentou. Este fenômeno também foi observado por Pinnegar et al.(2002, 2006), e descrito por Sumaila (1998a) como "pricing down the food web", baseado no fato de que os mercados se direcionam para as categorias previamente indesejáveis quando as espécies-alvo se tornam indisponíveis (SUMAILA, 1998a, b). Esses padrões são reforçados pela análise do $\mathrm{IPRL}$, em que a diminuição significativa das tendências ao longo do tempo corresponde apenas à parte posterior do modelo conceitual proposto por Pinnegar et al. (2006). A tendência decrescente do IPRL (com ressalvas, veja seção 5.7) possivelmente reflete um período de substituição nos mercados em que as categorias de pescado de NT-alto começaram a se tornar "comercialmente extintas" e foram substituídas pelas categorias de NT inferior. Neste estudo, o aumento dos preços das espécies de NT-inferior pode ser tanto devido à substituição das categorias de NT-alto como devido a sua escassez (por exemplo, sardinha). Esta situação contrasta com a crescente tendência de IPRL, quando as espécies de NT-alto tornaramse relativamente mais caras do que as espécies de NT-baixo, como demonstrado na análise do Mar Céltico (PINNEGAR et al., 2002; 2006) e Portugal (BAETA et al., 2009).

Outra evidência enfatizada através da análise do preço ponderado em função dos parâmetros ecológicos mostra que, de modo geral, o preço médio seguiu um padrão no qual categorias com NT-alto, Long-alta e Lmáx-alto apresentaram um aumento relativamente maior do que as outras categorias (Figs. 46-49). Essas espécies são, geralmente, mais caras e, quando escassas 
no mercado tendem ao padrão encontrado nos resultados em relação às outras categorias. Isso ocorre pois, segundo Pinnegar et al. (2006), a inflação, agindo de forma não-linear, em termos absolutos, aumenta mais o preço das categorias de NT-alto, Long-alta, Lmáx-alto e de profundidade maior. Esse fato pode sugerir um incentivo para a pesca dessas categorias mais valiosas.

Além disso, a tendência do total do valor das categorias do mercado (Fig. 56) mostra um ponto relevante: o valor máximo atingido pelo mercado em 1989 correspondeu a um período de declínio dos desembarques (Fig. 58).

Ainda, a explicação das mudanças na importância relativa do valor total da comercialização e de seu declínio é dada pelo fato de que a sardinha apesar do seu preço por kilo baixo, compensava o valor total pela sua quantidade e, assim, representava $45 \%$ do valor total da comercialização (Fig. 57, incluída na categoria "Clupeidae e Engraulidae"). Com seu declínio (VALENTINI e PEZZUTO, 2006) essa importância foi reduzida e algumas categorias como cações e serranídeos, que se valorizaram muito devido provavelmente à pressão pesqueira (escassez da oferta), mas não contrabalancearam o valor total anteriormente obtido.

Um ponto importante é o padrão similar entre o total das quantidades comercializadas ao longo dos anos e o total dos desembarques pesqueiros do Brasil (Fig. 58), apesar de suas escalas espaciais diferentes. Isso indica que tendências do mercado local se relacionam mais à pesca em si (ou seja, a curva de oferta), do que a uma demanda local particular, embora esta relação possa existir.

O desenvolvimento da pesca no período inicial até meados dos anos 1980 (Fig. 58) pode ser explicado pela política de incentivos fiscais do governo 
implementada na década de 1970, a qual resultou no aumento significativo do esforço total de pesca (ABDALLAH e SUMAILA, 2007). Mais recentemente, enquanto o total dos desembarques (Brasil) manteve-se estável devido à introdução de novas pescarias em outras partes do país, o volume total do pescado comercializado na CEAGESP diminuiu (Fig. 58). Isto é consistente com as tendências regionais dos desembarques (INSTITUTO DE PESCA, 2004), mas também pode ser devido a fatores externos pela atuação dos supermercados como intermediários (SONODA et al., 2002).

Por último, este estudo indica que as mudanças se tornam mais perceptíveis através da análise dos dados de mercado aliados aos parâmetros ecológicos. Assim, processos intrínsecos que ocorrem dentro do complexo ecossistema parecem ser melhor identificados por diversos indicadores e também pela análise das tendências individuais agrupadas do que por um único indicador. Alguns estudos avaliando a eficiência de alguns indicadores (FULTON et al., 2005; LINK, 2005; COLL et al., 2010) concluíram que nenhum indicador ecossistêmico sozinho descreve todos os aspectos da dinâmica e do estado do ecossistema. Então, é necessário um conjunto de indicadores focando em diferentes aspectos, utilizando diferentes tipos de dados e abrangendo grupos e processos tanto de dinâmica rápida como lenta, para assim descrever diferentes aspectos da resposta do ecossistema.

5.7. Vantagens e desvantagens do uso de indicadores

A principal vantagem do uso de indicadores está relacionada ao seu objetivo. Por exemplo, um indicador ecossistêmico deve contribuir para a 
determinação do estado de sobrepesca do ecossistema e também para estabelecer de forma clara e concisa uma ligação entre as diferentes áreas envolvidas no manejo, através de seu monitoramento ao longo dos anos (DEGNBOL, 2005, POWERS e MONK, 2010).

Segundo Powers e Monk (2010), existem pelo menos quatro usos dos índices ecológicos em um manejo da pesca baseado no ecossistema para: (1) motivar uma ação político-social para alcançar o objetivo de uso do ecossistema ou o manejo daquele uso; (2) providenciar informação aos usuários dos bens e serviços do ecossistema, os quais então usam a informação a fim de modificar decisões pessoais e estratégias; (3) implementar regras de decisões para o EBFM usando indicadores ecossistêmicos para monitorar características do ecossistema; e (4) identificar aspectos da estrutura e/ou funcionamento do ecossistema. Por não serem usos mutuamente exclusivos, eles representam uma linha continua entre os usos sócio-políticos e os puramente científicos. Os indicadores aplicados neste estudo fazem parte do uso mencionado no item quatro supra-citado, isto é, identificaram aspectos da estrutura e/ou funcionamento do ecossistema. De uma forma eficiente, os indicadores sintetizaram o que a análise da importância relativa das categorias de pescado detalhou.

Um aspecto essencial do uso de indicadores ecossistêmicos no EBFM é a relação dos índices com a tomada de decisões. Os índices devem monitorar um importante aspecto do ecossistema e, a partir desse monitoramento, devem ser definidos níveis aceitáveis ou inaceitáveis (POWERS e MONK, 2010). Dessa forma, é possível direcionar mais adequadamente, por exemplo, o aumento do orçamento de pesquisas, a 
regulação para a pesca, os padrões de consumo, etc. (POWERS e MONK, 2010). Tal aspecto constitui um próximo passo importante a ser estabelecido dentro do processo de manejo da pesca no Grande Ecossistema Marinho da Plataforma Sul do Brasil.

As desvantagens referentes ao uso dos indicadores são geralmente relacionadas com as potenciais limitações que os mesmos podem apresentar. Um único indicador pode ter múltiplas e controversas interpretações. Além disso, segundo Blanchard et al. (2010) a detecção de tendências em indicadores ecológicos multiespecíficos é difícil, por diversas razões. Primeiro, as relações do estado da pressão pesqueira e os indicadores não são necessariamente lineares e, então, as tendências podem ser irreais. Segundo, o tempo de resposta do indicador à pressão pesqueira pode variar nos diferentes indicadores e, em alguns casos, é difícil de determinar. Além disso, o tempo de resposta de um indicador pode variar dependendo de quais efeitos da pesca realmente estão ocorrendo durante o período. Quando espécies de tamanhos pequenos e de NTs baixos são admitidas como espécies-alvo pode ocorrer um aumento nas estimativas dos indicadores ao contrário do esperado declínio.

Nesse sentido, os indicadores calculados com os dados do mercado podem apresentar uma pequena defasagem de tempo de resposta em relação aos indicadores aplicados aos desembarques, ou, até mesmo, podem não seguir as mesmas direções de mudança e nem a mesma amplitude de resposta à pressão pesqueira.

Há ainda algumas potenciais limitações que também devem ser consideradas durante a avaliação dos resultados da análise através de 
indicadores multiespecíficos. Primeiro, os parâmetros ecológicos (nível trófico, longevidade, comprimento máximo, profundidade, isóbata máxima, habitat e grupo trófico) das categorias podem incorporar alguma incerteza, já que são estimados a partir de dados baseados em diferentes métodos, períodos e áreas, além de serem obtidos a partir de algumas literaturas consideradas "cinza" (teses, dissertações e resumos de congressos). Isso não pode ser superado até que novos estudos referentes a esses parâmetros sejam realizados na área de estudo e/ou publicados em revistas científicas.

Ainda em relação aos parâmetros ecológicos, não foi considerado neste estudo que tais parâmetros possam ser modificados ao longo dos anos, inclusive por impactos da pesca. Por exemplo, o comprimento máximo de uma dada espécie antigamente pode não ser mais o mesmo encontrado nos dias de hoje. A alimentação considerada atualmente de uma espécie pode não mais ser a mesma que no passado, por modificações no ambiente.

A ausência de "resolução taxonômica", ou seja, a agregação de espécies em uma unidade taxonômica maior, também influencia a estimação dos níveis tróficos médios, como verificado em Baeta et al. (2009) e Freire e Pauly (2010). Isso também é válido para os outros parâmetros estimados neste trabalho (comprimento máximo, longevidade, profundidade, etc). De acordo com Pauly et al. (1998b), quanto melhor a resolução taxonômica, mais forte será a verificação do efeito do fenômeno "fishing down the marine food web", isto é, espera-se que as mudanças no ecossistema se tornem mais evidentes.

Além disso, a não inclusão de categorias como 'mistura', representando outros peixes de baixo valor comercial e exemplares de pequeno porte, pode alterar os resultados das análises, pois representa uma 
significante proporção do total dos desembarques (mais do que $15 \%$ nos últimos 24 anos, VALENTINI e PEZZUTO, 2006). Entretanto, não há informação detalhada suficiente que permita incluir essa categoria nas análises dos indicadores, da mesma forma que em Freire e Pauly (2010).

Quanto ao indicador IPRL, há uma possível restrição, pois para uma interpretação bem sucedida desse índice, espera-se uma correlação linear positiva entre o preço e o nível trófico. Neste caso, verificamos que essa correlação, apesar de não ser muito forte (ou seja, o erro de regressão anual foi alta, ca. $\pm 0,3)$, é uma correlação positiva. A principal razão para essa linearidade ser suave (Fig. 4) é que algumas categorias de NT-alto (e.g., alguns cações, espada e cioba) não seguem o padrão de preços elevados.

Além disso, considerando outros aspectos que influenciam o preço de mercado, tais como mudança nas preferências de pesca ou gostos dos consumidores (SUMAILA et al., 1998b), os dados de preço e quantidade de pescado comercializada na CEAGESP parecem ser muito consistentes com o comportamento da pesca local e com a disponibilidade do pescado no meio, em vez de serem orientados pela demanda. Entretanto, futuramente, análises mais refinadas dos processos de interpolação poderiam ser aprofundadas para contabilizar tais variáveis subjetivas, incluindo as incertezas (MAUNDER e DERISO, 2010). Outras melhorias da presente análise poderiam incluir os modelos de demanda, que envolvem a elasticidade de substituição entre as categorias de pescado (ASCHE et al., 2007; PINCINATO e GASALLA, 2010). Além disso, os dados econômicos de algumas categorias como sardinha, camarões e atuns poderiam ter influência do mercado externo 
(importação/exportação; BRASIL, 2005). Para análises futuras, seria interessante explorar também esse aspecto do mercado.

5.8. Efeitos potenciais das mudanças no ecossistema e manejo

Uma das principais conclusões do estudo (Fig. 59), seguindo a lei do mercado, foi o fato de que o aumento de preços das categorias com NT-alto, Long-alta e Lmáx-alto (com exceção dos atuns e afins) foi possivelmente devido à escassez da sua oferta. Isso é verificado pelas tendências decrescentes das quantidades comercializadas, pressupondo-se uma situação de demanda constante. O mesmo padrão foi observado para as espécies-alvo mais importantes da pesca (a sardinha e os camarões). A escassez dessas espécies também é destacada pelo fato de que as categorias da fauna acompanhante com parâmetros intermediários aumentaram em preço e quantidade comercializada (Fig. 19, 26 e 34). Essas evidências apontam para possíveis impactos da pesca principalmente no topo da cadeia trófica (NT-alto, Long-alta e Lmáx-alto) e, também, na base da cadeia (sardinhas e camarões).

Um dos efeitos potenciais dessas mudanças ao longo do tempo está relacionado ao topo da cadeia trófica. O controle trófico topo-base pode ser acionado, pois predadores exercem considerável efeito sobre suas presas, o que pode gerar um efeito cascata ao longo da cadeia trófica marinha (DASKALOV, 2002; WORM e MYERS, de 2003; HEITHAUS et al., 2009). Assim, uma diminuição na abundância de NTs 4 leva a uma diminuição na taxa de mortalidade por predação em NTs 3 e, portanto, um aumento em sua biomassa, e assim por diante. 


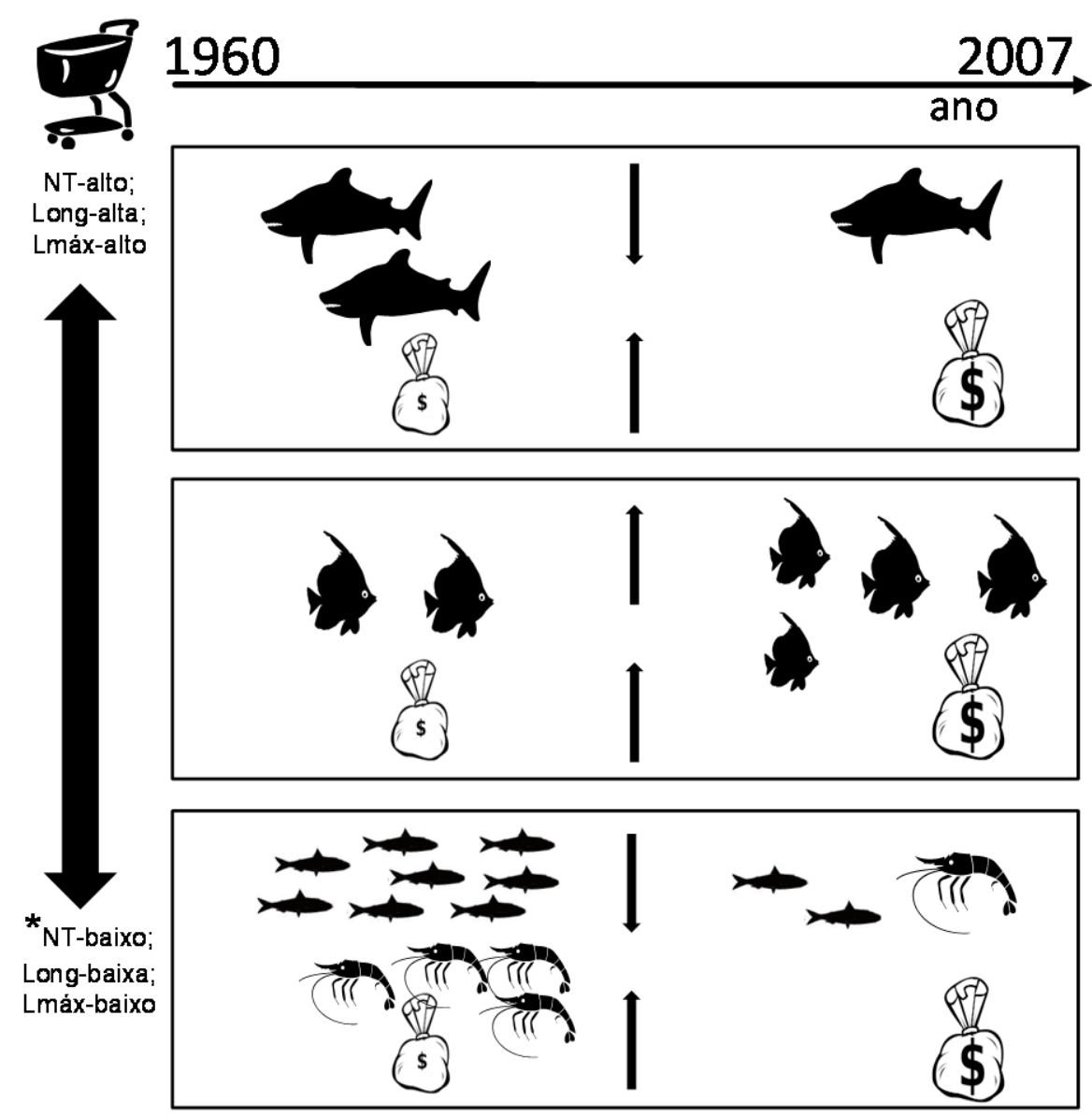

Figura 59. Síntese das principais mudanças detectadas pela análise de mercado dos grupos ecológicos. Os peixes e camarões apresentados na ilustração representam as quantidades disponíveis no mercado nas diferentes classes de níveis tróficos, longevidades e comprimentos ao longo dos anos, enquanto "\$" representa o preço. (O asterisco indica que NT-baixo, Long-baixa e Lmáx-baixo refere-se aqui somente à categoria sardinha e camarão-rosa). As setas dentro das caixas indicam as tendências nas quantidades e preços de cada classe de NT, longevidade e comprimento máximo.

$\mathrm{Na}$ área da PCSE, estudos anteriores demonstraram e simularam o controle topo-base na cadeia alimentar marinha (GASALLA et al., 2003; GASALLA, 2004a; GASALLA e ROSSI-WONGTSCHOWSKI, 2004). A redução das populações de piscívoros foi apresentada para essa área graças à reconstrução de dados de estudos científicos referentes à época anterior à expansão da pesca industrial (GASALLA, 2004a) e aqueles dados advindos do conhecimento dos pescadores (GASALLA 2004a; GASALLA, 2004c). 
Tanto dados pesqueiros dependentes como independentes (com base em pesquisas científicas) sugerem o declínio de grandes piscívoros e mudanças na composição das espécies. O depoimento de pescadores com longa experiência na pesca indicou que os cações foram considerados "desaparecidos" durante os últimos 50 anos na PCSE (GASALLA et al., 2003; GASALLA et al., 2007). O ecossistema costeiro "pré-pescarias" suportava as populações de grandes cações, carangídeos, serranídeos e lutjanídeos, além de grandes estoques de sardinha e tainha (GASALLA, 2004b). Seguindo essas tendências, algumas evidências encontradas nestas análises parecem confirmar as conclusões anteriores, como no caso do cação-machote (Fig. 50d), espadarte (Fig. 50f), namorado (Fig. 50g) e serra (Fig. 50h), que mostraram claramente uma diminuição de suas quantidades comercializadas e um aumento nos seus preços.

Os efeitos topo-base na cadeia alimentar marinha têm sido amplamente discutidos na literatura (JACKSON, 2001; VASCONCELLOS e GASALLA, 2001; BAUM et al. 2003; WORM e MYERS 2003; GASALLA e ROSSI-WONGTCHOWSKI, 2004; MYERS et al., 2007). Há várias consequências possíveis para o ecossistema vinculados à remoção de grandes predadores pela pesca. Além da extinção de populações, haveria também a redução da biomassa de peixes a níveis muito baixos que comprometeria a sustentabilidade da pesca e, eventualmente geraria baixos rendimentos econômicos (MYERS e WORM, 2003). Por outro lado, a remoção intensa de recursos junto à base da cadeia alimentar pode desencadear alterações de base-topo (MENGE, 1992). 
Um mecanismo que compensaria tais efeitos da pesca é o aumento de espécies "não-alvo", devido à redução da predação ou da concorrência (WORM e MYERS, 2003). Em nossas análises, sinais de compensação podem ser observados, por exemplo, no caso do aumento do peixe-porco ou de alguns Sciaenidae, categorias consideradas fauna acompanhante da pesca do camarão-rosa. No entanto, previsões precisas das conseqüências ecológicas relacionadas aos declínios passados e futuros são fundamentais para a pesca e para o manejo dos ecossistemas (HEITHAUS et al., 2009). Porém é difícil de serem elaboradas, especialmente quando estudos científicos de monitoramento de mudança nas populações são escassos. Buscando uma perspectiva da gestão da pesca, os resultados deste estudo podem contribuir para a implementação de práticas com abordagem ecossistêmica, como ecolabelling e técnicas de modelagem. Globalmente, este estudo pretendeu contribuir para elucidar possíveis alterações nos ecossistemas e impactos da pesca na PCSE e no GEMSB. 


\section{Conclusões}

A análise, sem precedentes, de 40 anos da série temporal das variáveis do mercado de pescado aqui apresentadas mostraram sinais valiosos dos impactos da pesca ocorridos no ecossistema marinho, como a possível escassez de categorias relacionadas ao topo da cadeia trófica, com maior longevidade, maior comprimento e mais profundas.

O Índice Trófico Marinho não mostrou claramente o fenômeno "fishing down the marine food web", mas, alternativamente, outros indicadores demonstraram a escassez das espécies de NT-alto, Long-alta e Lmáx-alto. Isto foi evidenciado pelos indicadores: Fishing-in-Balance, Longevidade média, Comprimento-Máximo médio, os indicadores do preço ponderado em função dos parâmetros ecológicos ao longo do tempo, o Índice do Preço Relativo Logaritmizado (IPRL) e a análise inferencial dos pescados.

A profundidade média e a Isóbata Máxima média principalmente das quantidades desembarcadas apontaram para uma expansão da pesca oceânica.

O comportamento do IPRL foi frequentemente relacionado com a escassez de espécies muito explotadas. Além disso, os preços do mercado de pescado aumentaram durante 1968-2007, com uma forte tendência demonstrada pelas categorias com NT-alto, Long-alta e Lmáx-alto e com características intermediárias. Essas tendências evidenciaram o fenômeno "pricing down the food web". 
A análise inferencial e as correlações entre as tendências dos preços e das quantidades das categorias estudadas parecem ser úteis como indicadores. A correlação negativa entre preço e quantidade pode sugerir pressão da pesca ou uma explotação excessiva, enquanto que uma correlação positiva pode indicar alta demanda da categoria de pescado estudada. Principalmente categorias de NT-alto, Long-alta, Lmáx-alto e também espéciesalvo (sardinha e camarão-rosa) demonstraram um padrão de correlação negativa. E categorias como atuns e afins apresentaram um padrão de correlação positiva.

A utilização de um único indicador, como o Índice Trófico Marinho, ou somente a análise dos desembarques pesqueiros, pode mascarar algumas mudanças ocorridas, enquanto que a análise de preços ao longo do tempo pode tornar essas mudanças mais explícitas. Portanto, a primeira hipótese norteadora deste trabalho de que o comportamento dos indicadores selecionados refletiria mudanças ocorridas no ecossistema marinho não foi verificada para todos os indicadores selecionados.

Por fim, a base de dados do mercado provou ser valiosa para compreender a dinâmica da pesca numa perspectiva ecossistêmica e poderá ser usada especialmente em sistemas que não disponham de suficientes dados científicos e estatísticos sobre a pesca e os recursos, mas onde dados de mercado são arquivados. Isso corrobora a segunda hipótese norteadora do trabalho segundo a qual os dados econômicos podem ser considerados úteis para identificar alterações no ecossistema em questão ao longo do tempo. 


\section{Referências}

ABDALLAH, P. R.; SUMAILA, U. R. An historical account of Brazilian public policy on fisheries subsidies. Marine Policy, v. 31, n. 4, p. 444-450, 2007.

ALEGRIA, J. R. C.; MENEZES, M. F. Edad y crecimiento del ariacó, Lutjanus synagris (Linnaeus), em el nordeste del Brasil. Arquivos de Ciências do Mar, v. 10, n. 1 , p. 65-68, 1970.

ALVERSON, D. L.; PRUTER, A. T.; RONHOLT, L. L. A Study of Demersal Fishes and Fisheries of the Northeastern Pacific Ocean. Vancouver: Institute of Fisheries, University of British Columbia, 1964.

AMÂNCIO, I. M. Hábitos alimentares de crustáceos decápodos braquiúros da plataforma interna de São Sebastião, SP. 2000. 104 f. Dissertação (Mestrado) - Instituto Oceanográfico, Universidade de São Paulo.

ANDERSON, L. G. The economics of fisheries management. Baltimore: The Johns Hopkins University Press, 1977.

ANDRADE, H. A.; DUARTE-PEREIRA, M.; ABREU-SILVA, J. L. Idade e crescimento da abrótea (Urophycis brasiliensis) capturada no sul do Brasil. Notas Técnicas da FACIMAR, v. 8, p. 107-117, 2004.

ARANTES, L. P. L.; SOARES, L. S. H.; MUTO, E. Y. Papel trófico de Dactylopterus volitans (Linnaeus, 1758) na Plataforma Continental de Santos (SP). In: CONGRESSO BRASILEIRO DE OCEANOGRAFIA, 3., Fortaleza. Anais... Fortaleza: AOCEANO, 2008. v. 1. p. 1-1.

ARAÚJO, P. C. Relações de produção e a pesca empresarial em Santos. 1979. 101 f. Dissertação (Mestrado) - Faculdade de Filosofia Letras e Ciências Humanas, Universidade de São Paulo.

ARAUJO, J. N.; MARTINS, A. S.; COSTA, K. G. Idades e crescimento da cioba, Ocyururs chrysurus, da Costa Central do Brasil. Revista Brasileira de Oceanografia, v. 50, p. 47-57, 2002.

ARMSTRONG, M. P.; MUSICK, J. A.; COLVOCORESSES, J. A. Age, growth, and reproduction of the goosefish Lophius americanus (Pisces: Lophiiformes). Fishery Bulletin, v. 90, n. 2, p. 217-230, 1992.

ASCHE, F.; BJØRNDAL T.; GORDON, D. V. Studies in the demand structure for fish and seafood products. In: WEINTRAUB, A.; ROMERO, C.; BJØRNDAL, T.; EPSTEIN, R. (Ed.). Handbook on operations research in natural resources. New York: Kluwer, 2007.

ATES, C.; MUSICK, J. A.; COLVOCORESSES, J. A. Age and growth of Atlantic bonito (Sarda sarda Bloch, 1793) in the Sea of Marmara and Black Sea, Turkey. Journal of Applied Ichthyology, v. 24, n. 5, p. 546-550, 2008.

ÁVILA-DA-SILVA, A. O. Idade, crescimento, mortalidade e aspectos reprodutivos do pargo, Pagrus pagrus (Teleostei: Sparidae), na costa do Estado de São Paulo e adjacências. 1996. 116 f. Dissertação (Mestrado) Instituto Oceanográfico, Universidade de São Paulo.

ÁVILA-DA-SILVA, A. O. A evolução da pesca de linha-de-fundo e a dinâmica de população do peixe-batata, Lopholatilus villarii (Teleostei: 
Malacanthidae) na margem continental da costa brasileira entre os paralelos '22 graus' e '28 graus S'. 2002. 218 f. Tese (Doutorado) - Instituto Oceanográfico, Universidade de São Paulo.

ÁVILA-DA-SILVA, A. O.; CARNEIRO, M. H. Produção pesqueira marinha do estado de São Paulo no ano 2001. Série Relatórios Técnicos, n. 12, p. 1-14, 2003 .

BAETA, F.; COSTA, M. J.; CABRAL, $H$. Changes in the trophic level of Portuguese landings and fish market price variation in the last decades. Fisheries Research, v. 97, n. 3, p. 216-222, 2009.

BAUM, J. K.; MYERS, R. A.; KEHLER, D.; WORM, B.;HARLEY, S. J.; DOHERTY, P. A. Collapse and conservation of shark populations in the northwest Atlantic. Science, v. 299, n. 5605, p. 389-392, 2003.

BAZZINO, G.; QUINONES, R. A. Feeding of the squid Illex argentinus (Cephalopoda, Ommastrephidae) in the Argentine-Uruguayan common fishing zone. Gayana, v. 65, n. 2, p. 173-180, 2001.

BEGOSSI, A.; CLAUZET, M.; FIGUEIREDO, J. L.; GARUANA, L.; LIMA, R. V.; LOPES, P. F.; RAMIRES, M.; SILVA, A. L.; SILVANO, R. A. M. Are biological species an higher ranking categories real?: fish folk taxonomy on Brasil's Atlantic forest coast and in the Amazon. Current Anthropology, v. 49, n. 2, p. 291-306, 2008.

BERNARDES, R. Á.; FIGUEIREDO, J. L. DE; RODRIGUES, A. R.; FISCHER, L. G.; VOOREN, C. M.; HAIMOVICI, M.; ROSSI-WONGTSCHOWSKI, C. L. D. B. Peixes de zona econômica exclusiva da região sudeste-sul do Brasil: levantamento com armadilhas, pargueiras e rede de arrasto de fundo. São Paulo: Edusp, 2005.

BERVIAN, G.; FONTOURA, N. F. Growth of the Silverside Atherinella brasiliensis in Tramandaí Estuary, Southern Brazil (Actinopterygii: Atherinopsidae). Neotropical Ichthyology, v. 5, n. 4, p. 485-490, 2007.

BHATHAL, B.; PAULY, D. 'Fishing down marine food webs' and spatial expansion of coastal fisheries in India, 1950-2000. Fisheries Research, v.91, n.1, p. 26-34, 2008.

BLANCHARD, J. L.; COLL, M.; TRENKEL, V. M.; VERGNON, R.; YEMANE, D.; JOUFFRE, D.; LINK, J. S.; SHIN, Y-J. Trend analysis of indicators: a comparison of recent changes in the status of marine ecosystems around the world. ICES Journal of Marine Science, v. 67, p. 732-744, 2010.

BOUCHEREAU, J. L.; BODY, P.; CHAUVET, C. Growth of the dusky grouper Epinephelus marginatus (Linnnaeus, 1758) (Teleostei, Serranidae), in the natural marine reserve of Lavezzi Islands, Corsica, France. Scientia Marina, v. 63, n. 1, p. 71-77, 1999.

BRANCO, J. O.; LUNARDON-BRANCO, M. J.; SOUTO, F. X.; GUERRA, C. R. Estrutura Populacional do Camarão Sete-Barbas Xiphopenaeus kroyeri (Heller, 1862), na Foz do Rio Itajaí-Açú, Itajaí, SC, Brasil. Brazilian Archives of Biology and Technology, v. 42, n. 1, p.115-126, 1999.

BRANCO-LUNARDON, M. J.; BRANCO, J. O.; VERANI, J. R. Relações tróficas entre macroinvertebrados e peixes, na Armação do Itapocoroy, Penha, SC. In: 
BRANCO, J. O.; MARENZI, A. W. C. (Org.). Bases ecológicas para um desenvolvimento sustentável: estudos de caso em Penha, SC. 291. Itajaí: Editora da UNIVALI ,2006. p. 183-196.

BRASIL. Ministério do Meio Ambiente (MMA). Os ecossistemas brasileiros e os principais macrovetores de desenvolvimento: subsídios ao planejamento da gestão ambiental. Brasília:MMA, 1995.

BRASIL. Ministério do Meio Ambiente (MMA). Pesca e Aquicultura no Brasil: produção e balança comercial (1991-2000). Brasília, MMA, 2005.

BRASIL. Ministério do Meio Ambiente (MMA). Estatística da Pesca 2005: Brasil: grandes regiões e unidades da federação. Brasília: MMA, 2007.

BRASIL. Ministério da Pesca e Aqüicultura. 0 diagnóstico da pesca extrativa no Brasil. Disponível em: $<\mathrm{http}: / /$ www.mpa.gov.br/mpa/seap/html/diagnostico.htm>. Acessado em: 04 jun. 2010a.

BRASIL. Ministério do Meio Ambiente (MMA). Estatística da Pesca 20082009: Brasil: grandes regiões e unidades da federação. Brasília MMA, 2010b.

BURTON, M. L. Age, growth and mortality of mutton snapper, Lutjanus analis, from the east coast of Florida, with a brief discussion of management implications. Fisheries Research, v. 59, n. 1/2, p. 31-41, 2002.

BUSSAB, W. O.; MORETTIN, P. A. Estatística básica. São Paulo: Saraiva, 2006.

CADDY, J. F.; CSIRKE, J.; GARCIA, S. M.; GRAINGER, R. J. R. How pervasive is "fishing down marine food webs"?. Science, v. 282, n. 5393, p.1383, 1998.

CADDY, J. F.; GARIBALDI, L. Apparent changes in the trophic composition of world marine harvests: the perspective from the FAO capture database. Ocean \& Coastal Management, v. 43, n. 8/9, p. 615-655, 2000.

CAMARA, J. J. C.; CERGOLE, M. C.; CAMPOS, E. C.; BARBIERI, G. Estrutura populacional, crescimento, mortalidade e taxa de explotação do estoque de manjuba, Anchoviella lepidentostole do rio Ribeira de lguape, sudeste do Estado de São Paulo, Brasil, durante o período de 1993-1996. Boletim do Instituto de Pesca, v. 27, n. 2, p. 219-230, 2001.

CARGO, D. G.; SCHULTZ, L. P. Notes on the biology of the sea nettle, Chrysaora quinquecirrha, in Chesapeake Bay. Chesapeake Science, v. 7, n. 2, p. 95-100, 1966.

CARVALHO-FILHO, A. Peixes: costa brasileira. São Paulo: Marca D'Agua, 1992.

CARVALHO, M. O. X.; FONTELES-FILHO, A. A. Estudo da idade e crescimento de espécies do gênero Haemulon (Pisces: Pomadasyidae), no estado do Ceará, Brasil. Arquivos de Ciências do Mar, v. 29, n. 1/2, p. 14-19, 1995.

CASARINI, L. M. Dinâmica populacional de raias demersais dos gêneros Atlantoraja e Rioraja (Elasmobranchii, Rajidae) da costa sudeste e sul do 
Brasil. 2006 . 206 f. Tese (Doutorado) - Instituto Oceanográfico, Universidade de São Paulo.

CASTRO, B. M.; MIRANDA, L. B.; MIYAO, S. Y. Condições hidrográficas na plataforma continental ao largo de Ubatuba: variações sazonais e em media escala. Boletim do Instituto Oceanográfico, São Paulo, v. 32, n. 2, p. 135151, 1987.

CASTRO, B. M.; MIRANDA, L. B. Physical oceanography of the Western Atlantic continental shelf located between $4^{\circ} \mathrm{N}$ and $34^{\circ} \mathrm{S}$ coastal segment $(4, \mathrm{~W})$. In: ROBINSON, A. R.; BRINK, K. H. (Ed.). The Sea. v. 11. Oxford: John Wiley \& Sons, 1998. p. 209-51.

CASTRO, M. G. Estrutura e Dinâmica da Frota de Parelhas do Estado de São Paulo e Aspectos Biológicos dos Principais Recursos Pesqueiros Demersais Costeiros da Região sudeste/sul do Brasil (23-29S). 2000. Tese (Doutorado) - Instituto Oceanográfico, Universidade de São Paulo.

CASTRO, J. I. Sharks of North American waters. College Station, TX: Texas A\&M University Press, 1983.

CBD (CONVENTION ON BIOLOGICAL DIVERSITY). Decision VII/30. In: MEETING OF THE CONFERENCE OF THE PARTIES TO THE CONVENTION ON BIOLOGICAL DIVERSITY, 7, 2004 , Kuala Lumpur, Malaysia. Disponível em:< http://www.cbd.int/doc/decisions/cop-07/full/cop-07-dec-en.pdf>. Acesso em: 3 ago. 2009.

BOLETIM MENSAL [da] CEAGESP. São Paulo: CEAGESP, 1968-2007.

CEAGESP - Companhia de Entrepostos e Armazéns Gerais de São Paulo, 2009.Disponível em: <http://www.ceagesp.gov.br/>.Acesso em: 3 ago. 2009.

CERGOLE, M. C. Avaliação do estoque da sardinha-verdadeira, Sardinella brasiliensis da costa sudeste do Brasil, 1977-1990. 1993. 245 f. Tese (Doutorado) - Instituto Oceanográfico, Universidade de São Paulo.

CERGOLE, M. C.; VALENTINI, H. Growth and mortality estimates of Sardinella brasiliensis in the southeastern Brazilian bight. Boletim do Instituto Oceanográfico, São Paulo, v. 42, n. 1/2, p. 113-127, 1994.

CERGOLE, M. C.; WONGTSCHOWSKI, C. D. B. R.; PINTO, Y. A. Estudo da idade e do crescimento da tainha, Mugil planatus, da região de Cananéia, SP. In: ENCONTRO BRASILEIRO DE ICTIOLOGIA, 11., 1995, Campinas. Resumos... Campinas: Puc de Campinas; Sociedade Brasileira de Ictiologia, 1995. p. H6.

CERGOLE, M. C.; VALENTINI, H.; SACCARDO, S. A.; ROSSIWONGTSCHOWSKI, C. L. D. B.; PINTO, Y. A. 1997. Peixes pelágicodemersais na região sudeste-sul do Brasil: II-pesca e biologia das espécies selecionadas. In: ENCONTRO BRASILEIRO DE ICTIOLOGIA, 12, 1997, São Paulo. Resumos ... São Paulo: IOUSP/SBI, 1997. p. 313.

CERGOLE, M. C.; SACCARDO, S. A.; ROSSI-WONGTSHOWSKI, C. L. D. B. Fluctualtions in the spawning stock biomass and recruitment of the Brazilian sardine: 1977-1997. Revista Brasileira de Oceanografia, v. 50, p. 13-26, 2002. 
CERGOLE, M. C.; ÁVILA-DA-SILVA, A. O.; ROSSI-WONGTSCHOWSKI, C. L. D. B. (Ed.). Análise das principais pescarias comerciais da região SudesteSul do Brasil: dinâmica populacional das species em explotação. São Paulo: Instituto Oceanográfico-USP, 2005. (Série documentos Revizee).

CLARK, M. Are deepwater fisheries sustainable? - the example of orange roughy (Hoplostethus atlanticus) in New Zealand. Fisheries Research, v. 51, n. 2/3, p. 123-135, 2001.

CLARK, C. W. The worldwide crisis in fisheries: economic models and human behavior. Cambridge: Cambridge University Press, 2006

CLAUZET, M.; RAMIRES, M.; BARRELLA, W. Pesca artesanal e conhecimento local de duas populaçõescaiçaras (enseada do mar Virado e Barra do Una) no litoral de São Paulo, Brasil. A Linguagem da Ciência, n. 4, p. 1-22, 2005.

CHAO, L.N. 1978. Sciaenidae. In FISCHER, W. (Ed.). FAO species identification sheets for fishery purposes, West Atlantic (fishing area 31).Rome: FAO, 1978. $v 4$.

CHAVES, P. D. T. D. C.; SERENATO, A. Diet diversity in the flatfishes assemblage (Teleostei, Pleuronectiformes) in the mangrove of the Guaratuba Bay, Parana, Brazil. Revista Brasileira de Oceanografia, v. 46, n. 1, p. 61-68, 1998.

CHRISTENSEN, V.; PAULY, D. Trophic models of aquatic ecosystems. Makati: International Center for Living Aquatic Resources Management, 1993.

CHRISTENSEN, V. Fishery-induced changes in a marine ecosystem: insight from models of the Gulf of Thailand. Journal of Fish Biology, v. 53, p. 128142, 1998. Supplement A.

CHRISTENSEN, V. Indicators for marine ecosystems affected by fisheries. Marine and Freshwater Research, v. 51, n. 5, p. 447-450, 2000.

COLL, M.; SHANNON, L. J.; YEMANE, D.; LINK, J. S.; OJAVEER, H.; NEIRA, S.; JOUFFRE, D.; LABROSSE, P.; HEYMANS, J. J.; FULTON, E. A.; SHIN, YJ. Ranking the ecological relative status of exploited marine ecosystems. ICES Journal of Marine Science, v. 67, n. 4, p. 769-786, 2010.

CONOVER, W. J. Practical nonparametric statistics. 2. ed. New York : Wiley, 1980.

CORBISIER, T. N. Aspectos ecológicos das associações de espécies da macrofauna bentônica e avaliação do efeito da predação sobre a sua estrutura na Praia do Codo (Ubatuba, SP, Brasil). 1989. 88 f. Tese (Doutorado) - Instituto Oceanográfico, Universidade de São Paulo.

CRABTREE, R. E.; HOOD, P. B.; SNODGRASS, D. Age, growth, and reproduction of permit (Trachinotus falcatus) in Florida waters. Fishery Bulletin, v. 100, n. 1, p. 26-34, 2002.

CUNNINGHAM, P. T. M. Bionomia e ciclo de vida de Ctenosciaena gracilicirrhus (Metzelaar, 1919) na plataforma continental brasileira entre as latitudes de 22010'S e 30S. São Paulo. 1978. 106 f. Dissertação (Mestrado) - Instituto Oceanográfico, Universidade de São Paulo.

CURY, P. A.; CHRISTENSEN, V. Quantitative ecosystem indicators for 
fisheries management: introduction. ICES Journal of Marine Science, v. 62, n. 3, p. 307-310, 2005.

CURY, P. M.; SHANNON, L. J.; ROUX, J-P.; ROUX, DASKALOV, G. M.; JARRE, A.; MOLONEY, C. L.; PAULY, D. Trophodynamic indicators for an ecosystem approach to fisheries. ICES Journal of Marine Science, v. 62, n. 3, p. 430-442, 2005.

DASKALOV, G. M. Overfishing drives a trophic cascade in the Black Sea. Marine Ecology-Progress Series, v. 225, p. 53-63, 2002.

DEGNBOL, $P$. Indicators as a means of communicating knowledge. ICES Journal of Marine Science, v. 62, n. 3, p. 606-11, 2005.

DE LEIVA MORENO, J. I.; AGOSTINI, V. N.; CADDY, J. F.; CAROCCI, F. Is the pelagic-demersal ratio from fishery landings a useful proxy for nutrient availability? A preliminary data exploration for the semi-enclosed seas around Europe. ICES Journal of Marine Science, v. 57, n. 4, 1091-1102, 2000.

DELGADO, C. L.; WADA, N.; ROSEGRANT, M. W.; MEIJER, S.; AHMED, M. Fish to 2020: supply and demand in changing global markets. Washington, D.C.: International Food Policy Research Institute, 2003.

DEUDERO, S. Interspecific trophic relationships among pelagic fish species underneath FADs. Journal of Fish Biology, v. 58, n. 1, p. 53-67, 2001.

DIAS NETO, J.; MARRUL FILHO, S. Síntese da situação da pesca extrativa marinha no Brasil. Brasília, 2003. Documento elaborado para apresentação aos integrantes do Grupo de Trabalho Interministerial. Disponível em:<http://www.ibama.gov.br/rec_pesqueiros/download.php?id_download=45>. Acesso em: 1 abr. 2010.

DUARTE, L. F. D.; SEVERINO-RODRIGUES, E.; GASALLA, M. A. Slipper lobster (Crustacea, Decapoda, Scyllaridae) fisheries off the southeastern coast of Brazil: I. exploitation patterns between $23^{\circ} 00$ ' and $29^{\circ} 65^{\prime} \mathrm{S}$. Fisheries Research , v. 102, n. 1/2, p. 141-151, 2010.

ELIAS, I.; RAJOY, C. R. The feeding habits of the sand perches Pseudopercis semifasciata (Cuvier, 1829): Pinguipedidae in northern Argentine waters. Revista de Biologia Marina, v. 27, n. 1, p. 133-146, 1992.

ESSINGTON, T. E.; BEAUDREAU, A. H.; WIEDENMANN, J. Fishing through marine food webs. Proceedings of the National Academy of Sciences of the United States of America, v. 103, n. 9, p. 3171-3175, 2006.

FAILLER, P.; PAN, H. Global value, full value and societal costs: capturing the true cost of destroying marine ecosystems. Social Science Information, v. 46, n. 1, p. 109-134, 2007.

FAO. Fisheries Department. Fisheries management: 2 - the ecosystem approach to fisheries. FAO Technical Guidelines for Responsible Fisheries, v. 4, p. 1-112, 2003. Supplement 2.

FERNANDES, L. M. B. Sobre a alimentação de lagosta Panulirus argus (Latreille, 1804): II - Estágios pós-puerulus e adulto. Recife: SUDENE, Divisão de Recursos Pesqueiros: 1985. (Séries Estudos de Pesca, n.1). 
FERNANDEZ, W. S. Dinâmica populacional de Atherinella brasiliensis (Quoy e Gaimard, 1824) da praia de Itamambuca, Ubatuba, SP. 2007. 123 f. Dissertação (Mestrado) - Instituto Oceanográfico, Universidade de São Paulo.

FERREIRA, M. G. S.; SOUZA, D. C. Nomes vulgares e científicos de peixes encontrados na região sudeste e sul com seus correspondentes em inglês e espanhol. Rio de Janeiro: IBAMA, 1990.

FGV (FUNDAÇÃO GETÚLIO VARGAS). Instituto Brasileiro de Economia. 2009. Disponível em: <http://www.ibre.fgv.br/>. Acesso em: 14 dez. 2009.

FIGUEIREDO, J. L. Manual de peixes marinhos do sudeste do Brasil: v.1 cações, raias e quimeras. São Paulo, Museu de Zoologia - USP, 1977.

FIGUEIREDO J. L.; MENEZES, N. A. Manual de peixes marinhos do sudeste do Brasil: v. 2 - Teleostei 1. São Paulo, Museu de Zoologia - USP, 1978.

FIGUEIREDO J. L.; MENEZES, N. A. Manual de peixes marinhos do sudeste do Brasil: v. 3 - Teleostei 2. São Paulo, Museu de Zoologia - USP, 1980.

FIGUEIREDO J. L.; MENEZES, N. A. Manual de peixes marinhos do sudeste do Brasil:v 4 - Teleostei 5. São Paulo, Museu de Zoologia-USP, 2000.

FISCHER, W.; SCHNEIDER, M.; BAUCHOT, M. L. Fiches FAO d'identification des espèces pour les besoins de la pêche (Révision 1): Méditerranée et mer Noire. Zone de Pêche 37. Rome: FAO, 1987.

FISCHER, A. J.; BAKER, M. S. JR; WILSON, C. A.; NIELAND, D. L. Age, growth, mortality, and radiometric age validation of gray snapper (Lutjanus griseus) from Louisiana. Fishery Bulletin, v. 103, n. 2, p. 307-319, 2005.

FRÉDOU, T.; FERREIRA, B. P.; LETOURNEUR, Y. A univariate and multivariate study of reef fisheries off northeastern Brazil. ICES Journal of Marine Science, v. 63, n. 5, p. 883-896, 2006.

FREIRE, K. M. F.; FERREIRA, A. V.; LESSA, R. P.; LINS-OLIVEIRA, J. E. First studies on age and growth of sailfish (Istiophorus albicans) caught off Northeastern Brazil. Boletim do Instituto de Pesca, São Paulo, v. 25, p. 7-12, 1999.

FREIRE, K. M. F.; PAULY, D. Fishing down Brazilian marine food webs, with emphasis on the east Brazil Large Marine Ecosystem. Fisheries Research, v. 105, n. 1, p. 57-62, 2010.

FROESE, R.; PAULY, D. (Ed.). FishBase: Concepts, Design and Data Sources, ICLARM, Los Baños, Laguna, Philippines, 2000.

FROESE, R.; PAULY, D. (Ed.). FishBase: World Wide Web electronic publication Disponível em: <http://www.fishbaseorg>. Acesso em: 20 ago. 2010.

FULTON, E. A.; SMITH, A. D. M.; PUNT, A. E. Which ecological indicators can robustly detect effects of fishing? ICES Journal of Marine Science, v. 62, n. 3, p. 540-551, 2005. 
FURIA, R. R. Composição das capturas de peixes na Enseada das Palmas - Ilha Anchieta, Ubatuba, SP: variabilidade espaço-temporal. 1996. $137 \mathrm{f}$. Dissertação (Mestrado) - Instituto Oceanográfico, Universidade de São Paulo.

GARCIA, S. M.; STAPLES, D. Sustainability indicators in Marine Capture Fisheries: introduction to the special issue. Marine and Freshwater Research, v. 51, n. 5, p. 381-384, 2000.

GASALLA, M. A. Organização trófica da ictiofauna do saco de Mamanguá, Paraty, Estado do Rio de Janeiro. 1995. 145 f. Dissertação (Mestrado) Instituto Oceanográfico, Universidade de São Paulo.

GASALLA, M. A.; SERVO, G. J.; TOMÁS, A. R. G. Dinâmica da frota de traineiras da região de Santos, SP. In: CERGOLE, M. C.; ROSSIWONGTSCHOWSKI, C. L. D. B. Dinâmica das frotas pesqueiras: Análise das principais pescarias comerciais do Sudeste-Sul do Brasil. São Paulo: Evoluir, 2003. p. 227-249.

GASALLA, M. A. Impactos da pesca industrial no ecossistema da plataforma continental interna do sudeste do Brasil: a abordagem ecossistêmica e a integração do conhecimento. 2004a. 276 f. Tese (Doutorado) - Instituto Oceanográfico, Universidade de São Paulo.

GASALLA, M. A. Multispecies indicators of long-term changes and fishing impacts in the South Brazil Bight: integrating scientific surveys, fisher's knowledge and forgotten data sets for fishery management. In: QUANTITATIVE ECOSYSTEM INDICATORS FOR FISHERIES MANAGEMENT INTERNATIONAL SYMPOSIUM, 2004. Paris. Proceedings ... Baltimore: SCOR/IOC, 2004b.

GASALLA, M. Modelling the state of fisheries and coastal ecosystem in the South Brazil Bight before industrial fisheries. In: WORLD FISHERIES CONGRESS, 4, 2004c, Vancouver. Reconciling fisheries with conservation. Bethesda: American Fisheries Society, 2004.

GASALLA, M. A.; ROSSI-WONGTSCHOWSKI, C. L. D. B. Contribution of ecosystem analysis to investigating the effects of changes in fishing strategies in the South Brazil Bight coastal ecosystem. Ecological Modelling, v. 172, n. 2-4, p. 283-306, 2004.

GASALLA, M. A. Ecosystem-based fisheries modelling in the South Brazil Shelf: a review based on the LME perspective. In: GLOBAL CONFERENCE ON LARGE MARINE ECOSYSTEMS, 2., Qingdao, China. 2007.

GERMANO, P. L. M.; SOARES, C. M. Higiene Alimentar: Análise da qualidade microbiológica de sashimis comercializados em shopping centers da cidade de São Paulo, Brasil. Higiene Alimentar, v. 18, n. 116/117, p. 88-92, 2004.

GIAMBIAGI, F.; VILLELA, A.; CASTRO, L. B.; HERMANN, J. (Org.). Economia brasileira contemporânea. 6. ed. Rio de Janeiro: Elsevier, 2005.

GIANNINI, R.; PAIVA-FILHO, A. M. Aspectos bioecológicos de Stellifer rastrifer (Perciformes: Sciaenidae) na Baía de Santos, SP. Boletim do Instituto Oceanográfico, São Paulo, v. 38, n. 1, p. 57-67, 1990.

GIBRAN, F. Z. Activity, habitat use, feeding behavior, and diet of four sympatric species of Serranidae (Actinopterygii : Perciformes) in southeastern Brazil. 
Neotropical Ichthyology, v. 5, n. 3, p. 387-398, 2007.

GOITEIN, R. Aspectos de alimentação dos clupeidae Harengula clupeola (Cuvier, 1829) e Opisthonema oglinum (Le Suem, 1818) e dos Engraulidae, Anchoviella lepindentostole (Fowler, 1911) e Cetengraulis edentulus (Cuvier, 1828) no estuário de São Vicente, São Paulo. 1984. 161 f. Tese (Doutorado) - Instituto Oceanográfico, Universidade de São Paulo.

GOMES, I. D. A estrutura da ictiofauna demersal na plataforma interna rasa do sul do Paraná, e dieta das espécies mais abundantes. 2004. $106 \mathrm{f}$. Tese (Doutorado) - Setor de Ciências Biológicas, Universidade Federal do Paraná.

GREENSTREET, S. P. R.; HALL, S. J. Fishing and the ground-fish assemblage structure in the north-western North Sea: An analysis of long-term and spatial trends. Journal of Animal Ecology, v. 65, n. 5, p. 577-598, 1996.

GUDMUNDSSON, E.; ASCHE, F.; NIELSEN, M. Revenue distribution through the seafood value chain. FAO Fisheries Circular, n. 1019, p. 1-42, 2006.

GUNN, J. S.; CLEAR, N. P.; CARTER, T. I.; REES, A. J.; STANLEY, C. A.; FARLEY, J. H.; KALISH, J. M. Age and growth in southern bluefin tuna, Thunnus maccoyii (Castelnau): Direct estimation from otoliths, scales and vertebrae. Fisheries Research, v. 92, n. 2/3, p. 207-220, 2008.

HAIMOVICl, M. Estructura y dinamica poblacional del Pargo blaco Umbina canosai (Scianenidae, pisces) del litoral de RS, Brasil. 1982. 274 f. Tese (Doutorado) - Universidad Nacional de Buenos Aires.

HAIMOVICI, M. Edade y crecimiento del Pargo Rosa no sul do Brasil. In: SIMPÓSIO CIENTÍFICO DE LA COMISIÓN MIXTA DEL FRENTE MARITIMO, 8., 1991, Montevideo. Resumenes... Montevideo: Comision Tecnica Mixta Del Frente Maritimo, 1991. p. 49.

HAIMOVICI, M., MARTINS, A. S., FIGUEIREDO, J. L, VIEIRA, P. C. Demersal bony fish of the outer shelf and upper slope of the southern Brazil Subtropical Convergence Ecosystem. Marine Ecology-Progress Series, v. 108, n. 1/2, p. 59-77, 1994.

HAIMOVICl, M. Recursos pesqueiros demersais da região sul: Rio de Janeiro: FEMAR, 1997.

HAIMOVICl, M.; VELASCO, G. A pesca de espinhel de fundo no sul do Brasil em 1997 e 1998. Rio Grande: Ed. FURG, 2001. (Série Documentos Técnicos, n. 11).

HAIMOVICI, M.; CERGOLE, M. C.; LESSA, R. P.; MADUREIRA, L. S. P.; JABLONSKI, S.; WONTCHOWSKI, C. R. Panorama nacional In: BRASIL. Ministério do Meio Ambiente. Avaliação do potencial sustentável de recursos vivos na zona econômica do Brasil: relatório executivo. Brasília: MMA, 2006. p.77-120.

HAIMOVICI, M.; ROSSI-WONGTSCHOWSKI, C. L. D. B.; BERNARDES, R. A.; FISHER, L. G.; VOOREN, C. M.; SANTOS, R. A.; RODRIGUES, A. R.; SANTOS, S. Prospecção pesqueira de espécies demersais com rede de arrasto-de-fundo na região sudeste-sul do Brasil. São Paulo: IOUSP, 2008. 
HANNESSON, R. Globalisation of seafood prices: some examples. ACP-EU Fisheries Research Report, n. 5, p. 15-16, 1998.

HARRIS, P. J.; WYANSKI D. M.; WHITE, D. B.; MIKELL, P. P.; EYO, P. B. Age, growth, and reproduction of greater amberjack off the southeastern US Atlantic coast. Transactions of the American Fisheries Society, v. 136, n. 6, p. 15341545, 2007.

HAYSE, J. W. Feeding-habits, age, growth, and reproduction of Atlantic Spadefish Chaetodipterus Faber (Pisces, Ephippidae) in South-Carolina. Fishery Bulletin, v. 88, n. 1, p. 67-83, 1990.

HEEMSTRA, P. C.; RANDALL, J. E. FAO species catalogue v. 16: groupers of the world. Fisheries Synopsis, n. 125, p. 1-382, 1993.

HEILEMAN, S.; GASALLA, M. South Brazil Shelf LME. UNEP Regional Seas Report and Studies, n. 182, p. 723-34, 2008.

HEITHAUS, M. R.; FRID, A.; WIRSING, A. J.; WORM, B. Predicting ecological consequences of marine top predator declines. Trends in Ecology \& Evolution, v. 23, n. 4, p. 202-210, 2008.

HOLLING, C. S. Resilience and stability of ecological systems. Annual Review of Ecology and Systematics, v. 4, p. 1-23., 1973.

IBAMA. Camarões do sudeste e sul. Brasília: Ibama, 1993a. (Coleção Meio Ambiente. Série Estudos: Pesca ; n. 5 ).

IBAMA. Peixes demersais: relatório da III Reunião do Grupo Permanente de Estudos (GPE) sobre peixes demersais. Brasília : Ibama, 1993b. (Coleção Meio Ambiente. Série Estudos: Pesca ; n. 8).

IBAMA. Sardinhas, atuns e afins. Brasília : Ibama, 1994. (Coleção Meio Ambiente. Série Estudos: Pesca ; n. 11 ).

IBAMA. Estatística da pesca 2005: Brasil e grandes regiões e unidades da federação . Brasília : Ibama, 2007.

ICES JOURNAL OF MARINE SCIENCE. London: Published for ICES by Academic Press, v. 62 (3), 2005.

IPEA (Instituto de Pesquisas em Economia Aplicada). IPEADATA. Base de dados. 2008. Disponível em: <http://www.ipeadata.gov.br/>. Acesso em: 20 maio 2008.

ISAAC-NAHUM, V. J. Analysis of methods for the estimation of fish growth parameters, based on data from the family sciaenidae and on simulated data. 1989. 244 f. Dissertation - Mathematisch-Naturwissenschaftlichen Fakultaet, Christian-Albrechts Univ., Kiel (Germany).

ISAAC, V. J.; MARTINS, A. S.; HAIMOVICI, M.; ANDRIGUETO-FILHO, J. M. (Org.). A pesca marinha e estuarina do Brasil no início do século XXI: recursos, tecnologias, aspectos socioeconômicos e institucionais. Belém: UFPA, 2006.

JACKSON, J. B. C.; KIRBY, M. X.; BERGER, W. H. BJøRNDAL, K. A. L. W.; BOTSFORD, L. W.; BOURQUE, J. J.; BRADBURY, R. H.; COOKE, R.; ERLANDSON, J.; ESTES, J. A.; HUGHES, T. P.; KIDWELL, S.; LANGE, C. B.; LENIHAM, H. S.; PANDOLFI, J. M.; PETERSON, C. H.; STENECK, R. S.; 
TEGNER, M. J.; WARNER, R. R. Science, v. 293, n. 5530, p. 629-638, 2001. JACKSON, J. B. C. What was natural in the coastal oceans? Proceedings of the National Academy of Sciences, v. 98, n. 10, 5411-5418, 2001.

JAUREGUIZAR, A. J.; MILESSI, A. C. Assessing the sources of the fishing down marine food web process in the Argentinean-Urugnayan Common Fishing Zone. Scientia Marina, v. 72, n. 1, p. 25-36, 2008.

JENNINGS, S.; GREENSTREET, S. P. R.; REYNOLDS, J. D. Structural change in an exploited fish community: a consequence of differential fishing effects on species with contrasting life histories. Journal of Animal Ecology, v. 68, n. 3, p. 617-627, 1999.

JENNINGS, S.; KAISER, M. J.; REYNOLDS, J. D. Marine fisheries ecology. Oxford: Blackwell, 2001.

KEITH, P.; LE BAIL, P.-Y. E PLANQUETTE, P. Atlas des poissons d'eau douce de Guyane, tome 2, fascicule I. Collection Patrimoines Naturels, v. 43, n. 1, p. 1-286, 2000.

KING, M. Fisheries biology: assessment and management. OXFORD: Fishing News Books, 1995.

KISHORE, R.; SOLOMON, F. Age and growth studies of Caranx hippos (crevalle jack) from Trinidad using hard-parts. Proceedings of the Gulf and Caribbean Fisheries Institute, n. 56, p. 227-239, 2005.

KOSLOW, J. A.; BOEHLERT, G. W.; GORDON J. D. M.; HAEDRICH, R. L.; LORANCE, P.; E PARIN, N. Continental slope and deep-sea fisheries: implications for a fragile ecosystem. ICES Journal of Marine Science, v. 57, n. 3, p. 548-557, 2000.

KOTAS, J. Dinâmica de populações e pesca do tubarão-martelo Sphyrna lewini (Griffith \& Smith, 1834), capturado no mar territorial e zona econômica exclusiva do sudeste-sul do Brasil. 2004. 2 v. Tese (Doutorado) Escola de Engenharia de São Carlos, Universidade de São Paulo.

KOZUL, V.; SKARAMUCA, B; KRALJEVIC, M; DULCIC, J; GLAMUZINA, B. Age, growth and mortality of the Mediterranean amberjack Seriola dumerili (Risso 1810) from the south-eastern Adriatic Sea. Journal of Applied Ichthyology, v. 17, n. 3, p. 134-141, 2001.

KRUG, L. C.; HAIMOVICI, M. Análise da pesca da enchova, Pomatomus saltarix no sul do Brasil. Atlântica, v. 13, n. 1, p. 119-129, 1991.

KRUSE, G. H.; GALLUCCI, V. F.; HAY, D. E.; PERRY, R. I.; PETERMAN, R. M.; SHIRLEY, T. C.; SPENCER, P. D.; WILSON, B.; WOODBY, D. (Ed.). Fisheries assessment and management in data-limited situations. Fairbanks: Alaska Sea Grant College Program, University of Alaska, 2003.

LAMARDO, E. Z.; BíCEGO, M. C.; CASTRO FILHO, B. M.; MIRANDA, L. B.; PRÓSPERI, V. A. Southern Brazil. In: SHEPPARD, C. R. C. Seas at the millenium: an environmental evaluation. Amsterdam: Pergamon, 2000. p. 731 747. 
LAROE, E. A contribution to the biology of the Loliginidae (Cephalopoda Myopsida) of the tropical Western Atlantic. 1967. $220 \mathrm{f}$. Thesis (Master in Science) - University of Miami.

LEAL, L. C. N.; BEMVENUTI, M. A. Levantamento e caracterização dos peixes mais freqüentes no mercado público do Rio Grande. Cadernos de ecologia aquática, v. 1, n. 1, p. 45-61, 2006.

LEGAT, J. F. A. Distribuição, abundância, reprodução e morfometria de Prionace glauca no Sul do Brasil. 2001. 118 f. Dissertação (Mestrado). Universidade Federal do Rio Grande.

LEITE-JÚNIOR. Determinação de idades e análise do crescimento do batata, Lopholatilus villarii Miranda-Ribeiro, 1915 (Teleostei; Branchiostegidae), no extremo sul do Brasil. 1999. Monografia (Bacharelado) - Departamento de Oceanografia, Fundação Universidade do Rio Grande.

LE LOEUFF, P.; INTES, A. Note stir le regime alimentaire de quelques poissons demersaux de Cote d ivoire. Documents scientifiques - Centre de recherches océanographiques Abidjan, v. 4, n. 2, p. 17-44, 1973.

LESSA, R. P. T. Biologie et dynamique des populations de Rhinobatos horkelii du plateau Continental du Rio Grande do Sul. 1982. Thesis (PhD) Faculté des Sciences de Brest, Université de Bretagne Occidentale, France.

LINK, J. S. Translating ecosystem indicators into decision criteria. ICES Journal of Marine Science, v. 62, n. 3, p. 569-576, 2005.

LIU, K. M.; CHIANG, P-J; CHEN, C-T. Age and growth estimates of the bigeye thresher shark, Alopias superciliosus, in northeastern Taiwan waters. Fishery Bulletin, v. 96, n. 3, p. 482-491, 1998.

LIU, Y.; NANDAKUMAR, D.; SALAS, S.; CHUENPAGDEE, R. Economics discussion at the 4th World Fisheries Congress. Fisheries Centre Research Reports. v. 13, n. 2, 1-113, 2005.

LIZAMA, M. D. L. A. P. L.; TAKEMOTO, R. M. Relationship between the growth pattern and different trophic categories: a hypothesis to be tested. Acta Scientiarum, v. 22, n. 2, p. 455-463, 2000.

LOWE-MCCONNELL, R. H. Estudos ecológicos de comunidades de peixes tropicais. São Paulo: Edusp, 1999.

IUDICELLO, S.; WEBER, M.; WIELAND, R. Fish, markets and fishermen: the economics of overfishing. Washington: Island, 1999.

MCBRIDE, R. S.; RICHARDSON, A. K.; MAKI, K. L. Age, growth, and mortality of wahoo, Acanthocybium solandri, from the Atlantic coast of Florida and the Bahamas. Marine and Freshwater Research, v. 59, n. 9, 799-807, 2008.

MAGRO, M.; CERGOLE, M. C.; ROSSI-WONGTSCHOWSKI, C. L. D. B. Síntese de conhecimentos dos principais recursos pesqueiros costeiros potencialmente explotáveis na costa sudeste-sul do Brasil: peixes. Brasília: Ministério do Meio Ambiente; Comissão Inteministerial para os Recursos do Mar, 2000. 
MAGRO, M. Aspectos da pesca e dinâmica de populações do espada, Trichiurus lepturus (Trichiuridae, Teleostei), da costa sudeste-sul do Brasil. 2006. 174 f. Tese (Doutorado) - Instituto Oceanográfico, Universidade de São Paulo.

MANNING, R. B.; HOLTHUIS, L. B. Two new genera and nine new species of geryonid crabs (Crustacea, Decapoda, Geryonidae). Proceedings of the Biological Society of Washington, v. 102, n. 1, p. 50-77, 1989.

MANTELATTO, F. L. M.; CHRISTOFOLETTI, R. A. Natural feeding activity of the crab Callinectes ornatus (Portunidae) in Ubatuba Bay (Sao Paulo, Brazil): influence of season, sex, size and molt stage. Marine Biology, v. 138, n. 3, p. 585-594, 2001.

MARQUES, H. L. A.; PEREIRA, R. T. L. Mexilhões: biologia e criação. Boletim técnico do Instituto de Pesca, São Paulo, n. 12, p. 1-32, 1988.

MARTINS, A. S. As assembléias e as guildas tróficas de peixes ósseos e cefalópodes demersais da plataforma continental e talude superior do extremo sul do Brasil. 2000. 169 f. Tese (Doutorado) - Fundação Universidade de Rio Grande.

MASON, D. L.; MANOOCH, C. S. Age and growth of mutton snapper along the East coast of Florida. Fisheries Research, v. 3, n. 2, p. 93-104, 1985.

MATSUURA, Y. Análise econômica da produção da sardinha na região sudeste do Brasil. Boletim do Instituto Oceanográfico, São Paulo, v. 30, n. 1, p. 5764, 1981.

MAUNDER, M. N.; DERISO, R. B. Dealing with missing covariate data in fishery stock assessment models. Fisheries Research, v. 101, n. 1/2, p. 80-86, 2010.

MELO, G. A. S. Manual de identificação dos Brachyura (caranguejos e siris) do litoral brasileiro. São Paulo: Plêide/FAPESP, 1996.

MENDO, J. A. Edad, crecimiento y algunos aspectos reproductivos y alimentarios de la caballa (Scomber japonicus peruanus). Boletin [del] Instituto del mar del Peru, v. 8, n. 4, p. 101-156, 1984.

MENEZES, N. A.; FIGUEIREDO, J. L. Manual de peixes marinhos do sudeste do Brasil: v. 4, Teleostei 3. São Paulo, Museu de Zoologia - USP, 1980.

MENEZES, N. A.; FIGUEIREDO, J. L. Manual de peixes marinhos do sudeste do Brasil: v. 5, Teleostei 4. São Paulo, Museu de Zoologia - USP, 1985.

MENGE, B. A. Community regulation: under what conditions are bottom-up factors important on rocky shores. Ecology, v. 73, n. 3, p. 755-765, 1992.

METHRATTA, E. T.; LINK, J. S. Evaluation of quantitative indicators for marine fish communities. Ecological Indicators, v. 6, n. 3, p. 575-588, 2006.

MIANZAN, H. W.; MARI, N.; PRENSKI, B.; SANCHEZ, F. Fish predation on neritic ctenophores from the Argentine continental shelf: a neglected food resource? Fisheries Research, v. 27, n. 1-3, p. 69-79, 1996.

MILESSI, A. C.; ARANCIBIA, H.; NEIRA, S.; DEFEO, O. The mean trophic level of Uruguayan landings during the period 1990-2001. Fisheries Research, v. 
74, n. 1-3, p. 223-231, 2005.

MINAGAWA, M.; WADA, E. Stepwise enrichment of $n-15$ along food-chains further evidence and the relation between delta- $n-15$ and animal age. Geochimica et Cosmochimica Acta, v. 48, n. 5, p. 1135-1140, 1984.

MIRANDA, L. V.; CARNEIRO, M. H. A pesca da tainha Mugil platanus (Perciformes: Mugilidae) desembarcada no estado de São Paulo: subsídio ao ordenamento. Série Relatórios Técnicos [do] Instituto de Pesca, São Paulo, n. 30, p. 1-13, 2007.

MOORE, G.; JENNINGS, S. Commercial fishing: the wider ecological impacts. London: British Ecological Society, 2000.

MORATO, T.; WATSON, R.; PITCHER, T. J.; PAULY, D. Fishing down the deep. Fish and Fisheries, v. 7, n. 1, p. 24-34, 2006.

MORENO, J. I. L.; AGOSTINI, V. N.; CADDY, J. F.; CAROCCI, F. Is the pelagic-demersal ratio from fishery landings a useful proxy for nutrient availability?:a preliminary data exploration for the semi-enclosed seas around Europe. ICES Journal of Marine Science, v. 57, n. 4, p. 1091-1102, 2000.

MULLER, R. G.; TISDEL, K.; MURPHY, M. D. The 2002 update of the stock assessment of Florida Pompano (Trachinotus carolinus). St. Petersburg, FL: Florida Marine Research Institute, 2002.

MUTO, E. Y. Variações isotópicas de $13 \mathrm{C}$ e $15 \mathrm{~N}$ de peixes demersopelágicos do ecossistema de plataforma ao largo de Cabo Frio (RJ) e Ubatuba (SP). 2004. 142 f. Tese (Doutorado) - Instituto Oceanográfico, Universidade de São Paulo.

MYERS, R. A.; BAUM, J. K.; SHEPHERD, T. D.; POWERS, S. P.; PETERSON, $C$. $H$. Cascading effects of the loss of apex predatory sharks from a coastal ocean. Science, v. 315, n. 5820, p. 1846-1850, 2007.

MYERS, R. A.; WORM, B. Rapid worldwide depletion of predatory fish communities. Nature, v. 423, n. 6937, p. 280-283, 2003.

NAKAMURA, I.; INADA, T.;TAKEDA, M.; HATANAKA, H. Important fishes trawled off Patagonia: Fishes Japan Marine Fishery Resource Research Center, Tokyo. 369 p., 1986.

NAKAMURA, I.; PARIN, N. V. FAO species catalogue: v. 15 - Snake mackerels and cutlassfishes of the world (families Gempylidae and Trichiuridae). FAO Fisheries Synopsis, n. 125, p. 1-129, 1993.

NAKATANI, K.; MATSUURA, Y.; SATO, G. Estudo do ciclo de vida do peixeespada Trichiurus lepturus. Boletim do Instituto Oceanográfico, São Paulo, v. 29, n. 2, p. 255-259, 1980.

NATALI-NETO, J. F. Ictiofauna do ecossistema tropical marinho de

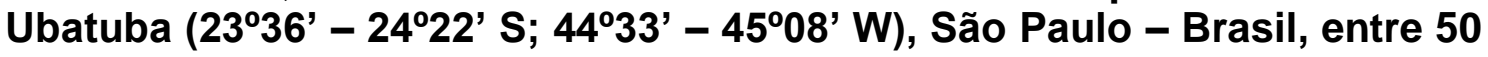
e 100 metros de profundidade: composição, abundância e diversidade. São Paulo. 1994. 2 v. Dissertação (Mestrado) - Instituto Oceanográfico. Universidade de São Paulo.

NETTO, E. B. F.; OLIVEIRA, E. S. Aspectos da biologia de Merluccius hubbsi Marini, 1933 (Pisces, merluciidae) na região de Arraial do Cabo, RJ. In: 
ENCONTRO BRASILEIRO DE ICTIOLOGIA, 9, 1991, Maringá. Resumos...Maringá: Sociedade Brasileira de Ictiologia: Fundação Universidade Estadual de Maringá, Núcleo de Pesquisas em Limnologia, Ictiologia e Aqüicultura, 1991. p. 106.

NEVES, L. M.; PEREIRA, H. H.; MARCUS, R. C.; ARAUJO, F. G.. Uso do manguezal de Guaratiba, Baia de Sepetiba, RJ, pelo peixe-rei Atherinella brasiliensis. Revista Brasileira de Zoologia, v. 23, n. 2, p. 421-428, 2006.

ODUM, W. E.; HEALD, E. J. The detritus based food webs of an estuarine mangrove comunity. In: CRONIN, L. E. Estuarine research. New York, Academic Press, 1975. p. 265-86.

OLIVEIRA, J. E. L.; VASCONCELOS, J. A.; TRAVASSOS, P.; GARCIA JR., J.; ALDATZ, J. P. Length-weight relantionships and length-length conversions of tunas and swordfish in the northeast of Brazil. International Commission for the Conservation of Atlantic Tunas Collective Volume of Scientific Papers, v. 58, n. 5, p. 1724-28, 2005.

PAIVA, M. P.; ANDRADE, M. F. Pescarias de barcos linheiros ao largo da costa sudeste do Brasil (1979-1985). Boletim técnico do Instituto de Pesca, n. 18, p. 1-21, 1994.

PAIVA, M. P. Recursos pesqueiros estuarinos e marinhos do Brasil. Fortaleza: EUFC, 1997.

PALAZÓN, J. L.; GONZÁLES, L. W. Edad y crecimiento del pargo criollo, Lutjanus analis (Cuvier, 1828) (Teleostei: Lutjanidae) en la isla de Margarita y alrededores, Venezuela. Investigación Pesquera, v. 50, n. 2, p. 151-165, 1986.

PALKO, B. J.; BEARDSLEY, G. L.; RICHARDS, W. J. Synopsis of the biological data on dolphin-fishes, Coryphaena hippurus and Coryphaena equiselis. NOAA Technical Report National Marine Fisheries Service. Circular, n. 443, p. 1-28, 1982.

PAULY, D. Tropical fishes: patterns and propensities. Journal of Fish Biology, v. 53, p. 1-17, 1998. Supplement A.

PAULY, D.; CHUA, T. E. The overfishing of marine resources: socioeconomic background in Southeast Asia. AMBIO, v. 17, n. 3, p. 200-206, 1988.

PAULY, D.; CHRISTENSEN, V.; DALSGAARD, J.; FROESE, R.; TORRES, F. Fishing down marine food webs. Science, v. 279, n. 5352, p. 860-863, 1998.

PAULY, D.; CHRISTENSEN, V.; WALTERS, C. Ecopath, Ecosim, and Ecospace as tools for evaluating ecosystem impact of fisheries. ICES Journal of Marine Science, v. 57, n. 3, p. 697-706, 2000.

PAULY, D.; PALOMARES, M. L.; FROESE, R.; SA-A, P.; VAKILY, M.; PREIKSHOT, D. Fishing down Canadian aquatic food webs. Canadian Journal of Fisheries and Aquatic Sciences, v. 58, n. 1, p. 51-62, 2001.

PAULY, D.; CHRISTENSEN, V.; GUÉNETTE, S.; PITCHER, T. J.; SUMAILA, U. R.; WALTERS, C. J.; WATSON, R.; ZELLER, D. Towards sustainability in world fisheries. Nature, v. 418, n. 6898, p. 689-695, 2002. 
PAULY, D.; PALOMARES, M. L. Fishing down marine food web: It is far more pervasive than we thought. Bulletin of Marine Science, v. 76, n. 2, p. 197-211, 2005.

PAULY, D.; WATSON, R. Background and interpretation of the 'Marine Trophic Index' as a measure of biodiversity. Philosophical Transactions of the Royal Society B-Biological Sciences, v. 360, n. 1454, p. 415-423, 2005.

PÉREZ-ESPAÑA, H.; ABARCA-ARENAS, L. G.; JIMÉNEZ-BADILLO, M. L. Is fishing-down trophic web a generalized phenomenon?: the case of Mexican fisheries. Fisheries Research, v. 79, n. 3, p. 349-352, 2006.

PESSANHA, A. L.; ARAÚJO, F. G. Recrutamento de peixe-rei Xenomelaniris brasiliensis (Atheriniformes, Atherinopsidae), na margem continental da Baía de Sepetiba, RJ, Brasil. Revista Brasileira de Zoologia, v. 18, n. 4, p. 1265-74, 2001.

PETTI, M. A. V. Papel dos crustáceos braquiúros na rede trófica da plataforma interna de Ubatuba, São Paulo (Brasil). Nerítica, v. 11, n. 1/2, p. 123-38, 1997.

PEZZUTO, P. R.; PEREZ, J. A. A.; WAHRILICH, R. A pesca de camarões-deprofundidade (Decapoda: Aristeidae) nas regiões de talude da costa brasileira. 2005. Relatório Técnico. Disponível em: < http://alunoca.io.usp.br/ cesar/disciplinas/semestre7/biopesq/camaroes_prof/D OC-10-SCC-CPG-03-2005.pdf >. Acesso em: 03 fev 2010.

PINCINATO, R. B. M. e GASALLA, M. L. Changes in a seafood market: substitution and elasticity of fish categories behavior in SE Brazil. In: IIFET 2010 ECONOMICS OF FISH RESOURCES AND AQUATIC ECOSYSTEMS: BALANCING USES, BALANCING COSTS, 2010, Montpellier, França.

PINHO, D. B.; VASCONCELLOS, M. A. S. (Org.). Manual de economia. São Paulo: Saraiva, 2003.

PINNEGAR, J. K.; JENNINGS, S.; O'BRIEN, C. M.; POLUNIN, V. C. Long-term changes in the trophic level of the Celtic Sea fish community and fish market price distribution. Journal of Applied Ecology, v. 39, n. 3, p. 377-390, 2002.

PINNEGAR, J. K; HUTTON, T. P.; PLACENTI, V. What relative seafood prices can tell us about the status of stocks. Fish and Fisheries, v. 7, n. 3, p. 219226, 2006.

PORTSEV, P. I. The feeding of the cutlassfish, Trichiurus lepturus (Trichiuridae), off the west coast of India. Journal of Ichthyology, v. 20, n. 5, p. 60-65, 1980.

POWERS, J. E.; MONK, M. H. Current and future use of indicators for ecosystem based fisheries management. Marine Policy, v. 34, n. 3, p. 723727, 2010.

PRISCO, A. R.; GARCÍA DE LA ROSA, S. B.; DÍAZ DE ASTARLOA, L. Feeding ecology of flatfish juveniles (Pleuronectiformes) in Mar Chiquita coastal lagoon (Buenos Aires, Argentina). Estuaries, v. 24, n. 6A, p. 917-925, 2001.

PUCCI, M. C. J. Dieta e partilha alimentar de seis espécies de peixes piscívoros da plataforma continental sudeste do Brasil. 2004. $137 \mathrm{f}$. Dissertação (Mestrado) - Instituto Oceanográfico. Universidade de São Paulo. 
RABELO, L. Alimentação e impactos da espécie exótica bagre-africano (Clarias gariepinus Burchell, 1822) no estuário do rio Itanhaém, Bahia. 2009. 64 f. Dissertação (Mestrado) - Instituto Oceanográfico, Universidade de São Paulo.

REZENDE, S. M.; FERREIRA, B. P. Age, growth and mortality of dog snapper Lutjanus jocu (Bloch e Schneider, 1801) in the northeast coast of Brazil. Brazilian Journal of Oceanography, v. 52, n. 2, 2004

RICHARDSON, I. D.; VAZZOLER, G.; FARIA, A.; MORAES, M. N. Report on sardine investigations in Brazil. In: WORLD SCIENTIFIC MEETING ON THE BIOLOGY OF SARDINES AND RELATED SPECIES, Rome. Proceedings... Rome: FAO, 1960. p. 1051-1079.

RIOS, M. A. T. Alimentação dos Sciaenidae Ctenosciaena gracilicirrhus, Cynoscion jamaicensis, C. guatucupa e Paralonchurus brasiliensis da região costeira de Ubatuba, SP, Brasil. 1994. 138 f. Dissertação (Mestrado) Instituto Oceanográfico, Universidade de São Paulo.

RODRIGUES, A. R. Caracterização da estrutura populacional e alimentação das lulas Loligo plei (Blainvlille, 1823) e Loligo sanpaulensis (Brakoniecki, 1984) (Cephalopoda: Loliginidae) capturadas pela pesca industrial do estado de São Paulo, entre 23 graus S e 26 55S. 2007. 88 f. Dissertação (Mestrado) - Instituto de Pesca, São Paulo. Secretaria de Agricultura e Abastecimento.

ROSA, R.; MARQUES, A. M.; NUNES, M. L.; BANDARRA, N.; REIS, C. S. Spatial-temporal changes in dimethyl acetal (octadecanal) levels of Octopus vulgaris (Mollusca, Cephalopoda): relation to feeding ecology. Scientia Marina, v. 68, n. 2, p. 227-236, 2004.

ROSSI-WONGTSCHOWSKI, C. L. D. B.; ÁVILA-DA-SILVA, A. O.; CERGOLE, M. C. (Ed.). Análise das principais pescarias comerciais do sudeste-sul do Brasil: dinâmica populacional das espécies em explotação II. São Paulo: Instituto Oceanográfico, 2006.

ROSSI-WONGTSCHOWSKI, C. L. D. B.; ÁVILA-DA-SILVA, A. O. CERGOLE, M. C. (Ed.). Dinâmica das frotas pesqueiras: análise das principais pescarias comerciais do sudeste-sul do Brasil. Reedição. São Paulo: Instituto Oceanográfico, 2007.

SABATIÉ, R.; POTIER, M.; BROUDIN, C.; SERET, B.; MÉNARD, F.; MARSAC, F. Preliminary analysis of some pelagic fish diet in the eastern central Atlantic. International Commission for the Conservation of Atlantic Tunas Collective Volume of Scientific Papers, v. 55, n. 1, p. 292-302, 2003.

SACCARDO, S. A.; ROSSI-WONGTSCHOWSKI, C. L. D. B; CERGOLE, M. C.; BITTENCOURT, M. M. Age and growth of the southeastern Brazilian sardine, Sardinella brasiliensis, 1981-1983. Boletim do Instituto Oceanográfico, São Paulo, v. 36. n. 1, p. 1988.

SANTOS, E. Nossos Peixes Marinhos. Rio de Janeiro: Villa Rica, 1992.

SÃO PAULO. Instituto de Pesca. Relatório técnico 2004. São Paulo: Instituto de Pesca, 2004. 
SAZIMA, I.; UIEDA, V. S. Comportamento lepidofágico de Oligoplites saurus e registro de lepidofagia em $O$. palometa e $O$. saliens (Pisces, Carangidae). Revista Brasileira de Biologia, v. 40, n. 4, p. 701-710, 1980.

SAZIMA, I. Similarities in feeding-behavior between some marine and freshwater fishes in 2 tropical communities. Journal of Fish Biology, v. 29, n. 1, p. 53-65, 1986.

SEA AROUND US PROJECT. A global database on marine fisheries and ecosystems. 2007. Disponível em: <http://www.seaaroundus.org>. Acesso em: 20 jun. 2010.

SEALIFEBASE. Base de dados. Disponível em: <http://www.sealifebase.org/ >. Acesso em: 23 set. 2009.

SERGIPENSE, S.; CARAMASCHI, E. P.; SAZIMA, I. Morfologia e hábitos alimentares de duas espécies de Engraulidae (Teleostei, Clupeiformes) na Baía de Sepetiba, Rio de Janeiro. Revista Brasileira de Oceanografia, v. 47, n. 2, p. 173-188, 1999.

SEVERINO-RODRIGUES, E.; HEBLING, N.; GRAÇA-LOPES, J. R. Biodiversidade no produto da pesca de arrasto-de-fundo dirigida ao lagostim, Metanephrops rubellus (Moreira, 1903), desembarcado no litoral do estado de são Paulo, Brasil. Boletim Instituto de Pesca, São Paulo, v. 33, n. 2, p. 171182, 2007.

SHANNON, L. J.; COLL, M.; NEIRA, S. Exploring the dynamics of ecological indicators using food web models fitted to time series of abundance and catch data. Ecological Indicators, v. 9, n. 6, p. 1078-1095, 2009.

SHERMAN, K.; AQUARONE, M. C.; ADAMS, S. (Ed.). Sustaining the world's Large Marine Ecosystems. Gland, Switzerland: IUCN, 2009.

SIERRA, L. M.; CLARO, R.; POPOVA, O. A. Alimentacion y relaciones tróficas. In: CLARO, R. (Ed.). Ecología de los peces marinos de Cuba. Cuba: Instituto de Oceanología Academia de Ciencias de Cuba; Quintana Roo: Centro de Investigaciones de Quintana Roo, 1994. p. 263-84.

SILVA, C. M. L.; ALMEIDA, Z. S. Alimentação de Rhizoprionodon porosus (Elasmobranchii: Carcharhinidae) da costa do Maranhão, Brasil. Boletim do Instituto de Pesca, São Paulo, v. 27, n. 2, p. 201-207, 2001.

SILVA, D. H. Idade e crescimento de Carcharhinus signatus no Sul do Brasil. 2001. 77 f. Dissertação (Mestrado) - Universidade Federal do Rio Grande.

SILVA, R. D. Nomes vulgares de peixes encontrados no Entreposto de Pesca do Rio de Janeiro, com seus correspondentes em sistemática. Voz do Mar, v. 23, n. 189, p. 123-126, 1944.

SILVEIRA, I. C. A.; SCHMIDT, A. C. K.; CAMPOS, E. J. D.; GODOI, S. S. , IKEDA, Y. A corrente do Brasil ao largo da costa leste brasileira. Revista Brasileira de Oceanografia, v. 48, n. 2, p. 171-183, 2000. 
SIMPFENDORFER, C. A.; POULAKIS, G. R.; O'DONNELLS, P. M.; WILEY, T. R. Growth rates of juvenile smalltooth sawfish Pristis pectinata Latham in the western Atlantic. Journal of Fish Biology, v. 72, n. 3, p. 711-723, 2008.

SOARES, L. S. H. Aspectos da biologia e ecologia de Isopisthys parvipinnis (Cuvier, 1830) (Perciformes: Sciaenidae) entre Cabo Frio e Torres, Brasil. 1983. 123f. Dissertação (Mestrado) - Instituto Oceanográfico, Universidade da São Paulo.

SONODA, D. Y.; CONTE, L, SCORVO-FILHO, J. D.; SHIROTA, R.; CYRINO, J. E. P. Análise comparativa dos dados de comercialização de pescados da CEAGESP nas décadas de 80 e 90. Informações Econômicas, v. 32, n. 11, p. 50-55, 2002.

SPANIER, E.; LAVALLI, K. L. Natural history of Scyllarides latus (Crustacea : Decapoda): a review of the contemporary biological knowledge of the Mediterranean slipper lobster. Journal of Natural History, v. 32, n. 10/11, p. 1769-1786, 1998.

STEWART, J.; FERREL, D. J.; DER WALT, B. V. Size and ages in commercial landings with estimates of growth, mortality and yield per recruit of yellowtail kingfish (Seriola lalandi) from New South Wales, Australia. Marine and Freshwater Research, v. 55, n. 5, p. 489-497, 2004.

SUDEPE. Estatística da pesca: produção 1969. 1969.

SUDEPE. Estatística da pesca: produção de 1978. 1978.

SUMAILA, U. R. Economic analyses of fisheries impacts on food webs: pricing down marine food webs. ACP-EU Fisheries Research Report, n. 5, p. 13-15, 1998a.

SUMAILA, U. R. Markets and the fishing down marine food webs phenomenon. EC Fisheries Cooperation Bulletin, v.11, n. 3, p. 25-28, 1998b.

SUMAILA, U. R.; MARSDEN, A. D.; WATSON, R.; PAULY, D. A global exvessel fish price database: constructions and applications. Journal of Bioeconomics, v. 9, n. 1, p. 39-51, 2007.

SUN, C. L.; WANG, S. P.; YEH, S. Z. Age and growth of the swordfish (Xiphias gladius $L$.) in the waters around Taiwan determined from anal-fin rays. Fishery Bulletin, v. 100, n. 4, p. 822-835, 2002.

TARARAM, A. S; WAKABARA, Y.; WQUI, M. B. Hábitos alimentares de onze espécies da megafauna bêntica da plataforma continental de Ubatuba, SP. Publicação especial do Instituto Oceanográfico, São Paulo, n. 10, p. 159167, 1993.

TEIXEIRA, G. S.; ABDALLAH, P. R.; MOREL, B. L. G. Pesca com embarcações arrendadas no Brasil: uma análise econômica desta atividade no período de 1988-2002. In: CONGRESSO DA SOCIEDADE BRASILEIRA DE ECONOMIA E SOCIOLOGIA RURAL, 43., 2004, Cuiabá. Brasília: SOBER, 2005. 1 CD-ROM.

THOMPSON, B. A.; BEASLEY, M.; WILSON, C. A. Age distribution and growth of greater amberjack, Seriola dumerili, from the north-central Gulf of Mexico. Fishery Bulletin, v. 97, n. 2, p. 362-371, 1999. 
URTEAGA, J. R. Estudio sobre la edad, el crecimiento, area de distribucion y pesca de la corvina negra, Pogonias cromis en el litoral de la provincia de Buenos Aires. 2000. 28 f. Thesis (Lic. en Ciencias Biologicas) - Facultad de Ciencias Exactas y Naturales, Universidad Nacional de Mar del Plata (Argentina).

VAL, A. L.; ALMEIDA-VAL, V. M. F. Fishes of the Amazon and their environment: physiological and biochemical aspect. Berlin: Springer, 1995.

VALEIRAS, X.; MACIAS, D.; GOMEZ, M. J.; LEMA, L.; ALOT, E.; ORTIZ DE URBINA, J. M.; DE LA SERNA, J. M. Age and growth of the Atlantic bonito (Sarda sarda) in the western Mediterranean Sea. International Commission for the Conservation of Atlantic Tunas Collective Volume of Scientific Papers, v. 62, n. 5, p. 1649-1670, 2008.

VALENTINI, H.; CARDOSO, R. D. Análise da pesca da sardinha verdadeira, Sardinella brasiliensis, na costa sudeste-sul do Brasil. Atlântica, v. 13, n. 1, p. 45-54, 1991.

VALENTINI, H.; D'INCAO, F.; RODRIGUES, L. F.; NETO, J.; RAHN, E. Análise da pesca do camarão-rosa (Penaeus brasiliensis e Penaeus paulensis) nas regiões sudeste e sul do Brasil. Atlântica, v. 13, n. 1, p. 143-157, 1991a.

VALENTINI, H.; D'INCAO, F.; RODRIGUEZ, L. F.; REBELO NETO, J. E.; DOMIT, L. G. Análise da pesca do camarão-sete-barbas (Xiphopenaeus kroyeri) nas regiões sudeste e sul do Brasil. Atlântica, v. 13, n. 1, p. 171177.1991b

VALENTINI, H.; PEZZUTO, P. R. Análise das principais pescarias comerciais da região Sudeste-Sul do Brasil com base na produção controlada do período 1986-2004. São Paulo: Instituto Oceanográfico - USP, 2006.

VASCONCELLOS, M.; GASALLA, M. A. Fisheries catches and the carrying capacity of marine ecosystems in southern Brasil. Fisheries Research, v. 50, n. 3, p. 279-295, 2001.

VASCONCELLOS, M.; MACKINSON, S.; SLOMAN, K; PAULY, D. The stability of trophic mass-balance models of marine ecosystems: a comparative analysis. Ecological Modelling, v. 100, n. 1-3, p. 125-134, 1997.

VASKE-JUNIOR, T.; VOOREN, C. M.; LESSA, R. P. Feeding habits of four species of Istiophoridae (Pisces: Perciformes) from northeastern Brazil. Environmental Biology of Fishes, v. 70, n. 3, p. 293-304, 2004.

VASKE-JUNIOR.; T.; RÍNCON-FILHO, G. Conteúdo estomacal dos tubarões azul (Prionace glauca) e anequim (Isurus oxyrinchus) em águas oceânicas no sul do Brasil. Revista Brasileira de Biologia, v. 58, n. 3, p. 445-452, 1998.

VAZ-DOS-SANTOS, A. M.; ROSSI-WONGTSCHOWSKI, C. Age and growth of the Argentine hake Merluccius hubbsi Marini, 1933 in the Brazilian SouthSoutheast Region during 1996-2001. Neotropical ichthyology, v. 5, n. 3, p. 375-386, 2007.

VERA, G. R. Modelagem ecotrófica da plataforma continental e talude das regiões Sudeste e Sul do Brasil. 2006. 46 f. Dissertação (Mestrado) - Instituto Oceanográfico, Universidade de São Paulo. 
VIANNA, M.; VERANI, J. R. Biologia populacional de Orthopristis ruber (teleostei, haemulidae) espécie acompanhante da pesca de arrasto do camarão-rosa, no sudeste brasileiro. Atlântica, v. 23, n. 1, p. 27-36, 2002.

VIANNA, M.; ALMEIDA, T. Bony fish bycatch in the southern Brazil pink shrimp (Farfantepenaeus brasiliensis and F. paulensis) fishery. Brazilian Archives of Biology and Technology, v. 48, n. 4, p. 611-623, 2005.

VILELA, M. J. A. Idade, crescimento, alimentação e avaliação do estoque de bonito-listrado, explorado na região sudeste-sul do Brasil. 1990. $81 \mathrm{f}$. Dissertação (Mestrado) - Universidade Federal do Rio Grande.

VIVEKANANDAN, E.; SRINATH, M.; KURIAKOSE, S. Fishing the marine food web along the Indian coast. Fisheries Research, v. 72, n. 2/3, p. 241-252, 2005.

WAKABARA, Y. TARARAM, A. S.; FLYNN, M. N. A macrofauna como alimento para os peixes jovens da região estuarina-lagunar de Cananéia. In: ENCONTRO BRASILEIRO DE ICTIOLOGIA, 10., 1993, São Paulo. Resumos..., São Paulo: Universidade de São Paulo, 1993. p. 166.

WHITEHEAD, J. P.; NELSON, G. J.; WONGRATANA, T. FAO species catalogue: v. 7, part 2 - Clupeoid fishes of the world (suborder Clupeiodei). FAO Fisheries Synopsis, n. 125, p. 305-579, 1988.

WINIK, S.; CARNEIRO, M. H.; MENDONÇA, J. T. 2007. Alimentação da Guaivira Oligoplites saliens (BLOCH, 1793) (PERCIFORMES: CARANGIDAE) proveniente da pesca da região de Cananéia-SP. Série Relatórios Técnicos. Instituto de Pesca, São Paulo, n. 27: p.1-13, 2007.

WORM, B.; MYERS, R. A. Meta-analysis of cod-shrimp interactions reveals topdown control in oceanic food webs. Ecology, v. 84, n. 1, p. 162-173, 2003.

XIMENES, M. O. C. Idade e crescimento da serra, Scomberomorus brasiliensis, no Estado do Ceara (Brasil). Arquivos de Ciências do Mar, v. 21, n. 1/2, p. 47-54, 1981.

XIMENES, M. O. C.; ANDRADE, M. F.; FONTELES FILHO, A. A.; TUBINO, R. A.; PAIVA, M. P. Idade e crescimento do namorado Pseudopercis numida, no sudeste do Brasil. In: ENCONTRO BRASILEIRO DE ICTIOLOGIA, 12., 1997, São Paulo. Resumos ... São Paulo: IO-USP, 1997. p. 206.

XIMENES-CARVALHO, M. O.; FONTELES FILHO, A. A.; TUBINO, R. A.; PAIVA, M. P. Parâmetros de crescimento e mortalidade do Cherne, Epinephelus niveatus (Valenciennes) (Osteichthyes: Serranidae), no sudeste do Brasil. Arquivos de Ciências do Mar, v. 32, p. 111-117, 1999.

XIMENES-CARVALHO, M. O.; FONTELES-FILHO, A. A.; PAIVA, M. P. Age and growth of common snook, Centropomus undecimalis (Bloch, 1792) and fat snook, Centropomus parellelus (Poey, 1860), off southeastern Brazil. Arquivos de Ciencias do Mar, v. 40, n. 1, p. 78-88, 2007.

ZABOUKAS, N.; MEGALOFONOU, P. Age estimation of the Atlantic bonito in the eastern Mediterranean Sea using dorsal spines and validation of the method. Scientia Marina, v. 71, n. 4, p. 691-698, 2007. 
ZANETI PRADO, E. M. 1979. Bionomia, ciclo de vida de Umbrina canosai (BERG, 1895). Boletim do Instituto Oceanográfico, São Paulo, v. 28, n. 1, p. 119-165, 1979.

ZAVALA-CAMIN, L. A. Ocorrência de atuns no sudeste e sul do Brasil. Boletim do Instituto de Pesca, São Paulo, v. 3, n. 3, p. 37-52, 1974. 


\section{Anexos}

Anexo 1. Quadro com o histórico das alterações da moeda nacional.

\begin{tabular}{|c|c|c|c|c|c|c|}
\hline $\begin{array}{l}\text { sPlano } \\
\text { Econômico }\end{array}$ & $\begin{array}{l}\text { Moeda } \\
\text { Corrente }\end{array}$ & Símbolo & $\begin{array}{l}\text { ×Período de } \\
\text { Validade }\end{array}$ & $\begin{array}{c}\text { sFundamento } \\
\text { Legal }\end{array}$ & sEquivalência & $\begin{array}{c}\text { yFator de } \\
\text { conversão para } \\
\mathbf{R} \$ \\
\end{array}$ \\
\hline- & Real & $\mathrm{R}$ & $\begin{array}{l}\text { Período Colonial } \\
\text { até } 7 / 10 / 1833\end{array}$ & $\begin{array}{c}\text { Alvará s/n de } \\
1 / 09 / 1808\end{array}$ & $\begin{array}{c}\mathrm{R} \$ 200= \\
1 / 8 \text { de ouro de } 22 \mathrm{~K}\end{array}$ & $1 /\left(1000^{5} * 2750\right)$ \\
\hline- & Mil-Réis & Rs & $\begin{array}{c}8 / 10 / 1833 \text { até } \\
31 / 10 / 1942\end{array}$ & $\begin{array}{l}\text { Lei no } 59 \text {, de } \\
8 / 10 / 1833\end{array}$ & $\begin{array}{c}\text { Rs } \$ 500= \\
1 / 8 \text { de ouro de } 22 \mathrm{~K}\end{array}$ & $1 /\left(1000^{4} * 2750\right)$ \\
\hline- & Cruzeiro & $\mathrm{Cr} \$$ & $\begin{array}{l}1 / 11 / 1942 \text { até } \\
30 / 11 / 1964\end{array}$ & $\begin{array}{l}\text { Decreto-Lei no } \\
4791, \text { de } \\
5 / 10 / 1942\end{array}$ & $\begin{array}{c}\mathrm{Cr} \$ 1,00= \\
\text { Rs } \$ 000(1 \text { cruzeiro } \\
\text { corresponde a } 1000 \\
\text { réis })\end{array}$ & $1 /\left(1000^{4} * 2750\right)$ \\
\hline- & $\begin{array}{c}\text { Cruzeiro } \\
\text { (eliminado os } \\
\text { centavos) }\end{array}$ & $\mathrm{Cr} \$$ & $\begin{array}{l}\text { 1/12/1964 até } \\
12 / 02 / 1967\end{array}$ & $\begin{array}{l}\text { Lei } n^{\circ} 4511 \text {, de } \\
\text { 1/12/1964 }\end{array}$ & $\operatorname{Cr} \$ 1=\operatorname{Cr} \$ 1,00$ & $1 /\left(1000^{4} * 2750\right)$ \\
\hline- & $\begin{array}{l}\text { Cruzeiro } \\
\text { Novo (volta } \\
\text { dos } \\
\text { centavos) }\end{array}$ & $\mathrm{NCr} \$$ & $\begin{array}{l}\text { 13/02/1967 até } \\
\text { 14/05/1970 }\end{array}$ & $\begin{array}{l}\text { Decreto-Lei } n^{0} 1 \\
\text { de } 13 / 11 / 1965\end{array}$ & $\begin{array}{l}\operatorname{NCr} \$ 1,00= \\
\operatorname{Cr} \$ 1.000\end{array}$ & $1 /\left(1000^{3} * 2750\right)$ \\
\hline- & Cruzeiro & $\mathrm{Cr} \$$ & $\begin{array}{l}\text { 15/05/1970 até } \\
14 / 08 / 1984\end{array}$ & $\begin{array}{c}\text { Resolução do } \\
\text { Banco Central noo } \\
\text { 144, de 31/03/70 }\end{array}$ & $\begin{array}{l}\operatorname{Cr} \$ 1,00= \\
\operatorname{NCr} \$ 1,00\end{array}$ & $1 /\left(1000^{3} * 2750\right)$ \\
\hline- & $\begin{array}{l}\text { Cruzeiro } \\
\text { (eliminado os } \\
\text { centavos) }\end{array}$ & $\mathrm{Cr} \$$ & $\begin{array}{l}\text { 15/08/1984 até } \\
27 / 02 / 1986\end{array}$ & $\begin{array}{c}\text { Lei no } 7214 \text {, de } \\
15 / 08 / 84\end{array}$ & $\operatorname{Cr} \$ 1=\operatorname{Cr} \$ 1,00$ & $1 /\left(1000^{3} * 2750\right)$ \\
\hline $\begin{array}{l}\text { Cruzado I: Fev } \\
\text { 1986 Cruzado } \\
\text { II: Jun } 1987\end{array}$ & $\begin{array}{l}\text { Cruzado } \\
\text { (volta dos } \\
\text { centavos) }\end{array}$ & $\mathrm{Cz} \$$ & $\begin{array}{c}\text { 28/02/1986 até } \\
15 / 01 / 1989\end{array}$ & $\begin{array}{c}\text { Decreto-Lei no } \\
2283, \text { de } \\
27 / 02 / 1986\end{array}$ & $\begin{array}{l}\mathrm{Cz} \$ 1,00= \\
\mathrm{Cr} \$ 1.000\end{array}$ & $1 /\left(1000^{2} * 2750\right)$ \\
\hline $\begin{array}{c}\text { Verão I - Jan } \\
1989 \text { Verão II - } \\
\text { Mai } 1989\end{array}$ & $\begin{array}{l}\text { Cruzado } \\
\text { Novo }\end{array}$ & $\mathrm{NCz} \$$ & $\begin{array}{l}6 / 01 / 1989 \text { até } \\
15 / 03 / 1990\end{array}$ & $\begin{array}{c}\text { Medida Provisória } \\
\text { no } 32, \text { de } \\
15 / 01 / 1989 \\
\text { convertida em Lei } \\
\text { no } 7730, \text { de } \\
31 / 01 / 1989\end{array}$ & $\begin{array}{l}\mathrm{NCz} \$ 1,00= \\
\mathrm{Cz} \$ 1.000,00\end{array}$ & $1 /(1000 * 2750)$ \\
\hline $\begin{array}{l}\text { Color I - Mar } \\
1990 \text { Color II - } \\
\text { Jan } 1991\end{array}$ & Cruzeiro & $\mathrm{Cr} \$$ & $\begin{array}{l}16 / 03 / 1990 \text { até } \\
31 / 07 / 1993\end{array}$ & $\begin{array}{c}\text { Medida Provisória } \\
\text { no } 168, \text { de } \\
15 / 03 / 1990 \\
\text { convertida na Lei } \\
\text { no } 8024, \text { de } \\
12 / 04 / 1990\end{array}$ & $\begin{array}{l}\mathrm{Cr} \$ 1,00= \\
\mathrm{NCz} \$ 1,00\end{array}$ & $1 /(1000 * 2750)$ \\
\hline $\begin{array}{c}\text { Transição para } \\
\text { o Real - Ago } \\
1993\end{array}$ & Cruzeiro Real & $\mathrm{CR} \$$ & $\begin{array}{l}\text { 1/08/1993 até } \\
30 / 06 / 1994\end{array}$ & $\begin{array}{c}\text { Medida Provisória } \\
\text { no } 336 \text {, de } \\
28 / 07 / 1993, \\
\text { convertida em Lei } \\
\text { no } 8697, \text { de } \\
27 / 08 / 1993, \text { e } \\
\text { Resolução } \\
\text { BACEN no } 2010 \text {, } \\
\text { de } 28 / 07 / 1993\end{array}$ & $\begin{array}{c}\operatorname{CR} \$ 1,00= \\
\operatorname{Cr} \$ 1.000,00\end{array}$ & $1 / 2750$ \\
\hline Real - Jul 1994 & Real & $R \$$ & Desde 1/07/1994 & $\begin{array}{l}\text { Leis no } 8880 \text {, de } \\
27 / 05 / 1994, \text { e } \\
9069, \text { de } \\
\text { 29/06/1995 }\end{array}$ & $\begin{array}{c}\mathrm{R} \$ 1,00= \\
\mathrm{CR} \$ 2.750,00\end{array}$ & 1 \\
\hline
\end{tabular}

Fonte: IPEA, 2008 (Banco Central e IOB - Informações Objetivas, Elaboração; IBGE, Diretoria de Pesquisas, Departamento de Índices de Preços. Quadro divulgado no site do IBGE na internet). 
Anexo 2. Categorias de pescado obtidas das estatísticas de desembarque e de comercialização, seus respectivos nomes científicos e seus parâmetros ecológicos associados quando possível, sendo o Comprimento Máximo (Lmáx) em milímetros, Profundidade (Prof) e Isóbata Máxima de ocorrência (Isob. Máx.) em metros, Longevidade (Long) em anos e Nível Trófico (NT) adimensional e Habitat (Hab) e Grupo Trófico (GT) nominais ( ${ }^{*}$ engloba só os dados de desembarque, ${ }^{* *}$ engloba ambos os dados, mercado e desembarques e " "engloba somente os dados de mercado). Das categorias "beto", "calsa", "canjuda", "celi", "céu", "cobra", "congrio-pré", "grelhado", "grumatam", "guaia", "gurujuba”, "kamaboco", "kindai”, "lacraia”, "lagostim”, "lei", "mistura”, "ovas", "ovas de tainha”, "paranaguai”, "peixe-boi", "rosado", "samaritaca", "senitra", "serpia", "serrilha", "serrote", "sete-volta", "tambica", "tartaruga", "umesati" não foram consideradas nas análises, ou por não ser conhecido o nome científico ou por falta de dados biológicos.

\begin{tabular}{|c|c|c|c|c|c|c|c|c|c|}
\hline Categorias & Espécie & $\mathrm{Hab}$ & GT & NT & Lmáx & Long & Prof & $\begin{array}{l}\text { Isob. } \\
\text { Máx. }\end{array}$ & Referências \\
\hline abrótea, brota** & Urophycis brasiliensis & dem & pis & 3,7 & 647,5 & 27,7 & 83,0 & 190,0 & $\begin{array}{l}\text { FishBase; Natali-Neto, 1994; Martins, 2000; Haimovici e Velasco, } \\
\text { 2001; Gasalla, 2004a; Andrade et al., 2004; Cergole et al., 2005; } \\
\text { Haimovici et al., 2008 }\end{array}$ \\
\hline agulha & $\begin{array}{c}\text { Hyporhamphus unifasciatus, } \\
\text { Hemiramphus brasiliensis, Strongylura } \\
\text { marina }\end{array}$ & dem & - & 2,7 & 642,5 & 5,2 & 8,3 & 20,0 & FishBase, Carvalho-Filho, 1992 \\
\hline $\begin{array}{l}\text { agulhão, basho, } \\
\text { kajiki, maka }\end{array}$ & $\begin{array}{c}\text { Istiophorus albicans, Makaira } \\
\text { nigricans, Tetrapturus albidus, } T \text {. } \\
\text { pfluegeri }\end{array}$ & pel & pis & 4,4 & 2204,8 & 15,1 & 66,7 & 5000,0 & $\begin{array}{l}\text { FishBase; Carvalho-Filho, 1992; Freire et al., 1999; Vaske-Júnior et al., } \\
\text { 2004; Gasalla et al., } 2007\end{array}$ \\
\hline agulhão-branco* & Tetrapturus albidus, T. pfluegeri & pel & pis & 4,4 & 2204,8 & 15,1 & 66,7 & 3500,0 & $\begin{array}{l}\text { FishBase; Carvalho-Filho, 1992; Freire et al., 1999; Vaske-Júnior et al., } \\
\text { 2004; Gasalla et al., } 2007\end{array}$ \\
\hline agulhão-negro* & Makaira nigricans & pel & pis & 4,4 & 2204,8 & 15,1 & 66,7 & 5000,0 & $\begin{array}{l}\text { FishBase; Carvalho-Filho, 1992; Freire et al., 1999; Vaske-Júnior et al., } \\
\text { 2004; Gasalla et al., } 2007\end{array}$ \\
\hline agulhão-vela* & Istiophorus albicans & pel & pis & 4,4 & 2204,8 & 15,1 & 66,7 & 3500,0 & $\begin{array}{l}\text { FishBase; Carvalho-Filho, 1992; Freire et al., 1999; Vaske-Júnior et al., } \\
\text { 2004; Gasalla et al., } 2007\end{array}$ \\
\hline $\begin{array}{l}\text { albacora- } \\
\text { bandolim* }\end{array}$ & & pel & pis & 4,3 & 1738,0 & 40,0 & 216,7 & 5000,0 & $\begin{array}{l}\text { FishBase; Vasconcellos e Gasalla, 2001; Gasalla et al., 2007; Gunn et } \\
\text { al., } 2008\end{array}$ \\
\hline albacora-branca* & Thunnus alalunga & pel & pis & 4,3 & 1738,0 & 40,0 & 216,7 & 4000,0 & $\begin{array}{l}\text { FishBase; Carvalho-Filho, 1992; Vasconcellos e Gasalla, 2001; Gasalla } \\
\text { et al., 2007; Gunn et al., } 2008\end{array}$ \\
\hline albacora-lage* & Thunnus albacares & pel & pis & 4,3 & 1738,0 & 40,0 & 216,7 & 4000,0 & $\begin{array}{l}\text { FishBase; Carvalho-Filho, 1992; Vasconcellos e Gasalla, 2001; Gasalla } \\
\text { et al., 2007; Gunn et al., } 2008\end{array}$ \\
\hline albacorinha* & Thunnus atlanticus & pel & pis & 4,3 & 1738,0 & 40,0 & 216,7 & 5000,0 & $\begin{array}{l}\text { FishBase; Carvalho-Filho, 1992; Vasconcellos e Gasalla, 2001; Gasalla } \\
\text { et al., 2007; Gunn et al., } 2008\end{array}$ \\
\hline
\end{tabular}




\section{Anexo 2. Continuação}

\begin{tabular}{|c|c|c|c|c|c|c|c|c|c|}
\hline anchovas, enchovas & Pomatomus saltatrix & pel & pis & 4,1 & 1200,0 & 9,0 & 73,3 & 180,0 & $\begin{array}{l}\text { FishBase; Figueiredo e Menezes, 1980; Carvalho-Filho, 1992; } \\
\text { Furia, 1996; Vasconcellos e Gasalla, 2001; Cergole et al., 2005; } \\
\text { Leal e Bemvenuti, } 2006\end{array}$ \\
\hline anequim $^{\star \star}$ & Isurus oxyrinchus & pel & pis & 4,4 & 3500,0 & 25,0 & 125,0 & 4000,0 & FishBase; Figueiredo, 1977; Gasalla et al., 2007 \\
\hline $\begin{array}{l}\text { atum, atum-dorimá, } \\
\text { albacora, bati, kiwada, } \\
\text { kimeji, tombo** }\end{array}$ & $\begin{array}{l}\text { Thunnus alalunga, } T \text {. albacares, } T \text {. } \\
\text { atlanticus, } T \text {. obesus }\end{array}$ & pel & pis & 4,3 & 1738,0 & 40,0 & 216,7 & 5000,0 & $\begin{array}{l}\text { FishBase; Carvalho-Filho, 1992; Vasconcellos e Gasalla, 2001; } \\
\text { Oliveira et al., 2005; Gasalla et al., 2007; Gunn et al., } 2008\end{array}$ \\
\hline badejo & Mycterope & dem & pis & 3,7 & 1240,0 & 34,0 & 13,0 & 100,0 & $\begin{array}{l}\text { FishBase; Figueiredo e Menezes, 1980; Carvalho-Filho, 1992; } \\
\text { Vasconcellos e Gasalla, } 2001\end{array}$ \\
\hline bagre ${ }^{\star \star}$ & $\begin{array}{l}\text { Arius spp., Cathorops spixii, } \\
\text { Genidens barbus, G. genidens, } \\
\text { Netuma barba }\end{array}$ & dem & - & 3,0 & 657,5 & - & 20,0 & 20,0 & $\begin{array}{l}\text { FishBase; Figueiredo e Menezes, 1978; Lowe-McConnell, 1999; } \\
\text { Haimovici, 1997; Martins, 2000; FishBase; Gasalla, 2004⿳亠丷厂 }\end{array}$ \\
\hline baiacu & Lagocephalus laevigatus & dem & & - & 295,0 & - & 8,3 & 100,0 & $\begin{array}{l}\text { FishBase; Carvalho-Filho, 1992; Natali-Neto, 1994; Vianna e } \\
\text { Verani, 1997; Natali-Neto, } 1994\end{array}$ \\
\hline batata** & Lopholatilus villarii & dem & & 4,2 & 1153,0 & 52,2 & 166,7 & 200,0 & $\begin{array}{l}\text { FishBase; Figueiredo e Menezes, 1980; LEITE-JUNIOR, 1999; } \\
\text { Ávila-da-Silva, 2002; Cergole et al., 2005; Gasalla et al., } 2007\end{array}$ \\
\hline berbigão, berbigão limpo & Anomalocardia brasiliana & dem & pla & 2,0 & - & - & - & 10,0 & SealifeBase \\
\hline $\begin{array}{l}\text { betara, papa-terra, perna- } \\
\text { de-moça }\end{array}$ & Menticirrhus americanus, M. littoralis & dem & - & 3,3 & 438,3 & 6,5 & 51,0 & 60,0 & $\begin{array}{l}\text { FishBase; Menezes e Figueiredo, 1980; Castilho, 1986; Santos, } \\
\text { 1992; Natali-Neto, 1994; Lowe-McConnel, 1999; Martins, 2000; } \\
\text { Leal e Bemvenuti, } 2006\end{array}$ \\
\hline bijupirá & Rachycentron canadum & - & pis & 3,9 & 2000,0 & - & 410,0 & 1200,0 & FishBase; Figueiredo e Menezes, 1980; Fredoú et al., 2006 \\
\hline bonito & $\begin{array}{l}\text { Auxis thazard, Euthynnus } \\
\text { alletteratus, Katsuwonus pelamis }\end{array}$ & pel & pis & 4,2 & 830,0 & 13,6 & 340 & 200,0 & $\begin{array}{l}\text { FishBase; Vilela, 1990; Carvalho-Filho, 1992; Vasconcellos e } \\
\text { Gasalla, 2001; Rossi-Wongtschowski et al., } 2006\end{array}$ \\
\hline bonito-cachorro* & $\begin{array}{l}\text { Auxis thazard, Euthynnus } \\
\text { alletteratus, Katsuwonus pelamis }\end{array}$ & pel & pis & 4,2 & 830,0 & 13,6 & 66,7 & 200,0 & $\begin{array}{l}\text { FishBase; Vilela, 1990; Carvalho-Filho, 1992; Vasconcellos e } \\
\text { Gasalla, 2001; Rossi-Wongtschowski et al., } 2006\end{array}$ \\
\hline bonito-listrado* & $\begin{array}{l}\text { Auxis thazard, Euthynnus } \\
\text { alletteratus, Katsuwonus pelamis }\end{array}$ & pel & pis & 4,2 & 830,0 & 13,6 & 340 & 400,0 & $\begin{array}{l}\text { FishBase; Vilela, 1990; Carvalho-Filho, 1992; Vasconcellos e } \\
\text { Gasalla, 2001; Rossi-Wongtschowski et al., } 2006\end{array}$ \\
\hline bonito-pintado* & $\begin{array}{l}\text { Auxis thazard, Euthynnus } \\
\text { alletteratus, Katsuwonus pelamis }\end{array}$ & pel & pis & 4,2 & 830,0 & 13,6 & 66,7 & 200,0 & $\begin{array}{l}\text { FishBase; Vilela, 1990; Carvalho-Filho, 1992; Vasconcellos e } \\
\text { Gasalla, 2001; Rossi-Wongtschowski et al., } 2006\end{array}$ \\
\hline
\end{tabular}




\section{Anexo 2. continuação}

\begin{tabular}{|c|c|c|c|c|c|c|c|c|c|}
\hline cabra** & Prionotus nudigula, P. punctatus & dem & - & 3,4 & 365,0 & - & 60,0 & 100,0 & $\begin{array}{l}\text { FishBase; Figueiredo e Menezes, 1980; Wakabara et al., 1993; Natali- } \\
\text { Neto, 1994; Gasalla, 1995; Haimovici, 1997; Martins, 2000; Lizama e } \\
\text { Takemoto, 2000; Cergole et al., 2005; Gasalla et al., } 2007\end{array}$ \\
\hline $\begin{array}{l}\text { cação, cação } \\
\text { congelado }\end{array}$ & $\begin{array}{l}\text { várias espécies das famílias: Lamnidae, } \\
\text { Carcharhinidae, Triakidae, Odontaspididae, } \\
\text { Sphyrnidae, Alopiidae e Squalidae. }\end{array}$ & dem & pis & 4,1 & 3179,17 & 26,2 & 106,3 & 500,0 & Basedo nas referências das outras categorias de cação \\
\hline cação-anjo & Squatina spp. & dem & pis & 3,9 & 1323,3 & 23,2 & 136,7 & 150,0 & $\begin{array}{l}\text { FishBase; Figueiredo, 1977; Soares et al., 1991; Haimovici, 1997; } \\
\text { Gasalla, 2004a; Cergole et al., 2005; Gasalla et al., } 2007\end{array}$ \\
\hline cação-azul* & Prionace glauca & pel & pis & 4,2 & 4000,0 & - & 150,0 & 2000,0 & $\begin{array}{l}\text { FishBase; Figueiredo, 1977; Carvalho-Filho, 1992; Vaske-Júnior e } \\
\text { Rincón-Filho, 1998; Legat, 2001; Gasalla, 2004a; Cergole et al., 2005; } \\
\text { Gasalla et al., 2007 }\end{array}$ \\
\hline $\begin{array}{l}\text { cação-caçoa, } \\
\text { mangona }\end{array}$ & Carcharias taurus & dem & pis & 3,9 & 3500 & 21,4 & 63,7 & - & Fishbase; Gasalla et al., 2007 \\
\hline $\begin{array}{l}\text { cação- } \\
\text { caçonete }\end{array}$ & Rhizoprionodon spp. & dem & pis & 3,9 & 1100,0 & 8,5 & 43,3 & 100,0 & FishBase; Figueiredo, 1977; Silva e Almeida, 2001; Gasalla, 2004a \\
\hline cação-enguia & & dem & pis & - & - & 42,2 & 103,7 & - & \\
\hline $\begin{array}{l}\text { cação- } \\
\text { machote }\end{array}$ & Carcharhinus brevipinna, C. signatus & dem & pis & 4,4 & 1972,5 & 42,0 & 33,3 & - & $\begin{array}{l}\text { FishBase; Castro, 1983; Silva 2001; Soares et al., 2001; Gasalla, } \\
\text { 2004a; Cergole et al., } 2005\end{array}$ \\
\hline $\begin{array}{l}\text { cação-martelo, } \\
\text { cambeva }^{\star *}\end{array}$ & Sphyrna lewini, S. zygaena & dem & pis & 4,3 & 3910,5 & - & 186,7 & - & Figueiredo, 1977; Kotas, 2004; Rossi-Wongtschowski et al., 2006 \\
\hline $\begin{array}{l}\text { cação-raia, } \\
\text { raias }^{\star \star}\end{array}$ & $\begin{array}{c}\text { Atlantoraja spp., Dasyatis spp., Gymnura } \\
\text { altavela, Rioraja agassizi }\end{array}$ & dem & pis & 3,8 & 733,3 & 46,8 & 66,7 & 100,0 & $\begin{array}{l}\text { FishBase; Figueiredo, 1977; Carvalho-Filho, 1992; Natali-Neto, 1994; } \\
\text { Vasconcellos e Gasalla, 2001; Bernardes et al., 2005; Cergole et al., } \\
\text { 2005; Casarini, 2006; Gasalla et al., 2007; Haimovici et al., } 2008\end{array}$ \\
\hline cação-viola & Rhinobatos horkelli & dem & - & 3,6 & 1185,0 & 15,4 & 50,0 & 100,0 & $\begin{array}{l}\text { Figueiredo, 1977; Lessa, 1982; Haimovici, 1997; Vasconcellos e } \\
\text { Gasalla, 2001; Gasalla, 2004a; Bernardes et al., 2005, Cergole et al., } \\
\text { 2005; Haimovici et al., 2008; }\end{array}$ \\
\hline calamar & Illex argentinus & pel & - & 4,0 & 395,0 & - & 500,0 & 500,0 & $\begin{array}{l}\text { Bazzino e Quiñones, 2001; Rossi-Wongtschowski et al., 2006; Gasalla } \\
\text { et al., 2007; Jaureguizar e Milessi, 2008; Haimovici et al., } 2008\end{array}$ \\
\hline $\begin{array}{l}\text { camarão- } \\
\text { cristalino }\end{array}$ & Parapeneus americanus, Plesionika edwardsii & dem & - & 2,0 & - & - & 10,0 & & $\begin{array}{l}\text { Gasalla e Rossi-Wongtschowski, 2004; Severino-Rodrigues et al., } \\
2007\end{array}$ \\
\hline
\end{tabular}


Anexo 2. continuação

\begin{tabular}{|c|c|c|c|c|c|c|c|c|c|}
\hline camarão-legítimo & Litopenaeus schimitti & dem & - & 2,0 & 205,0 & - & 41,7 & 100,0 & SealifeBase; Tararam et al., 1993; Gasalla e Rossi-Wongtschowski, 2004 \\
\hline camarão-rosa & $\begin{array}{l}\text { Farfantepenaeus } \\
\text { brasiliensis, F. paulensis, } \\
\text { F. subtilis }\end{array}$ & dem & - & 2,0 & 229,0 & - & 40,0 & 100,0 & $\begin{array}{l}\text { Corbisier, 1989; Tararam et al., 1993; Leite Jr., 2001; Gasalla e Rossi- } \\
\text { Wongtschowski, 2004; Haimovici et al., 2008; Branco-Lunardon et al., } 2006\end{array}$ \\
\hline $\begin{array}{l}\text { camarão-sete-barbas, } \\
\text { camarão-sete-barbas } \\
\text { limpo }\end{array}$ & Xiphopenaeus kroyeri & dem & - & 2,1 & 210,0 & - & 43,3 & 100,0 & Branco et al., 1999; Vasconcellos e Gasalla, 2001 \\
\hline camarão-vermelho & Pleoticus muelleri & dem & - & 2,2 & 210,0 & - & 467,0 & 600,0 & Pezzuto et al., 2005; Haimovici et al., 2006; Gasalla et al., 2007 \\
\hline camarões* & Penaeidae & dem & - & 2,3 & 212,90 & - & 31,1 & 100,0 & médias das outras categorias camarões \\
\hline canguá & $\begin{array}{l}\text { Ctenosciaena } \\
\text { gracilicirrhus }\end{array}$ & dem & - & 3,3 & 210,0 & 7,3 & 36,7 & 100,0 & $\begin{array}{l}\text { FishBase; Carvalho-Filho, 1992; McConnel, 1999; Menezes e Figueiredo, 1980; } \\
\text { Rios, 1994; Gasalla, 1995; Gasalla, 2004a; Gomes, 2004; }\end{array}$ \\
\hline caranguejo & Ucides cordatus & dem & - & - & - & - & - & 20,0 & \\
\hline $\begin{array}{l}\text { caranguejo-de- } \\
\text { profundidade }\end{array}$ & Chaceon spp. & dem & & 2,3 & - & - & 600,0 & 700,0 & Manning e Holthuts, 1989; Gasalla et al., 2007 \\
\hline caranha, vermelho & Lutjanus spp. & - & pis & 4,0 & 400,0 & 19,9 & 135,0 & 200,0 & $\begin{array}{l}\text { FishBase; Alegria e Menezes, 1970; Menezes e Figueiredo, 1980; Carvalho-Filho, } \\
\text { 1992; Burton, 2002; Vasconcellos e Gasalla, 2001; Araujo et al., 2002; Gomes, } \\
\text { 2004; Rezende e Ferreira, 2004; Fischer et al., 2005 }\end{array}$ \\
\hline carapau & Caranx crysus & pel & pis & 4,1 & 400,0 & - & 33,3 & 100,0 & $\begin{array}{l}\text { FishBase; Menezes e Figueiredo, 1980; Carvalho-Filho, 1992; Gasalla, 2004a; } \\
\text { Fredoú et al., } 2006\end{array}$ \\
\hline carapicu, carapeba & $\begin{array}{l}\text { Diapterus auratus, } \\
\text { Eucinostomus argenteus }\end{array}$ & dem & - & 3,1 & 400,0 & - & 32,3 & 50,0 & FishBase; Natali-Neto, 1994; Gasalla, 1995; Furia, 1996 \\
\hline caratinga & Eugerres brasilianus & dem & - & 3,4 & 400,0 & - & 32,3 & 50,0 & FishBase; Sierra et al., 1994 \\
\hline $\begin{array}{l}\text { castanha, chora- } \\
\text { chora }^{\star \star}\end{array}$ & Umbrina canosai & dem & - & 3,4 & 447,7 & 7,3 & 71,0 & 200 & $\begin{array}{l}\text { FishBase; Zaneti-Prado, 1979; Menezes e Figueiredo, 1980; Isaac-Nahrum, 1989; } \\
\text { Natali-Neto, 1994; McConnel, 1999; Martins, 2000; Lizama e Takemoto, 2000; } \\
\text { Vasconcellos e Gasalla, 2001; Gasalla, 2004a; Rossi-Wongtschowski et al., 2006; } \\
\text { Haimovici et al., 2006; Haimovici et al., } 2008\end{array}$ \\
\hline cavala & $\begin{array}{l}\text { Acanthocybium solandri, } \\
\text { Scomberomorus cavalla }\end{array}$ & pel & pis & 4,3 & 2250,0 & 7,9 & 48,3 & 300,0 & FishBase; Vasconcellos e Gasalla, 2001; Sabatié et al., 2003; McBride et al., 2008 \\
\hline $\begin{array}{l}\text { cavalinha, cavalinha } \\
\text { congelada, periquito }\end{array}$ & Scomber japonicus & pel & pla & 3,1 & 419,0 & - & 52,3 & 300,0 & $\begin{array}{l}\text { FishBase; Mendo, 1984; Martins, 2000; Haimovici e Velasco, 2001; Vasconcellos e } \\
\text { Gasalla, } 2001\end{array}$ \\
\hline
\end{tabular}




\section{Anexo 2. continuação}

\begin{tabular}{|c|c|c|c|c|c|c|c|c|c|}
\hline cherne $^{\star \star}$ & Epinephelus niveatus & dem & pis & 4,1 & 1358,0 & 61,5 & 343,3 & 400,0 & $\begin{array}{l}\text { FishBase; Fischer et al., 1987; Carvalho-Filho, 1992; Heemstra e Randall, 1993; } \\
\text { Natali-Neto, 1994; Haimovici et al., 1994; Ximenes-Carvalho et al., 1999; Martins, } \\
\text { 2000; Haimovici e Velasco, 2001; Deudero, 2001; Vasconcellos e Gasalla, 2001; } \\
\text { Gasalla, 2004a; Gasalla et al., 2007; }\end{array}$ \\
\hline cioba, realito & $\begin{array}{l}\text { Lutjanus analis, Rhomboplites } \\
\text { aurorubens, Ocyurus chrysurus }\end{array}$ & dem & - & 3,9 & 750,0 & 22,5 & 41,7 & 300,0 & $\begin{array}{l}\text { FishBase; Menezes e Figueiredo, 2000; Mason e Manooch, 1985; Palazon e } \\
\text { Gonzalez, 1986; Carvalho-Filho, 1992; Vasconcellos e Gasalla, 2001; Burton, } \\
\text { 2002; Araújo et al., 2002; Fredoú et al., } 2006\end{array}$ \\
\hline $\begin{array}{l}\text { congrio, tira- } \\
\text { vira, vira }\end{array}$ & $\begin{array}{l}\text { Conger orbignyanus, Genypterus } \\
\text { brasiliensis, Ophidion holbrooki, } \\
\text { Percophis brasiliensis, Raneya } \\
\text { fluminensis }\end{array}$ & dem & pis & 3,5 & 817,5 & - & 177,0 & 200,0 & $\begin{array}{l}\text { FishBase; Figueiredo e Menezes, 1978; Natali-Neto, 1994; Mianzan et al., 1996; } \\
\text { Martins, 2000; Haimovici e Velasco, 2001; Gasalla, 2004a; Pucci, 2004; Cergole } \\
\text { et al., 2005; Gasalla et al., 2007; Haimovici et al., } 2008\end{array}$ \\
\hline congrio-rosa & $\begin{array}{l}\text { Genypterus brasiliensis, Ophidion } \\
\text { holbrooki, Raneya fluminensis }\end{array}$ & dem & pis & 3,5 & 817,5 & - & 177,0 & 200,0 & $\begin{array}{l}\text { FishBase; Figueiredo e Menezes, 1978; Natali-Neto, 1994; Mianzan et al., 1996; } \\
\text { Martins, 2000; Haimovici e Velasco, 2001; Gasalla, 2004a; Pucci, 2004; Cergole } \\
\text { et al., 2005; Gasalla et al., 2007; Haimovici et al., } 2008\end{array}$ \\
\hline corcoroca & $\begin{array}{l}\text { Boridia grossodens, Haemulon } \\
\text { plumieri, Orthopristis ruber, } \\
\text { Pomadasys corvinaeformis }\end{array}$ & dem & - & 3,4 & 350,0 & - & 30,0 & 100,0 & $\begin{array}{l}\text { Menezes e Figueiredo, 1980; Isaac-Nahrum, 1989; Wakabara et al., 1993; Natali- } \\
\text { Neto, 1994; Gasalla, 1995; Carvalho e Fonteles-Filho, 1995; Furia, 1996; } \\
\text { Haimovici, 1997; Vianna e Verani, 2002; Leal e Bemvenuti, 2006; Fredoú et al., } \\
\text { 2006; Lunardon-Branco et al., } 2006\end{array}$ \\
\hline corvina** $^{\star *}$ & Micropogonias furnieri & dem & - & 3,3 & 660,0 & 11,1 & 42,0 & 100,0 & $\begin{array}{l}\text { Menezes e Figueiredo, 1980; Carvalho-Filho, 1992; McConnel, 1999; Castro, } \\
\text { 2000; Martins, 2000; Vasconcellos e Gasalla, 2001; Gasalla, 2004a; Cergole et } \\
\text { al., } 2005\end{array}$ \\
\hline dourado** & Coryphaena hippurus & pel & pis & 4,3 & 2000,0 & - & 28,3 & 500,0 & $\begin{array}{l}\text { FishBase; Menezes e Figueiredo, 1980; Palko et al., 1982; Carvalho-Filho, 1992; } \\
\text { Vasconcellos e Gasalla, 2001; Fredoú et al., } 2006\end{array}$ \\
\hline espada ${ }^{\star \star}$ & Trichiurus lepturus & pel & pis & 4,1 & 1626,4 & 24,0 & 164,7 & 300,0 & $\begin{array}{l}\text { FishBase; Portsev, 1980; Furia, 1996; Cergole et al., 1997; Lowe-McConnell, } \\
\text { 1999; Martins, 2000; Vasconcellos e Gasalla, 2001; Magro, 2003; Gasalla, } \\
\text { 2004a; Cergole et al., 2005; Magro, 2006; Gasalla et al., 2007; Haimovici et al., } \\
2008\end{array}$ \\
\hline $\begin{array}{l}\text { espadarte, } \\
\text { marlim, } \\
\text { meca** }^{*}\end{array}$ & Xiphias gladius & pel & pis & 4,2 & 2930,0 & 54,9 & 183,3 & 3000,0 & $\begin{array}{l}\text { FishBase; Carvalho-Filho, 1992; Vasconcellos e Gasalla, 2001; Sun et al , 2002; } \\
\text { Sabatié et al., 2003; Oliveira et al., 2005; Gasalla et al., } 2007\end{array}$ \\
\hline galo** & Selene setapinnis & pel & pis & 3,7 & 400,0 & 13,0 & 33,3 & 100,0 & $\begin{array}{l}\text { Le Loeuff e Intes 1973; Menezes e Figueiredo, 1980; Cergole et al., 1997; } \\
\text { McConnel, 1999; Cergole et al., 2005; }\end{array}$ \\
\hline garoupa & Epinephelus marginatus & dem & pis & 3,7 & 1500,0 & 37,5 & 102,7 & 200,0 & FishBase; Bouchereau et al., 1999; Vasconcellos e Gasalla, 2001; Gilbran, 2007 \\
\hline
\end{tabular}


Anexo 2. continuação

\begin{tabular}{|c|c|c|c|c|c|c|c|c|c|}
\hline gordinho & Peprilus paru & pel & pis & 3,7 & 339,0 & - & 48,7 & 100,0 & $\begin{array}{l}\text { FishBase; Cargo e Schultz, 1966; McConnel, 1999; Martins, 2000; } \\
\text { Haimovici e Velasco, 2001; Gasalla, 2004a; Gomes, 2004; Cergole et al., } \\
2005\end{array}$ \\
\hline $\begin{array}{l}\text { guaivira, } \\
\text { salteira }\end{array}$ & Oligoplites saliens, O. saurus & pel & pis & 3,8 & 433,3 & - & 21,0 & 100,0 & $\begin{array}{l}\text { FishBase; Menezes e Figueiredo, 1980; Sazima e Uieda, 1980; Winik et al, } \\
2007\end{array}$ \\
\hline lagosta & Panulirus spp. & dem & - & 2,6 & - & - & - & 100,0 & Sealifebase; Fernandes, 1985; Vasconcellos e Gasalla, 2001 \\
\hline $\begin{array}{l}\text { lagosta- } \\
\text { sapateira, } \\
\text { cavaquinha }\end{array}$ & Scyllarides spp. & dem & - & - & - & - & 102,0 & 200,0 & Spanier e Lavalli, 1998; Duarte e Gasalla, 2010 \\
\hline lanceta & Thyrsitops lepdopoides & dem & pis & 3,8 & - & - & 126,7 & 300,0 & $\begin{array}{l}\text { Carvalho-Filho, 1992; Nakamura e Parin, 1993; Haimovici et al., 1994; } \\
\text { McConnel, 1999; Figueiredo e Menezes, 2000; Martins, 2000; Gasalla, 2004a; } \\
\text { Gasalla et al., } 2007\end{array}$ \\
\hline linguado** & $\begin{array}{l}\text { Bothus spp., Citharichthys spp., } \\
\text { Cyclopsetta spp., Etropus spp., } \\
\text { Gymnachirus spp., Monolene spp., } \\
\text { Paralichthys spp., Scyacium spp. }\end{array}$ & dem & pis & 3,4 & 406,7 & 12,0 & 67,0 & 200,0 & $\begin{array}{l}\text { FishBase; Figueiredo e Menezes, 2000; Haimovici, 1982; Natali-Neto, 1994; } \\
\text { Gasalla, 1995; Furia, 1996; Chaves e Serenato 1998; McConnel, 1999Leal e } \\
\text { Bemvenuti, 2006; Lizama e Takemoto, 2000; Prisco et al., 2001; Gasalla, } \\
\text { 2004a; Gomes, 2004; Cergole et al., 2005; Vera, 2006; Haimovici et al., 2006; } \\
\text { Leal e Bemvenuti, 2006; Gasalla et al., 2007 }\end{array}$ \\
\hline lua & Lampris guttatus & pel & pla & - & 1800,0 & - & 170,0 & 2000,0 & FishBase; Figueiredo e Menezes, 2000; Zavala-Carmim, 1981 \\
\hline Iula** & Loligo plei, L. sanpaulensis & pel & pis & 3,4 & 200,5 & - & 34,7 & 200,0 & $\begin{array}{l}\text { Laroe, 1967; Martins, 2000; Vasconcellos e Gasalla, 2001; Gasalla, 2004a; } \\
\text { Cergole et al., 2005; Rodrigues, } 2007\end{array}$ \\
\hline manjuba & $\begin{array}{l}\text { Anchoa spp., Anchoviella spp., } \\
\text { Centengraulis edentulus, } \\
\text { Lycengraulis grossidens }\end{array}$ & pel & pla & 2,9 & 133,3 & 3,3 & 16,7 & 50,0 & $\begin{array}{l}\text { FishBase; Figueiredo e Menezes, 1978; Whitehead et al., 1988; Cergole et al., } \\
\text { 1989; Carvalho-Filho, 1992; McConnel, 1999; Sergipense et al., 1999; Camara } \\
\text { et al., 2001; }\end{array}$ \\
\hline $\begin{array}{l}\text { marisco, } \\
\text { mexilhão, } \\
\text { mexilhão limpo }\end{array}$ & Perna perna, Mytella spp. & - & - & 2,0 & - & - & - & 20,0 & Marques e Pereira, 1988 \\
\hline merluza & Merluccius hubbsi & - & pis & 3,6 & 1000,0 & 10,9 & 66,7 & 200,0 & $\begin{array}{l}\text { FishBase; Figueiredo e Menezes, 1978; Netto e Oliveira, 1991; Soares et al., } \\
\text { 1991; Martins, 2000; Gasalla, 2004a; Cergole et al., 2005; Muto, 2006; Vaz dos } \\
\text { Santos, 2006; Gasalla et al., } 2007\end{array}$ \\
\hline mero & Epinephelus itajara & - & pis & 4,0 & 2700,0 & 23,8 & 33,3 & 100,0 & FishBase; Figueiredo e Menezes, 1980 \\
\hline $\begin{array}{l}\text { miraguaia, } \\
\text { burriguete }\end{array}$ & Pogonias cromis & dem & - & 3,6 & 1420,0 & 16,2 & 20,3 & 50,0 & FishBase; Martins, 2000; Urteaga, 2000; Haimovici et al., 2006. \\
\hline
\end{tabular}


Anexo 2. continuação

\begin{tabular}{|c|c|c|c|c|c|c|c|c|c|}
\hline $\begin{array}{l}\text { moréia, cação- } \\
\text { enguia, enguia }\end{array}$ & Gymnothorax spp. & dem & pis & - & 807,5 & - & 103,7 & 150,0 & $\begin{array}{l}\text { Figueiredo e Menezes, 1978; Gasalla, 1995; 2004; Pucci, 2004; Cergole et al., 2005; } \\
\text { Haimovici et al., } 2008\end{array}$ \\
\hline namorado & $\begin{array}{l}\text { Pseudopercis } \\
\text { semifasciata, } P \text {. numida }\end{array}$ & dem & pis & 4,0 & 1200,0 & 36,9 & 78,3 & 200,0 & $\begin{array}{l}\text { FishBase; Menezes e Figueiredo, 1985; Carvalho-Filho, 1992; Elias e Rajoy, 1992; } \\
\text { Ximenes et al., 1997; Haimovici e Velasco, 2001; Cergole et al., 2005; Gasalla, 2004a; } \\
\text { Gasalla et al., } 2007\end{array}$ \\
\hline olhete, pintagola & Seriola lalandi & pel & pis & 4,0 & 1250,0 & 29,9 & 276,0 & 300,0 & FishBase; Menezes e Figueiredo, 1980; Carvalho-Filho, 1992; Stewart et al., 2004 \\
\hline olho-de-boi & Seriola dumerili & pel & pis & 4,3 & 1700,0 & 12,8 & 120,0 & 500,0 & $\begin{array}{l}\text { FishBase; Menezes e Figueiredo, 1980; Thompson et al., 1999; Kozul et al., 2001; } \\
\text { Fredoú et al., 2006; Harris et al., } 2007\end{array}$ \\
\hline olho-de-cão & Priacanthus arenatus & dem & pis & 3,9 & 381,0 & - & 47,3 & 150,0 & FishBase; Natali-Neto, 1994; Martins, 2000; Gasalla, 2004a; Cergole et al., 2005 \\
\hline ostra & Crassostrea brasiliana & dem & - & 2,0 & - & - & - & 20,0 & \\
\hline oveva & Larimus breviceps & dem & - & 3,3 & 300,0 & - & 25,0 & 50,0 & FishBase; Menezes e Figueiredo, 1980; McConnel, 1999; Gomes, 2004 \\
\hline palombeta** & $\begin{array}{l}\text { Chloroscombrus } \\
\text { chrysurus }\end{array}$ & pel & pla & 3,3 & 425,0 & 6,0 & 33,3 & 100,0 & FishBase; Cergole et al., 1997; McConnel, 1999; Gomes, 2004; Cergole et al., 2005; \\
\hline pampo & Trachinotus spp. & - & pis & 3,6 & 635,0 & 13,4 & 23,3 & 100,0 & $\begin{array}{l}\text { FishBase; Menezes e Figueiredo, 1980; Haimovici e Velasco, 2001; Crabtree et al., } \\
\text { 2002; Muller et al., 2002; Cergole et al., 2005 }\end{array}$ \\
\hline parati & Mugil curema & - & - & 2,6 & 816,7 & 7,9 & 20,0 & 100,0 & $\begin{array}{l}\text { FishBase; Carvalho-Filho, 1992; Cergole et al., 1995; Lowe-McConnell, 1999; Lizama e } \\
\text { Takemoto, 2000; Rossi-Wongtschowski et al., 2006; Miranda e Carneiro, } 2007\end{array}$ \\
\hline pargo, pargo-rosa & $\begin{array}{l}\text { Lutjanus purpureus, } \\
\text { Pagrus pagrus }\end{array}$ & dem & pis & 3,6 & 500,5 & 13,9 & 43,3 & 200,0 & $\begin{array}{l}\text { FishBase; Lowe-McConnell, 1999; Menezes e Figueiredo, 1980; Haimovici, 1991; Natali- } \\
\text { Neto, 1994; Ávila-da-Silva, 1996; Martins, 2000; Rossi-Wongtschowski et al., 2006; } \\
\text { Haimovici et al., } 2008\end{array}$ \\
\hline pargo-rosa* & Pagrus pagrus & dem & pis & 3,6 & 440,0 & 13,9 & 43,3 & 200,0 & $\begin{array}{l}\text { FishBase; Lowe-McConnell, 1999; Menezes e Figueiredo, 1980; Haimovici, 1991; Natali- } \\
\text { Neto, 1994; Ávila-da-Silva, 1996; Martins, 2000; Rossi-Wongtschowski et al., 2006; } \\
\text { Haimovici et al., } 2008\end{array}$ \\
\hline paru & Chaetodipterus faber & - & & 3,5 & 900,0 & 8,8 & 22,0 & 100,0 & FishBase; Menezes e Figueiredo, 1985; Hayse, 1990; Gasalla, 2004a \\
\hline peixe-rei & Atherinella brasiliensis & - & & 2,5 & 160,0 & 2,5 & 6,7 & 20,0 & $\begin{array}{l}\text { FishBase; Sazima, 1986; Giannini e Paiva-filho, 1990; Gasalla, 1995; Pessanha e } \\
\text { Araujo, 2001; Neves et al., 2006; Bervian et al., 2007; Fernandez, 2007 }\end{array}$ \\
\hline peixe-voador, coió & Dacytlopteron volitans & dem & - & - & - & - & - & 100,0 & FishBase; Natali-Neto, 1994; Arantes et al., 2008 \\
\hline pescada & Sciaenidae & dem & pis & 3,6 & 590,96 & 10,6 & 30,4 & 100,0 & Baseado nas referências de pescadas \\
\hline
\end{tabular}


Anexo 2. continuação

\begin{tabular}{|c|c|c|c|c|c|c|c|c|c|}
\hline pescada-amarela & Cynoscion acoupa & dem & - & 3,5 & 1000,0 & 11,1 & 6,7 & 100,0 & $\begin{array}{l}\text { FishBase; Chao, 1978; Menezes e Figueiredo, 1980; Gasalla e Rossi- } \\
\text { Wongtschowski, 2004; Clauzet et al., } 2005\end{array}$ \\
\hline $\begin{array}{l}\text { pescada-banana, } \\
\text { pescada-inglesa }\end{array}$ & Nebris microps & dem & - & 3,6 & 400,0 & - & 16,7 & 100,0 & FishBase; Menezes e Figueiredo, 1980; Chao, 1978 \\
\hline pescada-bicuda & Sphyraena spp. & dem & - & 3,9 & 957,5 & - & 51,0 & 100,0 & FishBase; Menezes e Figueiredo, 1985; Fredoú et al., 2006 \\
\hline pescada-branca & Cynoscion leiarchus & dem & pis & 3,4 & 600,0 & - & 16,7 & 200,0 & $\begin{array}{l}\text { FishBase; Santos, 1992; Menezes e Figueiredo, 1980; Gasalla, 1995; Gasalla, } \\
\text { 2004a; Gomes, 2004; Gasalla e Rossi-Wongtschowski, } 2004\end{array}$ \\
\hline pescada-cambucu & Cynoscion virescens & dem & pis & 3,8 & 925,0 & - & 25,3 & 100,0 & $\begin{array}{l}\text { FishBase; Vazzoler, 1970; Menezes e Figueiredo, 1980; Keith et al., 2000; Gasalla, } \\
\text { 2004a; Gomes, 2004; Gasalla e Rossi-Wongtschowski, } 2004\end{array}$ \\
\hline $\begin{array}{l}\text { pescada-foguete, } \\
\text { pescada-pam, } \\
\text { membeca, bembeca }\end{array}$ & Macrodon ancylodon & dem & pis & 3,7 & 475,0 & 6,2 & 23,3 & 100,0 & $\begin{array}{l}\text { FishBase; Menezes e Figueiredo, 1980; Isaac-Nahum, 1989; McConnel, 1999; } \\
\text { Castro, 2000; Martins, 2000; Gasalla, 2004a; Cergole et al., 2005 }\end{array}$ \\
\hline $\begin{array}{l}\text { pescada-goete, } \\
\text { calafate**}\end{array}$ & Cynoscion jamaicensis & dem & pis & 3,9 & 500,0 & 5,8 & 46,3 & 150,0 & $\begin{array}{l}\text { FishBase; Menezes e Figueiredo, 1980; Isaac-Nahum, 1989; Rios, 1994; Gasalla, } \\
\text { 1995; McConnel, 1999; Castro, 2000; Martins, 2000; Vasconcellos e Gasalla, 2001; } \\
\text { Gasalla, 2004a; Gomes, 2004; Cergole et al., } 2005\end{array}$ \\
\hline pescada-grande & Sciaenidae & dem & pis & 3,6 & - & 10,6 & 30,4 & 100,0 & Baseado nas referências das outras pescadas \\
\hline pescada-maria-luiza & $\begin{array}{l}\text { Paralonchurus } \\
\text { brasiliensis }\end{array}$ & dem & - & 3,2 & 300,0 & 10,0 & 16,7 & 100,0 & FishBase; Natali-Neto, 1994; Lowe-McConnell, 1999; Martins, 2000 \\
\hline $\begin{array}{l}\text { pescada-maria-mole, } \\
\text { pescada-olhuda }\end{array}$ & Cynoscion guatucupa & dem & pis & 3,9 & 537,5 & 11,8 & 66,0 & 200,0 & $\begin{array}{l}\text { FishBase; Menezes e Figueiredo, 1980; Isaac-Nahum, 1989; Natali-Neto, 1994; } \\
\text { Rios, 1994; Haimovici, 1997; Haimovici e Velasco, 2001; Cergole et al., } 2005\end{array}$ \\
\hline pescada-média & Sciaenidae & dem & pis & 3,6 & - & 10,6 & 30,4 & 100,0 & Baseado nas referências das outras pescadas \\
\hline pescada-pequena & Sciaenidae & dem & pis & 3,6 & - & 10,6 & 30,4 & 100,0 & Baseado nas referências das outras pescadas \\
\hline pescada-real e olhuda* & $\begin{array}{l}\text { Macrodon ancylodon e } \\
\text { Cynoscion guatucupa }\end{array}$ & dem & pis & 3,8 & 443,5 & 12,1 & 66,0 & 150,0 & Média entre as categorias pescada-real e olhuda \\
\hline pescada-tortinha & Isopisthus parvipinnis & dem & - & 3,3 & 250,0 & 10,6 & 20,0 & 50,0 & $\begin{array}{l}\text { FishBase; Vazzoler, 1970; Chao, 1978; Soares, 1983; Wakabara et al., 1993; Lowe- } \\
\text { McConnell, 1999; Menezes e Figueiredo, } 1980\end{array}$ \\
\hline pirangica & Kyphosus sectatrix & - & - & 2,1 & 500,0 & - & 10,0 & 100,0 & FishBase; Menezes e Figueiredo, 1985; Carvalho-Filho, 1992; Santos, 1992 \\
\hline polvo, polvo congelado & Octopus spp., & dem & - & - & 250,0 & - & 60,0 & 200,0 & Rosa et al., 2004; Cergole et al., 2005 \\
\hline
\end{tabular}


Anexo 2. continuação

\begin{tabular}{|c|c|c|c|c|c|c|c|c|c|}
\hline $\begin{array}{l}\text { porco, peroá, } \\
\text { cangulo, porco } \\
\text { congelado** }\end{array}$ & Balistes capriscus & - & - & 3,4 & 500,0 & 13,7 & 30,0 & 150,0 & $\begin{array}{l}\text { Carvalho-Filho, 1992; Lowe-McConnell, 1999; Figueiredo e Menezes, 2000; } \\
\text { Martins, 2000; Cergole et al., } 2005\end{array}$ \\
\hline prego & Lepidocybium flavobrunneur & - & pis & - & 2000,0 & - & 433,3 & - & FishBase; McConnel, 1999; \\
\hline prejereba & Lobotes surinamensis & pel & pis & 4,0 & 750,0 & - & - & 100,0 & FishBase; Menezes e Figueiredo, 1980 \\
\hline rabudo, raposa & Alopias vulpinus & dem & pis & - & 6000,0 & 33,3 & 183,3 & 500,0 & Figueiredo, 1977 \\
\hline rato & Ruvettus pretiosus & - & pis & - & - & - & 266,7 & 1000,0 & $\begin{array}{l}\text { FishBase; Figueiredo e Menezes, 2000; Liu et al., 1998; FishBase; Gasalla, } \\
\text { 2004a }\end{array}$ \\
\hline robalo, camorim & Centropomus spp. & dem & pis & 3,0 & 1000,0 & 21,4 & - & 50,0 & $\begin{array}{l}\text { FishBase; Figueiredo e Menezes, 1980; Carvalho-Filho, 1992; Ximenes-Carvalho } \\
\text { et al., 2007; Rabelo, } 2009\end{array}$ \\
\hline roncador & Conodon nobilis & dem & - & 3,3 & 300,0 & - & 33,3 & 50,0 & FishBase; Menezes e Figueiredo, 1980; Carvalho-Filho, 1992; Furia, 1996 \\
\hline sapo** & Lophius gastrophysus & dem & pis & 4,4 & 720,0 & 31,5 & 213,3 & - & $\begin{array}{l}\text { FishBase; Figueiredo e Menezes, 1978; Soares et al., 1991; Armstrong, 1992; } \\
\text { Natali-Neto, 1994; Martins, 2000; Gasalla, 2004a; Cergole et al., 2005; Muto et } \\
\text { al., 2005; Vera, 2006 }\end{array}$ \\
\hline $\begin{array}{l}\text { sardinha, sardinha } \\
\text { congelada, sardinha } \\
\text { fresca** }\end{array}$ & Sardinella brasiliensis & pel & pla & 3,0 & 270,0 & 4,7 & 43,3 & 150,0 & $\begin{array}{l}\text { Richardson et al., 1960; Saccardo et al., 1988; Carvalho-Filho, 1992; Cergole, } \\
\text { 1993; Cergole, 1995; Cergole et al., 1997; Lowe-McConnell, 1999; Cergole e } \\
\text { Valentini, 1994; Cergole et al., 2002; Gasalla, 2004a; Bernardes et al., 2005; } \\
\text { Cergole et al., } 2005\end{array}$ \\
\hline sardinha-boca-torta & Anchovia clupeoides & pel & pla & 3,4 & 210,0 & - & 16,7 & 100,0 & FishBase; Figueiredo e Menezes, 1978; Carvalho-Filho, 1992 \\
\hline sardinha-lage $^{\star *}$ & Opisthonema oglinum & pel & pla & 3,2 & 178,0 & - & 33,3 & 100,0 & $\begin{array}{l}\text { FishBase; Figueiredo e Menezes, 1978; Goiten, 1984; Wakabara et al., 1993; } \\
\text { Furia, 1996; Vasconcellos et al., 1997; Cergole et al., 2005; Fredoú et al., } 2006\end{array}$ \\
\hline savelha** & $\begin{array}{l}\text { Brevoortia aurea, } B \text {. } \\
\text { pectinata }\end{array}$ & pel & pla & 3,6 & 325,0 & - & - & 100,0 & $\begin{array}{l}\text { FishBase; Figueiredo e Menezes, 1978; Nakamura et al., 1986; Carvalho-Filho, } \\
\text { 1992; Val e Almeida-Val, 1995; Furia, 1996; Haimovici e Velasco, 2001; } \\
\text { Vasconcellos e Gasalla, 2001 }\end{array}$ \\
\hline serra & $\begin{array}{l}\text { Pristis pectinata, Sarda } \\
\text { sarda, Scomberomorus } \\
\quad \text { brasiliensis }\end{array}$ & pel & pis & 4,4 & 5500,0 & 12,8 & 73,3 & 100,0 & $\begin{array}{l}\text { FishBase; Figueiredo e Menezes, 1978; Figueiredo e Menezes, 2000; Ximenes, } \\
\text { 1981; Lizama e Takemoto, 2000; Simpfendorfer et al., 2008; Zaboukas e } \\
\text { Megaforow, 2007; Ates, 2008; Valeiras et al., } 2008\end{array}$ \\
\hline siri, carne de siri & $\begin{array}{l}\text { Callinectes spp., Portunus } \\
\text { spp. }\end{array}$ & dem & - & 2,9 & 160,0 & - & 25,0 & - & $\begin{array}{l}\text { FishBase; Melo, 1996; Petti, 1997; Amâncio, 2000; Mantelatto e Christofoletti, } \\
\text { 2001; Haimovici et al., 2006; Branco- Lunardon et al., 2006; }\end{array}$ \\
\hline sororoca & Scomberomorus brasiliensis & pel & pis & 3,8 & 1250,0 & 17,0 & 26,7 & 200,0 & FishBase; Carvalho-Filho, 1992; Vasconcellos e Gasalla, 2001 \\
\hline tábua & Parona signata & dem & pis & - & - & - & - & - & \\
\hline
\end{tabular}


Anexo 2. continuação

\begin{tabular}{|c|c|c|c|c|c|c|c|c|c|}
\hline tainha, virote ${ }^{\star \star}$ & Mugil spp. & - & - & 2,6 & 816,7 & 7,9 & 20,0 & 100,0 & $\begin{array}{l}\text { FishBase; Carvalho-Filho, 1992; Cergole et al., 1995; Lowe-McConnell, } \\
\text { 1999; Lizama e Takemoto, 2000; Rossi-Wongtschowski et al., 2006; } \\
\text { Miranda e Carneiro, } 2007\end{array}$ \\
\hline tamburitaca & $\begin{array}{l}\text { Lysiosquilla scabricauda, } \\
\text { Hemisquilla brasilienzis, Squilla } \\
\text { brasiliensis }\end{array}$ & dem & - & - & - & - & - & - & \\
\hline tintureira & Galeocerdo cuvier & - & pis & 4,3 & 5500,0 & 28,0 & 140,3 & 300,0 & FishBase; Figueiredo, 1977; Carvalho-Filho, 1992 \\
\hline trilha** & Mullidae & dem & - & 3,5 & 260,0 & 10,7 & 69,7 & 100,0 & $\begin{array}{l}\text { FishBase; Haimovici et al., 1994; Natali-Neto, 1994; Lowe-McConnell, 1999; } \\
\text { Martins, 2000; Gasalla et al., } 2007\end{array}$ \\
\hline vieira & Euvola ziczac & - & - & 2,0 & - & - & - & - & \\
\hline xaréu & Caranx hippos & - & pis & 4,0 & 1000,0 & 23,0 & 116,7 & 300,0 & $\begin{array}{l}\text { FishBase; Menezes e Figueiredo, 1980; Carvalho-Filho, 1992; Gasalla, } \\
\text { 2004a; Kishore and Solomon, } 2005\end{array}$ \\
\hline $\begin{array}{l}\text { xerelete, cavaca, } \\
\text { manézinho, solteira }\end{array}$ & Caranx latus & pel & pis & 4,2 & 800,0 & - & 46,7 & 250,0 & $\begin{array}{l}\text { FishBase; Menezes e Figueiredo, 1980; Carvalho-Filho, 1992; Furia, 1996; } \\
\text { Gasalla, 2004a; Fredoú et al., } 2006\end{array}$ \\
\hline xixarro** & Trachurus lathami & pel & pla & 3,5 & 400,0 & 11,5 & 59,0 & 400,0 & $\begin{array}{l}\text { FishBase; Carvalho-Filho, 1992; Cergole et al., 1997; McConnel, 1999; } \\
\text { Martins, 2000; Magro et al., 2000; Gasalla, 2004a; Cergole et al., } 2005\end{array}$ \\
\hline
\end{tabular}

